RENATA MONTE

CARACTERIZAÇÃO E CONTROLE DO COMPORTAMENTO MECÂNICO DO CONCRETO REFORÇADO COM FIBRAS PARA TUBOS

São Paulo 2015 


\section{RENATA MONTE}

\section{CARACTERIZAÇÃO E CONTROLE DO COMPORTAMENTO MECÂNICO DO CONCRETO REFORÇADO COM FIBRAS PARA TUBOS}

Tese apresentada à Escola Politécnica da Universidade de São Paulo para obtenção do Título de Doutor em Ciências.

São Paulo 


\title{
RENATA MONTE
}

\section{CARACTERIZAÇÃO E CONTROLE DO COMPORTAMENTO MECÂNICO DO CONCRETO REFORÇADO COM FIBRAS PARA TUBOS}

\author{
Tese apresentada à Escola Politécnica \\ da Universidade de São Paulo para \\ obtenção do Título de Doutor em \\ Ciências. \\ Programa: \\ Engenharia Civil. \\ Área de Concentração: \\ Engenharia de Construção Civil e \\ Urbana. \\ Orientador: \\ Prof. Dr. Antonio Domingues de \\ Figueiredo
}

\section{São Paulo}


Este exemplar foi revisado e corrigido em relação à versão original, sob responsabilidade única do autor e com a anuência de seu orientador.

São Paulo de de

Assinatura do autor:

Assinatura do orientador:

Catalogação-na-publicação

\section{Monte, Renata}

Caracterização e controle do comportamento mecânico do concreto reforçado com fibras para tubos / R. Monte -- versão corr. -- São Paulo, 2015. $159 \mathrm{p}$.

Tese (Doutorado) - Escola Politécnica da Universidade de São Paulo. Departamento de Engenharia de Construção Civil.

1.Concreto reforçado com fibras 2.Tubos de concreto 3.Ensaios de materiais 4.Simulação numérica I.Universidade de São Paulo. Escola Politécnica. Departamento de Engenharia de Construção Civil II.t. 
DEDICATÓRIA

Dedico este trabalho aos meus pais,

e ao Daniel com todo amor. 


\section{AGRADECIMENTOS}

Ao professor Antonio Domingues de Figueiredo, meu eterno carinho e gratidão, por me acolher novamente como sua orientanda oito anos após o término do mestrado. Por acreditar no meu potencial e por me orientar com competência e segurança e, acima de tudo, por me mostrar o que é realmente importante.

Ao professor Albert de la Fuente Antequera, por toda ajuda com a simulação numérica e toda explicação acerca do comportamento estrutural dos tubinhos. Os inúmeros rascunhos com equações e croquis que produziu poderão compor um livro completo a esse respeito. Aproveito para agradecer aos professores Antonio Aguado e Sergio Cavalaro, por todas as sugestões e contribuições para este trabalho! Agradeço também pelo nosso convívio em Barcelona, período de muito trabalho, mas de muita alegria e realização profissional. Gracias profesores!

Ao professor Mounir Khalil El Debs, pela leitura cuidadosa e todos os apontamentos oportunos durante o exame de qualificação. Certamente suas palavras me acompanharam até o término deste trabalho.

Aos professores Romildo Dias Toledo Filho e Vahan Agopyan, por aceitarem o convite para participar da banca de avaliação da tese. As contribuições certamente serão excepcionais e proporcionais à competência e profundo conhecimento de materiais compósitos por parte de ambos.

Ao Eng. Alírio Brasil Gimenez e toda equipe da Fermix tubos por todo apoio no programa experimental desta tese. Em especial ao Sr. José Miranda, ao Sr. Abílio e equipe, e ao Daniel (dosagem do concreto).

Aos meus colegas do laboratório Adilson, Jessica, Mario e Reginaldo, pelo convívio harmonioso, por me ajudarem nas atividades experimentais e por cuidarem do nosso laboratório enquanto eu estava em Barcelona ou imersa na reta final da tese. Agradeço a compreensão e carinho de vocês!

Ao professor Rafael Pileggi, por ter apoiado o meu desenvolvimento como pesquisadora e, principalmente, pela compreensão nesses últimos meses de finalização deste trabalho. 
Ao Departamento de Engenharia de Construção Civil da EPUSP, em nome dos professores Francisco Cardoso e Alex Abiko, por apoiarem a capacitação e desenvolvimento de nós funcionários.

À professora Mercia Barros, por sempre me apoiar no trabalho, na pesquisa e na vida pessoal. Saiba que é para mim um exemplo de professora, profissional, pesquisadora e principalmente ser humano. Muito obrigada por todo carinho!

Aos funcionários do departamento Alcione, Denise, Eliany e Paulinho, por me apoiar sempre que precisei. À Paty, ao Edson (Titi) e Rogerio, por resolverem os problemas informáticos. À Leo e à Fatima, por toda ajuda na busca pelas bibliografias e pelas correções das referências. Aos anjos Eliany, Gessimara e Wandrea, pela ajuda sempre que precisei. À Fatima Domingues, por sempre me acolher com as eternas dúvidas de estudantes de pós-graduação e pelos momentos de descontração em almoços, fondue e cineminhas com nossa amiga Alci.

Ao professor Vanderley John, pelas palavras de incentivo, brincadeiras e "puxões de orelha". Por me dizer que trabalhando sério é possível chegar longe e que é disso que a sociedade precisa. Quem sabe um dia nós publicaremos juntos um artigo na Science.

Aos colegas dos laboratórios do LEM Antonio, Marcia, Ivan, José, Rui e Valdineia, por me ajudar sempre que solicitei. Aos colegas do laboratório de tecnologia de pavimentação Edson, Erasmo e Robson, pela ajuda sempre que precisei.

À todos os professores das disciplinas de pós-graduação que cursei. Professores Mercia, Luiz Sergio e Sabbatini, cuja disciplina não pude aproveitar os créditos, mas que aproveitei muito os conhecimentos apresentados. Professor Pileggi pela disciplina de reologia, tanto gostei que cursei duas vezes. Professores Figueiredo e Tulio pela disciplina de materiais fibrosos, com direito a prova de PEF. Professora M. Elena Takeda pela excelente disciplina de planejamento de experimentos. Professora Linda Lee por compartilhar comigo do amor pela estatística e me forçar a aprender um pouco de R. Professores Fernando e Cheng, que na reta final compartilharam seus conhecimentos acerca da simulação numérica em CFD.

Amigos, eles são tantos... Começarei por ela, a assistente social, mãe e amiga, Engracia, que sempre ajuda a todos e a mim em particular, por muitas e muitas vezes, inclusive na impressão desta tese. À Fezinha, por ser minha querida amiga, espero 
que possamos continuar nos ajudando mutuamente e compartilhando alegria de nossas realizações. Aos amigos Luana, Deh e Ale Rosa, sempre incentivando e dizendo, vai Renatinha. Aos queridos Isaac Galobardes e Marco Quattrone, pela generosidade e paciência em me ajudar na formatação final do texto, podem contar comigo para o que precisarem!

Um agradecimento ao Team 2.0 da UPC. Ao meu amigo querido Pablo, por todo carinho e ajuda sempre que precisei, eres un crack doctor! À querida Ana, por toda ajuda, carinho e apoio no período que estive em Barcelona, gracias por todo. À querida Sandra, por me ajudar com tudo no período de quatro meses em Barcelona, me ajudando com a documentação da residência e a dificuldade da língua quando cheguei, muchas gracias. Aos amigos Renan e Talita, um casal nota 1000, sempre com um sorriso no rosto e dispostos para qualquer programação, quero vocês sempre por perto.

Enfim a minha família, minha base! Meus pais Laercio e Terezinha, por sempre me apoiarem em tudo, inclusive na moldagem de corpos de prova na fabrica de tubos. Ao meu marido Daniel, uma luz no meu caminho, que cuida de mim todo o tempo, mesmo no meu mau humor matinal. Obrigada pelo seu amor, pela preocupação comigo e pelas figuras da tese. Aos meus irmãos Bruno e Luiz, obrigada por existirem, por me trazerem preocupação constante e darem sentido a minha vida, amo vocês. À minha irmã de coração Euzeni, por me apoiar em momentos de alegria e tristeza, saúde e doença. Aos meus amados sobrinhos Gil, Ric, Manu, PH e Helo, que cultivem o amor pela leitura e a curiosidade por novas descobertas, para que possam crescer e melhorar a vida da geração de vocês. A toda minha família, cunhadas, padrinhos, sogra, tios e tias, primos e agregados, pela torcida de sempre!

Ao bondoso e misericordioso Deus, por me dar saúde, inteligência e paz para vencer essa etapa da minha vida. 
We keep moving forward, opening new doors, and doing new things, because we're curious and curiosity keeps leading us down new paths.

(Walt Disney) 


\section{RESUMO}

Os estudos focando a otimização do reforço dos tubos de concreto para obras de saneamento são importantes por estes componentes estarem vinculados a grandes necessidades sociais que ainda atingem o Brasil e outros países em desenvolvimento bem como pelo fato destes componentes serem produzidos em série, o que gera economia de escala. Neste sentido, a utilização de fibras como reforço dos tubos trás consigo um grande número de vantagens aplicativas e de desempenho. A tendência internacional de busca por um consenso no dimensionamento e controle do concreto reforçado com fibras (CRF) como material estrutural está sendo direcionada para o fib Model Code 2010. Geralmente, para a caracterização do CRF são utilizados os ensaios de flexão de vigas. Porém, a moldagem desses corpos de prova para 0 controle do CRF dos tubos apresentou resultados inadequados em estudos anteriores.

A definição do reforço ótimo de tubos de CRF através da tentativa e erro no ensaio de compressão diametral do componente deve ser evitada pelos elevados gastos (financeiros, de material e tempo) associados a esta metodologia. O projeto deve ser atingido através de modelos confiáveis que possam otimizar o reforço através da previsão adequada do desempenho do componente. Da mesma forma, deve-se obter procedimentos de controle do material que sejam concatenados com os procedimentos de controle do produto.

Neste sentido, esta tese propõe uma metodologia para a caracterização e controle do comportamento mecânico do CRF para a produção de tubos, que permita modelar o comportamento do componente no ensaio de compressão diametral e verificar sua adequação a uma aplicação estrutural. O estudo foi dividido em três fases principais. $\mathrm{Na}$ primeira houve a avaliação de um método de ensaio alternativo ao de flexão de prismas para o controle do CRF. Na segunda fase experimental houve a incorporação de modificações no método de ensaio de compressão diametral do componente de modo a aproximá-lo à filosofia do fib Model Code 2010. Nesta etapa foram avaliados tubos com reforço de fibras de aço, macrofibras poliméricas e vergalhões para comprovar a pertinência da nova metodologia de ensaio. Na terceira fase do estudo foi realizada uma simulação numérica para previsão de comportamento dos componentes ensaiados utilizando os parâmetros do material caracterizados através do método de ensaio alternativo validado na primeira fase. Os resultados obtidos na modelagem foram comparados com o resultado experimental do ensaio do componente de modo a validar a metodologia proposta.

Os resultados demonstraram a adequação do ensaio Barcelona para a caracterização e controle do comportamento mecânico do CRF destinado à produção de tubos. Essa caracterização poderá subsidiar simulações numéricas do comportamento do componente no ensaio de compressão diametral. Com isto, ábacos de projeto de tubos de concreto reforçados com diferentes tipos de fibras poderão ser desenvolvidos, identificando as classes resistentes que serão atendidas dependendo do diâmetro do tubo e do teor de fibras empregados. Esta tese aponta também para a necessidade de uma revisão na normalização vigente, estabelecendo critérios relacionados ao comportamento pós-fissuração que avaliem o estado limite de serviço e o estado limite último. Isto permitirá uma avaliação homogênea do tipo de reforço e tornará mais adequada a comparação entre distintos tipos de reforço (fibras ou convencional).

Palavras chave: Concreto reforçado com fibras; tubos de concreto; ensaios de materiais; simulação numérica. 


\begin{abstract}
The international trend for a consensus about the design and control of fibre reinforced concrete (FRC) as a structural material is based on the fib Model Code 2010. Generally, in order to characterize the FRC, bending tests are used. However, the moulding of these control test specimens of the FRC pipes is not quite simple as has been shown by previous studies.

The design of FRC pipes through trial and error in the component-crushing test should be avoided. This test shall be limited to the acceptance control or final validation of a new component, designed through reliable models that optimize the reinforcement and the component performance. These models should allow both design and prediction of the component behaviour related to the quality control. In that sense, this thesis proposes a methodology for characterizing and controlling the mechanical behaviour of FRC for the production of pipes. This study allows modelling the component behaviour in crushing test and verifying their suitability for structural application.

The methodology considered consisted in three main topics: evaluation of an alternative method of FRC control test; modification of the procedure of the crushing test method in order to approach the fib Model Code 2010 philosophy, and prediction the mechanical behaviour of the components comparing numerical simulation results with experiments results. In this last topic, the characterization of the materials performance by the alternative test method was considered.

The results indicated that the Barcelona test is suitable in order to characterize and control the mechanical behaviour of the FRC used for the production of pipes. This characterization is able to support numerical simulations of the component behaviour in crushing test. It allows the development of design tables identifying the pipes resistant classes considering a variety of parameters such as types and contents of fibres and pipes diameters. This thesis also points out the need for a review of the current standards, establishing parameters related to the post-cracking behaviour to assess the serviceability limit state and the ultimate limit state. This allows a homogeneous evaluation of the reinforcement type and makes it more suited to comparing different types of reinforcement (fibre or conventional).
\end{abstract}

Keywords: Fibre reinforced concrete; concrete pipe; materials characterization; numerical simulation. 


\section{LISTA DE FIGURAS}

Figura 1.1 - Diagrama $\sigma-\varepsilon$ para o dimensionamento de elementos com CRF apresentando comportamento de softening (a) e hardening (b) segundo o fib Model Code. Fonte: di Prisco; Plizzari; Vandewalle, 2009.

Figura 1.2 - Resultados experimentais e do modelo MAP para a compressão diametral de tubos de concreto de $600 \mathrm{~mm}$ de diâmetro e reforçados com $10 \mathrm{~kg} / \mathrm{m}^{3}$ de fibras de aço. Fonte: de la Fuente et al. (2012b) ....................................................... 26

Figura 1.3 - Organização da tese de doutorado. ................................................... 28

Figura 2.1 - Esquema de configuração do ensaio Barcelona. Fonte: Adaptado de Saludes (2006).

Figura 2.2 - Exemplo do ensaio Barcelona realizado utilizando o extensômetro de circunferência. Fonte: Saludes (2006).

Figura 2.3 - Curvas de carga- $\delta$ e carga-TCOD registradas simultaneamente no ensaio Barcelona para um concreto com $25 \mathrm{~kg} / \mathrm{m}^{3}$ de fibras de aço. Fonte: Adaptado de Carmona; Aguado; Molins (2012). 35

Figura 2.4 - Estágios que ocorrem durante o ensaio Barcelona. Fonte: Pujadas (2013).

Figura 2.5 - Conversão do resultado do ensaio Barcelona com deslocamento vertical (esquerda) para TCOD (direita). Fonte: Adaptado de Monte; Toaldo; Figueiredo (2014).

Figura 2.6 - Diferentes direções de aplicação de carga no ensaio Barcelona. Fonte: Pujadas (2013). 38

Figura 2.7 - Representação dos eixos durante a moldagem de corpos de prova: a) prismáticos e b) cúbicos. Fonte: Pujadas (2013).

Figura 2.8 - Curvas tensão-deslocamento vertical em ensaios Barcelona nos eixos $X$, Y e Z de concretos reforçados com fibra de polipropileno: a) $5 \mathrm{~kg} / \mathrm{m}^{3}$; b) $7 \mathrm{~kg} / \mathrm{m}^{3}$; c) 9 $\mathrm{kg} / \mathrm{m}^{3}$. Fonte: Adaptado de Pujadas et al. (2014)

Figura 2.9: Curvas tensão-CMOD dos ensaios DEWS, eixos $X$ e Z, para concretos reforçados com $45 \mathrm{~kg} / \mathrm{m}^{3}$ de fibra de aço. Fonte: Adaptado de Borges; Monte; Figueiredo (2014).

Figura 2.10 - Comparação entre o ensaio Barcelona cúbico no eixo Z e o ensaio Barcelona cilíndrico em concretos reforçados com fibra de polipropileno: a) $5 \mathrm{~kg} / \mathrm{m}^{3}$; b) $7 \mathrm{~kg} / \mathrm{m}^{3}$; c) $9 \mathrm{~kg} / \mathrm{m}^{3}$. Fonte: Adaptado de Pujadas et al. (2014).

Figura 2.11 - Esquema do ensaio de flexão quatro pontos. Fonte: Adaptado de NBN 15-238 (1992). 
Figura 2.12 - Modo de ruptura idealizado para o ensaio NBN 15-238. Fonte: Adaptado de Saludes (2006).

Figura 2.13 - Relações geométricas desenvolvidas para o ensaio de flexão quatro pontos. Fonte: Saludes (2006). 42

Figura 2.14 - Relações geométricas no ensaio Barcelona. Fonte: Saludes (2006). ....42 Figura 2.15 - Diagrama $\sigma-\varepsilon$ simplificado baseado no ensaio Barcelona. Fonte: Blanco (2013).

Figura 2.16 - a) Corpo de prova com cunha formada; b) medida do comprimento da cunha. Fonte: Adaptado de Blanco et al. (2014). 45

Figura 2.17 - a) Fibra de aço utilizada; b) Fibra de polipropileno utilizada. 50

Figura 2.18 - Configuração do ensaio de flexão JSCE-SF4. Fonte: Monte; Toaldo; Figueiredo, (2014). .54

Figura 2.19 - Resultado de ensaio JSCE - SF4 com presença de instabilidade póspico. Fonte: Toaldo; Monte; Figueiredo (2013). 55

Figura 2.20 - Extração de testemunhos para ensaio Barcelona. .55

Figura 2.21 - Configuração do ensaio Barcelona. Fonte: Monte; Toaldo; Figueiredo, (2014).

Figura 2.22 - Curvas carga-deslocamento vertical dos ensaios de flexão JSCE-SF4 para os CRF de aço (SF) e polipropileno (PF), nos respectivos teores. 59

Figura 2.23 - Correlação entre o deslocamento vertical $(\delta)$ médio pós-fissuração e o volume de fibras (\% do volume de concreto).

Figura 2.24 - Boxplot e testes para igualdade de variâncias das cargas de ruptura do ensaio de flexão JSCE-SF4 em função do tipo e teor de fibras.

Figura 2.25 - Curvas de $F_{p}-\delta_{p}(\mathrm{a}, \mathrm{c}, \mathrm{e})$ e $F_{p}$-TCOD (b, d e f), para os ensaios Barcelona com fibra de aço (SF) em diferentes teores.

Figura 2.26 - Boxplot e testes para igualdade de variâncias das cargas máximas de puncionamento do ensaio Barcelona em função do teor de fibras de aço. 65 Figura 2.27 - Curvas carga- $\delta$ dos ensaios Barcelona com diferentes teores de fibra de polipropileno (PF). 66

Figura 2.28 - Boxplot e testes para igualdade de variâncias das cargas máximas de puncionamento $\left(F_{\text {pmax }}\right)$ do ensaio Barcelona em função do teor de fibras de polipropileno. 68

Figura 2.29 - Regressões lineares entre as tenacidades médias dos ensaios JSCESF4 (0 $\leq \delta \leq 2)$ e Barcelona $(0 \leq \mathrm{TCOD} \leq 4)$ para a fibra de aço. Fonte: Monte; Toaldo; Figueiredo (2014). 
Figura 2.30 - Regressões lineares entre as tenacidades médias dos ensaios JSCESF4 $(0 \leq \delta \leq 2)$ e Barcelona $(0 \leq \mathrm{TCOD} \leq 4)$ para a fibra de polipropileno. Fonte: Monte; Toaldo; Figueiredo (2014).

Figura 2.31 - Boxplot e teste para igualdade de variâncias das resistências residuais na RS em função do método de ensaio, do tipo e teor de fibras. .74 Figura 2.32 - Boxplot e teste para igualdade de variâncias das resistências residuais na RR em função do método de ensaio, do tipo e teor de fibras. 75 Figura 2.33 - a) Abertura de uma fissura no ensaio de flexão JSCE-SF4; b) Abertura de três fissuras no ensaio Barcelona. Fonte: Monte; Toaldo; Figueiredo (2014) ......... 76 Figura 2.34 - Regressões lineares entre as resistências residuais médias na região de serviço (RS) e na região de pré-ruptura (RR). Fonte: Monte; Toaldo; Figueiredo (2014).

Figura 3.1 - Ensaios de determinação da resistência de um tubo: (a) três cutelos; (b) dois cutelos; (c) colchão de areia e (d) Minnesota. Fonte: Zaidler (1983).

Figura 3.2 - Esquema mostrando a seção longitudinal e a seção transversal do ensaio de compressão diametral de três cutelos para avaliação das classes de resistência dos tubos de concreto. Fonte: Figueiredo; Chama Neto (2008).

Figura 3.3 - Lâmina padrão para medida de abertura de fissura 0,25 mm. Fonte: ABNT NBR 8890 (2007). 86

Figura 3.4 - Esquema do plano de carregamento proposto para o ensaio de compressão diametral de tubos de concreto reforçados com fibras. Fonte: ABNT NBR 8890 (2007).

Figura 3.5 - Configuração do ensaio com posicionamento dos LVDTs na ponta e na bolsa para medida do deslocamento diametral. Fonte: Figueiredo et al. (2007). 88 Figura 3.6 - Resultado de um tubo de concreto reforçado com $40 \mathrm{~kg} / \mathrm{m}^{3}$ de fibras de aço ensaiado segundo o procedimento cíclico e com uso de LVDTs. Fonte: Adaptado de Figueiredo et al. (2007). 88 Figura 3.7 - Comparação entre as curvas médias de carregamento medidos na ponta e, na ponta e bolsa para os tubos de concreto reforçados com $40 \mathrm{~kg} / \mathrm{m}^{3}$ de fibra de aço. Fonte: Adaptado de Figueiredo et al. (2012b).

Figura 3.8 - Curvas representativas dos carregamentos cíclico ou contínuo. Fonte: Figueiredo (2008).

Figura 3.9 - Diagrama tensão versus deformação para comportamento de softening em CRF. Fonte: Adaptado de Fib (2013).

Figura 3.10 - Esquema de comportamento de softening em TCRF. Fonte: Adaptado de Figueiredo et al. (2012a). 
Figura 3.11 - Dimensões nominais dos tubos produzidos.

Figura 3.12 - Equipamento de produção de tubos por compressão radial.

Figura 3.13 - a) Retirada do tubo do equipamento de moldagem e transporte até o local de desforma; b) Processo de desforma do tubo. .95

Figura 3.14 - Quebra da ponta durante a desforma do tubo. .95

Figura 3.15 - a) colocação do concreto em camadas; b) adensamento com soquete e sobre mesa vibratória. 98

Figura 3.16 - Ensaio de compressão diametral dos TCRF. .98 Figura 3.17: a) Leitura da abertura de fissura; b) registro simultâneo da variação do deslocamento diametral e abertura de fissura na ponta do tubo. 99 Figura 3.18 - Extração de testemunhos dos tubos fissurados: a) posicionamento e nivelamento da extratora; b) posicionamento das extrações em relação a fissura.... 100 Figura 3.19 - Efeito de interação entre os tipos e teores de fibra na resistência à compressão. 103

Figura 3.20 - Resultados de compressão diametral dos tubos de concreto com reforço convencional (TCA) em tela metálica. 104

Figura 3.21 - Distribuição de reforços na seção transversal dos tubos: a) de armadura convencional ou fibras. Fonte: Figueiredo; Chama Neto (2008); b) testemunho extraído mostrando a posição central da armadura convencional no tubo. 105 Figura 3.22 - Resultados de compressão diametral TCRF de aço (SF): a) com 10 $\mathrm{kg} / \mathrm{m}^{3}(0,13 \%)$; b) $20 \mathrm{~kg} / \mathrm{m}^{3}(0,25 \%)$. 105

Figura 3.23 - Resultados de compressão diametral dos TCRF de polipropileno (PF): a) $2,3 \mathrm{~kg} / \mathrm{m}^{3}(0,25 \%)$; b) $4,6 \mathrm{~kg} / \mathrm{m}^{3}(0,50 \%)$. 106 Figura 3.24 - Aparecimento de microfissura na região de medida da abertura de fissura. 109

Figura 3.25 - Correlação experimental entre a abertura de fissura $(w)$ e 0 deslocamento diametral $(v)$ de tubos de concreto com reforço convencional (TCA). 109 Figura 3.26 - Correlação experimental entre a abertura de fissura $(w)$ e 0 deslocamento diametral $(v)$ de tubos de concreto com fibras de aço (TCRF-SF)......111 Figura 3.27 - Correlação experimental entre a abertura de fissura $(w)$ e 0 deslocamento diametral $(v)$ de tubos de concreto com fibras de polipropileno (TCRF$\mathrm{PF})$

Figura 3.28 - Correlação experimental entre a abertura de fissura $(w)$ e 0 deslocamento diametral $(v)$ de tubos de concreto com diferentes reforços. .114 
Figura 3.29 - Curvas médias do ensaio de compressão diametral dos tubos com diferentes reforços: a) $F-d$, com requisitos da NBR 8890 para um tubo PA1-600; b) $F$ $d_{\%}$, com deslocamentos associados ao ELS e ELU. 118

Figura 4.1 - Ensaio de compressão diametral: (a) seção transversal; (b) seção longitudinal. Fonte: Adaptado de de la FUENTE et al. (2010). .124

Figura 4.2 - Comportamento esperado do TCRF no ensaio de compressão diametral, considerando o teor de fibras $\left(\mathrm{C}_{\mathrm{f}}\right) \mathrm{C}_{\mathrm{fA}}<\mathrm{C}_{\mathrm{fB}}<\mathrm{C}_{\mathrm{fC}}$. Fonte: de la Fuente et al. (2013)...124 Figura 4.3 - a) discretização da seção; b) modelo constitutivo para o CRF; c) esquema de corpo rígido articulado para avaliar a abertura de fissura $(w)$. Fonte: Adaptado de de la FUENTE et al. (2012a). 126 Figura 4.4 - Esquema do comportamento do tubo em: a) regime linear; b) regime linear com fissuração em $R$; c) regime linear com fissuração em $R$ e em $S$. Fonte: de la Fuente (2011). 129

Figura 4.5 - a) Ensaio Barcelona em corpos de prova moldados; b) Ensaio Barcelona em testemunhos extraídos dos tubos; c) corpos de prova após o término do ensaio.

Figura 4.6 - a) Diagrama multilinear $\sigma-\varepsilon$. Fonte: Blanco (2013); b) Diagrama trilinear $\sigma-\varepsilon$ simplificado. 134

Figura 4.7 - a) Comparação entre o diagrama $\sigma-\varepsilon$ completo e o multilinear; b) Comparação da formulação baseada no ensaio Barcelona, multilinear e trilinear, com modelos constitutivos baseados em flexão de prismas. Fonte: Adaptado de Blanco et al. (2014).

Figura 4.8 - Curvas de carga de puncionamento $\left(F_{p}\right)$ em função do deslocamento vertical $\left(\delta_{p}\right)$ para os ensaios Barcelona dos corpos de prova moldados. 136 Figura 4.9 - Curvas de carga de puncionamento $\left(F_{p}\right)$ em função do deslocamento vertical $\left(\delta_{p}\right)$ para os ensaios Barcelona dos testemunhos extraídos dos tubos. 138

Figura 4.10 - Resultados de carga versus deslocamento diametral $(F-V)$ experimentais e numéricos para os TCRF com $10 \mathrm{~kg} / \mathrm{m}^{3}(0,13 \%)$ e $20 \mathrm{~kg} / \mathrm{m}^{3}(0,26 \%)$ de SF. 141 Figura 4.11 - Resultados de carga versus deslocamento diametral $(F-v)$, experimentais e numéricos, para os TCRF 2,3 kg/m $\mathrm{m}^{3}(0,26 \%)$ e $4,6 \mathrm{~kg} / \mathrm{m}^{3}(0,52 \%)$ de PF. 141

Figura 4.12 - Correlação numérica e experimental entre a abertura de fissura $(w)$ e 0 deslocamento diametral ( $v$ ) para: a ) TCRF-SF; b) TCRF-PF. 144 


\section{LISTA DE TABELAS}

Tabela 1.1 - Níveis de atendimento com água e esgotos dos prestadores de serviço participantes do SNIS em 2013, segundo região geográfica. Fonte: SNIS (2014). .....21 Tabela 1.2 - Evolução dos níveis de atendimento com água e esgotos dos prestadores de serviço participantes do SNIS de 2008 e de 2013. Fonte: Adaptado de SNIS (2010, 2014).

Tabela 1.3 - Levantamento de artigos publicados em periódicos internacionais indexados entre 2012 e 2015 relacionados a tubos de concreto reforçados com fibras.

Tabela 2.1 - Modelos constitutivos apresentados em diferentes normas internacionais. Fonte: Blanco et al. (2013) 44

Tabela 2.2- Coeficiente de atrito estático indicado pelo fib Model Code 2010. Fonte: Adaptado de FIB (2013). 46

Tabela 2.3 - Massa específica dos materiais utilizados na pesquisa. 50

Tabela 2.4 - Resultados das características dimensionais das fibras e valores nominais dos fabricantes. Fonte: Monte; Toaldo; Figueiredo, (2014). .51

Tabela 2.5 - Teores de fibras utilizados. .52

Tabela 2.6 - Resultados médios de absorção de água e índice de vazios dos corpos de prova.

Tabela 2.7 - Análise de variância para a absorção de água. .57

Tabela 2.8 - Análise de variância para o índice de vazios.

Tabela 2.9 - Resultados de resistência à compressão dos concretos aos 28 dias. Fonte: Monte; Toaldo; Figueiredo (2014). .58

Tabela 2.10 - Deslocamento vertical máximo de cada curva, médios e coeficiente de variação, correspondentes ao final da região de instabilidade ocorrida no ensaio JSCESF4. 60

Tabela 2.11 - Tenacidades médias e coeficientes de variação para os ensaios JSCESF4 e Barcelona. Fonte: Monte, Toaldo e Figueiredo (2014). 69

Tabela 2.12 - Análise de variância para a tenacidade.

Tabela 2.13 - Resistências residuais para diferentes aberturas de fissuras nos ensaios JSCE-SF4 e Barcelona. Fonte: Monte; Toaldo; Figueiredo (2014).............................. 73

Tabela 2.14 - Análise de variância para a resistência residual na RS. .........................76

Tabela 2.15 - Análise de variância para a resistência residual na RR.........................76

Tabela 3.1 - Cargas mínimas de compressão diametral de tubos armados e/ou reforçados com fibras de aço. Fonte: ABNT NBR 8890 (2007). 
Tabela 3.2 - Identificação dos tubos de concreto moldados.

Tabela 3.3 - Teores de fibras utilizados nas moldagens dos tubos.

Tabela 3.4 - Resultados médios de absorção de água e índice de vazios dos testemunhos e dos corpos de prova moldados com os concretos dos tubos.

Tabela 3.5 - Resultados de resistência à compressão dos corpos de prova moldados com os concretos dos tubos.

Tabela 3.6 - Análise de variância da resistência à compressão dos concretos reforçados com fibras para produção dos tubos.

Tabela 3.7 - Comparação entre os resultados experimentais, com desvios padrão, e analíticos do deslocamento vertical antes da fissuração $\left(v_{c r}\right)$ dos tubos com diferentes tipos de reforço. 108

Tabela 3.8 - Análise de variância da equação de regressão entre a abertura de fissura $(w)$ e o deslocamento diametral $(v)$ de tubos de concreto com reforço convencional (TCA). 110

Tabela 3.9 - Teste de significância dos parâmetros da equação de regressão entre a abertura de fissura $(w)$ e o deslocamento diametral $(v)$ de tubos de concreto com reforço convencional (TCA). 110

Tabela 3.10 - Análise de variância da equação de regressão entre a abertura de fissura $(w)$ e o deslocamento diametral $(v)$ de tubos de concreto reforçados com fibras de aço (TCRF-SF).

Tabela 3.11 - Teste de significância dos parâmetros da equação de regressão entre a abertura de fissura $(w)$ e o deslocamento diametral $(v)$ de tubos de concreto reforçados com fibras de aço (TCRF-SF). 112

Tabela 3.12 - Análise de variância da equação de regressão entre a abertura de fissura $(w)$ e o deslocamento diametral $(v)$ de tubos de concreto reforçados com fibras de polipropileno (TCRF-PF).

Tabela 3.13 - Teste de significância dos parâmetros da equação de regressão entre a abertura de fissura $(w)$ e o deslocamento diametral $(v)$ de tubos de concreto reforçados com fibras de polipropileno (TCRF-PF).

Tabela 3.14 - Aplicação das equações de regressão para a predição da abertura de fissura (w) para os deslocamentos diametrais $d_{E L S}$ e $d_{E L U}$ em tubos de concreto com diferentes reforços.

Tabela 3.15 - Cargas relevantes $(\mathrm{kN} / \mathrm{m})$ obtidas no ensaio de compressão diametral de tubos de concreto com reforço convencional (TCA) em tela metálica.

Tabela 3.16 - Cargas relevantes $(\mathrm{kN} / \mathrm{m})$ obtidas no ensaio de compressão diametral dos TCRF de aço (SF) e polipropileno (PF). 116 
Tabela 3.17 - Resultados das cargas residuais no estado limite de serviço $\left(F_{E L S}\right)$ e estado limite último $\left(F_{E L U}\right)$ dos tubos de concreto com diferentes reforços. 118

Tabela 4.1 - Dimensões dos discos de carga dos corpos de prova e testemunhos utilizados nos ensaios Barcelona. 132

Tabela 4.2 - Parâmetros para construção do diagrama $\sigma-\varepsilon$ simplificado a partir do ensaio de Barcelona.

Tabela 4.3 - Resultados médios de cargas de puncionamento máximas e residuais para os corpos de prova moldados no ensaio Barcelona. 137

Tabela 4.4 - Resultados de análises de variância de cargas relevantes do ensaio Barcelona dos corpos de prova moldados.

Tabela 4.5 - Resultados médios de cargas de puncionamento máximas e residuais para os testemunhos extraídos no ensaio Barcelona. 139

Tabela 4.6 - Parâmetros do CRF utilizados para a simulação numérica da compressão diametral dos TCRF. 140

Tabela 4.7 - Comparação entre os resultados experimentais médios e os simulados numericamente para cargas de fissuração $\left(F_{c r}\right)$, máximas $\left(F_{\text {max }}\right)$ e para diferentes níveis de abertura de fissura $\left(F_{w}\right)$ 


\section{LISTA DE ABREVIATURAS E SIGLAS}

ABECE - Associação Brasileira de Engenharia e Consultoria Estrutural ABNT - Associação Brasileira de Normas Técnicas

AES - Analysis of Evolutionary Sections

ASTM - American Society for Testing Materials

$\mathrm{CPH}$ - Comisión Permanente del Hormigón

CRF - Concreto Reforçado com Fibras

DBV - German Society for Concrete and Construction Technology

DN - Diâmetro Nominal

EHE - Instrucción Española del Hormigón Estructural

ELS - Estado Limite de Serviço

ELU - Estado Limite Último

EN - Norma Europeia

FIB - Fédération internationale du béton

IC - Intervalo de Confiança

JSCE - Japan Society of Civil Engineers

MAP - Model for the Analysis of Pipes

NBN - Bureau de Normalisation

PF - Fibra de polipropileno

RILEM - Réunion Internationale des Laboratoires et Experts des Matériaux

$\mathrm{RR}$ - Resistência residual associada à região de pré-ruptura

RS - Resistência residual associada à região de serviço

SF - Fibra de aço

SNIS - Sistema Nacional de Informações sobre Saneamento

TCOD - Total Circumferential Opening Displacement

TCRF - Tubo de Concreto Reforçado com Fibras

UNE - Norma Española 


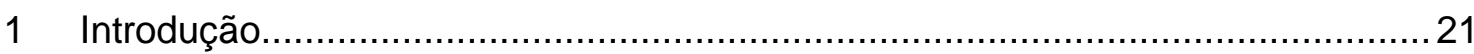

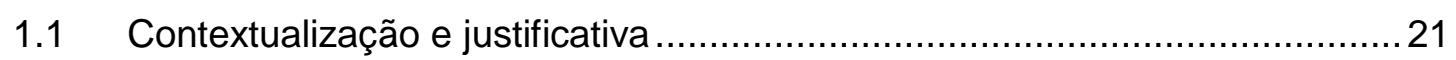

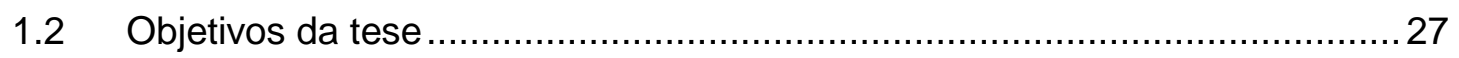

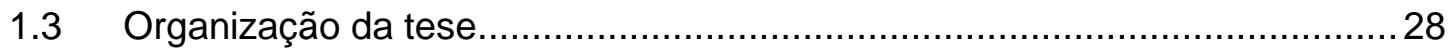

2 Comportamento mecânico do concreto reforçado com fibras ................................30

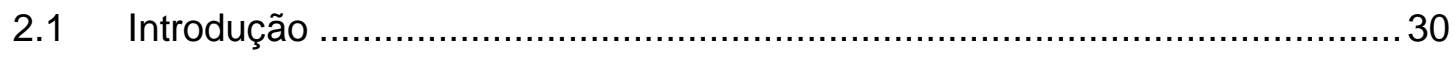

2.1.1 Objetivos do capítulo ………………………...................................

2.1.2 Organização do capítulo .....................................................................

2.2 Ensaio de duplo puncionamento ou ensaio Barcelona....................................32

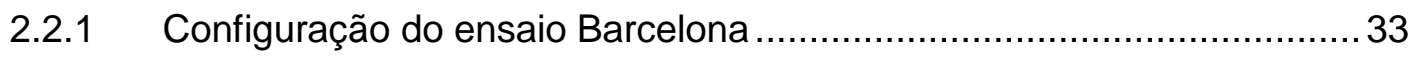

2.2.2 Propostas para correlação entre o TCOD e o deslocamento vertical .....35

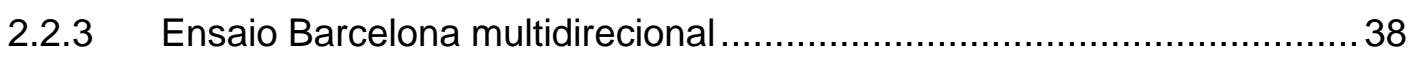

2.2.4 Correlação entre o ensaio Barcelona e o ensaio de flexão de prismas.. 41

2.2.5 Modelo constitutivo simplificado baseado no ensaio Barcelona ..............43

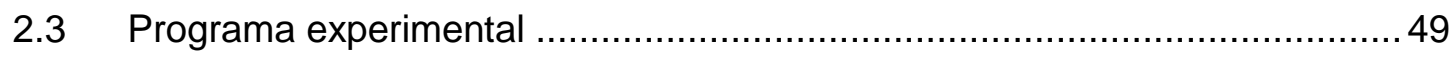

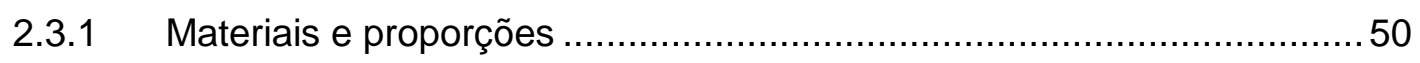

2.3.2 Preparação dos corpos de prova e métodos de ensaio ...........................52

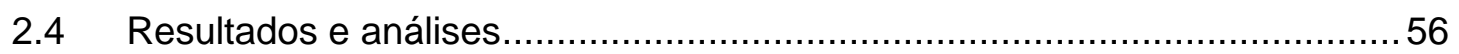

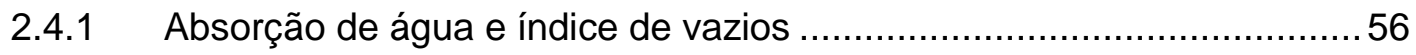

2.4.2 Resistência à compressão................................................................58

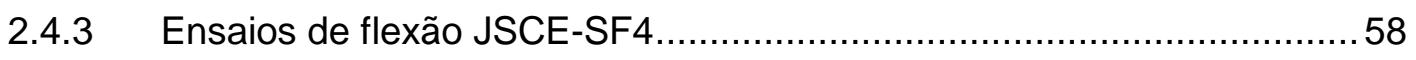

2.4.4 Ensaio Barcelona ............................................................................ 63

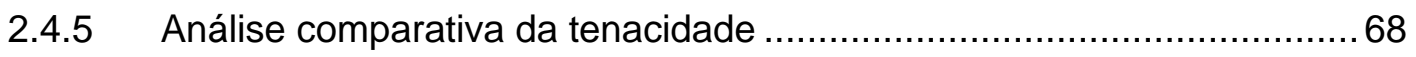

2.4.6 Análise comparativa do comportamento pós-fissuração ..........................72

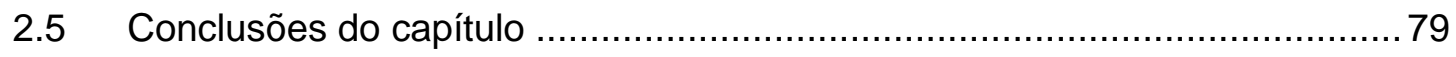

3 Comportamento mecânico dos tubos de concreto reforçados com fibras .............81 
3.1 Introdução

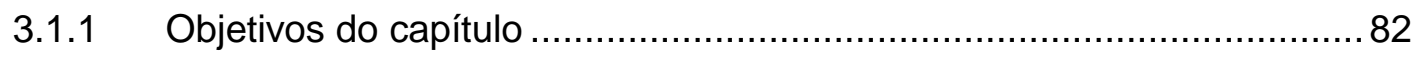

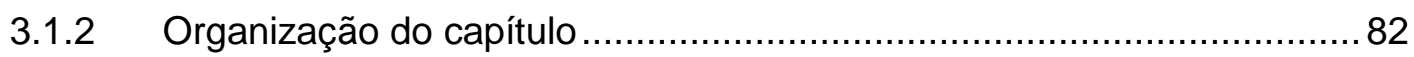

3.2 Projeto estrutural e controle dos tubos de concreto reforçados com fibras ... 83

3.2.1 Compressão diametral de tubos …................................................ 84

3.2.2 Compressão diametral de tubos - avanços no procedimento do ensaio 87

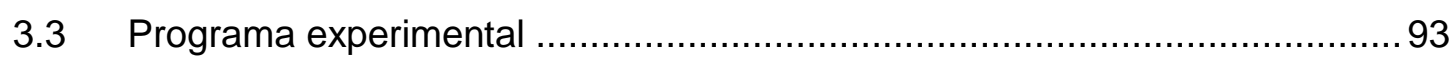

3.3.1 Produção de tubos de concreto com fibras .......................................93

3.3.2 Moldagem de corpos de prova …................................................... 97

3.3.3 Compressão diametral dos tubos …................................................ 98

3.3.4 Extração de testemunhos dos tubos ensaiados ................................ 100

3.4 Resultados e análises................................................................ 101

3.4.1 Absorção de água e índice de vazios ......................................... 101

3.4.2 Resistência à compressão ......................................................... 102

3.4.3 Compressão diametral dos tubos ….............................................. 104

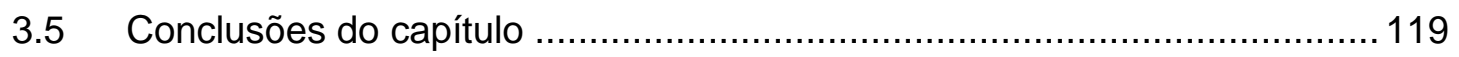

4 simulação numérica do comportamento mecânico dos tubos de concreto

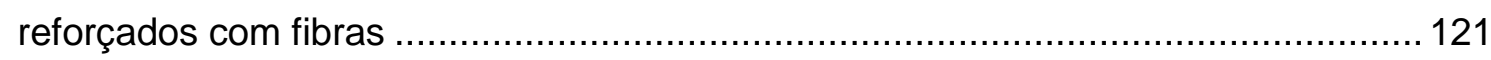

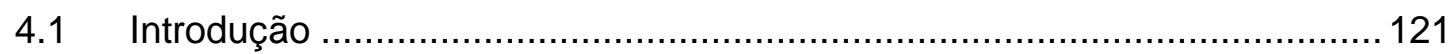

4.1.1 Objetivo do capítulo ................................................................... 122

4.1.2 Organização do capítulo ......................................................... 122

4.2 Modelo numérico para simulação do ensaio de compressão diametral de tubos de concreto 123

4.2.1 Comportamento estrutural do tubo de concreto no ensaio de compressão

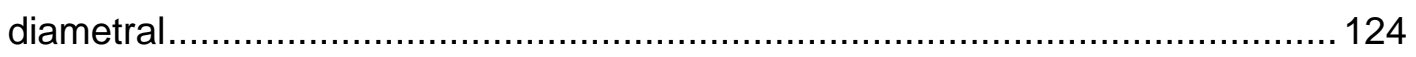

4.2.2 Modelo de análise seccional ........................................................... 126

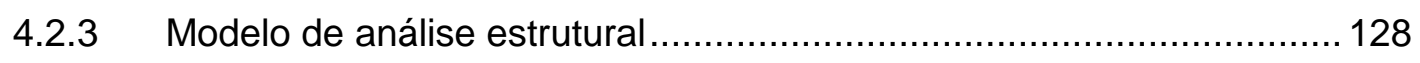

4.3 Programa experimental e simulação numérica ....................................... 130 
4.3.1 Produção dos concretos …........................................................ 131

4.3.2 Moldagem de corpos de prova e extração de testemunhos .................131

4.3.3 Ensaio Barcelona ....................................................................... 132

4.3.4 Simulação numérica ................................................................ 133

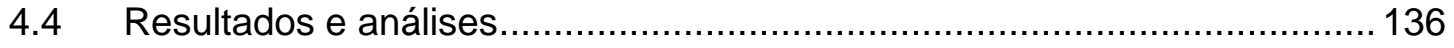

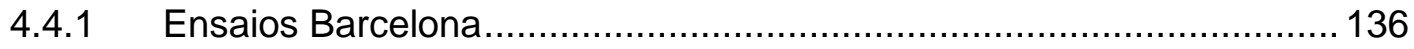

4.4.2 Simulações numéricas.................................................................. 139

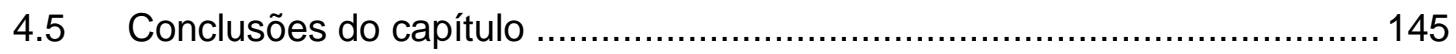

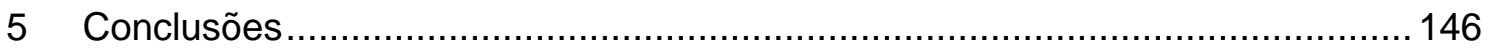

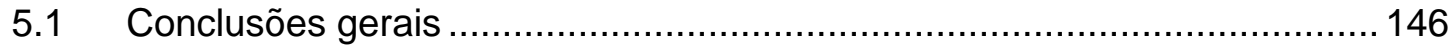

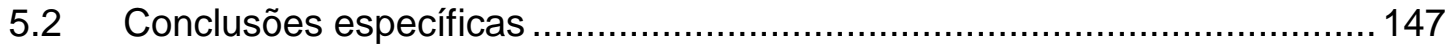

5.3 Sugestões para pesquisas futuras ..................................................... 149

Referências bibliográficas ................................................................. 150 


\section{INTRODUÇÃO}

\subsection{Contextualização e justificativa}

A necessidade de se ampliar as redes de coleta e de tratamento de esgotos no Brasil é urgente. Isto pode ser observado através dos relatórios apresentados periodicamente pelo Ministério das Cidades que, na publicação que apresenta os resultados de 2013, indica percentuais de atendimento inferiores a $50 \%$ na maioria das regiões (Tabela 1.1).

Tabela 1.1 - Níveis de atendimento com água e esgotos dos prestadores de serviço participantes do SNIS em 2013, segundo região geográfica. Fonte: SNIS (2014).

\begin{tabular}{ccccccc}
\hline \multirow{2}{*}{ Regiões } & \multicolumn{3}{c}{ Índice de atendimento (\%) } & \multicolumn{2}{c}{$\begin{array}{c}\text { Índice de tratamento dos } \\
\text { esgotos (\%) }\end{array}$} \\
\cline { 2 - 7 } & \multicolumn{2}{c}{ Água } & Coleta de esgotos & $\begin{array}{c}\text { Esgotos } \\
\text { gerados }\end{array}$ & $\begin{array}{c}\text { Esgotos } \\
\text { coletados } \\
\end{array}$ \\
\cline { 2 - 7 } & Total & Urbano & Total & Urbano & Total & Total \\
\hline Norte & 52,4 & 62,4 & 6,5 & 8,2 & 14,7 & 85,3 \\
Nordeste & 72,1 & 89,8 & 22,1 & 29,3 & 28,8 & 78,1 \\
Sudeste & 91,7 & 96,8 & 77,3 & 82,2 & 43,9 & 64,3 \\
Sul & 87,4 & 97,4 & 38,0 & 44,2 & 35,1 & 78,9 \\
Centro-oeste & 88,2 & 96,3 & 42,2 & 48,6 & 45,9 & 91,6 \\
Brasil & 82,5 & 93,0 & 48,6 & 56,3 & 39,0 & 69,4 \\
\hline
\end{tabular}

Mais crítico que a análise dos baixos índices de atendimento na distribuição de água, coleta e tratamento de esgoto levantados em 2013 é o fato desses valores terem avançado muito pouco ou reduzido em várias situações, quando comparados ao levantamento referente ao ano de 2008 (SNIS, 2010), conforme mostra a Tabela 1.2.

Tabela 1.2 - Evolução dos níveis de atendimento com água e esgotos dos prestadores de serviço participantes do SNIS de 2008 e de 2013. Fonte: Adaptado de SNIS (2010, 2014).

\begin{tabular}{|c|c|c|c|c|c|}
\hline \multirow{3}{*}{ Regiões } & \multicolumn{4}{|c|}{ Índice de atendimento (\%) } & \multirow{3}{*}{$\begin{array}{c}\text { Índice de tratamento dos } \\
\text { esgotos (\%) } \\
\text { Esgotos gerados } \\
\text { Total }\end{array}$} \\
\hline & \multicolumn{2}{|c|}{ Água } & \multicolumn{2}{|c|}{ Coleta de esgotos } & \\
\hline & Total & Urbano & Total & Urbano & \\
\hline Norte & $-5,2$ & $-9,6$ & 0,9 & 1,2 & 3,5 \\
\hline Nordeste & 4,1 & 0,4 & 3,2 & 3,7 & $-5,7$ \\
\hline Sudeste & 1,4 & $-0,8$ & 10,7 & 10,1 & 7,8 \\
\hline Sul & 0,7 & $-0,8$ & 5,6 & 5,9 & 4,0 \\
\hline Centro-oeste & $-1,3$ & 0,7 & $-2,6$ & $-0,9$ & 4,3 \\
\hline Brasil & 1,3 & $-1,7$ & 5,4 & 5,7 & 4,4 \\
\hline
\end{tabular}


Considerando particularmente a coleta de esgotos, percebe-se na Tabela 1.2 que o maior aumento nos níveis de atendimento ocorreu na região sudeste, cujo percentual era o menos crítico. Já as regiões norte e nordeste que apresentaram índices baixíssimos evoluíram muito pouco. Outro destaque é a região centro-oeste, na qual ouve regressão no percentual de atendimento à coleta de esgoto, indicando que o crescimento populacional não foi acompanhado pelas políticas de saneamento básico. A análise destes baixos índices de atendimento quanto à coleta de esgoto pressupõe que um investimento maciço e constante neste tipo de obra é necessário, e o mercado produtor de tubos deve ser capaz de atender esta demanda. Outra alternativa para a utilização em larga escala dos tubos de concreto consiste no seu uso no transporte de água para consumo na agricultura, na indústria ou mesmo doméstico. Experiências deste tipo foram realizadas na Líbia onde foram construídos mais de $2.000 \mathrm{~km}$ de tubulação de concreto para levar água ao deserto do Saara ${ }^{1}$ e no Canadá onde tubulações de concreto percorrem 135 km de distância para conduzir água do Lago Shoal até a cidade de Winnipeg² ${ }^{2}$.

A utilização dos tubos de concreto enterrados apresenta uma série de vantagens. Entre elas estão à relação custo-benefício, o domínio técnico que o mercado possui das propriedades do concreto, a flexibilidade na produção de tubos de vários diâmetros e a garantia da qualidade da obra depender fundamentalmente da resistência do tubo, diferente dos tubos flexíveis que dependem do sistema solo-tubo (CHAMA NETO, 2008). Além disso, o parâmetro sustentabilidade foi avaliado por Viñolas, Aguado e Josa (2009) que concluíram que para diâmetros de tubos pequenos a avaliação global da sustentabilidade é similar para a utilização de um tubo flexível ou de concreto, mas quando o diâmetro é aumentado, o tubo de concreto tem desempenho superior em termos de sustentabilidade global.

Ainda que tenha muitas vantagens o concreto apresenta algumas limitações, principalmente no que diz respeito a sua limitada capacidade de resistir a esforços de tração associada à baixa capacidade de deformação e a ruptura frágil. No caso dos tubos de concreto, estas limitações resultam na restrição da utilização de tubos de concreto simples apenas para diâmetros inferiores a $600 \mathrm{~mm}$. Para diâmetros maiores, que receberão esforços mais intensos, se faz necessário o uso do concreto com reforços com fios, telas ou fibras.

\footnotetext{
${ }^{1}$ Fonte: http://www.water-technology.net/projects/gmr/

${ }^{2}$ Fonte: http://www.water-technology.net/projects/winnipeg-treatment/
} 
A utilização das fibras nos tubos de concreto tem, como principal vantagem, a maior facilidade de produção em relação aos tubos com reforço convencional. Isto porque quando as fibras são utilizadas elimina-se a etapa de preparação da armadura, pois as fibras são adicionadas ao concreto diretamente na mistura. A eliminação desta etapa acelera o processo de produção, consome menos energia, mão de obra e espaço na indústria. Outra vantagem que pode ser destacada é a distribuição aleatória das fibras por todo o volume do componente, reforçando-o inclusive nas bordas, o que resulta no menor risco de quebra da peça durante as etapas de produção, transporte e manuseio (FIGUEIREDO e CHAMA NETO, 2006). Outra característica da fibra é a sua maior capacidade de reforço para baixos níveis de deformação e fissuração, quando comparada com o reforço convencional com fios de aço. Isto ocorre porque a fibra reforça toda a espessura do tubo, ao contrário da armadura convencional que acaba sendo posicionada no meio da espessura devido à necessidade de se garantir um cobrimento mínimo de concreto (FIGUEIREDO, 2008). A revisão da norma brasileira de tubos de concreto, que incorporou o concreto reforçado com fibras (CRF) como uma das alternativas tecnológicas para a produção desses componentes, representou um passo importante para o mercado de fibras. Isto porque trata-se da primeira norma nacional que parametriza o uso do CRF.

No Brasil, o tema tubos de concreto reforçados com fibras foi abordado em algumas dissertações de mestrado desenvolvidas na Universidade de São Paulo (CHAMA NETO, 2002; ESCARIZ, 2012), na Universidade Estadual de Campinas (RAMOS, 2002) e na Universidade Estadual Júlio de Mesquita Filho (FUGII, 2008). Além disso, nos últimos anos diversos artigos foram publicados em periódicos internacionais referentes a estudos experimentais e numéricos com tubos reforçados diferentes tipos e teores de fibras. Esses estudos foram desenvolvidos em universidades de diferentes países, como apresenta a Tabela 1.3. Um dos fatores que estimulam estas pesquisas é o fato dos tubos serem produzidos em série e otimizações representarem economia de escala, além da já mencionada necessidade de obras de saneamento básico que ocorre, de maneira especial, em países em desenvolvimento.

A tendência internacional de busca por um consenso no dimensionamento do CRF como material estrutural está direcionada a adoção dos critérios estabelecidos pelo fib Model Code 2010 (FIB, 2013). Inclusive no Brasil, uma comissão de estudos da ABECE tem trabalhado na produção de um documento de prática recomendada integralmente baseado na nova proposição do fib Model Code 2010, com uma versão 
preliminar já disponível no site da $\mathrm{ABECE}^{3}$. A adoção de critérios distintos de avaliação, dependendo do tipo de fibra ou do tipo de reforço, deve dar lugar a requisitos claros para dimensionamento e controle. No caso particular dos tubos de concreto, o reforço com fibras é prejudicado por uma exigência de desempenho muito mais rigorosa do que para o reforço convencional com armadura. O critério de classificação dos tubos é feito, basicamente, através da carga de fissura, para o reforço com armadura, ou carga mínima isenta de dano, para o reforço com fibras, determinadas no ensaio de compressão diametral. No entanto, a exigência para o reforço com fibras é que esta carga seja atingida sem fissuração visível, enquanto os tubos com armadura poderão apresentar fissuras com aberturas de até $0,25 \mathrm{~mm} e$ comprimento $300 \mathrm{~mm}$.

Tabela 1.3 - Levantamento de artigos publicados em periódicos internacionais indexados entre 2012 e 2015 relacionados a tubos de concreto reforçados com fibras.

\begin{tabular}{|c|c|c|c|c|}
\hline País & Universidade & Referência & $\begin{array}{c}\text { Título } \\
\text { periódico }\end{array}$ & $\begin{array}{c}\text { Tipo de reforço dos } \\
\text { tubos }\end{array}$ \\
\hline & $\begin{array}{l}\text { Universidade } \\
\text { de São Paulo }\end{array}$ & $\begin{array}{l}\text { de la Fuente et al., } \\
\qquad 2012 a\end{array}$ & $\begin{array}{l}\text { Construction and } \\
\text { building materials }\end{array}$ & $\begin{array}{c}\text { Fibras de aço } \\
\text { Reforço convencional }\end{array}$ \\
\hline Espanha & $\begin{array}{l}\text { Universitat } \\
\text { Politècnica de } \\
\text { Catalunya }\end{array}$ & $\begin{array}{l}\text { de la Fuente et al., } \\
2013\end{array}$ & $\begin{array}{l}\text { Construction and } \\
\text { building materials }\end{array}$ & $\begin{array}{l}\text { Fibras de polipropileno } \\
\text { Reforço convencional }\end{array}$ \\
\hline \multirow{6}{*}{$\begin{array}{l}\text { Estados } \\
\text { Unidos }\end{array}$} & \multirow{3}{*}{$\begin{array}{c}\text { Michigan State } \\
\text { University }\end{array}$} & $\begin{array}{l}\text { Peyvandi, Soroushian, } \\
\text { Jahangirnejad, } 2013\end{array}$ & $\begin{array}{l}\text { Construction and } \\
\text { building materials }\end{array}$ & $\begin{array}{c}\text { Fibras de PVA } \\
\text { Reforço convencional }\end{array}$ \\
\hline & & $\begin{array}{l}\text { Peyvandi, Soroushian, } \\
\text { Jahangirnejad, } 2014\end{array}$ & $\begin{array}{l}\mathrm{ACI} \text { structural } \\
\text { journal }\end{array}$ & $\begin{array}{c}\text { Fibra de aço } \\
\text { Fibra sintética } \\
\text { Reforço convencional }\end{array}$ \\
\hline & & $\begin{array}{l}\text { Peyvandi, Soroushian, } \\
2015\end{array}$ & $\begin{array}{l}\text { Materials and } \\
\text { structures }\end{array}$ & $\begin{array}{c}\text { Fibras de PVA } \\
\text { Reforço convencional }\end{array}$ \\
\hline & \multirow{3}{*}{$\begin{array}{l}\text { University of } \\
\text { Texas }\end{array}$} & Abolmaali et al., 2012 & $\begin{array}{c}\text { Transportation } \\
\text { Research Record }\end{array}$ & $\begin{array}{c}\text { Fibra de aço } \\
\text { Reforço convencional }\end{array}$ \\
\hline & & Park et al., 2014 & $\begin{array}{l}\text { Transportation } \\
\text { Research Record }\end{array}$ & $\begin{array}{l}\text { Fibra de polipropileno } \\
\text { Reforço convencional }\end{array}$ \\
\hline & & Park et al., 2015 & $\begin{array}{l}\text { Construction and } \\
\text { building materials }\end{array}$ & $\begin{array}{c}\text { Fibra de aço } \\
\text { Fibra de polipropileno } \\
\text { Borracha } \\
\text { Reforço convencional }\end{array}$ \\
\hline \multirow{2}{*}{ Canadá } & \multirow{2}{*}{$\begin{array}{l}\text { Western } \\
\text { University }\end{array}$} & $\begin{array}{l}\text { Mohamed, Soliman e } \\
\text { Nehdi, } 2014\end{array}$ & $\begin{array}{l}\text { Construction and } \\
\text { building materials }\end{array}$ & $\begin{array}{c}\text { Fibras de aço } \\
\text { Reforço convencional }\end{array}$ \\
\hline & & $\begin{array}{l}\text { Mohamed, Soliman e } \\
\text { Nehdi, } 2015\end{array}$ & $\begin{array}{l}\text { Engineering } \\
\text { structures }\end{array}$ & $\begin{array}{c}\text { Fibras de aço } \\
\text { Reforço convencional }\end{array}$ \\
\hline
\end{tabular}

${ }^{3}$ Associação Brasileira de Engenharia e Consultoria Estrutural. Estruturas de Concreto Reforçado com Fibras - Diretrizes para Projeto. Texto preliminar. Novembro, 2013. Disponível em: http://site.abece.com.br/index.php/comites-tecnicos. 
O ensaio de compressão diametral segundo a norma ABNT NBR 8890 (2007), concebida a partir da norma europeia EN 1916 (2002), simula a situação de serviço em uma condição crítica, pois avalia o componente sem o confinamento proporcionado pelo terreno. Figueiredo et al. (2012a) propõem alterações na metodologia de ensaio, buscando melhorar sua confiabilidade e aproximá-la às concepções de projeto e controle preconizados pelo fib Model Code 2010 (FIB, 2013). $\mathrm{Na}$ concepção do fib Model Code 2010 (FIB, 2013) são considerados dois comportamentos básicos esperados para o CRF em função da capacidade de reforço pós-fissuração, softening e hardening (Figura 1.1). Com isso o projeto pode ser balizado pelo comportamento residual pós-fissuração para níveis pré-estabelecidos de deformação e abertura de fissura.
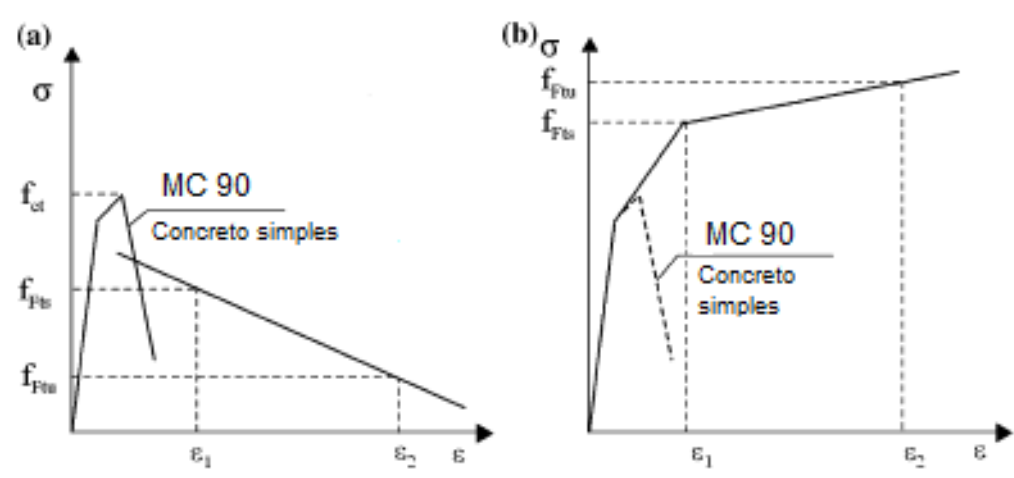

Figura 1.1 - Diagrama $\sigma-\varepsilon$ para o dimensionamento de elementos com CRF apresentando comportamento de softening (a) e hardening (b) segundo o fib Model Code. Fonte: di Prisco; Plizzari; Vandewalle, 2009.

O ensaio de compressão diametral do componente representa alto custo, além de gerar um importante resíduo de concreto, devendo limitar-se ao controle de aceitação ou à validação final de um novo componente projetado. Desta forma, os modelos que parametrizem o comportamento do tubo de concreto através de ensaios de menor escala devem ser desenvolvidos. Além disso, devem existir modelos de projeto confiáveis, que possam otimizar a dosagem e o desempenho do componente. Estes modelos devem possibilitar tanto o dimensionamento quanto a previsão do comportamento do componente, de modo concatenado com os procedimentos de controle do produto durante o processo de produção e de aceitação e no controle da execução.

$\mathrm{Na}$ busca pelo desenvolvimento de tal ferramenta de la Fuente, Aguado e Molins (2011) propôs o modelo Model for the Analysis of Pipes (MAP) para projeto e verificação de tubos de concreto com qualquer configuração de reforço (armadura e/ou 
fibras). Através do MAP diferentes parâmetros podem ser avaliados, os projetos de tubos podem ser otimizados e simulações para validação podem ser verificadas, sem a necessidade de executar o ensaio de vários componentes. Para que o MAP simule o comportamento do tubo de CRF no ensaio de compressão diametral até altos níveis de deformações devem ser considerados os aspectos de fissuração e a resposta pósfissuração dos materiais, modelando o comportamento do CRF.

Para a modelagem do comportamento à compressão e à tração do CRF vários modelos constitutivos podem ser adotados, como as propostas de Barros et al. (1999), Vandewalle et al. (2003), Bencardino et al. (2008), Laranjeira; Aguado; Molins (2008) e o fib Model Code 2010 (FIB, 2013). Os parâmetros básicos do comportamento à tração do CRF são determinados, para a maioria desses modelos constitutivos, através de ensaios de tração na flexão. No entanto, a moldagem de corpos de prova prismáticos que representem o material do tubo não é uma tarefa simples, como foi demonstrado por Chama Neto (2002) e Fugii (2008). Na ausência de ensaios de tração na flexão que caracterizem adequadamente o material podem ser utilizadas equações para o cálculo da resistência à flexão residual em função do teor de fibras, como as calibradas por Barros et al. (2005), mas para isto é preciso adotar o mesmo tipo de fibra (DRAMIX® RC-80/60-BN). Ressalta-se ainda que o trabalho de Barros et al. (2005) utilizou concretos convencionais, que diferem em dosagem e, principalmente, em reologia em comparação aos concretos para produção de tubos. De la Fuente et al. (2012b) aplicou estas equações para simular o comportamento à compressão diametral no modelo MAP e comparou com campanhas experimentais realizadas no Brasil (FIGUEIREDO et al., 2012b) apresentando, para este caso específico, erros de até 14\% (Figura 1.2).

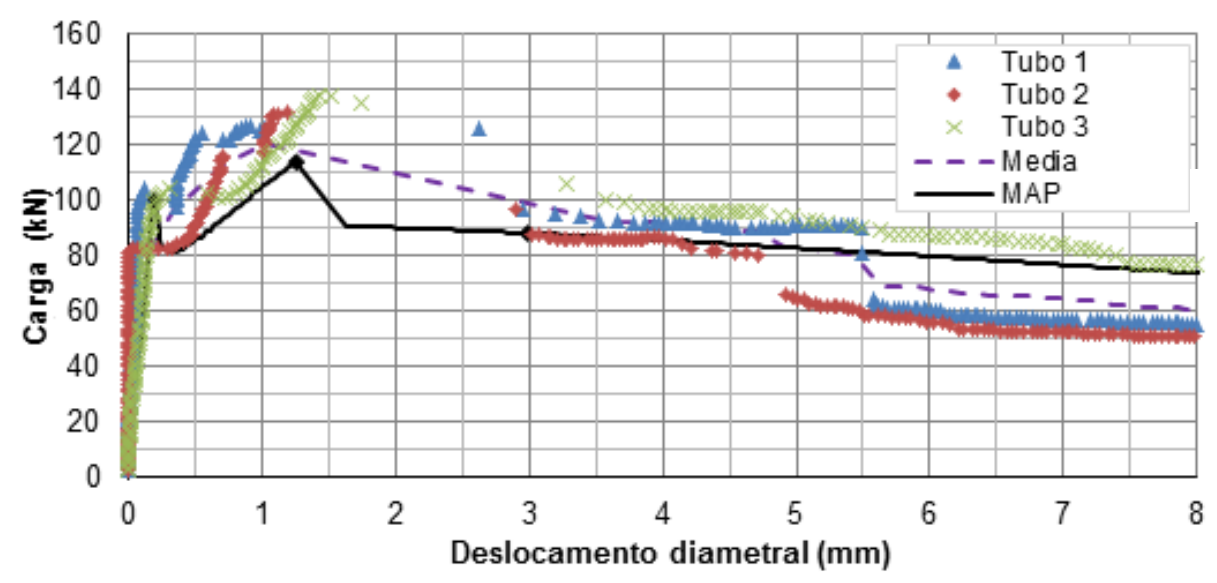

Figura 1.2 - Resultados experimentais e do modelo MAP para a compressão diametral de tubos de concreto de $600 \mathrm{~mm}$ de diâmetro e reforçados com $10 \mathrm{~kg} / \mathrm{m}^{3}$ de fibras de aço. Fonte: de la Fuente et al. (2012b). 
Para que a aplicação desse modelo numérico possa ser difundida como ferramenta de projeto de tubos com novas fibras (dimensões, caraterísticas ou matéria prima, por exemplo), a parametrização do comportamento mecânico do CRF deve ser melhor implementada. Além da dificuldade apontada para a moldagem do corpo de prova prismático, estudos recentes relataram a dificuldade de se controlar a resistência à compressão do concreto, que é um ensaio de concepção simples, devido à baixa qualidade dos ensaios realizados por laboratórios nacionais (CARROMEU et al., 2012; MAGALHÃES et al., 2013). Por isso, a utilização de um método de ensaio alternativo que seja confiável, mas de procedimento mais simples, pode qualificar minimamente mais laboratórios no Brasil para a caracterização mecânica do CRF e possibilitar subsídios para a simulação do comportamento mecânico dos tubos.

Diante deste panorama, a presente tese foi desenvolvida com a finalidade de avançar no conhecimento referente à simulação do ensaio de compressão diametral dos tubos de CRF, principalmente no que se refere a melhor parametrização mecânica do material. Com isso, será possível a partir de resultados de ensaios de menor escala simular o comportamento de tubos no ensaio de compressão diametral, determinando o tipo e teor de fibra que atende à demanda de carregamento necessário. A avaliação experimental servirá para verificar seu comportamento posteriormente no ensaio de compressão diametral, evitando-se os dispendiosos gastos associado ao procedimento de tentativa e erro.

\subsection{Objetivos da tese}

O objetivo geral é propor uma metodologia para a caracterização e controle do comportamento mecânico do concreto reforçado com fibras para a produção de tubos, que permita modelar o comportamento do componente no ensaio de compressão diametral e verificar sua adequação a uma aplicação estrutural. Essa metodologia deve ser respaldada e comparada com resultados experimentais de compressão diametral de tubos de concreto reforçados com fibras.

Para alcançar esse objetivo geral é necessário cumprir os seguintes objetivos específicos:

- Comprovar a viabilidade de um método alternativo ao ensaio de flexão de prismas para a caracterização do comportamento pós-fissuração do CRF para fins estruturais; 
- Avaliar o comportamento mecânico de tubos de concreto reforçados com fibras através do ensaio de compressão diametral, incorporando recentes modificações no método para aproximar as condições de controle do componente à filosofia proposta pelo fib Model Code 2010;

- Estabelecer uma correlação entre o deslocamento diametral e a abertura de fissura dos tubos com diferentes reforços, de modo a estabelecer parâmetros mais confiáveis para os requisitos de resistências pós-fissuração no estado limite de serviço e estado limite último;

- Verificar o ajuste do modelo de previsão de comportamento utilizando os parâmetros do material caracterizados através do método de ensaio alternativo ao de flexão.

\subsection{Organização da tese}

Esta tese de doutorado está organizada em cinco capítulos, conforme apresentado na Figura 1.3.

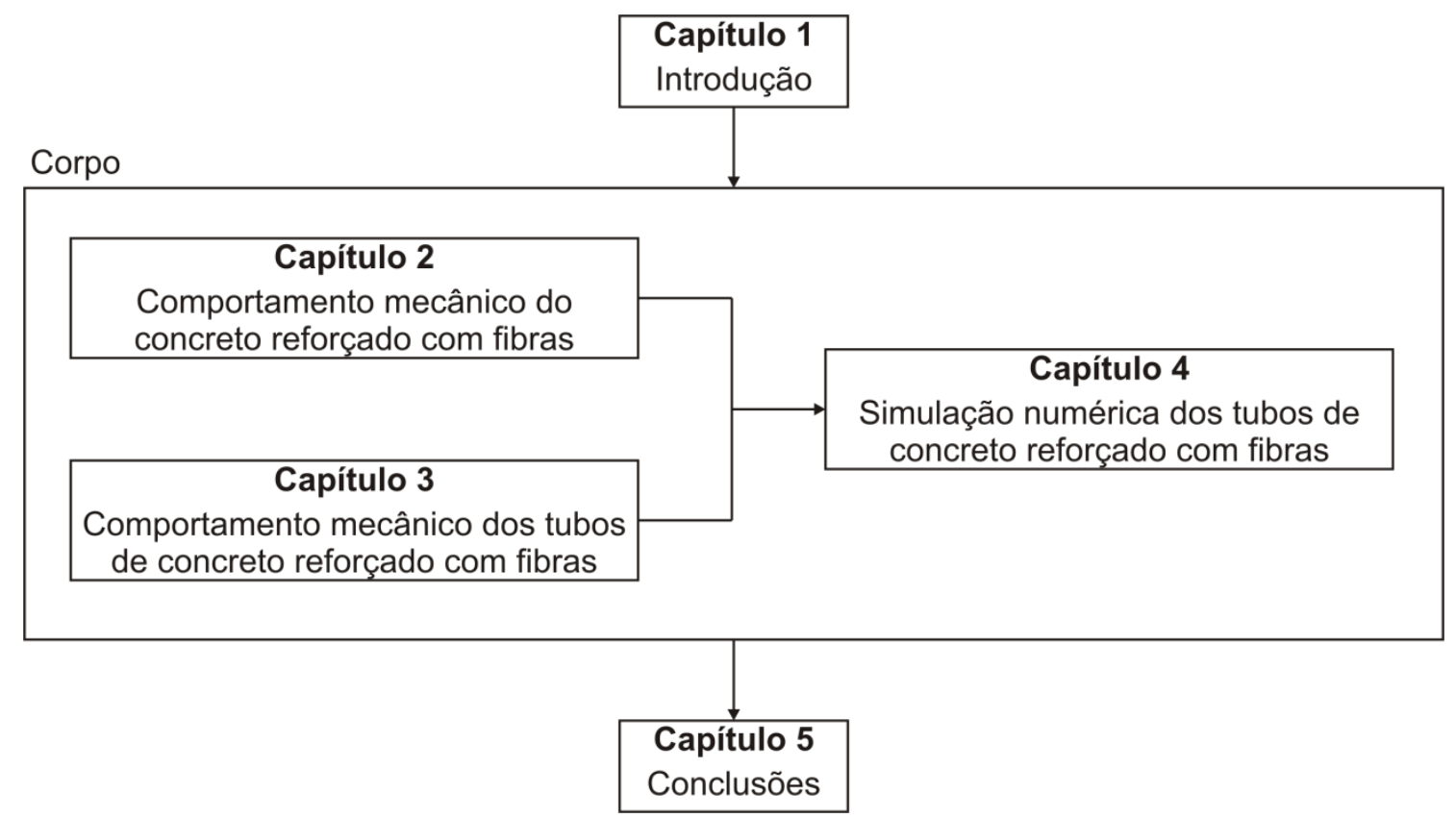

Figura 1.3 - Organização da tese de doutorado.

No Capítulo 1 é apresentada a contextualização e as motivações para a realização da tese. Além disso, o objetivo geral e os objetivos específicos estão apresentados, bem como a organização do trabalho. 
O Capítulo 2 aborda a caracterização do material utilizando ensaios alternativos ao tradicional ensaio de flexão de prismas, focando principalmente no ensaio de duplo puncionamento ou ensaio Barcelona. Uma campanha experimental é apresentada, comparando o ensaio Barcelona ao ensaio de flexão da norma japonesa, visto que este último é o mais difundido no Brasil.

No Capítulo 3 o foco é para a caracterização do componente. Nele se revisa as recentes abordagens para melhorar as condições de controle do componente aproximando-as da filosofia proposta pelo fib Model Code 2010. Neste sentido, um programa experimental é realizado no qual se avalia essas modificações no método de controle dos componentes. Além disso, os resultados permitiram propor uma correlação entre o deslocamento diametral e a abertura de fissura.

O Capítulo 4 propõe um modelo de parametrização do comportamento pósfissuração do CRF, baseado no ensaio Barcelona, e sua aplicação no modelo de simulação numérica do comportamento do componente no ensaio de compressão diametral. Os resultados das simulações numéricas foram validados através de ensaios de compressão diametral dos tubos.

O Capítulo 5 encerra a tese com as conclusões gerais e específicas que pretendem responder aos objetivos propostos. Além disso, algumas perspectivas de trabalhos futuros são apresentadas. 


\section{COMPORTAMENTO MECÂNICO DO CONCRETO REFORÇADO COM FIBRAS}

\subsection{Introdução}

O concreto reforçado com fibras (CRF) é um material compósito caracterizado pelo acréscimo de resistência residual pós-fissuração quando o material é solicitado à tração. Isto ocorre devido ao mecanismo de reforço das fibras que servem de ponte de transferência de tensões através das fissuras. Além das vantagens técnicas há também vantagens econômicas relacionadas ao uso das fibras como reforço. $O$ principal ganho econômico está relacionado à redução de etapas do processo produtivo e de mão de obra, garantindo maior produtividade ao processo (FIGUEIREDO, 2011).

As vantagens aplicativas desse material, aliado ao crescente número de estudos na área, podem ser responsáveis por um aumento significativo do uso do CRF para fins estruturais. No entanto, para garantir a qualidade dessa aplicação, é fundamental a existência de um método de caracterização do comportamento mecânico que seja confiável, econômico e compatível com modelos de dimensionamento.

A maioria dos métodos de ensaio utilizada atualmente para caracterização do CRF é baseado na flexão de pequenas vigas. Porém, este formato não representa adequadamente o comportamento de estruturas reais quanto ao mecanismo de fissuração e normalmente apresenta elevada dispersão (RAMBO; SILVA; TOLEDO FILHO, 2014). Como exemplo, podem ser citados os ensaios especificados pelas normas JSCE-SF4 (1984), ASTM C1609 (2010), EN 14651 (2007), entre outros. Salvador (2013) apresentou uma revisão e comparação experimental desses métodos de ensaio para a flexão, mostrando que podem ser correlacionados. $O$ fato de se utilizar de corpos de prova prismáticos nestes ensaios praticamente impossibilita a extração de testemunhos para avaliar as propriedades mecânicas de estruturas já executadas, especialmente no caso de dúvidas com relação ao desempenho do CRF. Além disso, os métodos de ensaio, com exceção do previsto na JSCE-SF4 (1984), indicam a utilização de máquinas de ensaio com sistema fechado (closed-loop), ou seja, o controle da velocidade de ensaio é feito pela deflexão real do corpo de prova ou pela abertura de fissura no mesmo. Esse tipo de controle possibilita um ensaio mais estável, sem a ocorrência de instabilidades pós-fissuração da matriz 
(GOPALARATNAM e GETTU, 1995). Porém, para a realização de ensaios com este tipo de sistema é necessária a utilização de máquinas de ensaio mais caras e sofisticadas, o que dificilmente é encontrado nos laboratórios privados. Outra dificuldade dos ensaios de flexão está relacionada à moldagem dos corpos de prova prismáticos que, além de demandarem um grande volume de concreto, são de difícil execução para os concretos secos como o utilizado na produção de tubos, como apontado por Chama Neto (2002) e Fugii (2008).

O ensaio Barcelona normalizado pela AENOR UNE 83515 (2010) surge como uma promissora alternativa tecnológica, pois permite a utilização de corpos de prova cilíndricos ou cúbicos e de dimensões bem menores que as dos prismas, permitindo a extração de amostras de estruturas, inclusive. Contudo, o ensaio foi normalizado especificando o uso de um extensômetro circunferencial para medida do aumento do perímetro do corpo de prova ou TCOD (Total Circumferential Opening Displacement). O uso deste extensômetro resulta numa limitação para o ensaio, pois se trata de um equipamento caro e incomum na maioria dos laboratórios. Neste sentido, novos estudos foram realizados com o objetivo de simplificar o arranjo experimental utilizando o deslocamento vertical da máquina de ensaio $\left(\delta_{p}\right)$. Carmona, Aguado e Molins (2012) realizaram uma extensa campanha experimental para correlacionar a tenacidade obtida através do TCOD e do deslocamento vertical $\left(\delta_{p}\right)$, para uma faixa de deslocamento vertical entre 1 e $4 \mathrm{~mm}$. Estas correlações são empíricas, válidas para uma faixa de deslocamento vertical $\left(\delta_{p}\right)$, correlacionam medidas de tenacidade e não diretamente os valores de TCOD e deslocamento vertical $\left(\delta_{p}\right)$, e não representam o mecanismo físico ocorrido durante o ensaio. Por essas razões, Pujadas et al. (2013) realizaram um estudo posterior, propondo um modelo analítico para conversão direta do deslocamento vertical $\left(\delta_{p}\right)$ em TCOD. Isto torna o ensaio possível de ser realizado utilizando os recursos disponíveis nas máquinas dos laboratórios brasileiros, inclusive aquelas máquinas produzidas no Brasil.

Ainda que a literatura tenha mostrado o potencial do ensaio Barcelona para a caracterização do CRF este ensaio ainda não foi difundido. $O$ ensaio mais utilizado para caracterização do CRF seja para estudo de dosagem ou controle tecnológico ainda continua sendo o ensaio de flexão em sistema aberto utilizando a norma japonesa JSCE-SF4 (1984). Molins, Aguado e Saludes (2009) comparam o ensaio Barcelona com o ensaio da norma belga NBN B 15-238 (1992), que apresenta configuração semelhante ao ensaio japonês, mas utiliza controle de velocidade por 
sistema fechado. Esse estudo verificou ótima correlação entre os ensaios, mas indica que mais estudos experimentais e teóricos devem ser realizados para complementar a validação do ensaio Barcelona como método alternativo para a caracterização do CRF.

Diante deste cenário, este capítulo apresenta uma abrangente revisão da literatura referente ao ensaio Barcelona e um programa experimental para comparação deste com o ensaio de flexão JSCE-SF4, visto que este último é o mais difundido no meio técnico que também serve de referência para vários projetistas.

\subsubsection{Objetivos do capítulo}

O objetivo geral deste capítulo é comprovar a viabilidade do ensaio Barcelona como método alternativo para caracterização do comportamento pós-fissuração do CRF para fins estruturais. Para isto, uma revisão do estado do conhecimento do ensaio Barcelona e um programa experimental comparando os ensaios Barcelona e flexão JSCE-SF4 foram desenvolvidos.

\subsubsection{Organização do capítulo}

Inicialmente é apresentada no item 2.2 uma revisão do atual estado do conhecimento em relação ao ensaio Barcelona, comparando-o com o tradicional ensaio de flexão de prismas. Apresenta-se também no item 2.2.5 um modelo constitutivo proposto pela literatura utilizando o ensaio Barcelona. Uma campanha experimental é apresentada no item 2.3, comparando os ensaios de flexão JSCE-SF4 e Barcelona; nela os resultados obtidos são analisados considerando a dispersão dos valores obtidos por cada método e as correlações entre as medidas de tenacidade (ver item 2.4.5) e resistências residuais (ver item 2.4.6).

\subsection{Ensaio de duplo puncionamento ou ensaio Barcelona}

O ensaio de duplo puncionamento foi idealizado por Chen (1970) para medida indireta da resistência à tração do concreto convencional. A partir desta ideia foi proposto por Saludes (2006) o ensaio Barcelona para a medida da tenacidade do CRF. Posteriormente, o ensaio foi normalizado na Espanha através da AENOR UNE 83515 (2010) para avaliar o comportamento pós-fissuração do CRF através do duplo puncionamento de corpos de prova cilíndricos moldados ou extraídos. 
O ensaio Barcelona consiste no duplo puncionamento de um corpo de prova cilíndrico de diâmetro igual à sua altura. O puncionamento é feito através de dois discos de cargas centrados nas superfícies superior e inferior do cilindro. A proporção entre o diâmetro do disco de carga e o diâmetro do corpo de prova é de 1:4, enquanto a razão entre as alturas é de 1:5. Ao aplicar a carga são induzidas tensões de tração sobre os planos que contém o eixo do cilindro e o corpo de prova se fratura ao redor destes planos (SALUDES, 2006). Pujadas (2013) indica que o mais comum é o aparecimento de três fissuras, mas entre duas a quatro fissuras podem ocorrer, e sob os discos de carga (ou punções) formam-se cunhas cônicas. A configuração normalizada para o ensaio será apresentada na sequência.

\subsubsection{Configuração do ensaio Barcelona}

A norma AENOR UNE 83515 (2010) estabelece que sejam utilizados diâmetros de $150 \mathrm{~mm}$ para corpos de prova moldados ou no mínimo $100 \mathrm{~mm}$ para testemunhos extraídos, mantendo a relação entre o diâmetro $(d)$ e a altura $(H)$ igual a um. $O$ puncionamento é feito a partir do contato de dois cilíndricos com diâmetro (a) igual a $1 / 4$ do diâmetro do corpo de prova e altura igual a $1 / 5$ da altura do mesmo, dispostos no centro das faces planas deste. A Figura 2.1 ilustra o esquema do ensaio Barcelona.

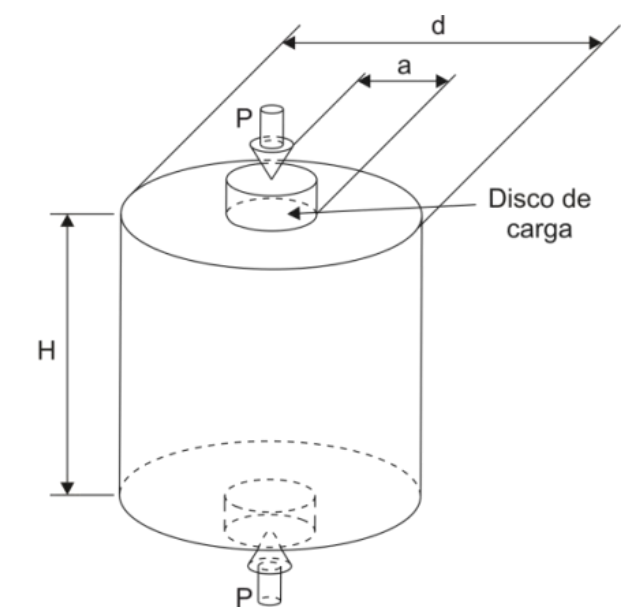

Figura 2.1 - Esquema de configuração do ensaio Barcelona. Fonte: Adaptado de Saludes (2006).

A carga deve ser aplicada de forma uniforme com velocidade de descida do equipamento de $0,5 \mathrm{~mm} / \mathrm{min}$. Na configuração original do ensaio Barcelona proposta pela norma AENOR UNE 83515 (2010) devem ser medidos a carga aplicada e o correspondente aumento do perímetro circunferencial ou TCOD através de um extensômetro de circunferência (Figura 2.2). 


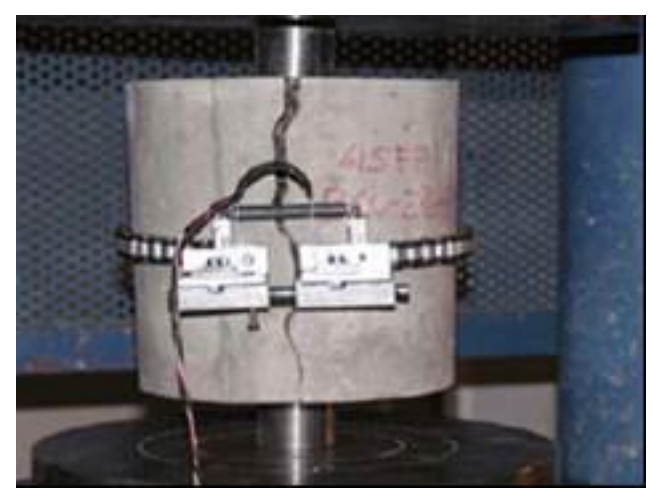

Figura 2.2 - Exemplo do ensaio Barcelona realizado utilizando o extensômetro de circunferência. Fonte: Saludes (2006).

A norma AENOR UNE 83515 (2010) estabelece que a resistência à tração do CRF através do ensaio Barcelona $\left(f_{t}\right)$ deve ser calculada através da Eq. 2-1. A dedução desta equação foi feita através do método de bielas e tirantes, e pode ser encontrada em Saludes (2006).

$$
f_{t}=\frac{4 \times P_{f}}{9 \times \pi \times \mathrm{a} \times \mathrm{H}}
$$

Onde:

$f_{t}$ é a resistência à tração, em $\mathrm{MPa}$;

$P_{f}$ é a carga que produz a fissuração, em N;

a é o diâmetro do disco de aplicação da carga, em mm;

$H$ é a altura do corpo de prova, em $\mathrm{mm}$.

A Eq. 2-2 apresenta o cálculo da resistência residual $\left(f_{t, T C O D x}\right)$ para diferentes níveis de deformação circunferencial TCOD.

$$
f_{t, T C O D x}=\frac{4 \times P_{T C O D x}}{9 \times \pi \times \mathrm{a} \times \mathrm{H}}
$$

Onde:

$f_{t, T C O D x}$ é a resistência residual correspondente a um $T C O D_{x}$;

$P_{T C O D x}$ é a carga correspondente a um $\mathrm{TCOD}_{x}$, em N;

a é o diâmetro do disco de aplicação da carga, em mm;

Hé a altura do corpo de prova, em $\mathrm{mm}$.

A norma AENOR UNE 83515 (2010) estabelece que a resistência residual seja determinada para valores de TCOD iguais a $2 \mathrm{~mm}, 2,5 \mathrm{~mm}, 4 \mathrm{~mm}$ e $6 \mathrm{~mm}$. Esta mesma norma estabelece que seja calculada a tenacidade em joules através da área 
sob a curva carga-TCOD. Além destas determinações deve ser anotado o número de fissuras obtidas no perímetro do corpo de prova após o término do ensaio.

O tipo de extensômetro indicado pela norma é um equipamento caro e que limita a difusão de utilização do ensaio. Por isso, uma simplificação foi proposta por Carmona, Aguado e Molins (2012) e por Pujadas et al. (2013) medindo-se o deslocamento vertical da máquina de ensaio, conforme detalhado a seguir.

\subsubsection{Propostas para correlação entre o TCOD e o deslocamento vertical}

Carmona, Aguado e Molins (2012) apresentam um amplo estudo experimental com objetivo de eliminar a utilização do extensômetro de circunferência através de equações que correlacionam o deslocamento vertical da máquina de ensaio $\left(\delta_{p}\right)$ e o TCOD. O estudo envolveu concretos reforçados com fibras de aço e de polipropileno, em três teores cada. Os ensaios foram realizados registrando os valores de TCOD com o extensômetro e, simultaneamente, o deslocamento vertical $\left(\delta_{p}\right)$. A Figura 2.3 apresenta um exemplo dos resultados obtidos.
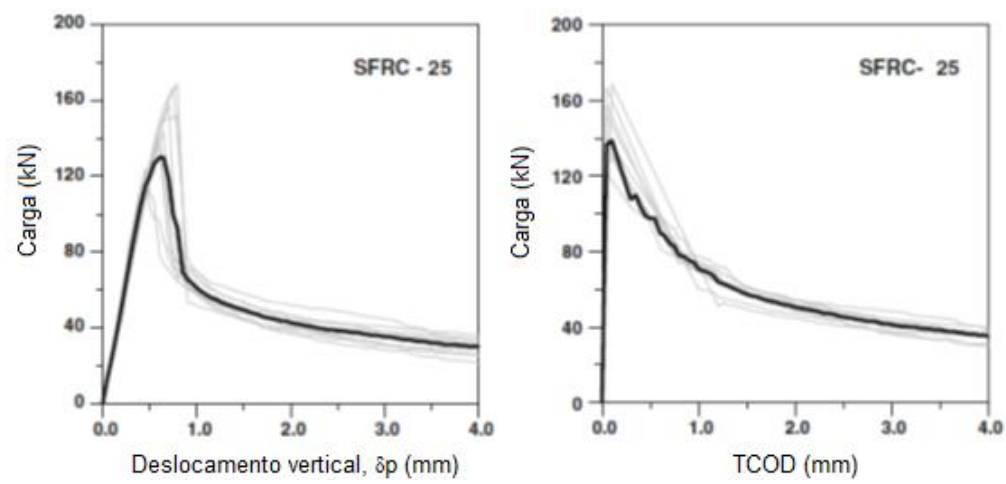

Figura 2.3 - Curvas de carga- $\delta$ e carga-TCOD registradas simultaneamente no ensaio Barcelona para um concreto com $25 \mathrm{~kg} / \mathrm{m}^{3}$ de fibras de aço. Fonte: Adaptado de Carmona; Aguado; Molins (2012).

Com estes resultados foram calculadas as tenacidades $T_{T C O D}$ e $T \delta_{p}$ através das integrais definidas representadas nas Eq. 2-3 e Eq. 2-4, onde $P$ é a carga de puncionamento (CARMONA; AGUADO; MOLINS, 2012).

$$
\begin{aligned}
T_{T C O D} & =\int_{0}^{T C O D} P d x \\
T_{\delta p} & =\int_{0}^{\delta p} P d x
\end{aligned}
$$


Estas tenacidades calculadas foram correlacionadas para os CRFs avaliados e apresentaram coeficientes de determinação $R^{2}$ aproximadamente iguais a um (CARMONA; AGUADO; MOLINS, 2012). Porém, o trabalho apresentado por Pujadas et al. (2013) indicou que tais correlações aplicadas a outros tipos de CRF resultaram erros médios de $51 \%$. Isto mostra que o uso de correlações empíricas e válidas para uma faixa específica de deslocamento não representam o mecanismo físico ocorrido durante o ensaio.

A partir desta constatação um método alternativo para conversão dos resultados de deslocamento vertical $\left(\delta_{p}\right)$ em TCOD foi apresentado por Pujadas (2013). Trata-se de um método analítico que parte da identificação de três diferentes estágios que ocorrem no ensaio Barcelona, uma primeira fase elástica linear, seguida de uma fase de transição e por fim a fase de resistência residual. A Figura 2.4 ilustra os três estágios que ocorrem durante o ensaio Barcelona.

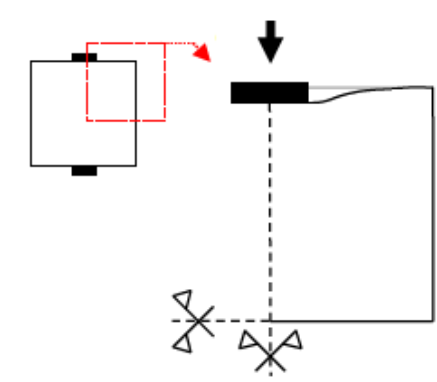

10 Estágio

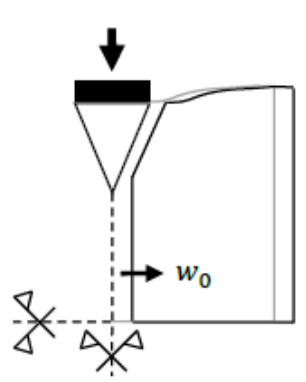

20 Estágio

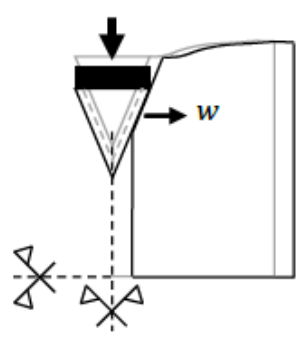

3o Estágio

Figura 2.4 - Estágios que ocorrem durante o ensaio Barcelona. Fonte: Pujadas (2013).

O primeiro estágio ocorre quando inicia o carregamento com a acomodação dos discos de carga nas superfícies do corpo de prova até que a resistência à tração seja atingida. Em seguida inicia o segundo estágio de forma abrupta, com a formação das fissuras principais e das cunhas cônicas sob os discos de carga. Por fim, com as fissuras principais formadas e estabilizadas inicia o trabalho das fibras, conferindo a resistência residual à medida que as cunhas deslizam para o interior do corpo de prova. Para cada estágio foi estabelecida uma equação a fim de converter os deslocamentos verticais $\left(\delta_{p}\right)$ em TCOD. As Eqs. 2-5, 2-6 e 2-7, apresentadas por Pujadas (2013), e utilizadas para esta conversão são:

$$
\mathrm{TCOD}=0 \quad \delta_{p} \leq \delta_{p, c r}
$$




$$
\begin{gathered}
\text { TCOD }=\mathrm{n} \times \frac{a \times \delta_{p, R, 0}}{2 \times l} \times \operatorname{sen} \frac{\pi}{n}\left(1-\frac{P}{P_{c r}}\right) \quad \delta_{p, c r}<\delta_{p}<\delta_{p, R, 0} \\
\mathrm{TCOD}=\mathrm{n} \times \frac{a}{2 \times l} \times \operatorname{sen} \frac{\pi}{n}\left[\delta_{p}-\delta_{p, c r}+\delta_{p, R, 0} \times\left(1-\frac{P_{R, 0}}{P_{c r}}\right)\right] \quad \delta_{p} \geq \delta_{p, R, 0}
\end{gathered}
$$

Onde:

$n$ : número de fissuras radiais formadas no ensaio;

a: diâmetro do disco de carga;

$l$ : comprimento da cunha formada;

$P$ : Carga no ponto calculado;

$P_{c r}, \delta_{p, c r}$ : Carga e deslocamento vertical no ponto de carga máxima;

$P_{R, 0}, \delta_{p, R, 0}$ : Carga e deslocamento vertical no ponto de início da resistência residual.

Essas equações utilizam como parâmetros grandezas que podem ser observadas ou medidas do corpo de prova, além da força e o seu correspondente $\delta$ em dois pontos específicos: o ponto de carga máxima e o de início da resistência residual, esses pontos encontram-se ilustrados na Figura 2.5.
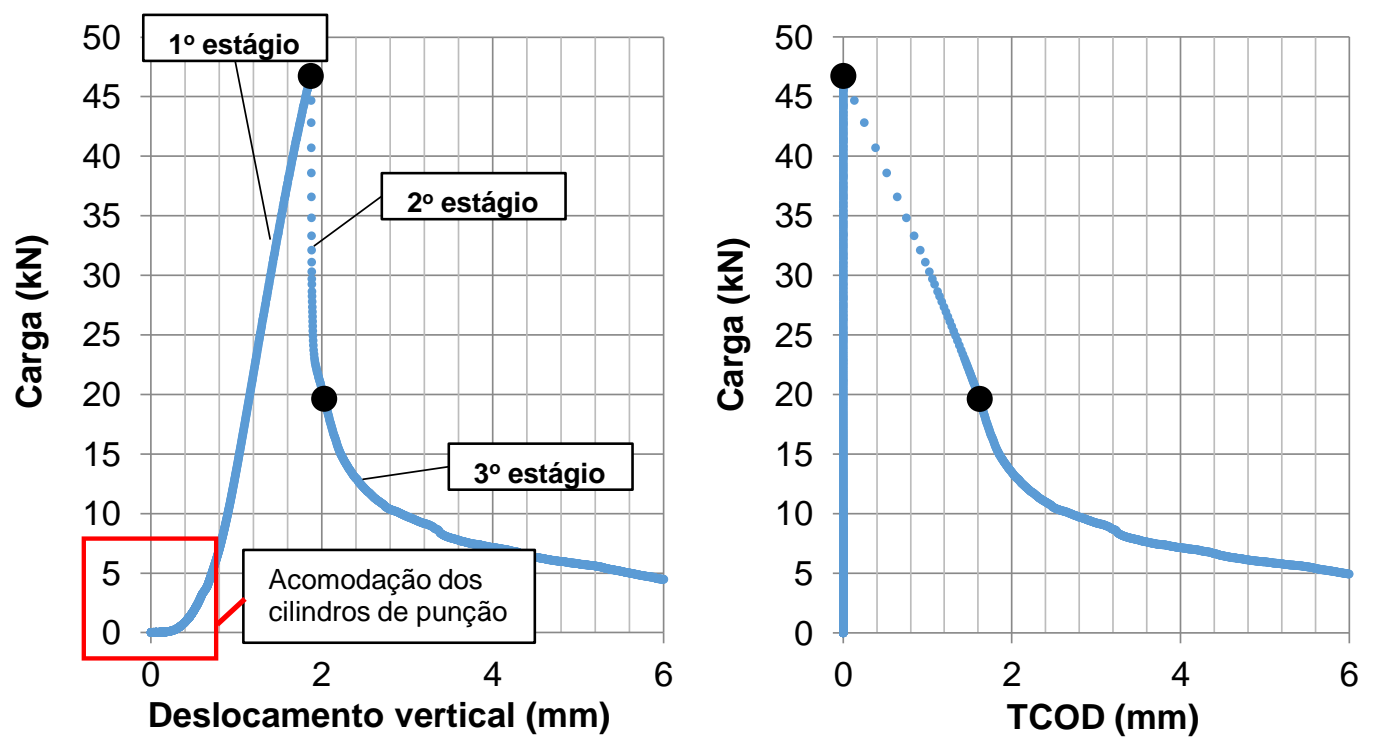

Figura 2.5 - Conversão do resultado do ensaio Barcelona com deslocamento vertical (esquerda) para TCOD (direita). Fonte: Adaptado de Monte; Toaldo; Figueiredo (2014).

Percebe-se também na Figura 2.5 que o início da curva não é linear, pois a irregularidade superficial do concreto deve ser vencida pelo disco de carga. Uma vez que a medida do TCOD pode ser estimada diretamente através do deslocamento vertical é possível à utilização de corpos de prova de outras geometrias como o 
formato cúbico. Este formato pode permitir de maneira indireta considerar a orientação das fibras, como será apresentado a seguir.

\subsubsection{Ensaio Barcelona multidirecional}

É notório, pelo grande número de publicações recentes (CAVALARO et al., 2014; di PRISCO; FERRARA; LAMPERTI, 2013; LARANJEIRA et al., 2012; SU-TAE; JIN-KEUN, 2011), o interesse das pesquisas acerca da influência da orientação das fibras no comportamento pós-fissuração do CRF.

A possibilidade de realizar o ensaio Barcelona em corpos de prova cúbicos, apresentada por Pujadas (2013), permite variar a face de aplicação do carregamento e consequentemente identificar possíveis diferenças na resposta pós-fissuração devido à orientação das fibras no CRF. A Figura 2.6 apresenta as direções de ensaio que podem ser utilizadas no ensaio Barcelona em corpos de prova cúbicos.
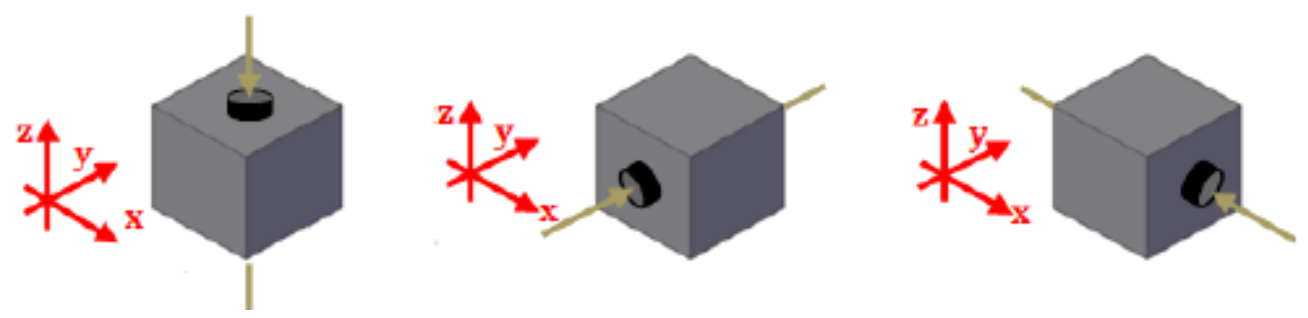

Figura 2.6 - Diferentes direções de aplicação de carga no ensaio Barcelona. Fonte: Pujadas (2013).

Pujadas (2013) avaliou o ensaio Barcelona em diferentes direções para corpos de prova moldados em fôrmas cúbicas e em testemunhos cortados de corpos de prova prismáticos. A Figura 2.7 ilustra a posição dos eixos durante a moldagem de corpos de prova prismáticos ou cúbicos. A Figura 2.8 ilustra o comportamento pós-fissuração de corpos de prova cúbicos ensaiados segundo as direções $X, Y$ e $Z$ no ensaio Barcelona.

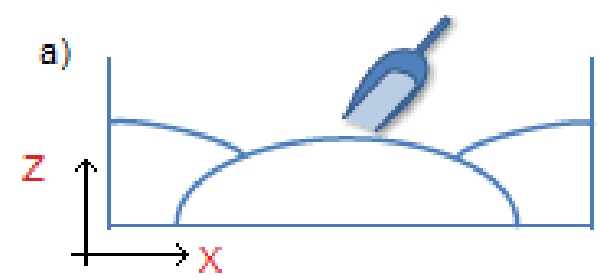

b)

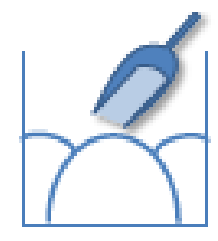

Figura 2.7 - Representação dos eixos durante a moldagem de corpos de prova: a) prismáticos e b) cúbicos. Fonte: Pujadas (2013). 

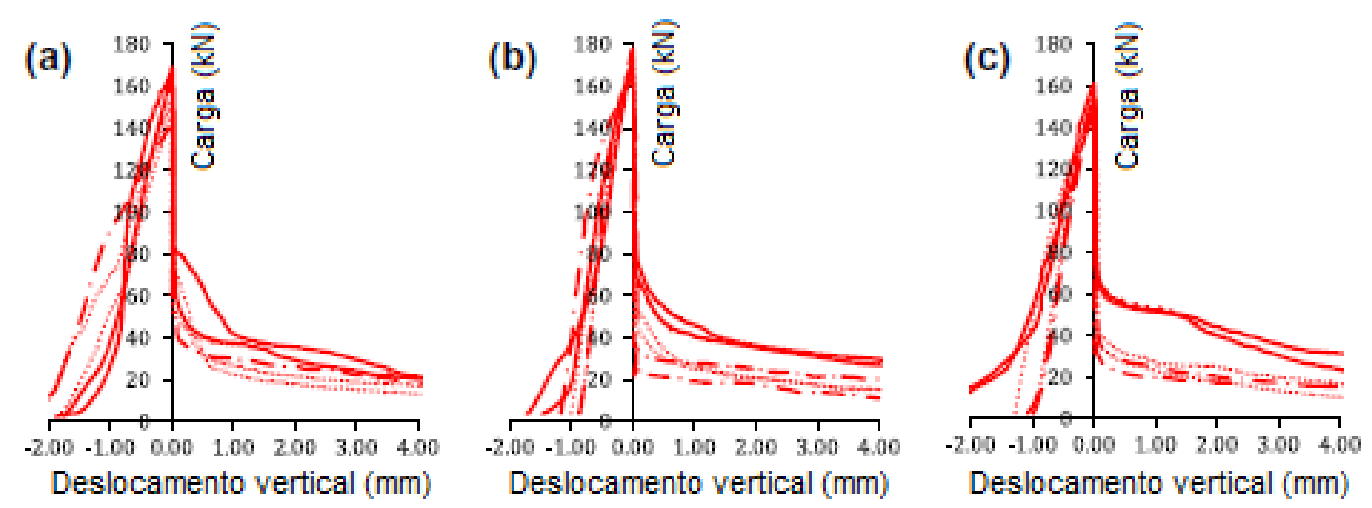

\begin{tabular}{|lll|}
\hline Eixo $Z$ & --- Eixo $Y$ & --- Eixo $X$ \\
\hline
\end{tabular}

Figura 2.8 - Curvas tensão-deslocamento vertical em ensaios Barcelona nos eixos $\mathrm{X}, \mathrm{Y}$ e Z de concretos reforçados com fibra de polipropileno: a) $5 \mathrm{~kg} / \mathrm{m}^{3}$; b) $7 \mathrm{~kg} / \mathrm{m}^{3}$; c) $9 \mathrm{~kg} / \mathrm{m}^{3}$. Fonte:

Adaptado de Pujadas et al. (2014)

Percebe-se que o ensaio Barcelona realizado em diferentes direções apresenta resultados pós-fissuração distintos, especialmente para a direção $Z$. $O$ fato das direções $\mathrm{X}$ e $\mathrm{Y}$ apresentarem comportamentos pós-fissuração semelhantes deve-se ao fato de se tratarem de corpos de prova cúbicos moldados, nos quais a distribuição das fibras é praticamente a mesma nas direções $\mathrm{X}$ e $\mathrm{Y}$ devido a influência das paredes da fôrma (PUJADAS, 2013). Quando o ensaio foi realizado em testemunhos cúbicos originados a partir do corte de prismas, Pujadas (2013) mostra resultados nos quais 0 eixo $\mathrm{X}$ apresenta resultados inferiores aos eixos $\mathrm{Z}$ e $\mathrm{Y}$. Isto ocorre devido ao alinhamento das fibras ocorrerem preferencialmente em direções ortogonais ao eixo $Z$. Borges, Monte e Figueiredo (2014) também avaliaram esta influencia em testemunhos cortados a partir de vigas utilizando o método de ensaio DEWS, como mostra a Figura 2.9 .
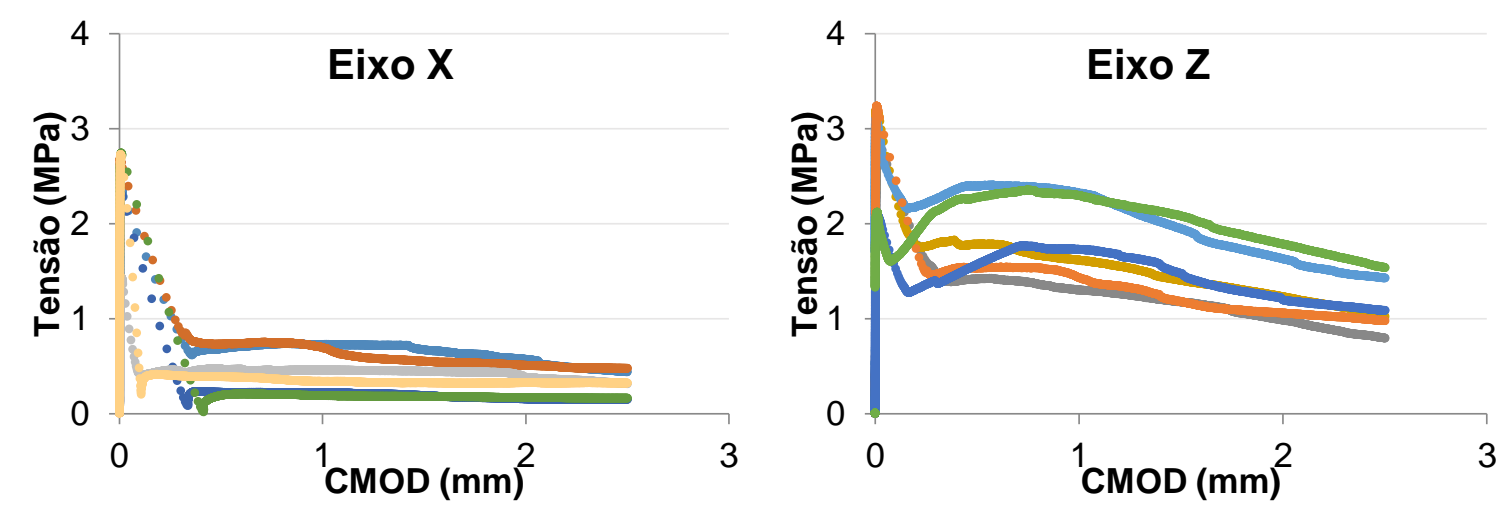

Figura 2.9: Curvas tensão-CMOD dos ensaios DEWS, eixos $X$ e $Z$, para concretos reforçados com $45 \mathrm{~kg} / \mathrm{m}^{3}$ de fibra de aço. Fonte: Adaptado de Borges; Monte; Figueiredo (2014). 
Observa-se na Figura 2.9 que o eixo $X$ apresenta menos da metade da resistência residual obtida com o eixo Z. Além disso, a maior capacidade portante pósfissuração medida no eixo $Z$ fez com que não fosse observada instabilidade no ensaio realizado nesta direção, diferentemente do que se observa no resultado do eixo $\mathrm{X}$.

No que se refere à equivalência entre o ensaio Barcelona realizado em corpo de prova de formato cúbico ou cilíndrico, Pujadas et al. (2014) mostra que o ensaio Barcelona realizado em formato cúbico no eixo $Z$ equivale ao ensaio Barcelona convencional em formato cilíndrico (Figura 2.10).
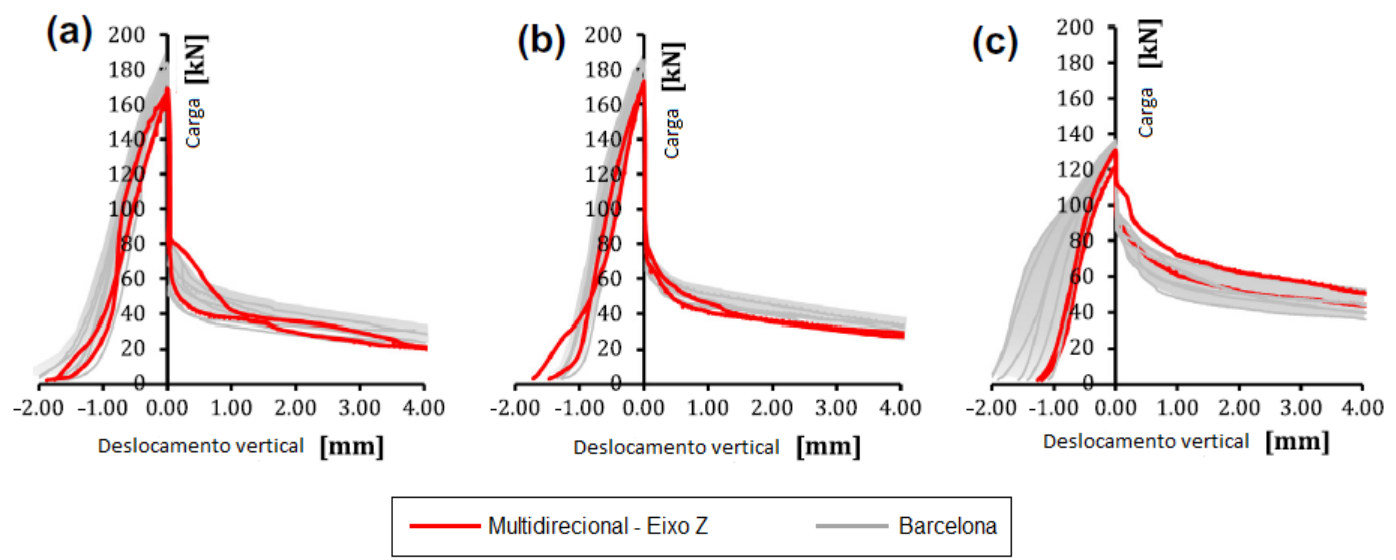

Figura 2.10 - Comparação entre o ensaio Barcelona cúbico no eixo $Z$ e o ensaio Barcelona cilíndrico em concretos reforçados com fibra de polipropileno: a) $5 \mathrm{~kg} / \mathrm{m}^{3}$; b) $7 \mathrm{~kg} / \mathrm{m}^{3}$; c) $9 \mathrm{~kg} / \mathrm{m}^{3}$. Fonte: Adaptado de Pujadas et al. (2014).

Diante do exposto é possível considerar o ensaio Barcelona como um método simples de controle do CRF, desde que sistema utilizado corresponda ao deslocamento vertical da máquina de ensaio. Este ensaio também pode ser considerado versátil, pois possibilita o uso de corpos de prova moldados, cilíndricos ou cúbicos, extraídos de estruturas existentes ou cortados a partir de vigas e lajes previamente moldadas. No entanto, o ensaio de flexão segue sendo o ensaio mais difundido no meio técnico e o estabelecimento de correlações são úteis. Especialmente quando se leva em conta que boa parte do histórico de uso do CRF é baseado neste tipo de ensaio e as práticas corriqueiras arraigadas tomam este ensaio como parâmetro. Porém, o fib Model Code 2010 (FIB, 2013) indica o uso de ensaios de flexão com entalhe através da norma EN 14651 (2007), mas permite a substituição por outros ensaios desde que correlações com o ensaio de referência sejam estabelecidas. Neste sentido, a seguir se apresenta a análise das correlações que já foram estabelecidas entre o ensaio Barcelona e o ensaio de flexão de prismas. 
2.2.4 Correlação entre o ensaio Barcelona e o ensaio de flexão de prismas

Saludes (2006) apresentou uma correlação geométrica entre o ensaio Barcelona e o ensaio de flexão de prismas proposto na norma belga NBN 15-238 (1992). O ensaio de flexão da norma belga é similar ao proposto na norma japonesa JSCE-SF4, pois ambos indicam dois pontos de aplicação de carga no terço médio e, portanto são conhecidos como ensaios de flexão com quatro pontos (Figura 2.11).

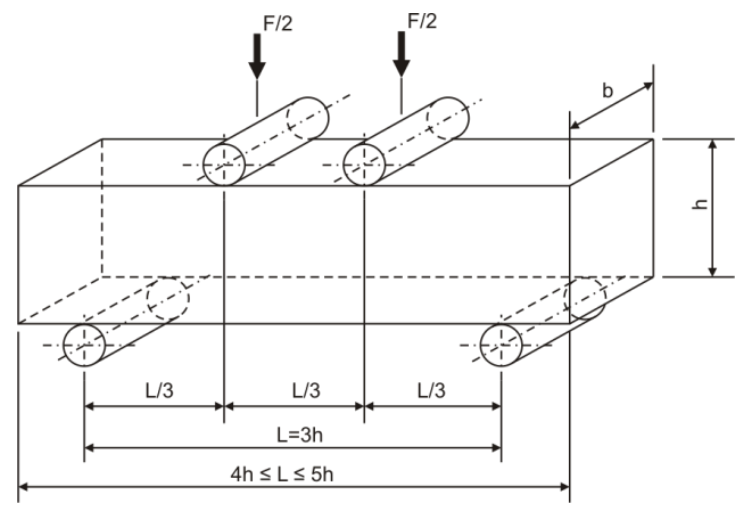

Figura 2.11 - Esquema do ensaio de flexão quatro pontos. Fonte: Adaptado de NBN 15-238 (1992).

A proposta de Saludes (2006) leva em consideração a abertura da fissura média no ensaio de flexão $\left(W_{N B N}\right)$, a metade do comprimento do vão $(L)$ e 0 deslocamento vertical ou flecha $(\delta)$, admitindo-se ângulos pequenos e valendo-se da aproximação $\operatorname{sen} \theta \approx \tan \theta \approx \theta$. A Figura 2.12 apresenta o modo de ruptura idealizado para estabelecimento da correlação geométrica e a Figura 2.13 mostra os parâmetros geométricos envolvidos.

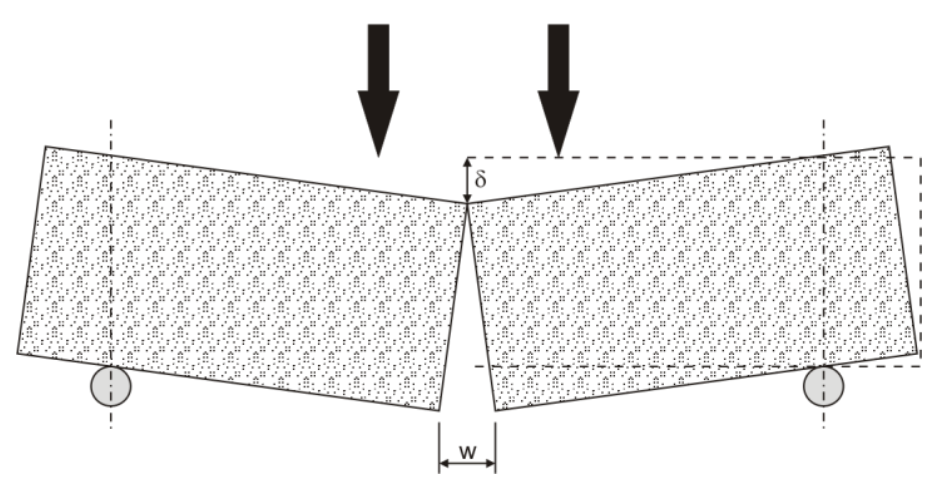

Figura 2.12 - Modo de ruptura idealizado para o ensaio NBN 15-238. Fonte: Adaptado de Saludes (2006). 


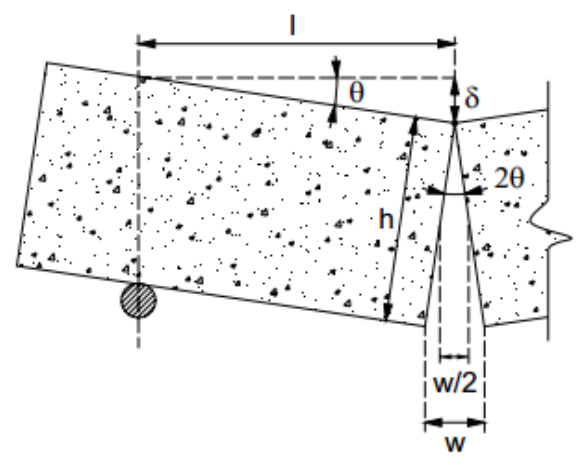

$$
\begin{gathered}
\theta=\frac{\delta}{l} \\
\theta=\frac{w / 2}{h} \\
w_{N B N}=\frac{h}{l} \times \delta
\end{gathered}
$$

Figura 2.13 - Relações geométricas desenvolvidas para o ensaio de flexão quatro pontos. Fonte: Saludes (2006).

Definidas as hipóteses de ruptura para o ensaio de flexão, a mesma filosofia foi aplicada ao ensaio Barcelona. Neste caso, Saludes (2006) assumiu, como representativo do ensaio, uma superfície de ruptura simplificada com três planos de fissuras radiais principais partindo desde o disco de aplicação da carga até a extremidade do corpo de prova (Figura 2.14). Definido o modo de ruptura, se relaciona a abertura total das fissuras (TCOD) com a abertura de cada fissura no plano radial $\left(w_{B C N}\right)$, considerando também que as três fissuras possuem mesma abertura (Figura 2.14).

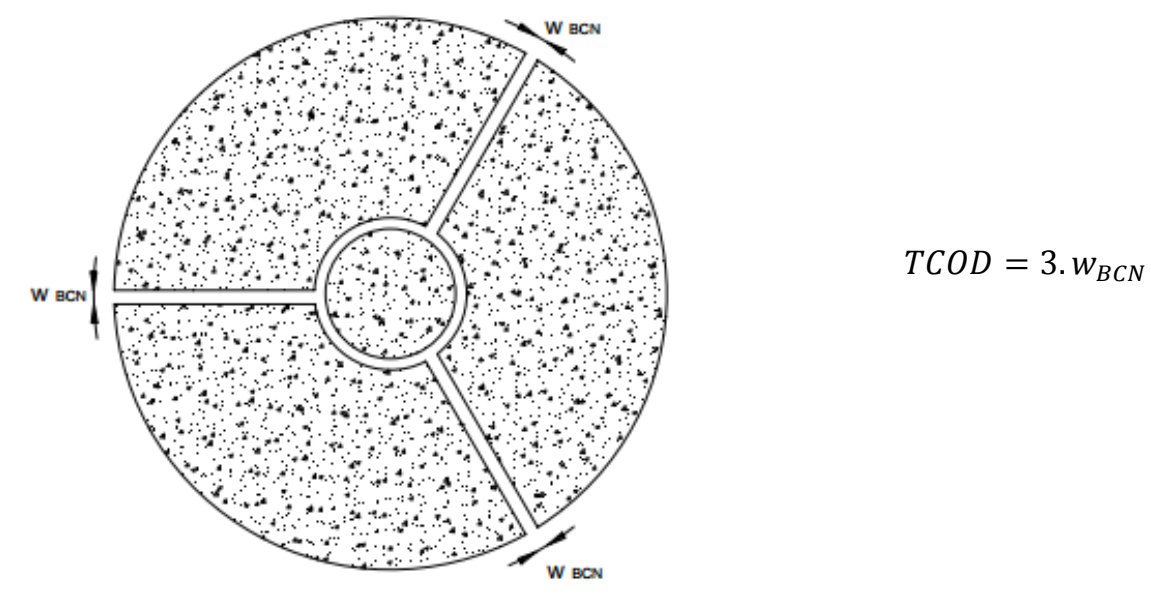

Figura 2.14 - Relações geométricas no ensaio Barcelona. Fonte: Saludes (2006).

Finalmente iguala-se a abertura da fissura média do ensaio de flexão ( $\left.w_{\text {NBN }}\right)$ com a abertura da fissura média do ensaio Barcelona $\left(\mathrm{w}_{\mathrm{BCN}}\right)$, conforme apresenta a Eq. 2-8.

$$
w_{B C N}=\frac{T C O D}{3}=w_{J S C E}=\frac{h}{l} \times \delta
$$


Considerando a geometria do ensaio de flexão com altura $(h)$ igual a $15 \mathrm{~cm}$ e a metade do vão igual a $22,5 \mathrm{~cm}$, temos a relação entre o deslocamento vertical ou flecha do ensaio de flexão e a abertura total de fissura do ensaio Barcelona na proporção 2:1.

Estabelecida à equivalência geométrica, os resultados de tenacidade $\mathrm{e}$ resistência residual para valores correspondentes de deslocamento vertical e TCOD podem ser comparados e correlacionados (MOLINS; AGUADO; SALUDES, 2009). Uma alternativa para esta comparação é avaliar a adequação de modelos constitutivos, baseados nos parâmetros obtidos a partir destes ensaios, na simulação do comportamento à tração do CRF, conforme apresentado no item 2.2.5.

\subsubsection{Modelo constitutivo simplificado baseado no ensaio Barcelona}

O aumento do uso do CRF em aplicações estruturais só será possível baseado em modelos de dimensionamento e controle confiáveis, que permitam torná-lo competitivo frente aos materiais convencionais em termos de desempenho, custo e segurança. A primeira norma a estabelecer um modelo constitutivo para o CRF foi a norma alemã DBV em 1992 (versão mais recente de 2001), contemplando apenas as fibras de aço (KOOIMAN, 2000). Atualmente, a Europa conta com diversas normas e códigos modelos com diferentes propostas de modelos constitutivos para o CRF (BLANCO et al., 2013). A Tabela 2.1 apresenta um resumo de alguns modelos constitutivos propostos pelas normas e recomendações DBV (DBV, 2001), RILEM (VANDEWALLE et al., 2003), EHE (CPH, 2008) e fib Model Code 2010 (FIB, 2013).

Percebe-se pela Tabela 2.1 que os modelos constitutivos apresentados baseiam-se em diagramas trilineares e multilineares, cujos parâmetros são caracterizados através de ensaios de flexão com três ou quatro pontos, com ou sem a presença de entalhe. 
Tabela 2.1 - Modelos constitutivos apresentados em diferentes normas internacionais. Fonte: Blanco et al. (2013).

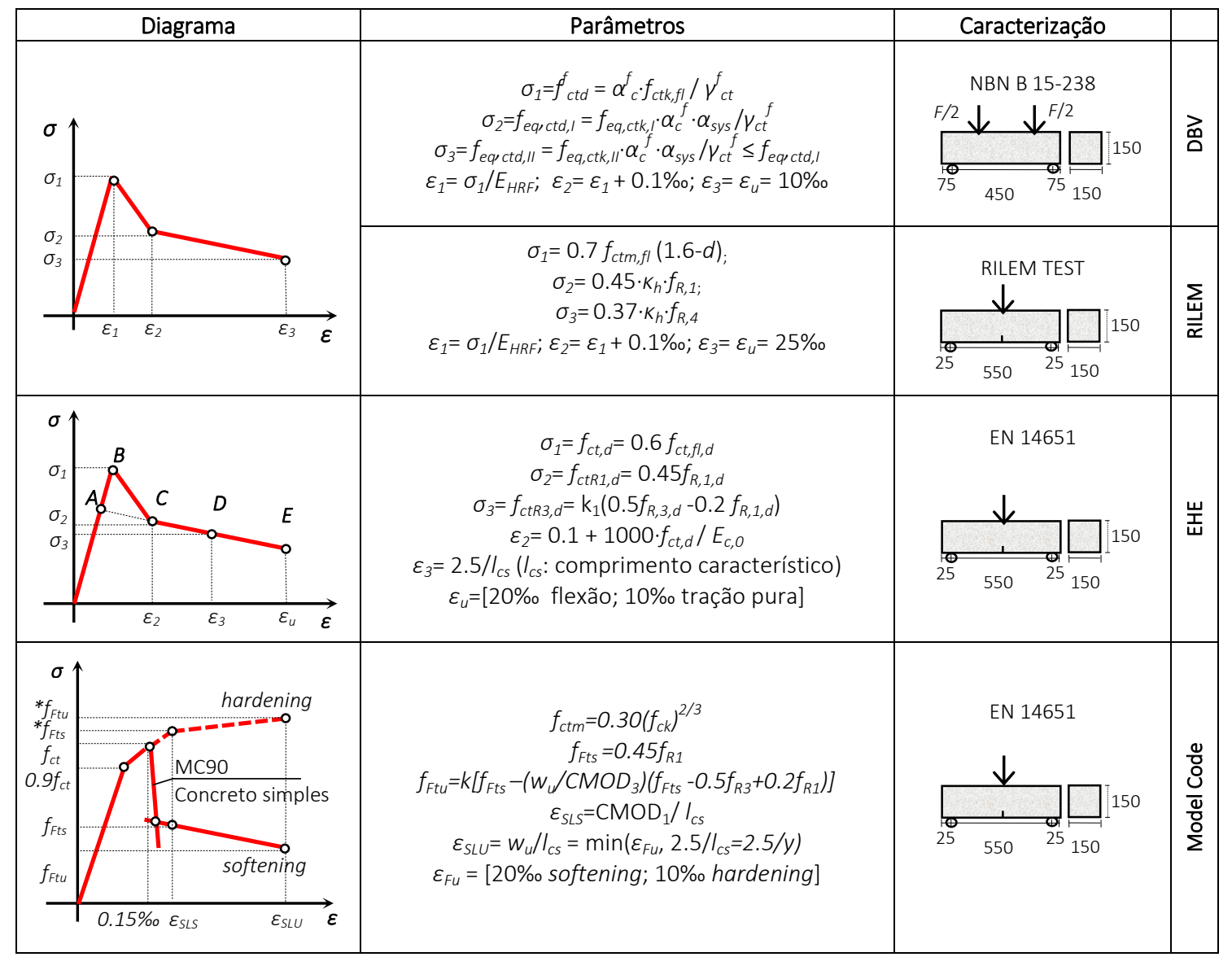

Com o objetivo de estabelecer o ensaio Barcelona como um método de ensaio alternativo para que guias e códigos possam basear seus procedimentos de dimensionamento em estruturas com CRF, Blanco (2013) propôs o modelo constitutivo $\sigma-\varepsilon$ simplificado ilustrado na Figura 2.15.

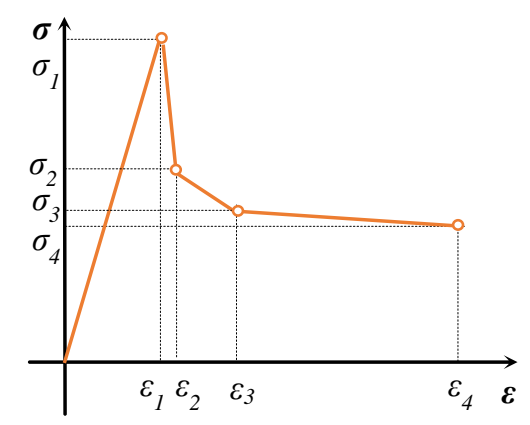

Figura 2.15 - Diagrama $\sigma-\varepsilon$ simplificado baseado no ensaio Barcelona. Fonte: Blanco (2013).

O primeiro estágio da curva do modelo constitutivo corresponde ao estágio elástico linear antes de ocorrer a fissuração. A tensão de tração $\left(\sigma_{1}\right)$ no ensaio 
Barcelona pode ser calculada através da Eq. 2-1 apresentada na norma do ensaio (AENOR UNE 83515, 2010). Uma alternativa para o cálculo da tensão de tração $\left(\sigma_{1}\right)$ está apresentada na Eq. 2-9, cujo desenvolvimento analítico está apresentado em Blanco (2013).

$$
\sigma_{1}=\frac{F_{p \max }}{2 \times \pi \times A} \times \frac{\cos \beta-\mu_{k} \times \operatorname{sen} \beta}{\operatorname{sen} \beta+\mu_{k} \times \cos \beta}
$$

Para calcular o valor de $\sigma_{1}$ deve-se conhecer a carga máxima registrada no ensaio $\left(F_{p, \max }\right)$, o valor do ângulo de fratura $(\beta)$ e o coeficiente de atrito cinético $\left(\mu_{k}\right)$. Segundo Blanco (2013) o ângulo de fratura $(\beta)$ é usualmente definido a partir do ângulo de atrito interno do material $(\varphi)$, que determina a superfície da cunha formada no corpo de prova após a fissuração. Uma revisão dos valores propostos por vários autores para ângulo de atrito interno do material $(\varphi)$ é apresentada por Carmona, Aguado e Molins (2012). O valor do ângulo de fratura pode também ser determinado experimentalmente a partir do comprimento da cunha cônica (Figura 2.16a) formada no corpo de prova (BLANCO et al., 2014; PUJADAS et al., 2013). Considerando um corpo de prova de $150 \mathrm{~mm}$ com disco de carga de $37,5 \mathrm{~mm}$ de diâmetro, tem-se um comprimento da cunha cônica de aproximadamente $40 \mathrm{~mm}$, como poder ser observado na Figura 2.16b.
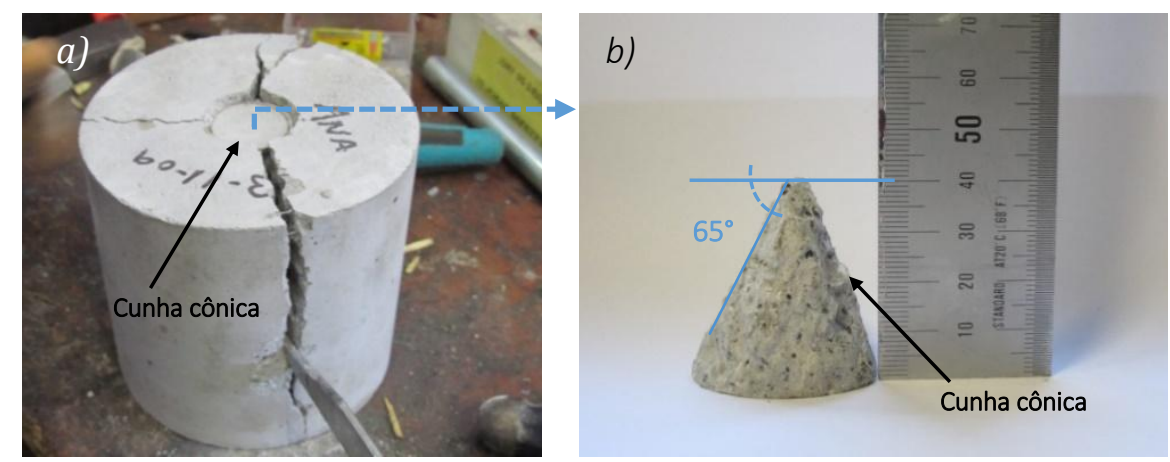

Figura 2.16 - a) Corpo de prova com cunha formada; b) medida do comprimento da cunha. Fonte: Adaptado de Blanco et al. (2014).

De posse do comprimento da cunha ( $l$ ), do diâmetro do disco de carga (a) e usando a Eq. 2-10, o ângulo de atrito interno $(\varphi)$ é $65^{\circ}$. Logo, se o valor do ângulo de atrito interno $(\varphi)$ é $65^{\circ}$ e o valor do ângulo de fratura $(\beta)$ é o seu complementar, $\beta=25^{\circ}$.

$$
l=\frac{a}{2} \times \operatorname{tg} \varphi
$$


O coeficiente de atrito cinético $\left(\mu_{k}\right)$ é de mais difícil obtenção de forma experimental. Os valores encontrados na literatura geralmente cobrem o coeficiente de atrito estático do concreto $\left(\mu_{s}\right)$, mas pouca informação sobre o coeficiente de atrito cinético é encontrado. No entanto é sempre esperado que o valor do coeficiente de atrito cinético $\left(\mu_{k}\right)$ seja inferior ao atrito estático. Isto pode ser considerado como particularmente plausível na situação do ensaio Barcelona no qual duas superfícies fissuradas de concreto estão sujeitas a deslocamento relativo considerável, suavizando a rugosidade superficial e reduzindo ainda mais o atrito (BLANCO et al., 2014). Na Figura $2.16 \mathrm{~b}$ percebe-se que a cunha apresenta superfície com rugosidade bastante reduzida após o ensaio. $\mathrm{Na}$ ausência de um valor mais confiável para o coeficiente de atrito cinético $\left(\mu_{k}\right)$, o valor de coeficiente de atrito estático $\left(\mu_{s}\right)$ proposto no fib Model Code 2010 (FIB, 2013) e apresentado na Tabela 2.2 pode ser utilizado como referência.

Tabela 2.2- Coeficiente de atrito estático indicado pelo fib Model Code 2010. Fonte: Adaptado de FIB (2013).

\begin{tabular}{cc}
\hline Rugosidade interfacial & Coeficiente de atrito $\left(\boldsymbol{\mu}_{\boldsymbol{s}}\right)$ \\
\hline Interface lisa & $0,5-0,7$ \\
Interface rugosa & $0,7-1,0$ \\
Interface muito rugosa & $1,0-1,4$ \\
\hline
\end{tabular}

Blanco et al., (2014) considera que o valor do coeficiente de atrito cinético $\left(\mu_{k}\right)$ igual a 0,7 é razoável para uma aproximação inicial, mas salienta que mais estudos são necessários para caracteriza-lo e identificar as variáveis que o afetam.

Uma vez adotados valores para o ângulo de fratura $(\beta)$ e para o coeficiente de atrito cinético $\left(\mu_{k}\right)$, e calculado o valor da tensão de tração $\left(\sigma_{1}\right)$, a deformação específica $\left(\varepsilon_{1}\right)$ pode ser calculada utilizando a Eq. 2-11 conhecendo o módulo de elasticidade médio do concreto $\left(E_{c m}\right)$.

$$
\varepsilon_{1}=\frac{\sigma_{1}}{E_{c m}}
$$

Atingida a resistência à tração da matriz de concreto ocorre a fissuração e a formação da cunha, com queda abrupta de tensão até que as fibras sejam solicitadas, no ponto correspondente a deformação específica $\left(\varepsilon_{2}\right)$ e a tensão $\left(\sigma_{2}\right)$. $O$ valor dessa 
deformação específica $\left(\varepsilon_{2}\right)$ foi definido seguindo a filosofia dos códigos e guias europeus através da equação (Eq. 2-12).

$$
\varepsilon_{2}=\varepsilon_{1}+0,1 \%
$$

Para determinar a tensão correspondente a esta deformação $\left(\sigma_{2}\right)$, a carga correspondente a deformação $\left(\varepsilon_{2}\right)$ deve ser conhecida. Porém, o ensaio é realizado medindo a variação no deslocamento vertical $\left(\Delta \delta_{p}\right)$ e sua correspondência em relação deformação específica deve ser antes realizada através da equação (Eq. 2-13). Deve ser considerado neste cálculo o número de fissuras $(n)$, o valor do ângulo de fratura $(\beta)$ em radianos e a variação na deformação específica $(\Delta \varepsilon)$ em \%o.

$$
\Delta \delta_{P}=\frac{\Delta \varepsilon \times \pi \times R}{n \times \operatorname{tg} \beta \times \operatorname{sen}\left(\frac{\pi}{n}\right)}
$$

Por exemplo, caso o corpo de prova tenha raio de $75 \mathrm{~mm}$, número de fissuras igual a $3, \beta$ igual a 0,436 radianos e $\Delta \varepsilon=\left(\varepsilon_{2}-\varepsilon_{1}\right)=0,1 \%$, o valor correspondente a $\Delta \delta_{p}$ é:

$$
\Delta \delta_{P}=\frac{\Delta \varepsilon \times \pi \times R}{n \times \operatorname{tg} \beta \times \operatorname{sen}\left(\frac{\pi}{n}\right)}=\frac{0,0001 \times \pi \times 75 \mathrm{~mm}}{3 \times \operatorname{tg}(0,436) \times \operatorname{sen}\left(\frac{\pi}{3}\right)}=0,02 \mathrm{~mm}
$$

Assim, a tensão $\left(\sigma_{2}\right)$ pode ser determinada pela Eq. 2-14 conhecendo o valor de carga correspondente a um deslocamento vertical igual a 0,02 $\mathrm{mm}\left(F_{p 0,02 \mathrm{~mm}}\right)$.

$$
\sigma_{2}=\frac{F_{p 0,02 m m}}{2 \times \pi \times A} \times \frac{\cos \beta-\mu_{k} \times \operatorname{sen} \beta}{\operatorname{sen} \beta+\mu_{k} \times \cos \beta}
$$

O mesmo procedimento é adotado para estimar os valores de $\sigma_{3}$ e $\varepsilon_{3}$. Blanco et al., (2014) após analisarem diversos resultados experimentais consideraram que 0 valor de $\varepsilon_{3}$ igual a $4,0 \%$ é um bom valor para ajustar a curva constitutiva ao comportamento do material no ensaio.

Isto corresponde a um $\Delta \varepsilon$ de $3,9 \%$ o $\left(\varepsilon_{3}-\varepsilon_{1}=4,0 \% 0-0,1\right)$. Novamente substituindo na Eq. 2-13, e considerando os valores do exemplo anterior, tem-se $\Delta \delta_{p}$ de aproximadamente $0,75 \mathrm{~mm}$. $O$ valor da tensão $\sigma_{3}$ pode ser calculada através da Eq. 2-15. 


$$
\sigma_{3}=\frac{F_{P 0,75 m m}}{2 \times \pi \times A} \times \frac{\cos \beta-\mu_{k} \times \operatorname{sen} \beta}{\operatorname{sen} \beta+\mu_{k} \times \cos \beta}
$$

O valor da deformação específica $\left(\varepsilon_{4}\right)$ foi assumido por Blanco et al., (2014) como sendo $20 \%$, seguindo o valor indicado em vários códigos para a deformação máxima para a curva constitutiva do CRF. Considerando os mesmos valores assumidos na deformação específica $\varepsilon_{3}$, o deslocamento vertical associado a deformação específica de $20 \%$ é aproximadamente $3,9 \mathrm{~mm}$ e o valor da tensão $\sigma_{4}$ pode então ser determinado através da Eq. 2-16.

$$
\sigma_{4}=\frac{F_{P 4,00 m m}}{2 \times \pi \times A} \times \frac{\cos \beta-\mu_{k} \times \operatorname{sen} \beta}{\operatorname{sen} \beta+\mu_{k} \times \cos \beta}
$$

O valor da área radial da superfície fissurada $(A)$ pode ser obtido através da Eq. 2-17, considerando o diâmetro do corpo de prova $(C)$, sua altura $(H)$ e o diâmetro do disco de carga (a).

$$
\mathrm{A}=\frac{\mathrm{d} \times \mathrm{H}}{4}-\frac{\mathrm{a}^{2}}{4 \times \operatorname{tg} \beta}
$$

A validação deste modelo constitutivo simplificado foi apresentada em Blanco et al. (2014) através de um amplo programa experimental envolvendo o ensaio Barcelona e o ensaio de flexão EN 14651 (2007). Estes resultados foram utilizados em simulações numéricas de um elemento tipo viga, comparando o modelo proposto com os modelos constitutivos DBV (DBV, 2001), RILEM (VANDEWALLE et al., 2003), EHE ( $\mathrm{CPH}, 2008)$ e fib Model Code 2010 (FIB, 2013). As simulações indicaram que 0 modelo constitutivo baseado no ensaio Barcelona apresenta-se entre a faixa de variação dos outros modelos, mas indica que o modelo baseado no ensaio Barcelona pode ser mais adequado para previsão do comportamento de outros tipos de elementos estruturais.

Através da revisão da literatura apresentada ao longo de todo item 2.2 percebe-se que muito se evoluiu desde a concepção do ensaio Barcelona. Uma configuração de ensaio mais simples, em relação ao inicial que utilizava uma cinta extensométrica, medindo-se apenas carga e deslocamento vertical foi comprovadamente eficiente para a caracterização do CRF. Porém este ensaio ainda não foi difundido no Brasil. Nem mesmo o ensaio da norma europeia EN 14651 (2007), ensaio de referência para o código modelo fib Model Code 2010 (FIB, 2013) em termos de dimensionamento de estruturas em CRF, tem sido utilizado. $\mathrm{O}$ ensaio mais 
utilizado para caracterização do CRF permanece sendo o da muito antiga norma japonesa JSCE-SF4 (1984). Por isso, um programa experimental, detalhado no item a seguir, que visa comparar o ensaio Barcelona com o ensaio de flexão da norma JSCESF4 foi realizado. Espera-se com isso difundir a utilização do método de ensaio Barcelona como alternativo a caracterização do comportamento pós-fissuração do CRF para fins estruturais.

\subsection{Programa experimental}

Um programa experimental envolvendo a comparação do ensaio Barcelona com o ensaio de flexão JSCE-SF4 foi desenvolvido. A utilização do ensaio de flexão JSCE-SF4 se justifica por ser ainda o método de ensaio mais utilizado no Brasil para caracterização do $\mathrm{CRF}$, principalmente por se tratar de um método que não exige equipamento com sistema de controle fechado. Além disso, comparações com outros ensaios de sistema de controle fechado (NBN 15-238, 1992; EN 14651, 2007) foram anteriormente estudadas. O experimento foi realizado avaliando uma matriz de concreto reforçada com dois tipos de fibra, uma de aço e outra polimérica, em três teores cada, totalizando seis composições. A escolha dos consumos de fibras foi feita buscando representatividade das aplicações mais frequentes do CRF no Brasil, como também é o caso dos tubos de concreto (Figueiredo, 2011), e que utilizam teores abaixo do crítico. O uso de baixos teores também permite avaliar a influência da instabilidade pós-pico nos resultados dos ensaios (BANTHIA; DUBEY, 1999; SALVADOR; FIGUEIREDO, 2013). O teor em volume das fibras de PP foi o dobro do teor das fibras de aço buscando proximidade de desempenho, como foi observado em estudos anteriores (FIGUEIREDO et al., 2012c; SALVADOR e FIGUEIREDO, 2013). Além dos ensaios Barcelona e JSCE-SF4 os concretos foram caracterizados quanto à resistência à compressão e à absorção de água. Os resultados foram submetidos a análises estatísticas utilizando o software Minitab® 17.1.0. O objetivo principal é comprovar a viabilidade do ensaio Barcelona como método alternativo para caracterização do comportamento pós-fissuração do CRF. Os objetivos específicos do programa experimental são:

- Comparar a facilidade de execução;

- Comparar a dispersão dos resultados;

- Confrontar eventuais instabilidades pós-pico;

- Correlacionar as medidas de tenacidade obtidas em ambos os ensaios; 
- Correlacionar as medidas de resistência residual para pequenos deslocamentos (região associada à condição de serviço) e maiores (região de pré-ruptura).

Os resultados deste programa experimental foram parcialmente publicados em Monte, Toaldo e Figueiredo (2014). Espera-se que a difusão deste conhecimento permita fornecer subsídios ao meio técnico para indicar o ensaio Barcelona como método alternativo para caracterização do comportamento pós-fissuração do CRF.

\subsubsection{Materiais e proporções}

Os materiais utilizados nas moldagens dos corpos de prova foram um cimento Portland CP II-F-32, uma areia artificial e um pedrisco. A areia possui dimensão máxima característica de 4,8 $\mathrm{mm}$ e módulo de finura 2,93, enquanto o pedrisco tem dimensão máxima característica de $9,5 \mathrm{~mm}$. A Tabela 2.3 apresenta resultados médios de três determinações da massa específica de cada material, medidas em um picnômetro de gás hélio.

Tabela 2.3 - Massa específica dos materiais utilizados na pesquisa.

\begin{tabular}{cc}
\hline Material & Massa específica $\left(\mathbf{g} / \mathbf{c m}^{3}\right)$ \\
\hline Areia Artificial & 2,684 \\
Pedrisco & 2,656 \\
Cimento CP II-F-32 & 3,009 \\
\hline
\end{tabular}

As fibras utilizadas foram uma de aço (Figura 2.17a) e uma macrofibra de polipropileno (Figura 2.17b).

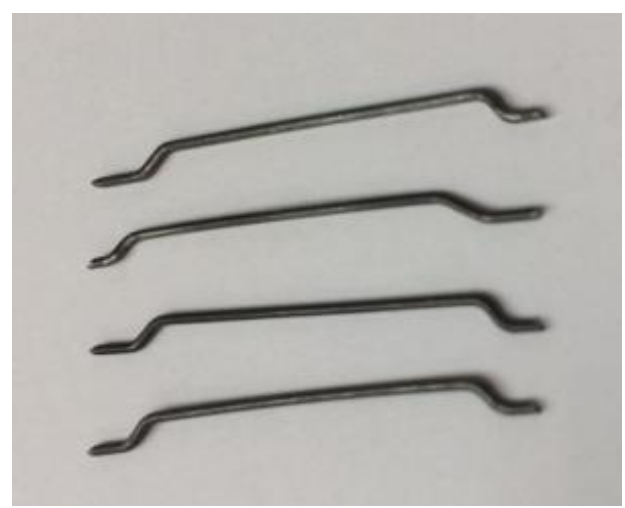

(a)

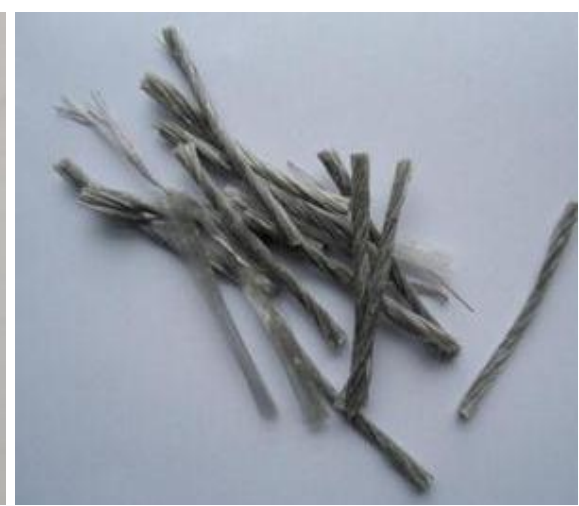

(b)

Figura 2.17 - a) Fibra de aço utilizada; b) Fibra de polipropileno utilizada. 
A norma ABNT NBR 15530 (2007) estabelece ensaios e requisitos para a caracterização de fibras de aço. As fibras poliméricas não são contempladas na normalização brasileira, o que dificulta a padronização do mercado deste tipo de fibras.

A fibra de aço utilizada nessa pesquisa (Figura 2.17a) é classificada como A-I (tipo A - ancoragem nas extremidades; classe I - oriunda de arame trefilado a frio). As fibras A-I são especificadas pelo diâmetro equivalente $\left(d_{e}\right)$ e comprimento total $(l)$. 0 fator de forma $(\lambda)$ é obtido através da razão $l / d_{e}$.

A fibra de polipropileno utilizada (Figura 2.17b) é composta de macrofibra estrutural monofilamento, produzida com $100 \%$ de copolímero de polipropileno virgem e uma fração fibrilada para o controle da retração.

Uma amostra de 60 fibras de cada uma foi coletada para caracterização geométrica utilizando um paquímetro digital. Na Tabela 2.4 são apresentados os resultados médios e os valores nominais indicados pelos fabricantes.

Tabela 2.4 - Resultados das características dimensionais das fibras e valores nominais dos fabricantes. Fonte: Monte; Toaldo; Figueiredo, (2014).

\begin{tabular}{ccccccc}
\hline \multirow{2}{*}{ FIBRA } & \multicolumn{3}{c}{ Resultados médios medidos } & \multicolumn{3}{c}{ Valores nominais dos fabricantes } \\
& $\boldsymbol{d}_{\boldsymbol{e}}(\boldsymbol{m} \boldsymbol{m})$ & $\boldsymbol{l}(\boldsymbol{m} \boldsymbol{m})$ & $\boldsymbol{\lambda}$ & $\boldsymbol{d}_{\boldsymbol{e}}(\boldsymbol{m m})$ & $\boldsymbol{l}(\mathbf{m m})$ & $\boldsymbol{\lambda}$ \\
\hline Aço - SF & 0,61 & 29,07 & 47,59 & 0,67 & 30 & 45 \\
Polipropileno - PF & 0,29 & 53,44 & 190,83 & $0,34^{*}$ & 54 & 158 \\
\hline
\end{tabular}

${ }^{*}$ Calculado em função dos valores nominais de comprimento e fator de forma.

Considerando as tolerâncias dimensionais apresentadas na norma ABNT NBR 15530 (2007) a fibra de aço utilizada pode ser considerada em conformidade com as exigências da norma. Já a fibra de polipropileno não poderia ser considerada conforme se as tolerâncias fossem as mesmas aplicadas às fibras de aço, indicando que um estudo específico para proposição de critérios adequados às características deste tipo de fibra se faz necessário.

Uma amostra de 10 fibras de aço foi coletada para o ensaio de dobramento e todas as fibras foram consideradas aprovadas segundo os critérios da norma ABNT NBR 15530 (2007). Além disso, uma amostra de 200 gramas desta fibra foi coletada para avaliação de defeitos (ausência de ancoragem, emendas de topo ou oxidação 
superficial de difícil remoção), apresentando defeitos em quantidade inferior ao limite estabelecido pela norma.

Para cada uma das fibras foram utilizados três teores. Estudos anteriores (FIGUEIREDO et al,. 2012c; SALVADOR e FIGUEIREDO, 2013) mostraram que, para o mesmo teor em volume, a fibra de aço tem desempenho superior à macrofibra de polipropileno. Por isso, na tentativa de se obter a mesma equivalência de desempenho entre as fibras obtida por Figueiredo et al. (2012c), utilizou-se o dobro do teor em volume da fibra de polipropileno em relação à de aço, conforme apresentado na Tabela 2.5.

Tabela 2.5 - Teores de fibras utilizados.

\begin{tabular}{|c|c|c|c|}
\hline \multicolumn{2}{|c|}{ FIBRA DE AÇO - SF } & \multicolumn{2}{|c|}{ FIBRA DE POLIPROPILENO - PF } \\
\hline $\begin{array}{c}\text { Consumo de fibra } \\
\qquad\left(\mathrm{kg} / \mathrm{m}^{3}\right)\end{array}$ & $\begin{array}{l}\text { Proporção em } \\
\text { volume (\%) }\end{array}$ & $\begin{array}{c}\text { Consumo de fibra } \\
\left(\mathrm{kg} / \mathrm{m}^{3}\right)\end{array}$ & $\begin{array}{c}\text { Proporção em } \\
\text { volume (\%) }\end{array}$ \\
\hline 20 & 0,25 & 4,6 & 0,50 \\
\hline 30 & 0,375 & 6,8 & 0,75 \\
\hline 45 & 0,50 & 9,1 & 1,00 \\
\hline
\end{tabular}

Os teores de fibra foram selecionados com base nos teores mais aplicados no Brasil para as fibras de aço, que são geralmente inferiores a $45 \mathrm{~kg} / \mathrm{m}^{3}$. Além disso, o emprego de teores mais baixos, como o de $20 \mathrm{~kg} / \mathrm{m}^{3}$ são mais críticos em relação a instabilidade pós-pico em ensaios de sistema aberto.

Os concretos foram produzidos a partir de uma matriz com proporção em massa de materiais secos de 1:1,57:1,96 e relação água/cimento igual a 0,60. A quantidade de água não foi corrigida pelo fato de se utilizar baixos volumes de fibra, 0 que não proporciona grande prejuízo à compactação quando o material é vibrado (CECCATO; NUNES; FIGUEIREDO, 1997).

\subsubsection{Preparação dos corpos de prova e métodos de ensaio}

Após a mistura dos concretos foram moldados dois corpos de prova cilíndricos para determinação da resistência à compressão, cinco corpos de prova prismáticos de $10 \times 10 \times 40 \mathrm{~cm}$ para o ensaio JSCE-SF4 e dois corpos de prova prismáticos de $15 \times 15 \times 55 \mathrm{~cm}$ para extração de oito testemunhos cilíndricos para o ensaio Barcelona. Os corpos de prova foram desmoldados no dia seguinte e mantidos em câmara úmida (95\% de umidade relativa) até os 27 dias de idade, ou seja, a véspera da idade de 
ensaio que foi de 28 dias. Evitou-se que os corpos de prova fossem retirados da câmara úmida no dia do ensaio de modo a evitar que a variação de umidade dos mesmos, especialmente na superfície, introduzisse uma maior variabilidade aos resultados. Isto ocorre porque a saturação do corpo de prova tem clara influência no resultado de ensaio (CERVO et al, 2010). A seguir serão detalhadas as etapas de preparação dos corpos de prova e os procedimentos de cada ensaio realizado.

\section{Resistência à compressão}

A resistência à compressão dos concretos foi caracterizada em dois corpos de prova cilíndricos de $10 \times 20 \mathrm{~cm}$ para todas as composições de CRF estudadas. $O$ ensaio foi realizado aos 28 dias de acordo com a norma brasileira ABNT NBR 5739 (2007).

\section{Absorção de água e índice de vazios}

Os concretos foram caracterizados quanto à absorção de água e ao índice de vazios (porosidade total), segundo o procedimento da ABNT NBR 9778 (2005). Para estas características foram utilizados três corpos de prova de cada composição, e para os cálculos de absorção de água (Abs) utilizou-se a Eq. 2-18 e para os cálculos de índice de vazios $\left(I_{v}\right)$ utilizou-se a Eq. 2-19.

$$
\text { Abs }=\frac{m_{s a t}-m_{s}}{m_{s}} \times 100
$$

Onde:

$m_{\text {sat: }}$ é a massa do corpo de prova saturado em água após imersão e fervura;

$m_{s}$ : é a massa do corpo de prova seco em estufa.

$$
\mathrm{I}_{v}=\frac{m_{\text {sat }}-m_{i}}{m_{\text {sat }}-m_{i}} \times 100
$$

Onde:

$m_{\text {sat: }}$ é a massa do corpo de prova saturado em água após imersão e fervura;

$m_{i}$ : é a massa do corpo de prova saturado imerso em água após fervura. 


\section{Ensaio de flexão JSCE-SF4}

Conforme comentado anteriormente, existem diversos métodos de ensaio para se avaliar a tenacidade dos CRF. Entretanto, nenhum ainda é normalizado no Brasil, onde se utiliza extensivamente o ensaio especificado na norma JSCE-SF4 (1984), que também é o de concepção mais simples (FIGUEIREDO, 2011). Trata-se de um ensaio realizado em prismas carregados por dois cutelos no seu terço médio com uso de um LVDT fixado em um sistema "yoke" para medida do deslocamento vertical no meio do vão (Figura 2.18). A variável de controle do ensaio é a velocidade de deslocamento da prensa que pode variar entre 0,15 e $0,5 \mathrm{~mm}$ por minuto, sendo a velocidade de ensaio adotada de $0,2 \mathrm{~mm} / \mathrm{min}$.

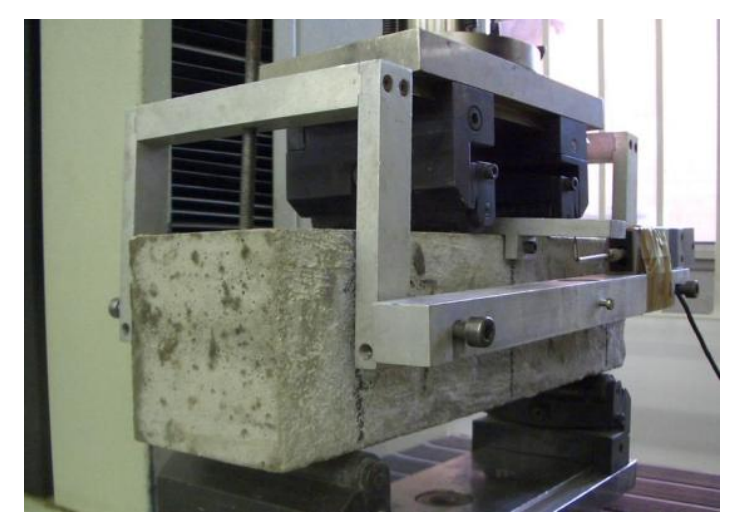

Figura 2.18 - Configuração do ensaio de flexão JSCE-SF4. Fonte: Monte; Toaldo; Figueiredo, (2014).

O fato do procedimento de ensaio permitir o uso de controle tipo open-loop, no qual a velocidade mantida constante é a do equipamento e não a do corpo de prova. Com isto o ensaio pode estar sujeito à instabilidade pós-pico, ao contrário do que aconteceria se fosse realizado com um sistema controle da velocidade de deslocamento fechado (BANTHIA; DUBEY, 1999; SALVADOR; FIGUEIREDO, 2013). Esta instabilidade pode ser identificada pelo aumento da separação dos pontos no gráfico de carga versus deslocamento, como ilustra a Figura 2.19. Nota-se claramente que o afastamento maior ocorre apenas após a carga de pico denotando aumento da velocidade de deslocamento registrado pelo LVDT, uma vez que a taxa de aquisição de dados é constante. 


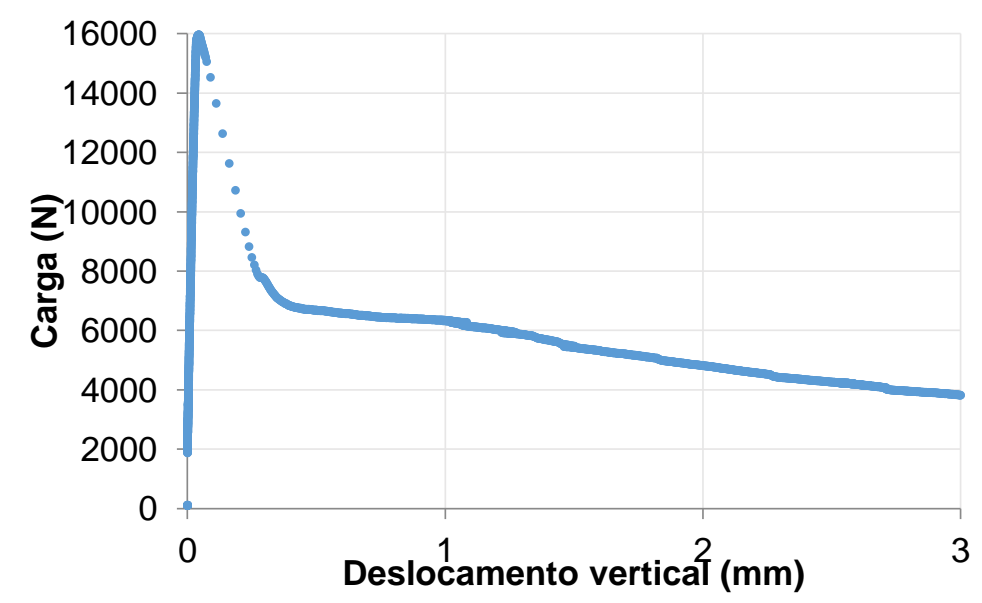

Figura 2.19 - Resultado de ensaio JSCE - SF4 com presença de instabilidade pós-pico. Fonte: Toaldo; Monte; Figueiredo (2013).

\section{Ensaio Barcelona}

O ensaio Barcelona foi realizado em testemunhos extraídos de vigas moldadas nas mesmas condições das vigas produzidas para o ensaio JSCE-SF4. Primeiramente foi necessário realizar as extrações dos cilindros e em seguida (Figura 2.20), cortá-los para que tenham a altura igual ao diâmetro. O diâmetro dos testemunhos extraídos foi de $100 \mathrm{~mm}$, dimensão mínima indicada pela norma do ensaio Barcelona (AENOR UNE 83515, 2010).

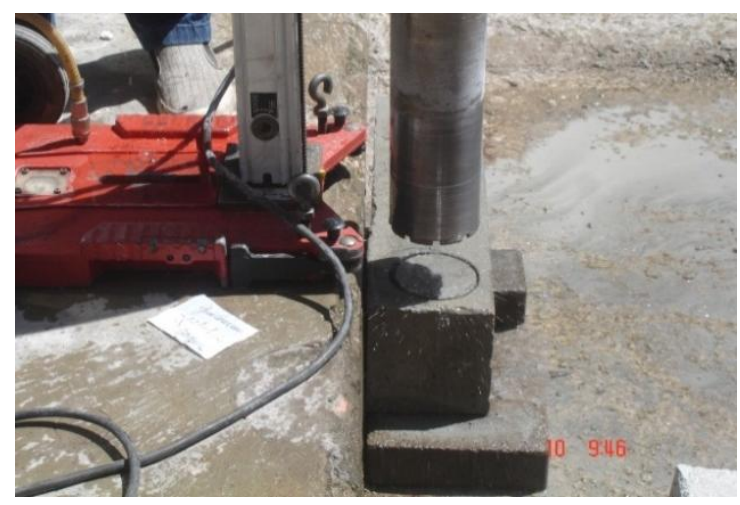

Figura 2.20 - Extração de testemunhos para ensaio Barcelona.

A utilização de testemunhos de menor diâmetro tem como vantagem a possibilidade de utilizar uma máquina de menor capacidade, pois as cargas de puncionamento são inferiores a $10 \mathrm{tf}$, além de serem mais leves e de fácil manuseio. Outra vantagem da utilização de testemunhos extraídos está no fato de se evitar o efeito de alinhamento das fibras junto à borda do molde, o que pode induzir a uma majoração da resistência pós-fissuração. Além disso, esta opção permite avaliar o 
potencial de utilização do ensaio para testemunhos extraídos de tubos ou estruturas de CRF, algo que atualmente não é considerado aplicável para outros métodos.

O puncionamento foi feito a partir de discos de carga com diâmetro de $25 \mathrm{~mm}$ e altura de $20 \mathrm{~mm}$, com velocidade de descida da máquina de ensaio de $0,5 \mathrm{~mm} / \mathrm{min}$. Os resultados registrados foram a carga e respectivo deslocamento vertical da máquina de ensaio, adotando o procedimento de ensaio simplificado estudado por Carmona, Aguado e Molins (2012) e Pujadas et al. (2013). A configuração de ensaio utilizada está ilustrada na Figura 2.21.

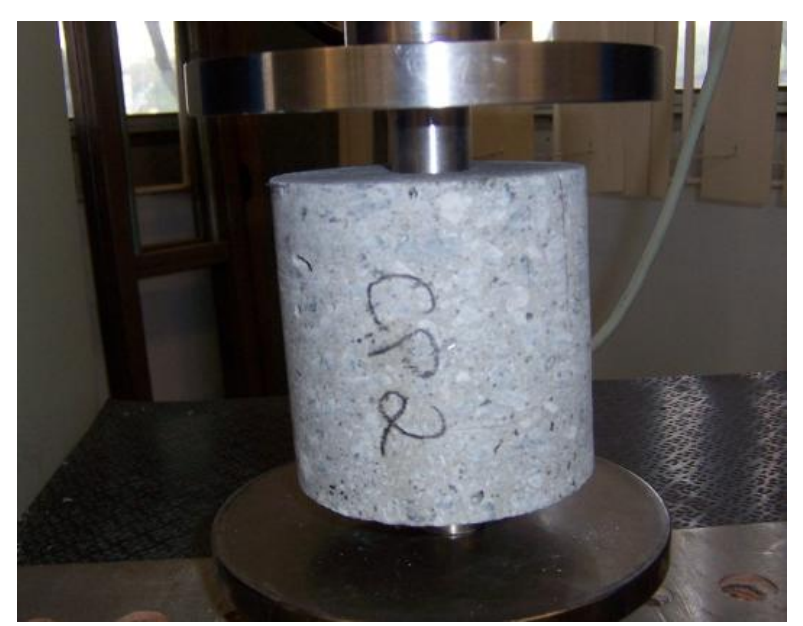

Figura 2.21 - Configuração do ensaio Barcelona. Fonte: Monte; Toaldo; Figueiredo, (2014).

Os resultados obtidos nos ensaios de absorção e índice de vazios, resistência à compressão, flexão JSCE-SF4 e Barcelona serão apresentados e analisados a seguir.

\subsection{Resultados e análises}

\subsubsection{Absorção de água e índice de vazios}

Os resultados de absorção de água e índice de vazios médios de três corpos de prova, com respectivos desvios padrão e coeficientes de variação, estão apresentados na Tabela 2.6 . 
Tabela 2.6 - Resultados médios de absorção de água e índice de vazios dos corpos de prova.

\begin{tabular}{ccccccc}
\hline $\begin{array}{c}\text { Tipo e Teor de } \\
\text { fibra }\left(\mathbf{k g} / \mathbf{m}^{3}\right)\end{array}$ & $\begin{array}{c}\text { Absorção } \\
(\%)\end{array}$ & $\begin{array}{c}\text { Desvio } \\
\text { padrão (\%) }\end{array}$ & $\begin{array}{c}\boldsymbol{C V} \\
(\%)\end{array}$ & $\begin{array}{c}\text { Índice de } \\
\text { vazios (\%) }\end{array}$ & $\begin{array}{c}\text { Desvio } \\
\text { padrão (\%) }\end{array}$ & $\begin{array}{c}\boldsymbol{C V} \\
(\%)\end{array}$ \\
\hline $\mathrm{SF}-20$ & 6,7 & 0,6 & 9 & 14,8 & 1,2 & 8 \\
$\mathrm{SF}-30$ & 5,6 & 0,8 & 15 & 12,5 & 1,7 & 14 \\
$\mathrm{SF}-45$ & 6,0 & 0,6 & 9 & 13,6 & 1,2 & 9 \\
$\mathrm{PF}-4,6$ & 6,1 & 0,9 & 15 & 13,5 & 1,9 & 14 \\
$\mathrm{PF}-6,8$ & 6,0 & 0,4 & 7 & 13,3 & 0,9 & 7 \\
$\mathrm{PF}-9,2$ & 7,2 & 1,3 & 17 & 15,7 & 2,5 & 16 \\
\hline
\end{tabular}

Os resultados apresentados na Tabela 2.6 mostram-se muito próximos para os dois tipos de fibra e respectivos teores utilizados. Na Tabela 2.7 e Tabela 2.8 apresentam-se as análises de variância dos resultados de absorção de água e índices de vazios, respectivamente.

Tabela 2.7 - Análise de variância para a absorção de água.

\begin{tabular}{ccccccc}
\hline $\begin{array}{c}\text { Fontes de } \\
\text { variação }\end{array}$ & GL & $\begin{array}{c}\text { Soma de } \\
\text { quadrados }\end{array}$ & $\begin{array}{c}\text { Quadrado } \\
\text { médio }\end{array}$ & Estatística $\boldsymbol{F}$ & Valor $\boldsymbol{P}$ & Significativo \\
\hline Tipo de fibra & 1 & 0,000055 & 0,000055 & 0,76 & 0,397 & Não \\
Teor de fibra & 2 & 0,000234 & 0,000117 & 1,61 & 0,230 & Não \\
Erro & 17 & 0,001239 & 0,000073 & & & \\
Total & 20 & 0,001536 & & & & \\
\hline
\end{tabular}

Tabela 2.8 - Análise de variância para o índice de vazios.

\begin{tabular}{ccccccc}
\hline $\begin{array}{c}\text { Fontes de } \\
\text { variação }\end{array}$ & GL & $\begin{array}{c}\text { Soma de } \\
\text { quadrados }\end{array}$ & $\begin{array}{c}\text { Quadrado } \\
\text { médio }\end{array}$ & Estatística F & Valor $\boldsymbol{P}$ & Significativo \\
\hline Tipo de fibra & 1 & 0,000146 & 0,000146 & 0,48 & 0,499 & Não \\
Teor de fibra & 2 & 0,000976 & 0,000488 & 1,59 & 0,233 & Não \\
Erro & 17 & 0,005212 & 0,000307 & & & \\
Total & 20 & 0,006358 & & & & \\
\hline
\end{tabular}

As análises de variância realizadas indicam diferenças não significativas para as absorções de água e índice de vazios medidos, independente do tipo de fibra, aço ou polipropileno, e teores empregados. Isto é um indicativo que a influência da adição dessas fibras na trabalhabilidade dos concretos não resultou incremento significativo de porosidade aos concretos, que poderiam implicar queda na resistência mecânica dos compósitos. A resistência à compressão dos concretos com essas fibras e teores está apresentada e discutida a seguir. 


\subsubsection{Resistência à compressão}

A Tabela 2.9 apresenta os resultados médios de resistência à compressão dos concretos estudados, medida aos 28 dias e em dois corpos de prova cilíndricos de $\Phi 10 \times 20 \mathrm{~cm}$.

Tabela 2.9 - Resultados de resistência à compressão dos concretos aos 28 dias. Fonte: Monte; Toaldo; Figueiredo (2014).

\begin{tabular}{cccc}
\hline Tipo e Teor de fibra & $\begin{array}{c}\boldsymbol{f}_{\text {cm,28 }} \\
\text { (MPa) }\end{array}$ & $\begin{array}{c}\text { Desvio padrão } \\
\text { (MPa) }\end{array}$ & $\begin{array}{c}\text { CV } \\
\text { (\%) }\end{array}$ \\
\hline SF - 20 & 33,5 & 2,1 & 6 \\
SF - 30 & 34,5 & 2,1 & 6 \\
SF - 45 & 34,0 & 0,0 & 0 \\
PF - 4,6 & 26,0 & 1,4 & 5 \\
PF - 6,8 & 28,5 & 0,7 & 2 \\
PF - 9,2 & 28,5 & 0,7 & 2 \\
\hline
\end{tabular}

Observa-se que os concretos produzidos com fibra de polipropileno resultaram menor resistência à compressão, quando comparados aos com fibras de aço, o que foi confirmado através de uma análise de variância com nível de significância ( $p$ ) igual a 0,05 (Hipótese de igualdade de médias rejeitada com valor $p=0,000$ ). Isto foi observado anteriormente por TIGUMAN (2004) que indicou que o polipropileno, devido a sua baixa resistência, pode atuar como um defeito no interior do concreto, reduzindo sua resistência à compressão. Como visto no item 2.4.1, a influência no índice de vazios (porosidade total) não foi significativa, portanto o nível de compactação dos corpos de prova não foi prejudicado. Verifica-se também que a resistência à compressão não foi alterada em função do aumento do teor de fibras, independente de ser fibra de aço ou de polipropileno, confirmado através de uma análise de variância (Hipótese de igualdade de médias entre fibra de aço e polipropileno não foi rejeitada ao nível de significância de 0,05 , valor $p=0,194$ ). Salienta-se que a quantidade de fibras de polipropileno empregada não ultrapassa $1 \%$ do volume do concreto, mas no esforço de compressão reduziu em até $20 \%$ a resistência do material.

\subsubsection{Ensaios de flexão JSCE-SF4}

A Figura 2.22 apresenta as curvas de carga por deslocamento vertical de cada uma das cinco vigas ensaiadas à flexão, correspondendo a cada variável independente, ou seja, para as fibras de aço e de polipropileno nos diversos teores avaliados. 

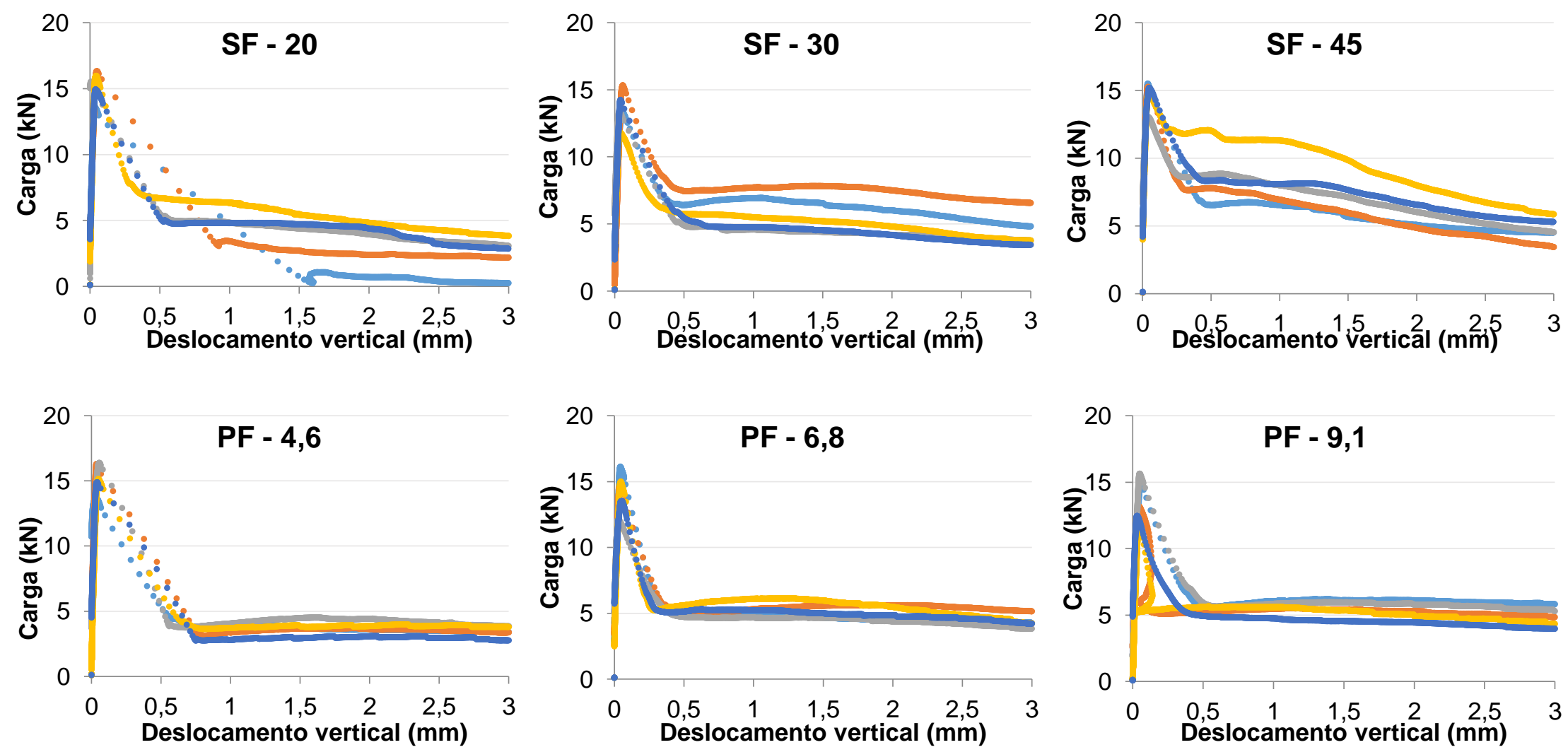

Figura 2.22 - Curvas carga-deslocamento vertical dos ensaios de flexão JSCE-SF4 para os CRF de aço (SF) e polipropileno (PF), nos respectivos teores. 
As curvas da Figura 2.22 serão avaliadas em relação às cargas de ruptura na flexão, a instabilidade pós-fissuração e a dispersão dos resultados. As resistências residuais pós-fissuração serão analisadas em conjunto com os resultados do ensaio Barcelona no item 2.4.6.

\section{Carga de ruptura à flexão}

Observam-se na Figura 2.22 que as cargas de ruptura à flexão foram muito próximas, independente do tipo e teor de fibra utilizados. Isto foi confirmado através de uma análise de variância com nível de significância $(p)$ igual a 0,05 (Hipótese de igualdade de médias não é rejeitada com valor $p=0,810$ para o tipo de fibra e com valor $p=0,067$ para o teor de fibra).

\section{Instabilidade pós-fissuracão}

A instabilidade é claramente evidenciada pela distância entre os pontos dos gráficos logo após a ruptura da matriz, conforme comentado anteriormente. A Tabela 2.10 apresenta os valores de deslocamento vertical máximos de cada curva e médios atingidos ao final do trecho de instabilidade.

Tabela 2.10 - Deslocamento vertical máximo de cada curva, médios e coeficiente de variação, correspondentes ao final da região de instabilidade ocorrida no ensaio JSCESF4.

\begin{tabular}{cccc}
\hline $\begin{array}{c}\text { Tipo e teor } \\
\text { de fibras }\end{array}$ & $\begin{array}{c}\text { Deslocamento vertical } \\
\text { máximo }(\mathbf{m m})\end{array}$ & $\begin{array}{c}\text { Deslocamento vertical } \\
\text { médio }(\mathbf{m m})\end{array}$ & $\begin{array}{c}\text { Coeficiente de } \\
\text { variação }(\%)\end{array}$ \\
\hline $\mathrm{SF}-20$ & 1,60 & 0,77 & 67 \\
$\mathrm{SF}-30$ & 0,43 & 0,35 & 23 \\
$\mathrm{SF}-45$ & 0,41 & 0,27 & 36 \\
$\mathrm{PF}-4,6$ & 0,78 & 0,66 & 15 \\
$\mathrm{PF}-6,8$ & 0,35 & 0,27 & 20 \\
$\mathrm{PF}-9,1$ & 0,39 & 0,24 & 53 \\
\hline
\end{tabular}

Percebe-se na Tabela 2.10 elevada instabilidade em alguns resultados do ensaio JSCE-SF4, principalmente para o menor teor de SF onde atinge no pior caso metade do deslocamento medido. Para os concretos reforçados com o menor teor de PF a instabilidade também é intensa, chegando a ultrapassar $0,5 \mathrm{~mm}$ do deslocamento medido. Quando o teor de fibra é aumentado, a instabilidade progressivamente reduzida com ambas as fibras, como ilustra a Figura 2.23. 


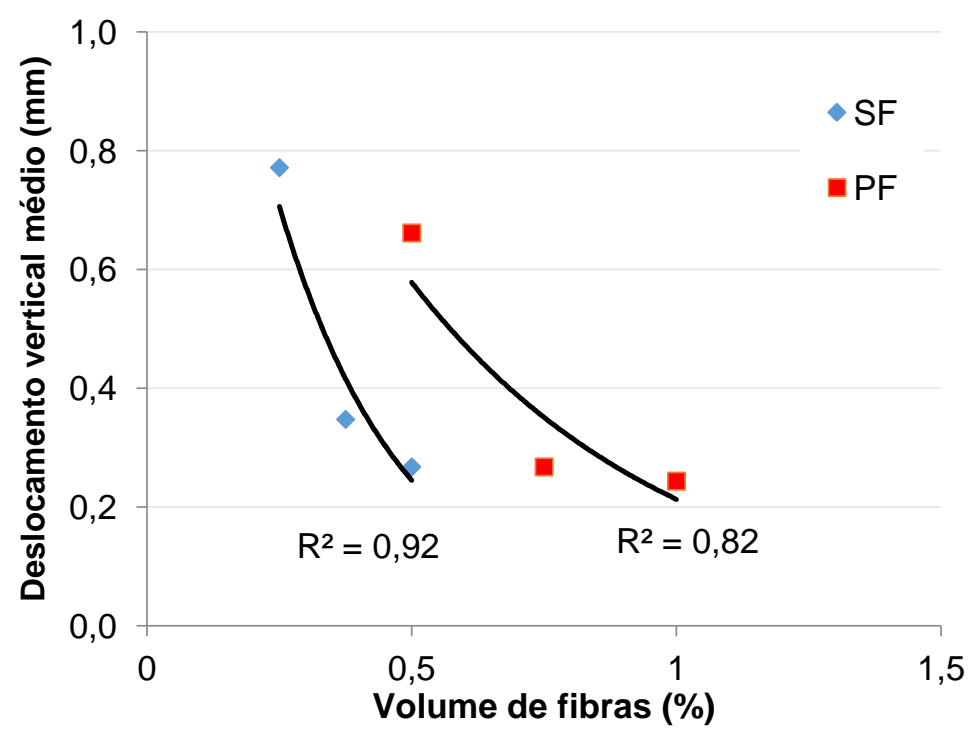

Figura 2.23 - Correlação entre o deslocamento vertical $(\delta)$ médio pós-fissuração e o volume de fibras (\% do volume de concreto).

A correlação existente entre o deslocamento vertical médio e o aumento do teor de fibra adicionado ocorre porque a capacidade resistente pós-fissuração também é aumentada, reduzindo a diferença entre a capacidade resistente residual do compósito e a resistência da matriz.

\section{Dispersão dos resultados}

Com relação à dispersão dos resultados relativos à carga de ruptura, as variâncias entre os tipos e teores de fibras foram analisadas através de gráficos do tipo boxplot e testes de igualdade de variâncias que estão apresentados na Figura 2.24 . 


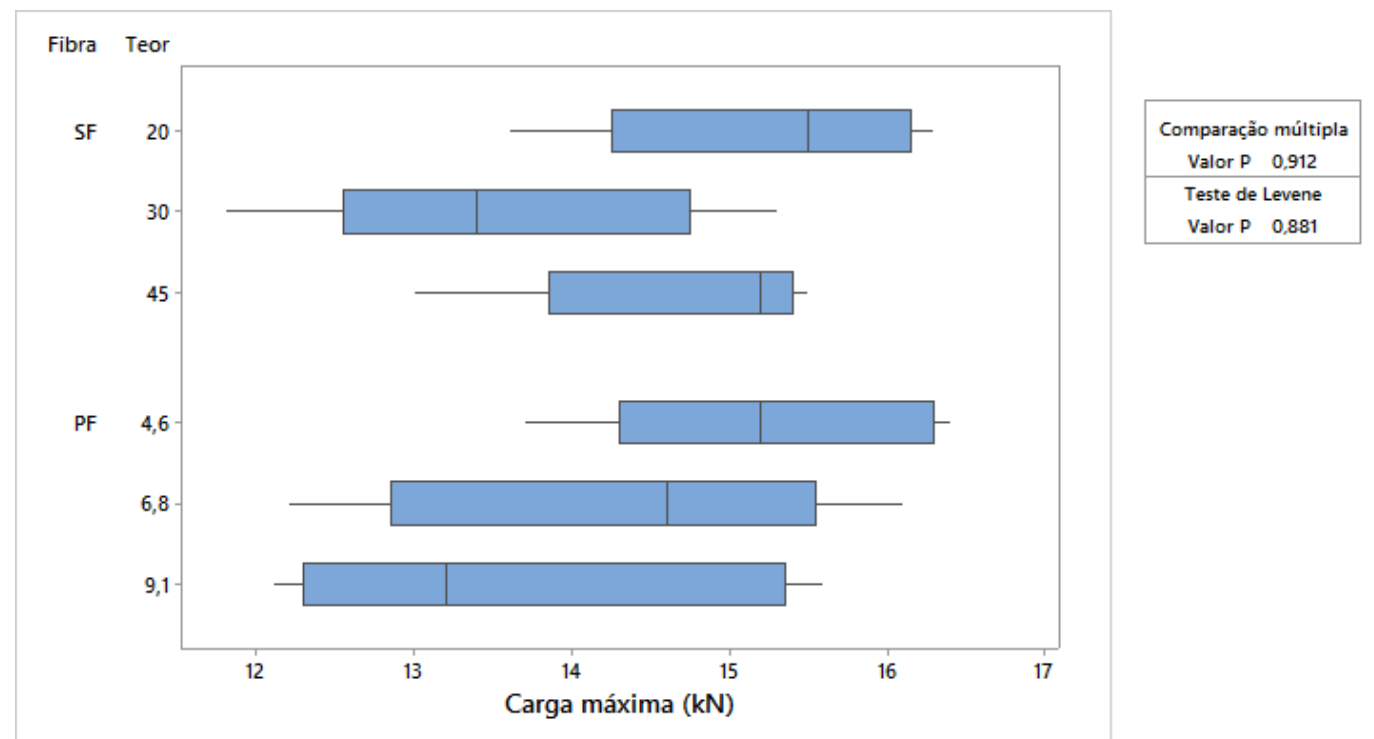

Figura 2.24 - Boxplot e testes para igualdade de variâncias das cargas de ruptura do ensaio de flexão JSCE-SF4 em função do tipo e teor de fibras.

Verifica-se na Figura 2.24 que a variabilidade dos resultados de carga de ruptura foram muito semelhantes, indicada pela dimensão das caixas do gráfico. Além disso, em ambos os testes estatísticos, de comparação múltipla e de Levene, a hipótese de igualdade das variâncias não foi rejeitada com nível de significância $(p)$ igual a 0,05 (Comparação múltipla com valor $p=0,912$ e Levene com valor $p=0,881$ ), indicando que as variâncias são significativamente iguais.

Quanto à dispersão no comportamento pós-fissuração, percebe-se na Figura 2.22 curvas mais dispersas para a fibra de aço em relação à fibra de polipropileno, para todos os teores avaliados. Isto pode estar associado ao número de fibras de polipropileno presente no concreto ser 3 a 4 vezes maior que o de fibra de aço (221.000 unidades/kg contra 13.000 unidades $/ \mathrm{kg}$ ). Salvador (2013) salienta que devido esta diferença no número de fibras a variação do número de fibras aço presentes na seção de ruptura do corpo de prova é superior à variação do número de fibras poliméricas nessa seção, conduzindo à maior dispersão nos dados experimentais para a fibra de aço. A análise estatística da dispersão das resistências residuais do ensaio JSCE-SF4 será apresentada em conjunto com a do ensaio Barcelona no item 2.4.6. 


\subsubsection{Ensaio Barcelona}

\section{FIBRA DE ACO}

A Figura 2.25 mostra as curvas de carga de puncionamento $\left(F_{p}\right)$ por deslocamento vertical $\left(\delta_{p}\right)$ de oito testemunhos no ensaio Barcelona, para a fibra de aço nos diversos teores avaliados. Os resultados após a conversão de $\delta_{p}$ em TCOD (ver item 2.2.2) também são apresentados. Os resultados da Figura 2.25 serão avaliados em relação às cargas máximas de puncionamento, a instabilidade pósfissuração e a dispersão dos resultados.

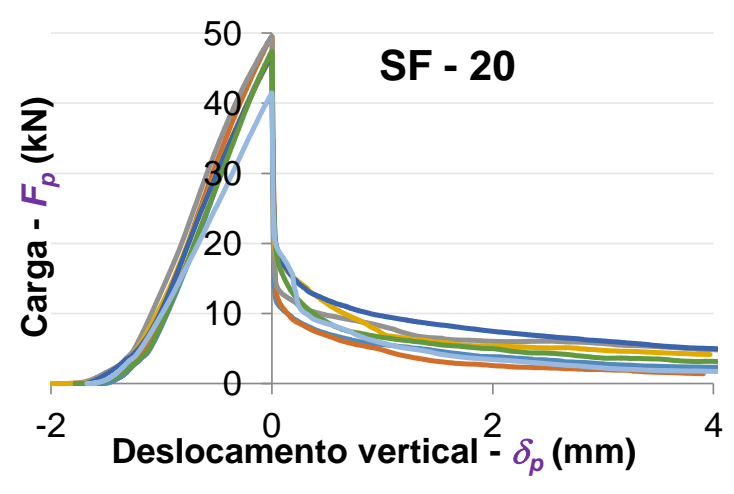

(a)

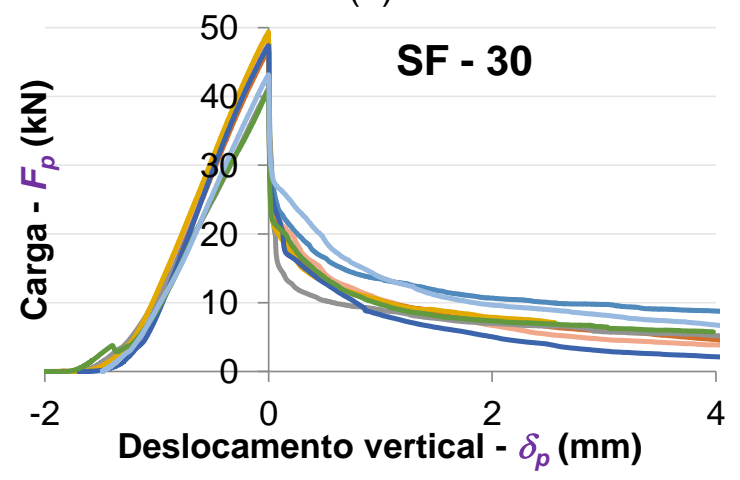

(c)

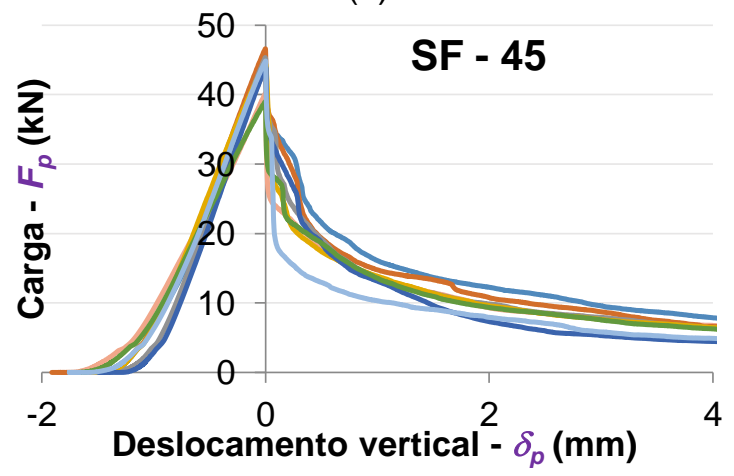

(e)

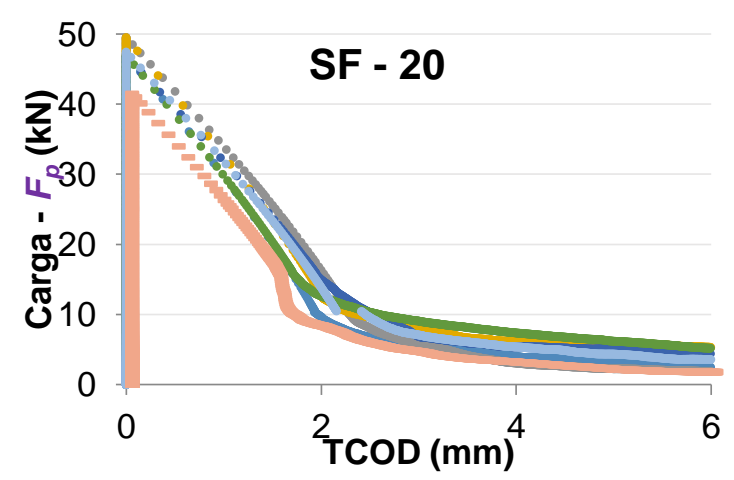

(b)

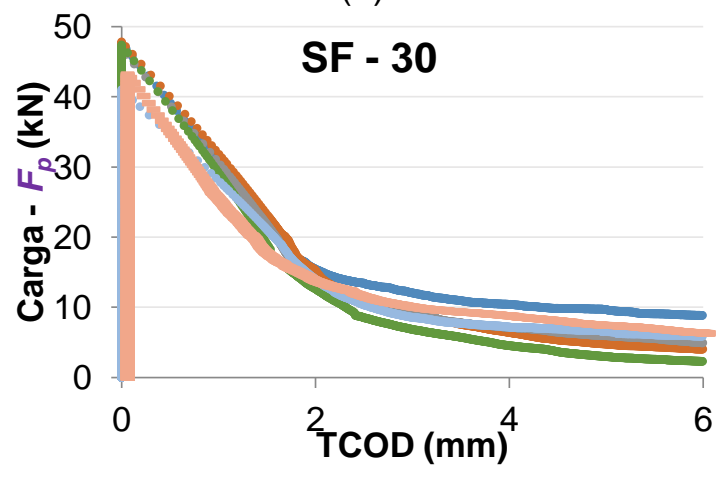

(d)

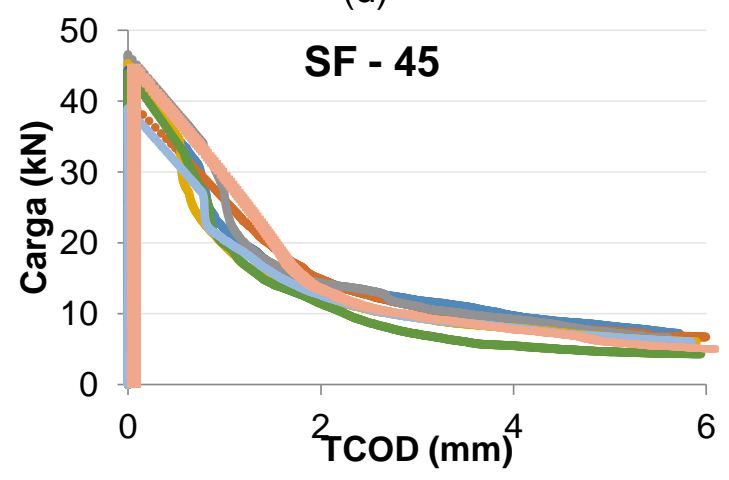

(f)

Figura 2.25 - Curvas de $F_{p}-\delta_{p}(\mathrm{a}, \mathrm{c}, \mathrm{e})$ e $F_{p}$-TCOD (b, d e f), para os ensaios Barcelona com fibra de aço (SF) em diferentes teores. 


\section{Carga máxima de puncionamento}

A Figura 2.25 mostra que as cargas máximas de puncionamento $\left(F_{p}\right)$ não variaram em função do aumento no teor de fibra de aço, confirmado através de uma análise de variância com nível de significância (p) igual a 0,05 (Hipótese de igualdade de médias não é rejeitada com valor $p=0,270)$. Isto também ocorreu para a resistência à compressão (item 2.4.2), que não foi significativamente influenciada pelo acréscimo no teor de fibra.

\section{Instabilidade pós-fissuração}

Quanto à instabilidade pós-pico percebe-se na Figura 2.25 que esta foi muito menos expressiva no ensaio Barcelona quando comparado ao ensaio JSCE-SF4, ainda que ambos os ensaios tenham sido realizados em sistema aberto de controle da velocidade. A instabilidade no ensaio Barcelona apenas foi percebida para os menores teores de fibra de aço e após a conversão do deslocamento vertical ( $\left.\delta_{p}\right)$ em TCOD (ver Figura 2.25b e 2.25d). No caso do menor teor, a instabilidade foi percebida até $1 \mathrm{~mm}$ de TCOD, o que corresponde a $0,5 \mathrm{~mm}$ de deslocamento vertical $(\delta)$ no ensaio de flexão. No caso do consumo de $30 \mathrm{~kg} / \mathrm{m}^{3}$, esse valor de instabilidade foi ainda mais reduzido. Nota-se na Tabela 2.10 que para esse teor de fibra de aço o deslocamento obtido no ensaio de flexão atingiu valores de até $1,6 \mathrm{~mm}$, representando uma instabilidade mais expressiva, o que compromete a quantificação da resistência residual associada à condição de serviço.

\section{Dispersão dos resultados}

A dispersão dos resultados de carga máxima de puncionamento $\left(F_{p}\right)$ foi analisada através de gráficos do tipo boxplot e testes estatísticos, conforme apresentado na Figura 2.26. A Figura 2.26 mostra que em ambos os testes, de comparação múltipla e de Levene, a hipótese de igualdade das variâncias não foi rejeitada considerando nível de significância $(p)$ igual a 0,05 (Comparação múltipla com valor $p=0,817$ e Levene com valor $p=0,654$ ), indicando que as variâncias são significativamente iguais. Também, observa-se nos gráficos que o teor de $20 \mathrm{~kg} / \mathrm{m}^{3} \mathrm{de}$ fibra apresentou um valor atípico (outlier), o que acabou aumentando a variância deste teor e aproximou-o da dispersão dos demais. 


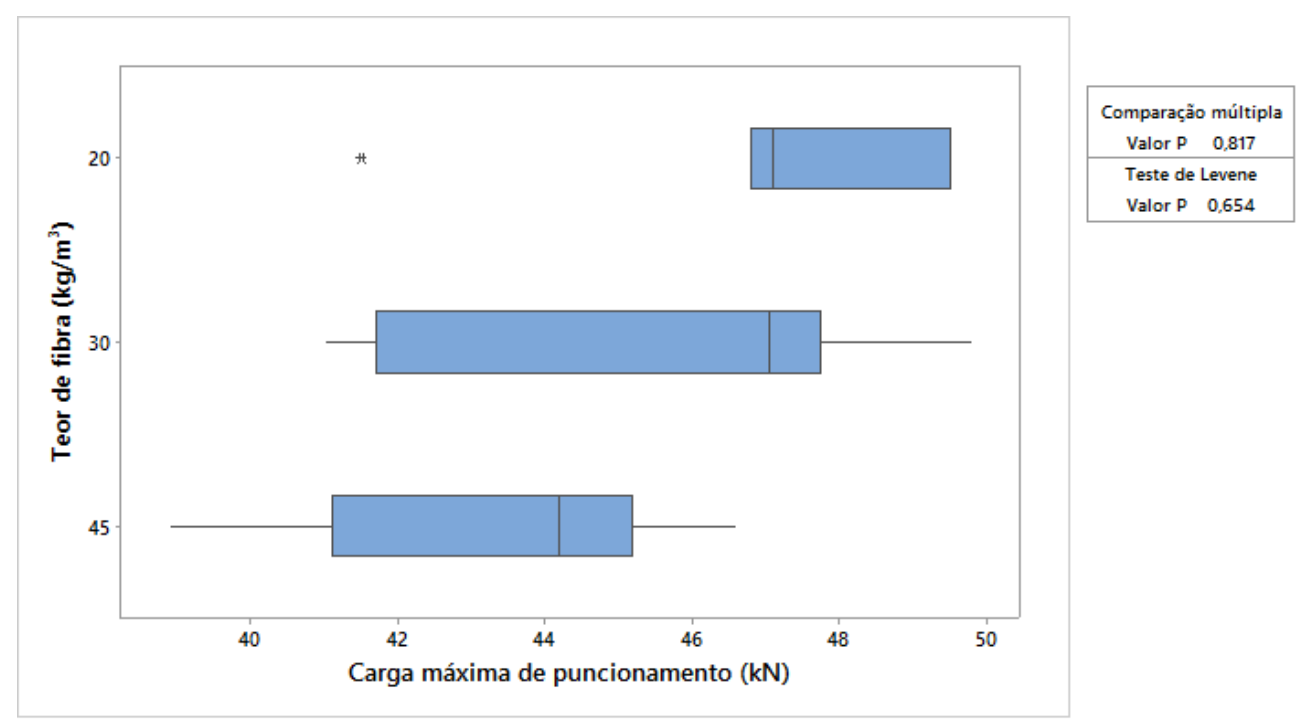

Figura 2.26 - Boxplot e testes para igualdade de variâncias das cargas máximas de puncionamento do ensaio Barcelona em função do teor de fibras de aço.

As curvas obtidas no ensaio Barcelona para a fibra de aço apresentam menor dispersão em relação àquela obtida no ensaio JSCE-SF4. Uma análise estatística com enfoque na dispersão das resistências residuais apresentadas por ambos os ensaios será apresentada no item 2.4.6.

\section{FIBRA DE POLIPROPILENO}

As curvas de carga de puncionamento $\left(F_{p}\right)$ por deslocamento vertical $\left(\delta_{p}\right)$ de cada um dos oito testemunhos no ensaio Barcelona, para a fibra de polipropileno nos diversos teores avaliados estão apresentadas na Figura 2.27. Em conjunto são apresentados os resultados da conversão do deslocamento vertical $\left(\delta_{p}\right)$ em TCOD, através das equações apresentadas no item 2.2.2. Os resultados da Figura 2.27 serão avaliados em relação às cargas máximas de puncionamento, a instabilidade pósfissuração e a dispersão dos resultados.

\section{Carga máxima de puncionamento}

Analisando a Figura 2.27 percebe-se que as cargas máximas de puncionamento são inferiores àquelas apresentadas com a fibra de aço (Figura 2.25), similar ao ocorrido na resistência à compressão (ver item 2.4.2), mas distinto da flexão que apresentou valores estatisticamente iguais (ver item 2.4.3). Isto ocorre porque 0 mecanismo dos ensaios Barcelona e de compressão são similares. A análise de variância realizada com nível de significância ( $p$ ) igual a 0,05 comprovou que as 
médias de cargas máximas de puncionamento não são estatisticamente iguais para fibra de aço e de polipropileno (Hipótese de igualdade de médias rejeitada com valor $p$ $=0,000)$. Além disso, as comparações de Tukey foram utilizadas para identificar se a fibra de aço e a fibra de polipropileno pertencem a grupos distintos em termos de carga máxima de puncionamento no ensaio Barcelona.

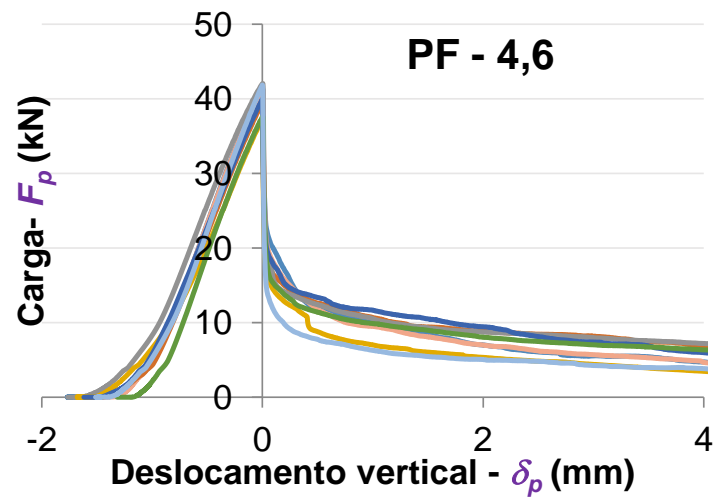

(a)

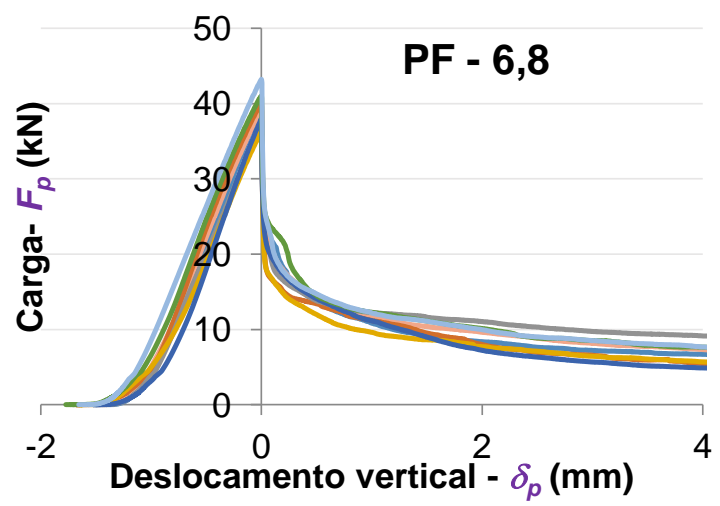

(c)

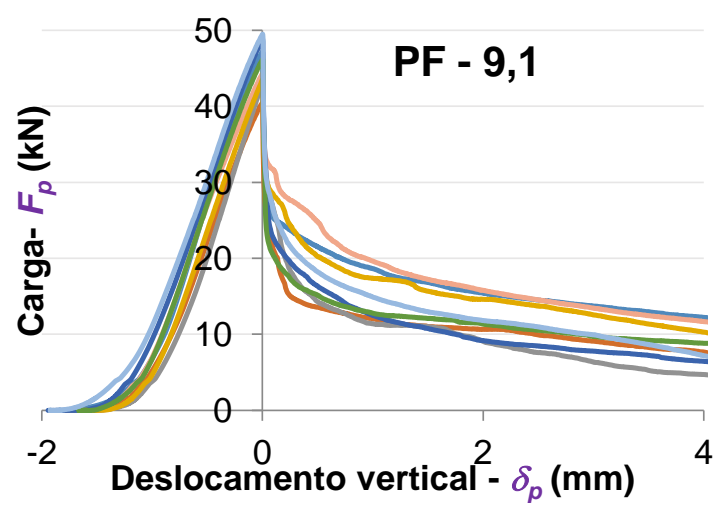

(e)

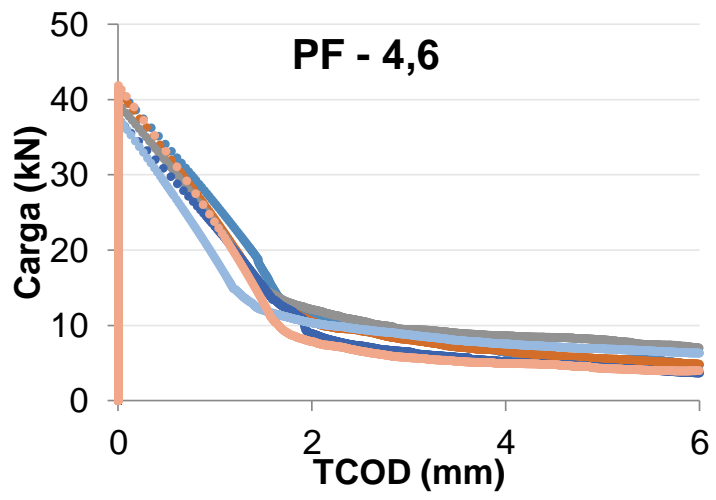

(b)

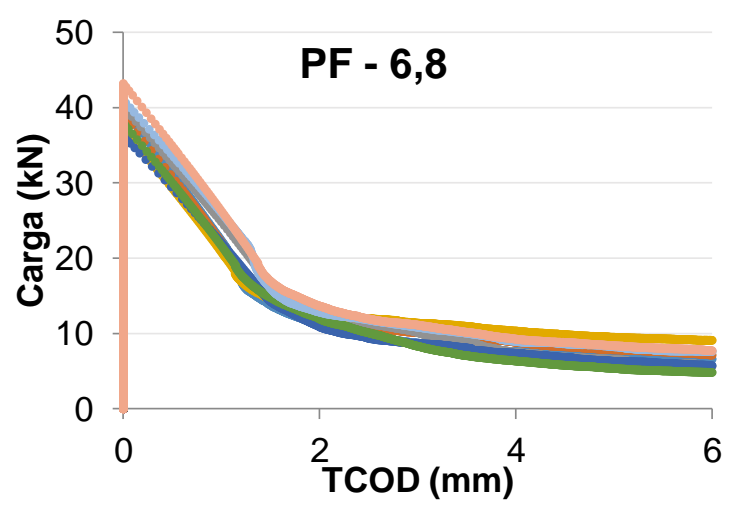

(d)

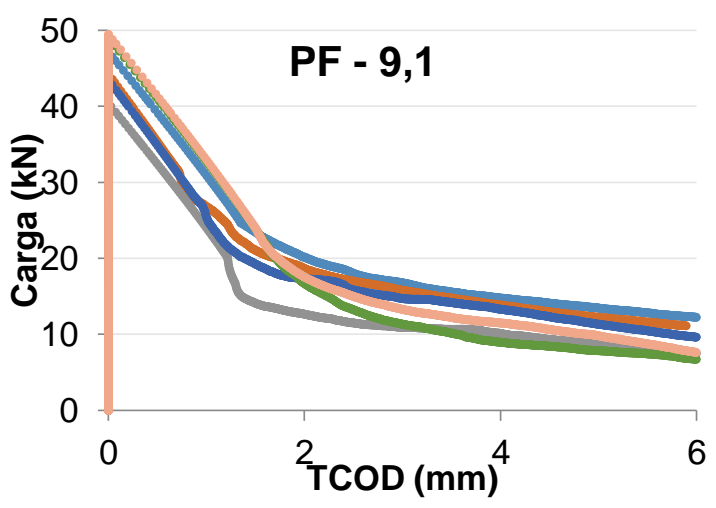

(f)

Figura 2.27 - Curvas carga- $\delta$ dos ensaios Barcelona com diferentes teores de fibra de polipropileno (PF). 
Comparações de Tukey pareadas: Resposta = Carga máxima de puncionamento do Barcelona, Termo de comparação = Tipo de fibra

Formação de grupos utilizando método de Tukey e 95\% de confiança

Tipo de fibra N Média geral Grupo

SF $\quad 23 \quad 45,3$

$\begin{array}{llll}\text { PF } & 24 & 41,6 & B\end{array}$

Obs: Médias que não compartilham a mesma letra são significativamente diferentes.

O teste de comparações de Tukey agrupou os resultados em dois grupos, um para a fibra de aço e outro para a fibra de polipropileno, com os diferentes teores de cada fibra pertencendo ao mesmo grupo. Ainda que para a carga máxima os ensaios Barcelona e tração na flexão indiquem comportamentos distintos, o objetivo principal do uso das fibras é o comportamento pós-fissuração e nesse caso os ensaios devem apresentar resultados correlacionáveis.

\section{Instabilidade pós-fissuracão}

Quanto à instabilidade pós-pico, esta não é percebida nas curvas dos ensaios Barcelona dos concretos reforçados com fibra de polipropileno. Isto pode ser observado claramente nas curvas de ensaio, onde não é observado afastamento entre os pontos do gráfico de carga versus deslocamento vertical (ver Figura 2.27). Comparados ao ensaio de flexão para os mesmos teores de fibra de polipropileno, o ensaio Barcelona apresentou instabilidade muito menor.

\section{Dispersão dos resultados}

Quanto à dispersão dos resultados de carga máxima de puncionamento da fibra de polipropileno, a análise foi feita através dos gráficos do tipo boxplot e os testes de igualdade de variância, como mostra a Figura 2.28. 


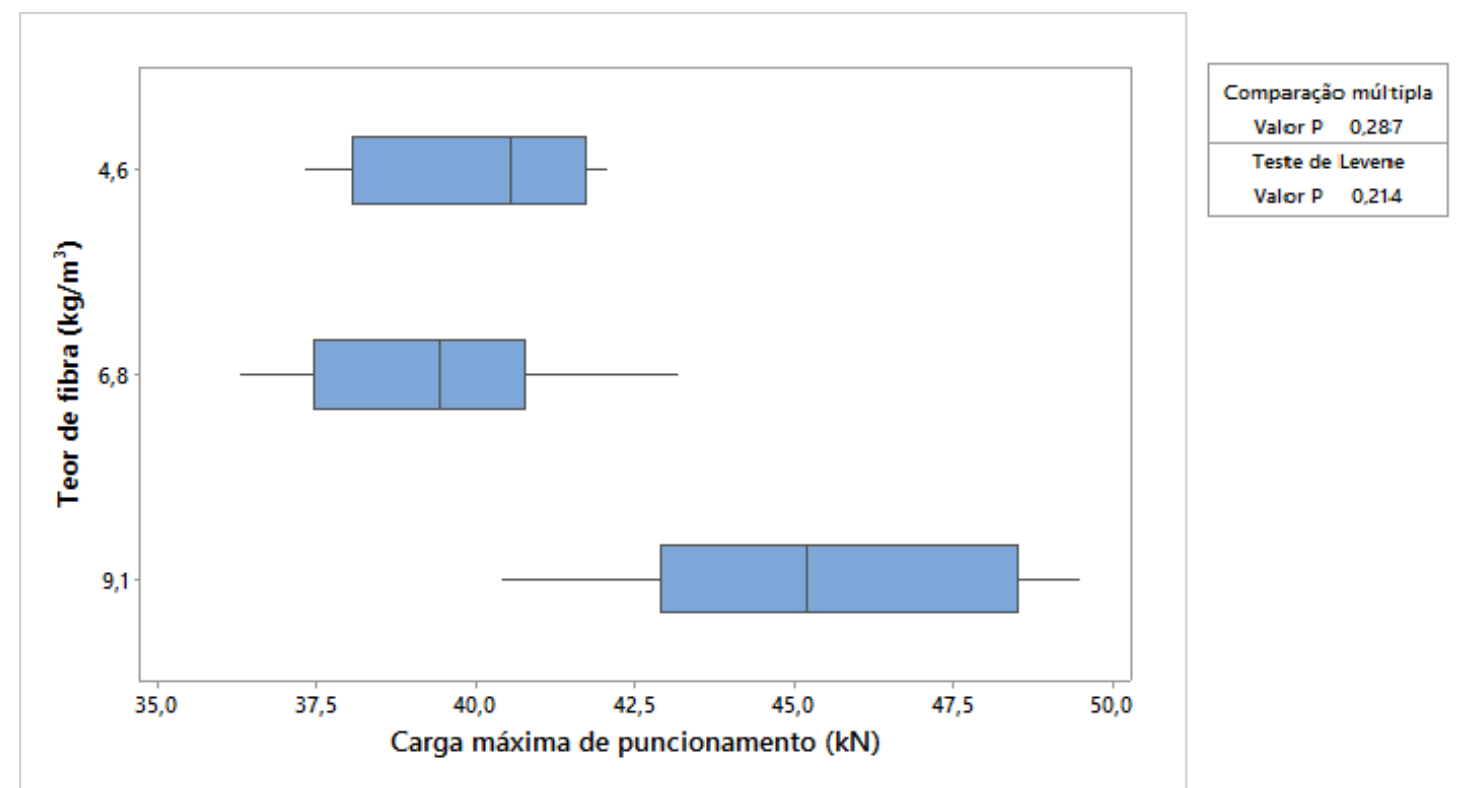

Figura 2.28 - Boxplot e testes para igualdade de variâncias das cargas máximas de puncionamento $\left(F_{p \max }\right)$ do ensaio Barcelona em função do teor de fibras de polipropileno.

A análise dos gráficos da Figura 2.28 indica que a dispersão dos resultados de carga máxima de puncionamento é semelhante. Isto também foi comprovado através dos testes de igualdade de variância, cujas hipóteses de igualdade das variâncias não foram rejeitadas com nível de significância (p) igual a 0,05 (Comparação múltipla com valor $p=0,287$ e Levene com valor $p=0,214)$, indicando que as variâncias são significativamente iguais.

As comparações dos ensaios de flexão JSCE-SF4 e Barcelona em termos de tenacidade e resistências residuais serão apresentadas, respectivamente, nos itens 2.4.5 e 2.4.6.

\subsubsection{Análise comparativa da tenacidade}

A comparação entre os métodos de ensaio também foi avaliada calculando-se a tenacidade. Para isto foram calculadas as áreas das curvas de carga versus deslocamento vertical em N.m, para ambos os ensaios. A Tabela 2.11 apresenta a síntese dos resultados médios de tenacidade obtidos nos ensaios JSCE-SF4 e Barcelona, com respectivos coeficientes de variação. 
Tabela 2.11 - Tenacidades médias e coeficientes de variação para os ensaios JSCE-SF4 e Barcelona. Fonte: Monte, Toaldo e Figueiredo (2014).

\begin{tabular}{ccccc}
\hline \multirow{2}{*}{$\begin{array}{c}\text { Tipo e teor de } \\
\text { fibras }\end{array}$} & \multicolumn{2}{c}{ JSCE-SF4 } & \multicolumn{2}{c}{ Barcelona } \\
& $\begin{array}{c}\text { Tenacidade } \\
\text { média (N.m) }\end{array}$ & $\begin{array}{c}\text { Coeficiente de } \\
\text { variação (\%) }\end{array}$ & $\begin{array}{c}\text { Tenacidade } \\
\text { (N.m) }\end{array}$ & $\begin{array}{c}\text { Coeficiente de } \\
\text { variação (\%) }\end{array}$ \\
\hline SF - 20 & 12,9 & 13 & 75,4 & 10 \\
SF-30 & 13,2 & 16 & 77,1 & 6 \\
SF - 45 & 16,8 & 16 & 71,9 & 7 \\
PF - 4,6 & 11,4 & 5 & 65,2 & 8 \\
PF - -6,8 & 11,8 & 5 & 66,7 & 7 \\
PF - 9,1 & 12,7 & 9 & 84,7 & 10 \\
\hline
\end{tabular}

Verifica-se na Tabela 2.11 que as maiores dispersões no cálculo da tenacidade foram obtidas para as fibras de aço e para o ensaio JSCE-SF4, chegando a 16\%. Este valor, considerando o histórico desde tipo de ensaio, não é muito alto uma vez que o coeficiente de variação pode superar $20 \%$ com frequência, como apontou Mindess Chen e Morgan (1994). O ensaio Barcelona apresentou valores de coeficientes de variação para o cálculo da tenacidade entre 6 e 10\%, valores inferiores aos obtidos por Molins, Aguado e Saludes (2009).

Para analisar a influência do método de ensaio, Barcelona e JSCE-SF4, e dos tipos e teores de fibra na tenacidade, foi realizado um teste de análise de variância, apresentado na Tabela 2.12 .

Tabela 2.12 - Análise de variância para a tenacidade.

\begin{tabular}{ccccccc}
\hline $\begin{array}{c}\text { Fontes de } \\
\text { variação }\end{array}$ & GL & $\begin{array}{c}\text { Soma de } \\
\text { quadrados }\end{array}$ & $\begin{array}{c}\text { Quadrado } \\
\text { médio }\end{array}$ & Estatística F & Valor $\boldsymbol{P}$ & Significativo \\
\hline $\begin{array}{c}\text { Método de } \\
\text { ensaio }\end{array}$ & 1 & 66141,7 & 66141,7 & 1409,15 & 0,000 & Sim \\
Tipo de fibra & 1 & 83,4 & 83,4 & 1,78 & 0,187 & Não \\
Teor de fibra & 2 & 513,2 & 256,6 & 5,47 & 0,006 & Sim \\
Erro & 71 & 3332,6 & 46,9 & & & \\
Total & 75 & 70194,3 & & & & \\
\hline
\end{tabular}

Quanto ao método de ensaio utilizado, a análise de variância indicou que as tenacidades calculadas não podem ser consideradas estatisticamente iguais entre 0 ensaio Barcelona e JSCE-SF4, considerando nível de significância (p) de 0,05 (Hipótese de igualdade de médias rejeitada, para ambos os casos, com valor $p=$ $0,000)$. Isto não indica que os valores não estejam correlacionados, o que será analisado em seguida. No que se refere ao tipo de fibra, aço ou polipropileno, a 
análise de variância indicou que as tenacidades calculadas não podem ser consideradas estatisticamente diferentes, considerando nível de significância ( $p)$ de 0,05 . Tal resultado mostra que a hipótese estabelecida no planejamento experimental de equivalência de desempenho entre as fibras utilizando o dobro do volume de fibra de polipropileno em relação à fibra de aço também se aplicou ao cálculo da tenacidade. Os teores de fibra utilizados resultaram tenacidades médias que não podem ser consideradas estatisticamente iguais, considerando nível de significância (p) de 0,05 (Hipótese de igualdade de médias rejeitada, para ambos os casos, com valor $p=0,000)$. No entanto, observando os valores de tenacidade e dispersão apresentados, apenas o concreto com maior teor de fibras de aço para o ensaio JSCE-SF4 e polipropileno para o ensaio Barcelona tiveram tenacidade significativamente maior, como mostra o teste de comparação múltipla de Tukey.

\begin{tabular}{|c|c|c|c|}
\hline \multicolumn{4}{|c|}{$\begin{array}{l}\text { Comparações de Tukey pareadas: Resposta = Ten } \\
\text { Termo de comparação = Método de ensaio, Tipo d } \\
\text { Formação de grupos utilizando método de Tukey e } 95\end{array}$} \\
\hline \multicolumn{4}{|c|}{\begin{tabular}{llcc} 
Método de ensaio & $\mathrm{N}$ & Média geral & Grupo \\
Barcelona & 46 & 73,5090 & $\mathrm{~A}$ \\
JSCE-SF4 & 30 & 13,1344 & \multicolumn{1}{c}{$\mathrm{B}$}
\end{tabular}} \\
\hline \\
\hline $\begin{array}{l}\text { Teor de fibra } \\
45 \text { e } 9,1 \\
30 \text { e } 6,8 \\
20 \text { e } 4,6\end{array}$ & $\begin{array}{l}N \\
26 \\
25 \\
25\end{array}$ & $\begin{array}{l}\text { Média geral } \\
46,8838 \\
42,2504 \\
40,8309\end{array}$ & $\begin{array}{l}\text { Grupo } \\
\text { A B } \\
\text { B }\end{array}$ \\
\hline
\end{tabular}

Obs: Médias que não compartilham a mesma letra são significativamente diferentes.

As comparações de Tukey confirmaram que os ensaios Barcelona e JSCE-SF4 resultam resultados diferentes em termos de tenacidade e que, com $95 \%$ de confiança, podem ser agrupados em dois grupos diferentes. Essa análise refere-se ao valor absoluto de tenacidade, que é maior no ensaio Barcelona, mas não indica que não são correlacionáveis, o que será analisado mais adiante. Quanto ao tipo de fibra foi confirmado que as fibras de aço e polipropileno pertencem a grupos equivalentes em termos de média geral de tenacidade. E, no que se refere ao teor de fibras, o teste mostrou que os teores mais baixos de fibras resultam pouca diferença em termos de tenacidade e acabam por serem agrupados em conjunto. Conforme comentado 
anteriormente o cálculo da tenacidade é feito através da determinação da área sob a curva de carga por deslocamento. Por isso, a ocorrência de instabilidade acaba gerando uma região de incerteza de resistência residual que terá uma influência muito grande especialmente para os menores valores de deslocamento. Quando ocorre a instabilidade há uma maior dificuldade de se diferenciar a resistência residual de concretos reforçados com baixo consumo de fibras principalmente. Para minimizar este efeito o cálculo de tenacidade foi realizado para diferentes níveis de deflexão e TCOD, obtendo-se as correlações apresentadas na Figura 2.29 e na Figura 2.30.

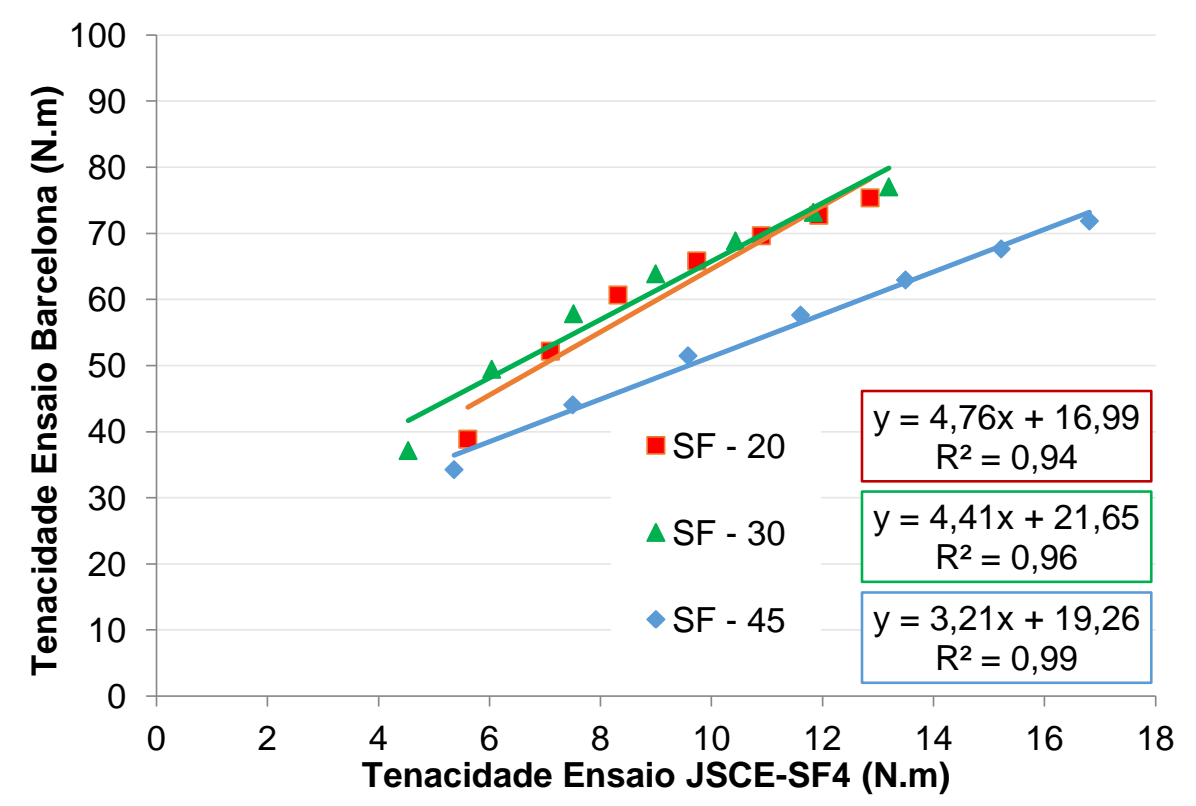

Figura 2.29 - Regressões lineares entre as tenacidades médias dos ensaios JSCE-SF4 $(0 \leq \delta$ $\leq 2)$ e Barcelona ( $0 \leq \mathrm{TCOD} \leq 4)$ para a fibra de aço. Fonte: Monte; Toaldo; Figueiredo (2014).

Os elevados coeficientes de determinação $R^{2}$ das regressões (acima de 0,94 ) apresentados na Figura 2.29 e na Figura 2.30 indicam ótima correlação entre as tenacidades calculadas pelos dois métodos de ensaio. Este resultado foi similar ao obtido por Molins, Aguado e Saludes (2009). É importante ressaltar que esta pesquisa utilizou tipos e teores de fibras diferentes, portanto esses resultados complementam uma validação mais ampla da possibilidade de correlação. 


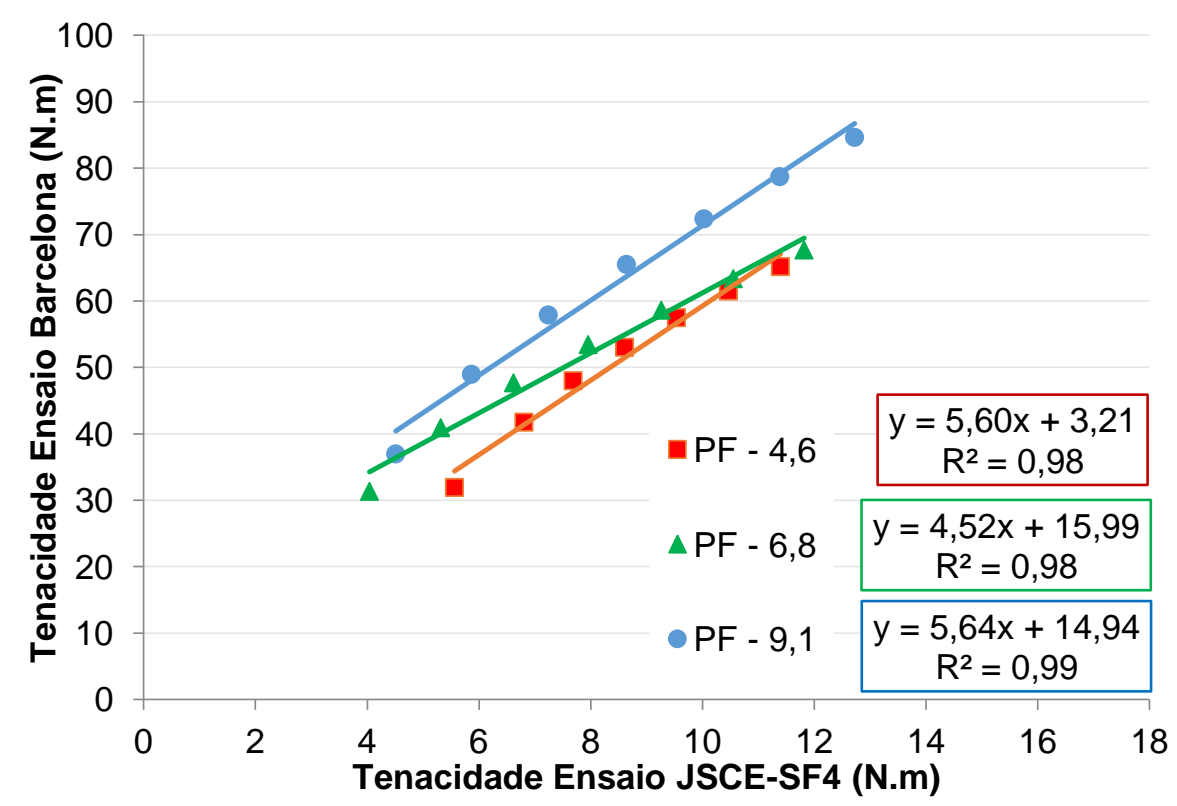

Figura 2.30 - Regressões lineares entre as tenacidades médias dos ensaios JSCE-SF4 $(0 \leq \delta$ $\leq 2)$ e Barcelona $(0 \leq T C O D \leq 4)$ para a fibra de polipropileno. Fonte: Monte; Toaldo; Figueiredo (2014).

As análises dos resultados de tenacidade mostram que há clara correlação entre a sua determinação no ensaio de flexão ou ensaio Barcelona. $O$ fato de não haver uma única correlação para todos os teores está correlacionado com os diferentes níveis de instabilidade que são mais intensos para os menores teores de fibras. No entanto, se houver a necessidade, em caso de instabilidade no ensaio, pode-se propor uma medida alternativa da tenacidade desprezando o trecho inicial. No entanto, a quantificação da tenacidade pode ser substituída por determinações de resistências residuais, aproximando-se do que há de mais moderno em termos de equação constitutiva para o comportamento do material, como o fib Model Code (FIB, 2013), e de controle do material, ensaio de flexão com entalhe EN 14651 (2007).

\subsubsection{Análise comparativa do comportamento pós-fissuração}

Para melhor analisar os resultados pós-fissuração dos ensaios JSCE-SF4 e Barcelona foram calculadas as resistências residuais para deslocamentos pequenos (região de serviço, denominada RS) e maiores (região de pré-ruptura, denominada RR). A norma japonesa de ensaio de flexão não apresenta critérios para determinação das tensões residuais. Isto torna impossível uma comparação direta entre os métodos de ensaio e, mais do que isso, uma avaliação compatível com os parâmetros de estabelecimento de equações constitutivas adequadas á parametrização do CRF como material estrutural. Assim, foi adotado o critério da ASTM C 1609 (2010), que 
determina as tensões residuais para deslocamentos L/600 (deslocamento vertical $\delta=$ $0,5 \mathrm{~mm}$ ) e L/150 (deslocamento vertical $\delta=2 \mathrm{~mm}$ ), utilizando as Eq. 2-20 e Eq. 2-21.

$$
\begin{aligned}
& f_{d, L / 600}=\frac{P_{d, L / 600} \times L}{b \times d^{2}} \\
& f_{d, L / 150}=\frac{P_{d, L / 150} \times L}{b \times d^{2}}
\end{aligned}
$$

Onde:

$f_{d, L 600}$ e $f_{d, L / 150}$ são as resistências residuais, quando o deslocamento vertical for L/600 e L/150, respectivamente (MPa);

$P_{d, L / 150}$ e $P_{d, L / 150}$ são as cargas residuais, quando o deslocamento vertical for $\mathrm{L} / 600 \mathrm{e}$ $\mathrm{L} / 150$, respectivamente $(\mathrm{N})$;

$L$ é o vão de ensaio $(\mathrm{mm})$;

b e $d$ são a largura e altura do corpo de prova, respectivamente (mm).

Para o ensaio Barcelona foi utilizada a Eq. 2-2 apresentada na norma AENOR UNE 83515 (2010) para valores de TCOD iguais a $1 \mathrm{~mm}$ e $4 \mathrm{~mm}$, mantendo a proporção geométrica de 2:1 com o ensaio de flexão (ver item 2.2.4). A Tabela 2.13 apresenta a síntese dos resultados médios de resistências residuais obtidas nos ensaios JSCE-SF4 e Barcelona, com respectivos coeficientes de variação.

Tabela 2.13 - Resistências residuais para diferentes aberturas de fissuras nos ensaios

\begin{tabular}{|c|c|c|c|c|c|c|c|c|}
\hline \multirow{3}{*}{$\begin{array}{l}\text { Tipo e teor } \\
\text { de fibras }\end{array}$} & \multicolumn{4}{|c|}{ JSCE-SF4 } & \multicolumn{4}{|c|}{ Barcelona } \\
\hline & \multicolumn{2}{|c|}{$\delta=0,5 \mathrm{~mm}$} & \multicolumn{2}{|c|}{$\delta=2 \mathbf{m m}$} & \multicolumn{2}{|c|}{$T C O D=1 \mathrm{~mm}$} & \multicolumn{2}{|c|}{$T C O D=4 \mathrm{~mm}$} \\
\hline & $\begin{array}{l}\text { Média } \\
\text { (MPa) }\end{array}$ & $\begin{array}{l}C V \\
\text { (\%) }\end{array}$ & $\begin{array}{l}\text { Média } \\
\text { (MPa) }\end{array}$ & $\begin{array}{l}C V \\
(\%)\end{array}$ & $\begin{array}{l}\text { Média } \\
\text { (MPa) }\end{array}$ & $\begin{array}{l}C V \\
\text { (\%) }\end{array}$ & $\begin{array}{l}\text { Média } \\
(\mathrm{MPa})\end{array}$ & $\begin{array}{l}C V \\
\text { (\%) }\end{array}$ \\
\hline$S F-20$ & 1,3 & 50 & 0,9 & 51 & 0,33 & 24 & 0,17 & 45 \\
\hline$S F-30$ & 1,8 & 15 & 1,6 & 27 & 0,51 & 20 & 0,27 & 36 \\
\hline$S F-45$ & 2,6 & 24 & 1,8 & 21 & 0,66 & 13 & 0,33 & 18 \\
\hline$P F-4,6$ & 1,1 & 19 & 1,1 & 13 & 0,45 & 20 & 0,28 & 25 \\
\hline$P F-6,8$ & 1,5 & 6 & 1,5 & 11 & 0,54 & 7 & 0,34 & 17 \\
\hline$P F-9,2$ & 1,7 & 9 & 1,6 & 13 & 0,70 & 23 & 0,45 & 29 \\
\hline
\end{tabular}
JSCE-SF4 e Barcelona. Fonte: Monte; Toaldo; Figueiredo (2014).

Analisando a Tabela 2.13 observam-se coeficientes de variação muito altos se comparados aos obtidos para o trecho elástico de avaliação do compósito (carga de ruptura à flexão e carga máxima de puncionamento). Estes coeficientes de variação 
foram superiores a $20 \%$ na maioria dos casos e chegando a $50 \%$ para o menor teor de fibra de aço. Um dos fatores que afetam o coeficiente de variação da resistência residual é a variabilidade relativa do número de fibras presente na seção de ruptura, o que confere a capacidade resistente residual, conforme discutido anteriormente na análise da dispersão do ensaio de flexão no item 2.4.3. Por essa razão, as fibras de aço, presentes em menor número, proporcionaram os maiores valores de coeficiente de variação para o ensaio JSCE-SF4, especialmente para os menores teores de fibras. Para as fibras de polipropileno, que apresentam maior número de fibras na seção de ruptura quando comparado com as fibras de aço, a variabilidade foi menor principalmente para o ensaio JSCE-SF4 e a região de serviço (RS). No entanto, a resistência residual calculada através do ensaio Barcelona apresenta resultados numericamente inferiores aos obtidos no ensaio de flexão. Por causa disso, apesar do fato do ensaio Barcelona apresentar menores valores de desvios padrão, obteve-se valores mais altos de coeficiente de variação. Os gráficos do tipo boxplot e testes de igualdade de variâncias para as resistências residuais na RS podem ser vistos na Figura 2.31.

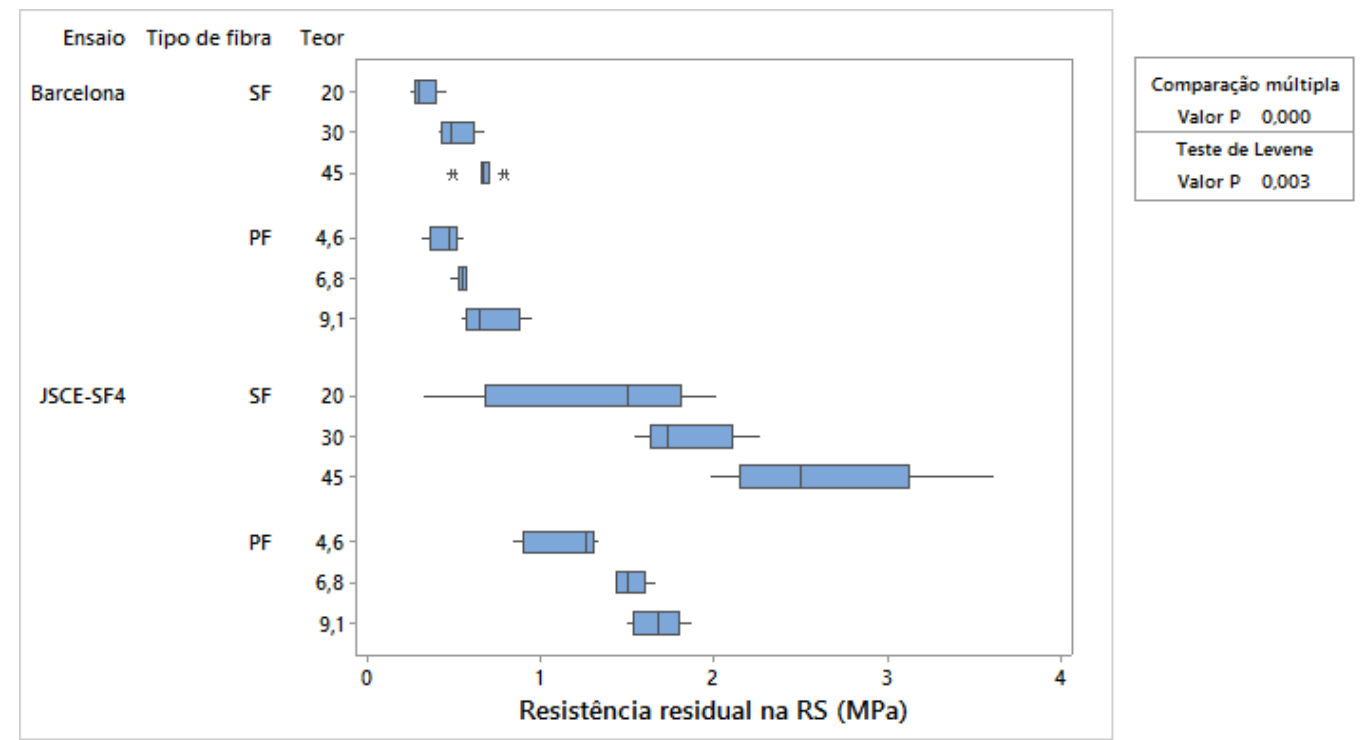

Figura 2.31 - Boxplot e teste para igualdade de variâncias das resistências residuais na RS em função do método de ensaio, do tipo e teor de fibras.

Percebe-se claramente nos gráficos da Figura 2.31 que as variâncias são diferentes entre os métodos de ensaio e muito maiores para a fibra de aço no ensaio JSCE-SF4 quando comparada as demais condições. Os resultados dos testes de igualdade de variância, teste de comparação múltipla e teste de Levene, rejeitaram a hipótese de igualdade das variâncias com nível de significância (p) igual a 0,05 
(Comparação múltipla com valor $p=0,000$ e Levene com valor $p=0,003$ ), indicando que pelo menos uma das variâncias é significativamente diferente das demais. De forma similar foram analisadas as variâncias das resistências residuais na $R R$, conforme apresenta a Figura 2.32 .

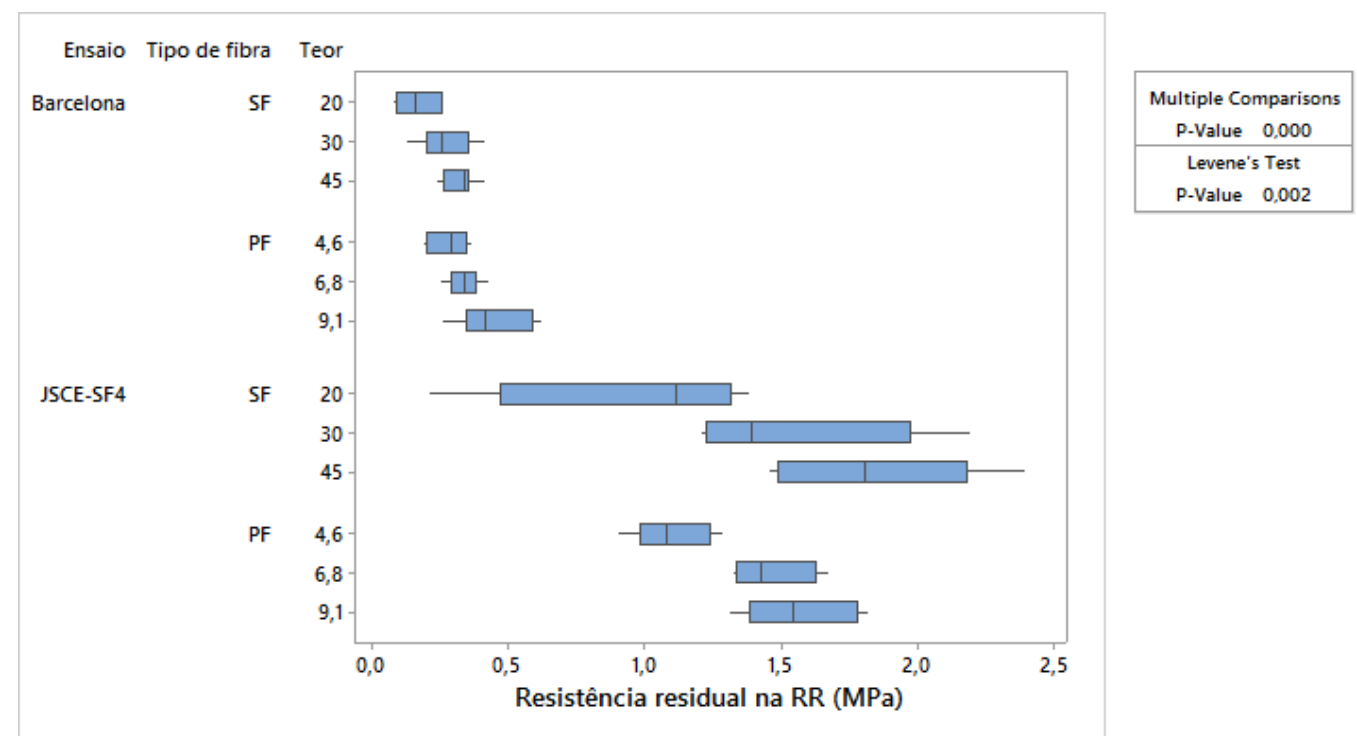

Figura 2.32 - Boxplot e teste para igualdade de variâncias das resistências residuais na RR em função do método de ensaio, do tipo e teor de fibras.

Observando os gráficos da Figura 2.32 nota-se que também para a RR as variâncias são diferentes entre os métodos de ensaio, e muito maiores para a fibra de aço no ensaio JSCE-SF4. Os testes de igualdade de variância resultaram a rejeição da hipótese de igualdade das variâncias com nível de significância $(p)$ igual a 0,05 (Comparação múltipla com valor $p=0,000$ e Levene com valor $p=0,002$ ), indicando que pelo menos uma das variâncias é significativamente diferente das demais. A maior dispersão no ensaio de flexão de vigas deve-se a forte influência da presença de um número maior ou menor de fibras na parte inferior da viga, onde a abertura da fissura é maior (Figura 2.33a), já discutido no trabalho de Salvador (2013). Já no caso do ensaio Barcelona a área de fissuração é maior, pois ocorrem entre 2 a 4 fissuras radiais, sendo o resultado deste ensaio menos influenciado por pequenas variações no número de fibras presentes nas sessões de fratura (Figura 2.33b). 


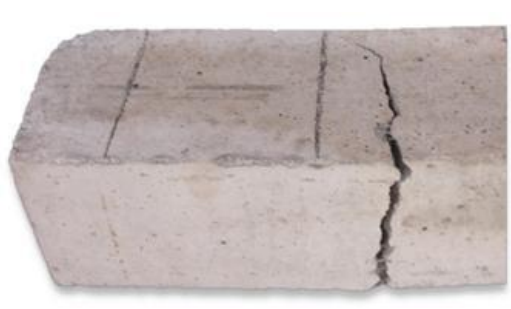

(a)

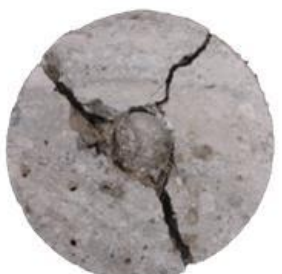

(b)

Figura 2.33 - a) Abertura de uma fissura no ensaio de flexão JSCE-SF4; b) Abertura de três fissuras no ensaio Barcelona. Fonte: Monte; Toaldo; Figueiredo (2014).

Para comparar as resistências residuais médias na $R S$ e $R R$ em função do método de ensaio, dos tipos de fibra e dos teores de fibra foram realizados testes de análise de variância que estão apresentados na Tabela 2.14 e na Tabela 2.15.

Tabela 2.14 - Análise de variância para a resistência residual na RS.

\begin{tabular}{|c|c|c|c|c|c|c|}
\hline $\begin{array}{l}\text { Fontes de } \\
\text { variação }\end{array}$ & $G L$ & $\begin{array}{c}\text { Soma de } \\
\text { quadrados }\end{array}$ & $\begin{array}{l}\text { Quadrado } \\
\text { médio }\end{array}$ & Estatística F & Valor $P$ & Significativo \\
\hline Tipo de fibra & 1 & 0,4024 & 0,4024 & 3,74 & 0,057 & Não \\
\hline Teor de fibra & 2 & 3,6414 & 1,8207 & 16,91 & 0,000 & Sim \\
\hline $\begin{array}{l}\text { Método de } \\
\text { ensaio }\end{array}$ & 1 & 23,6225 & 23,6225 & 219,37 & 0,000 & Sim \\
\hline Erro & 71 & 7,6454 & 0,1077 & & & \\
\hline Total & 75 & 35,2595 & & & & \\
\hline
\end{tabular}

Tabela 2.15 - Análise de variância para a resistência residual na RR.

\begin{tabular}{ccccccc}
\hline $\begin{array}{c}\text { Fontes de } \\
\text { variação }\end{array}$ & GL & $\begin{array}{c}\text { Soma de } \\
\text { quadrados }\end{array}$ & $\begin{array}{c}\text { Quadrado } \\
\text { médio }\end{array}$ & Estatística $\boldsymbol{F}$ & Valor $\boldsymbol{P}$ & Significativo \\
\hline Tipo de fibra & 1 & 0,0311 & 0,0311 & 0,54 & 0,465 & Não \\
$\begin{array}{c}\text { Teor de fibra } \\
\text { Método de }\end{array}$ & 2 & 1,7506 & 0,8753 & 15,21 & 0,000 & Sim \\
ensaio & 1 & 22,2953 & 22,2953 & 387,36 & 0,000 & Sim \\
Erro & 71 & 4,0866 & 0,0576 & & & \\
Total & 75 & 27,9957 & & & & \\
\hline
\end{tabular}

Para o tipo de fibra, aço ou polipropileno, a análise de variância indicou que, tanto para a RS quanto para a RR, as médias das resistências residuais não podem ser consideradas estatisticamente diferentes, considerando nível de significância $(p)$ de 0,05 (Hipótese de igualdade de médias não foi rejeitada com valor $p=0,057$, para a $\mathrm{RS}$ e com valor $p=0,465$ para a $R R$ ). Isto indica que a hipótese estabelecida no planejamento experimental de buscar equivalência de desempenho entre as fibras utilizando o dobro do volume de fibra de polipropileno em relação à fibra de aço foi bem sucedida. Os métodos de ensaio apresentaram resultados de resistências 
residuais estatisticamente distintos. Porém, as resistências residuais obtidas são correlacionáveis, o que será discutido mais adiante. Quanto aos teores de fibra utilizados, a análise de variância indicou que, as médias das resistências residuais não podem ser consideradas estatisticamente iguais. Tal resultado mostra que as variações nos teores de fibras utilizados foram suficientes para proporcionar variação significativa dos comportamentos pós-fissuração. Estas análises podem ser complementadas por comparações de Tukey, que visam identificar agrupamentos dos resultados para cada uma das variáveis estudadas.

\begin{tabular}{|c|c|c|c|}
\hline \multicolumn{4}{|c|}{$\begin{array}{l}\text { Comparações de Tukey pareadas: Resposta = Resistência residue } \\
\text { de comparação = Método de ensaio, Tipo de fibra e Teor de fibra }\end{array}$} \\
\hline \multicolumn{4}{|c|}{ Formação de grupos utilizando método de Tukey e 95\% de confiança } \\
\hline Método de ensaio & $\mathrm{N}$ & Média geral & Grupo \\
\hline Barcelona & 46 & 0,53451 & ${ }^{A} B$ \\
\hline Tipo de fibra & $\mathrm{N}$ & Média geral & Grupo \\
\hline SF & 37 & 1,17782 & A \\
\hline PF & 39 & 1,03217 & $A$ \\
\hline Teor de fibra & $\mathrm{N}$ & Média geral & Grupo \\
\hline 45 e 9,1 & 26 & 1,37345 & A \\
\hline 30 e 6,8 & 25 & 1,10264 & B \\
\hline 20 e 4,6 & 25 & 0,83890 & C \\
\hline
\end{tabular}

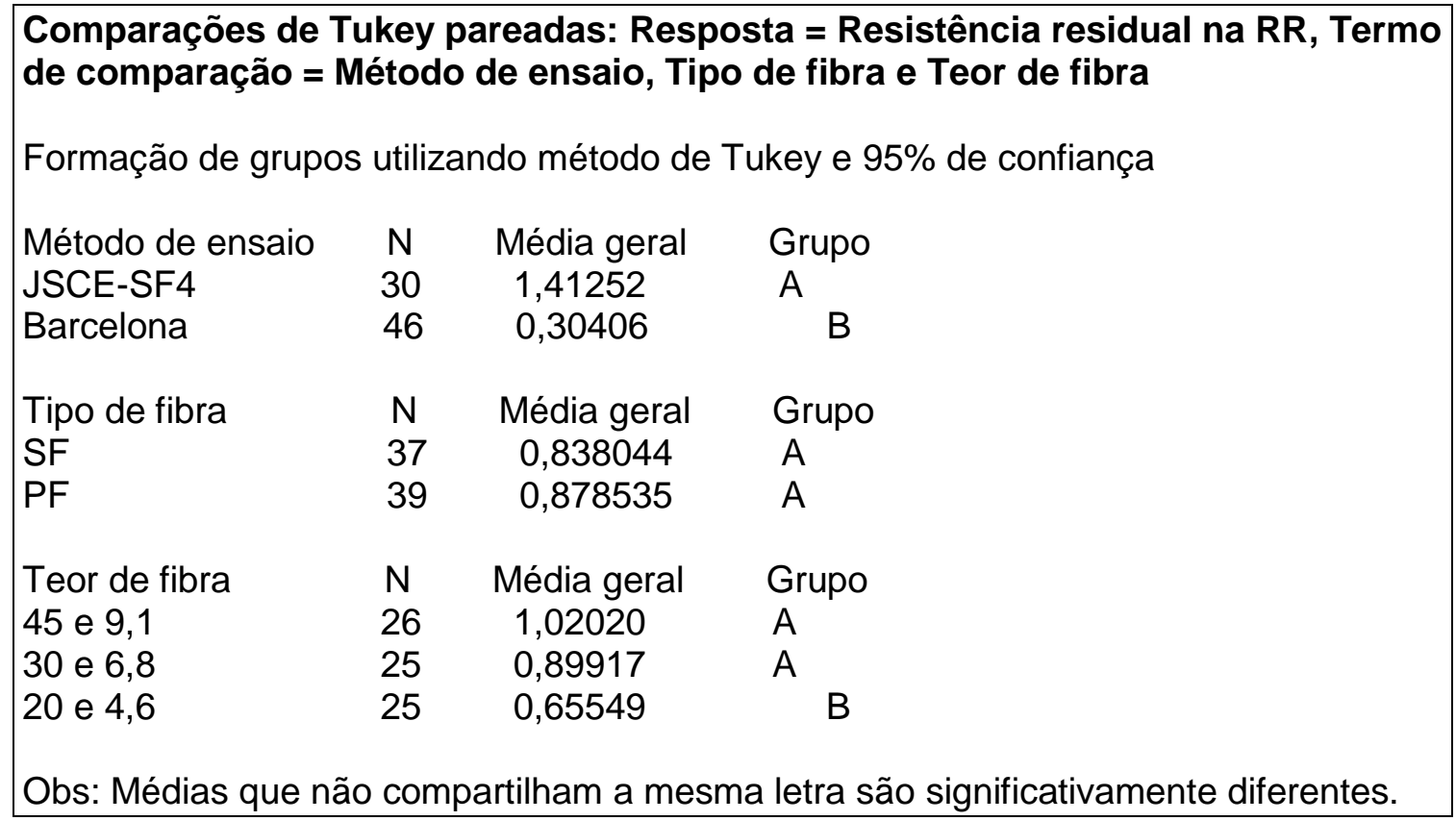


As comparações de Tukey indicaram que os ensaios Barcelona e JSCE-SF4 resultam resultados diferentes e que com $95 \%$ de confiança podem ser agrupados em dois grupos de resultados médios absolutos diferentes. Quanto ao tipo de fibra, o teste de Tukey confirma o resultado da análise de variância e ambas as fibras pertencem a grupos equivalentes em termos de média geral de resistência residual. Para o teor de fibras os resultados na RS e na RR foram distintos, sendo os teores agrupados em três grupos no primeiro caso e em apenas dois grupos no segundo caso. Isto se deve às resistências residuais calculadas para a RR apresentarem, para a maioria dos casos, resultados mais dispersos (Tabela 2.13).

Ainda que tenham sido obtidos resultados absolutos distintos, como mostra a Figura 2.34 os resultados médios das resistências residuais na RS e na RR medidas com os ensaios Barcelona e JSCE-SF4 podem ser correlacionados.

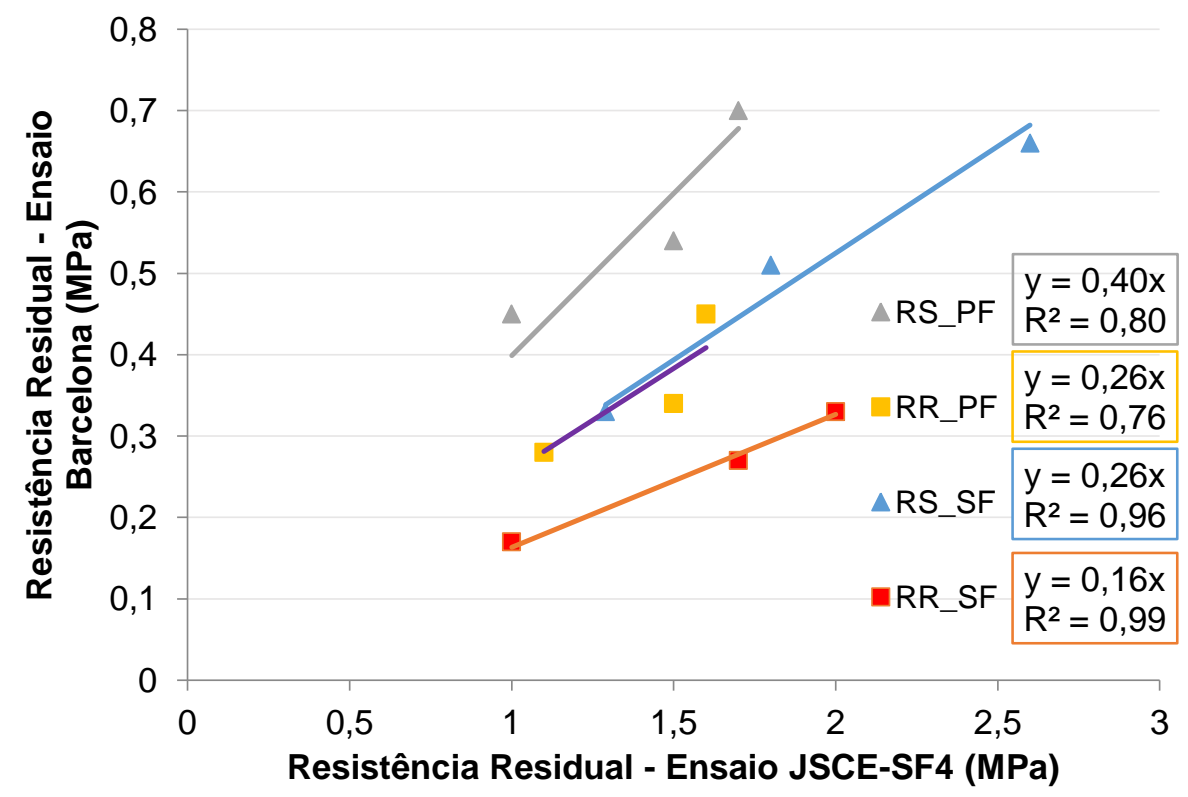

Figura 2.34 - Regressões lineares entre as resistências residuais médias na região de serviço (RS) e na região de pré-ruptura (RR). Fonte: Monte; Toaldo; Figueiredo (2014).

Percebe-se na Figura 2.34 que as melhores correlações foram obtidas para as fibras de aço, independente do nível de abertura de fissura. Para as fibras de polipropileno a regressão linear apresentou $\mathrm{R}^{2}$ menor. Isto pode ser associado à maior amplitude de capacidade resistente residual apresentada pela fibra de aço, o que proporcionou melhor correlação com os valores médios. Ou seja, a menor variabilidade apresentada pelas fibras de PP não colaborou para melhorar essas correlações uma vez que o aumento da resistência residual média obtido com 0 aumento do teor de fibras foi menor do que aquele obtido com as fibras de aço. Ainda 
que tenham sido avaliados apenas três teores para cada fibra verifica-se que ambos os ensaios apresentam resultados correlacionáveis e permitem diferenciar comportamento dos compósitos.

\subsection{Conclusões do capítulo}

Este capítulo avaliou comparativamente os métodos de ensaio Barcelona e de flexão JSCE-SF4, ambos utilizando sistema aberto para controle da velocidade. A partir dos resultados obtidos e as análises realizadas as seguintes conclusões podem ser destacadas.

- O uso do sistema aberto para controle de velocidade resultou elevada instabilidade no ensaio de flexão, principalmente para baixos teores de fibras e baixos níveis de deslocamento ou abertura de fissura. Isto confirma a indicação de estudos e normas para a realização do ensaio com sistema fechado, ou seja, a deformação imposta pelo ensaio deve ser controlada pelo deslocamento medido no corpo de prova, configuração dificilmente encontrada nos laboratórios de controle tecnológico de concreto no Brasil.

- O ensaio Barcelona, mesmo adotando o sistema aberto de controle de velocidade, resulta instabilidade sensivelmente menor ou não percebida, mostrando a robustez do método em relação a esse procedimento de controle de velocidade. Dessa forma, o ensaio Barcelona é um método de fácil execução e que não necessita de instrumentação laboratorial complexa. Esta condição poderá favorecer melhores condições de reprodutibilidade do ensaio uma vez que o ensaio de flexão não mostrou resultados positivos neste sentido em pesquisa anterior (GUIMARÃES; FIGUEIREDO, 2002).

- Existe correlação linear entre o ensaio Barcelona e o JSCE-SF4 em termos de tenacidade e de resistência residual pós-fissuração, possibilitando a utilização de um ou outro método de ensaio para avaliação destas características.

Dado o exposto, pode-se concluir que ambos os ensaios podem ser considerados equivalentes em termos de capacidade de avaliação e controle do CRF e são perfeitamente correlacionáveis, havendo uma vantagem para o Barcelona que consiste na simplificação da metodologia de ensaio e a consequente redução de custos e potencialização de obtenção de melhores condições de reprodutibilidade. Além disso, também é um ensaio passível de ser executado em testemunhos 
extraídos, o que configura uma opção de avaliação de estruturas existentes executadas com este tipo de compósito. No caso específico dos tubos de concreto o ensaio Barcelona possibilita a utilização de corpos de prova cilíndricos ao invés do prismático, que apresenta problemas de moldagem devido à consistência seca do concreto.

Os estudos que analisaram anteriormente o ensaio Barcelona utilizaram condições de reforço mais favoráveis, com fibras de maior fator de forma e/ou teores mais elevados, e comparações com ensaios de flexão realizados em condições favoráveis, ou seja, sistema de controle fechado. Por isso a contribuição desse estudo é importante por avaliar o ensaio Barcelona em situação mais desfavorável e mais próxima da condição prática de controle no Brasil e em outros países em desenvolvimento, uma vez que foi comparado ao procedimento de ensaio de flexão mais utilizado em laboratórios de controle que é o JSCE-SF4.

Estudos recentes apresentados nos Congressos Brasileiros do Concreto do IBRACON relataram a dificuldade de se controlar a resistência à compressão do concreto, devido à baixa qualidade dos ensaios realizados por laboratórios nacionais (CARROMEU et al., 2012; MAGALHÃES et al., 2013). Por isso, a utilização de um método de ensaio confiável, mas de procedimento de controle mais simples, permitirá qualificar minimamente e de maneira mais fácil um maior número de laboratórios de controle no Brasil para que possam realizar o controle tecnológico de obras que empreguem o CRF como material estrutural de maior responsabilidade. 


\section{COMPORTAMENTO MECÂNICO DOS TUBOS DE CONCRETO REFORÇADOS COM FIBRAS}

\subsection{Introdução}

A norma brasileira de tubos de concreto ABNT NBR 8890 (2007) contempla o uso de fibras de aço como reforço do concreto e surgiu antes mesmo da aplicação deste tipo de componente ser difundida no mercado. Isto ocorreu devido à compra de tubos de concreto ser feita por órgãos públicos e governamentais na maioria dos casos. Essa situação obriga que se utilizem edital de concorrência ou licitação e, por consequência, apenas tubos regularmente normalizados podem ser adquiridos. Dessa forma, a comissão da ABNT se valeu de pesquisas acadêmicas desenvolvidas no tema (CHAMA NETO, 2002; RAMOS, 2002; FIGUEIREDO et al., 2007) e da existência de norma europeia já publicada, a EN 1916 (2002), que já contemplava o uso de fibras, para viabilizar a concepção da norma brasileira.

Os tubos de concreto reforçado com fibras de aço são considerados pela norma brasileira como tubos armados, ou seja, podendo ser utilizados nas mesmas condições que os que são armados com fios e telas de aço. No entanto, estes tubos devem ser identificados como reforçados com fibras, não podendo ser utilizados no lugar de tubos convencionalmente armados sem prévia qualificação específica. Figueiredo (2011) salienta que na prática ocorre frequente omissão da realização dos procedimentos de controle de aceitação dos tubos nas obras, o que dificulta a difusão do uso do concreto reforçado com fibras (CRF) na produção dos tubos.

O plano de controle dos tubos envolve avaliação das tolerâncias dimensionais, defeitos, estanqueidade e, fundamentalmente, da capacidade resistente dos mesmos, a qual é medida através do ensaio de compressão diametral. Os tubos de concreto reforçado com fibras seguem, segundo a norma, a mesma classificação adotada para os tubos de concreto armado convencional. Esta classificação é feita, basicamente, pela carga de fissura, no caso dos tubos armados, ou carga mínima isenta de dano, para o caso dos tubos reforçados com fibras.

O ensaio indicado pela norma ABNT NBR 8890 (2007) é composto por dois ciclos de carregamento. Figueiredo (2008) sugere a utilização do ensaio em um único ciclo de carregamento e com o controle do deslocamento diametral do tubo através de um LVDT posicionado na sua ponta. Além disso, uma nova abordagem de método ensaio para os tubos reforçados com fibras foi proposta por Figueiredo et al. (2012a), 
buscando aproximar o sistema de controle destes tubos à concepção do fib Model Code (FIB, 2013). Neste caso, os requisitos estabelecidos seriam além da carga mínima isenta de dano e da carga máxima ou de pico, as resistências residuais pósfissuração associadas a deslocamentos verticais no estado limite de serviço (ELS) e no estado limite último (ELU). Os valores de deslocamentos diametrais específicos (deslocamento diametral dividido pelo diâmetro do tubo) indicados para o ELS e para o ELU são, respectivamente, 0,4\% e 2\% (FIGUEIREDO et al., 2012a). Contudo, o estabelecimento de correlações entre estes deslocamentos e o nível de abertura de fissura ainda não foi estudado.

Diante deste cenário, este capítulo apresenta uma revisão do estado da arte acerca do comportamento mecânico de tubos de concreto reforçados com fibras (TCRF) e um programa experimental que avalia as modificações propostas para o método de ensaio de compressão diametral vigente nas normas em vigor (ABNT NBR 8890, 2007; EN 1916, 2002).

\subsubsection{Objetivos do capítulo}

O objetivo geral deste capítulo é melhorar as condições de controle para o comportamento mecânico de tubos de concreto reforçados com fibras no ensaio de compressão diametral, considerando modificações propostas pela literatura e estabelecendo correlações entre os deslocamentos diametrais e os níveis de fissuração dos tubos.

\subsubsection{Organização do capítulo}

Primeiramente, o item 3.2 apresenta uma revisão do atual estado do conhecimento em relação ao comportamento mecânico dos tubos de concreto, em termos de projeto estrutural e controle tecnológico. Em seguida, no item 3.3 é apresentado um programa experimental para avaliação da compressão diametral de tubos. Os resultados estão avaliados no item 3.4, considerando os critérios estabelecidos na norma brasileira e novos critérios propostos pela literatura (item 3.2.2). Apresentam-se também as correlações experimentais estabelecidas entre o deslocamento vertical e o nível de fissuração dos tubos. Com isso são estabelecidos requisitos de cargas residuais equivalentes em termos de abertura de fissura para tubos com reforço de armadura convencional ou fibras. Finalmente, no item 3.5, apresenta as conclusões do capítulo, sintetizando as contribuições mais relevantes para o estado do conhecimento. 


\subsection{Projeto estrutural e controle dos tubos de concreto reforçados com fibras}

O projeto estrutural dos tubos de concreto é desenvolvido para atender esforços nos estados limites último e de serviço, igualmente ao que ocorre com outros tipos de estrutura de concreto. Esse dimensionamento pode ser realizado através de métodos diretos ou indiretos.

Nos métodos diretos são aplicadas as leis dos esforços e verificados os esforços solicitantes (momento fletor, força cortante, força normal) (EL DEBS, 2008). A interação solo-estrutura é considerada através de programas de elementos finitos, apresentado em Heger; Liepins e Selig (1985), Kurdziel e McGrath (1991) e Watkins e Anderson (1999) ou por cálculos de distribuição de pressões, conforme utilizado por Heger e McGrath (1982) e El Debs (2008). Esse tipo de dimensionamento, apesar de poder conduzir a projetos estruturalmente eficientes e econômicos como demonstrado por Kurdziel e McGrath (1991), demanda elevado esforço de cálculo e tempo. Por isso é geralmente indicado para projetos de tubos de grande diâmetro, situações onde a racionalização do projeto pode levar a importante redução nos custos ou ainda estudos paramétricos (de la FUENTE, AGUADO e MOLINS, 2011).

O método indireto utiliza a determinação experimental da resistência do tubo no ensaio de compressão diametral. Neste caso, apoia-se em tabelas de cargas mínimas a serem resistidas pelos tubos em função do seu diâmetro nominal (DN) e do tipo de verificação, em serviço ou ruptura, propostas em normas como a brasileira ABNT NBR 8890 (2007), a espanhola AENOR UNE 127916 (2004) e a americana ASTM C-76 (2014). A Tabela 3.1 apresenta as cargas mínimas requeridas no ensaio de compressão diametral dos tubos armados e/ou reforçados com fibras de acordo com a norma brasileira ABNT NBR 8890 (2007).

No ensaio de compressão diametral de três cutelos, o mais utilizado e que será detalhado no próximo item, reproduz a condição mais crítica de apoio em serviço, o apoio direto, estando a favor da segurança (de la FUENTE; ARMENGOU, 2007; SILVA; EL DEBS; BECK, 2008). 
Tabela 3.1 - Cargas mínimas de compressão diametral de tubos armados e/ou reforçados com fibras de aço. Fonte: ABNT NBR 8890 (2007).

\begin{tabular}{|c|c|c|c|c|c|c|c|c|c|c|c|c|c|c|}
\hline \multirow{3}{*}{$\begin{array}{c}\text { DN } \\
\text { Classe }\end{array}$} & \multicolumn{8}{|c|}{ Água pluvial } & \multicolumn{6}{|c|}{ Esgoto sanitário } \\
\hline & \multicolumn{4}{|c|}{$\begin{array}{c}\text { Carga de fissura } \\
\text { (armados) ou carga } \\
\text { isenta de dano (fibras) } \\
k N / m\end{array}$} & \multicolumn{4}{|c|}{$\begin{array}{l}\text { Carga mínima de } \\
\text { ruptura } \\
k N / m\end{array}$} & \multicolumn{3}{|c|}{$\begin{array}{c}\text { Carga de fissura } \\
\text { (armados) ou } \\
\text { carga isenta de } \\
\text { dano (fibras) } \\
k N / m\end{array}$} & \multicolumn{3}{|c|}{$\begin{array}{c}\text { Carga mínima de } \\
\text { ruptura } \\
k N / m\end{array}$} \\
\hline & PA1 & PA2 & PA3 & PA4 & PA1 & PA2 & PA3 & PA4 & EA2 & $E A 3$ & EA4 & EA2 & EA3 & EA4 \\
\hline 300 & 12 & 18 & 27 & 36 & 18 & 27 & 41 & 54 & 18 & 27 & 36 & 27 & 41 & 54 \\
\hline 400 & 16 & 24 & 36 & 48 & 24 & 36 & 54 & 72 & 24 & 36 & 48 & 36 & 54 & 72 \\
\hline 500 & 20 & 30 & 45 & 60 & 30 & 45 & 68 & 90 & 30 & 45 & 60 & 45 & 68 & 90 \\
\hline 600 & 24 & 36 & 54 & 72 & 36 & 54 & 81 & 108 & 36 & 54 & 72 & 54 & 81 & 108 \\
\hline 700 & 28 & 42 & 63 & 84 & 42 & 63 & 95 & 126 & 42 & 63 & 84 & 63 & 95 & 126 \\
\hline 800 & 32 & 48 & 72 & 96 & 48 & 72 & 108 & 144 & 48 & 72 & 96 & 72 & 108 & 144 \\
\hline 900 & 36 & 54 & 81 & 108 & 54 & 81 & 122 & 162 & 54 & 81 & 108 & 81 & 122 & 162 \\
\hline 1.000 & 40 & 60 & 90 & 120 & 60 & 90 & 135 & 180 & 60 & 90 & 120 & 90 & 135 & 180 \\
\hline 1.100 & 44 & 66 & 99 & 132 & 66 & 99 & 149 & 198 & 66 & 99 & 132 & 99 & 149 & 198 \\
\hline 1.200 & 48 & 72 & 108 & 144 & 72 & 108 & 162 & 216 & 72 & 108 & 144 & 108 & 162 & 216 \\
\hline 1.500 & 60 & 90 & 135 & 180 & 90 & 135 & 203 & 270 & 90 & 135 & 180 & 135 & 203 & 270 \\
\hline 1.750 & 70 & 105 & 158 & 210 & 105 & 158 & 237 & 315 & 105 & 158 & 210 & 158 & 237 & 315 \\
\hline 2.000 & 80 & 120 & 180 & 240 & 120 & 180 & 270 & 360 & 120 & 180 & 240 & 180 & 270 & 360 \\
\hline
\end{tabular}

\subsubsection{Compressão diametral de tubos}

Existem vários métodos para avaliar a compressão diametral, caracterizados principalmente pela forma de apoio dos tubos. Os mais conhecidos são o de três cutelos, o de dois cutelos, o do colchão de areia e o de Minnesota, conforme apresenta a Figura 3.1.

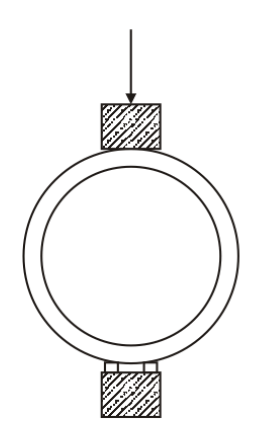

(a)

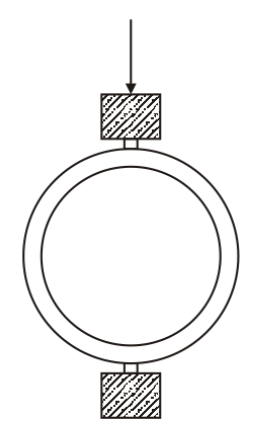

(b)

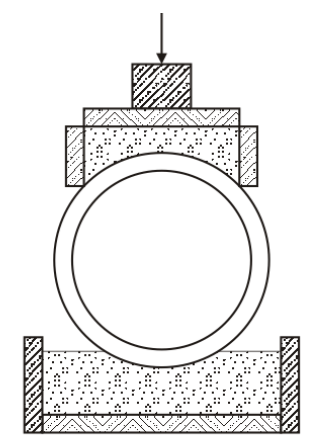

(c)

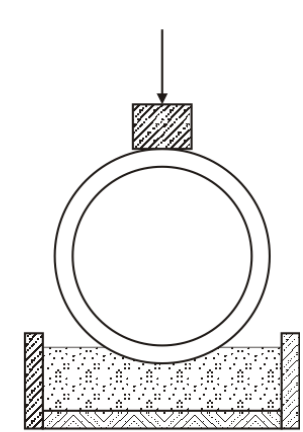

(d)

Figura 3.1 - Ensaios de determinação da resistência de um tubo: (a) três cutelos; (b) dois cutelos; (c) colchão de areia e (d) Minnesota. Fonte: Zaidler (1983). 
Dentre estes, o método mais amplamente utilizado é o de três cutelos, sendo o indicado pela norma europeia (EN 1916, 2002) e brasileira (ABNT NBR 8890, 2007). Diversos estudos salientam sua simplicidade e facilidade de execução, além da exatidão e uniformidade dos resultados (CHAMA NETO, 2002; de la FUENTE; ARMENGOU, 2007; SILVA; EL DEBS; BECK, 2008).

O ensaio de compressão diametral em três cutelos consiste no apoio do tubo em cutelos de madeira inferiores e o carregamento do componente a partir de um cutelo superior articulado, como ilustra o esquema da Figura 3.2.

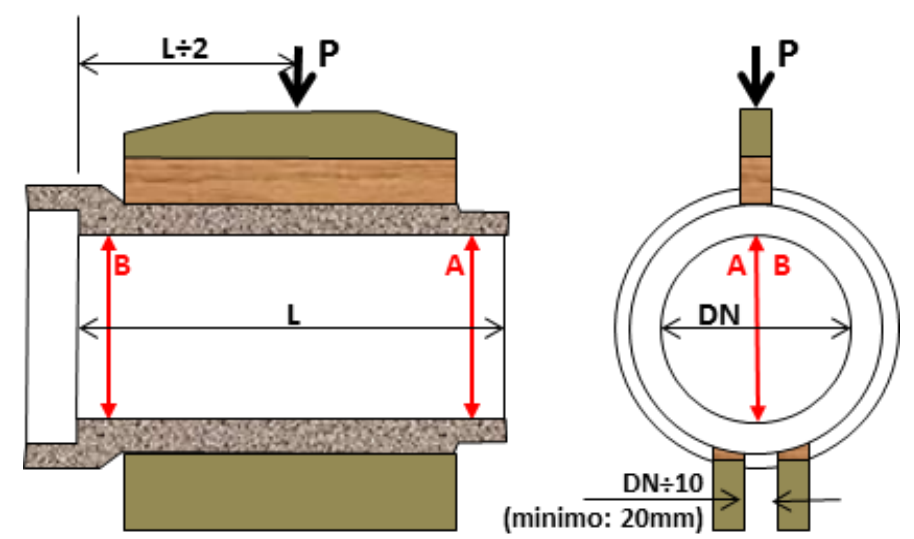

Figura 3.2 - Esquema mostrando a seção longitudinal e a seção transversal do ensaio de compressão diametral de três cutelos para avaliação das classes de resistência dos tubos de concreto. Fonte: Figueiredo; Chama Neto (2008).

O procedimento de ensaio previsto nas normas para os tubos convencionalmente armados ou reforçados com fibras é distinto. Apesar de o princípio básico do ensaio ser muito similar para ambos os tipos de reforço e o nível das exigências ser praticamente o mesmo, Figueiredo (2011) salienta que o requisito pode ser considerado mais exigente quando do uso de fibras. Os tubos convencionalmente armados sofrem carregamento contínuo até a sua ruptura e não se exige nada além da determinação da carga de fissura e da carga de ruptura. A carga de ruptura é a máxima obtida durante a realização do ensaio. Para a carga de fissura é considerada a carga necessária para que o tubo apresente uma fissura com abertura de 0,25 mm e comprimento mínimo de $300 \mathrm{~mm}$. Essa abertura da fissura é medida através da lâmina padrão apresentada na Figura 3.3. 


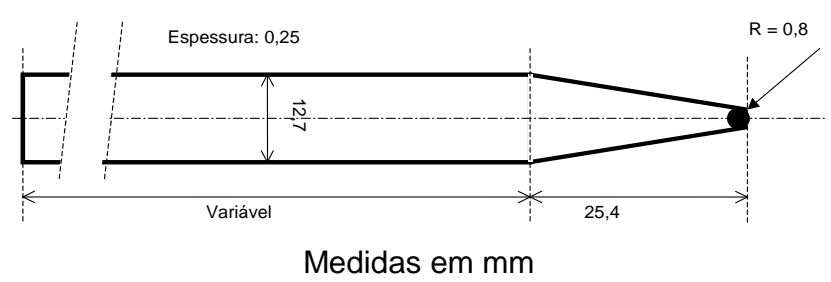

Figura 3.3 - Lâmina padrão para medida de abertura de fissura 0,25 mm. Fonte: ABNT NBR 8890 (2007).

No caso dos tubos reforçados com fibras o carregamento é feito de forma contínua até atingir uma carga equivalente a dois terços da carga de ruptura especificada para a sua classe resistente, mantendo-a por um minuto. Após este tempo o tubo não poderá apresentar qualquer dano oriundo deste carregamento. Por isto, esta carga foi denominada na norma como carga mínima isenta de dano, sendo equivalente à carga de fissura especificada para os tubos convencionalmente armados. Por isso pode-se considerar o procedimento mais exigente para o reforço com fibras, pois nenhuma fissura visível é permitida. Além disso, caso o tubo seja aprovado na verificação da carga mínima isenta dano, o carregamento deverá ser novamente retomado até que se atinja a sua carga máxima, que deve ser registrada. Após ocorrer uma queda na carga correspondente a 95\% desta carga máxima, retirase totalmente o carregamento, reaplicando uma carga de dois terços da carga especificada para a ruptura e mantê-la por mais um minuto. Desta forma é possível avaliar se o tubo apresenta capacidade resistente residual pós-fissuração para a carga mantida nesta situação. A Figura 3.4 apresenta o esquema de carregamento proposto na norma brasileira para o ensaio de compressão diametral de tubos de concreto reforçados com fibras.

O tubo deve ser rejeitado no caso dele não conseguir atingir ou manter essa carga de fissura durante o recarregamento. Se $o$ tubo atender a esta exigência, a norma brasileira pede que o carregamento continue, registrando a carga máxima atingida nesta etapa de carregamento pós-fissuração. Essa carga máxima atingida não deve ser inferior a 105\% da carga mínima isenta de dano. Tal exigência de 105\% é particular da norma brasileira, não existindo na norma europeia que considera o ensaio encerrado quando da verificação da capacidade do tubo suportar a carga mínima isenta de dano durante o recarregamento. 


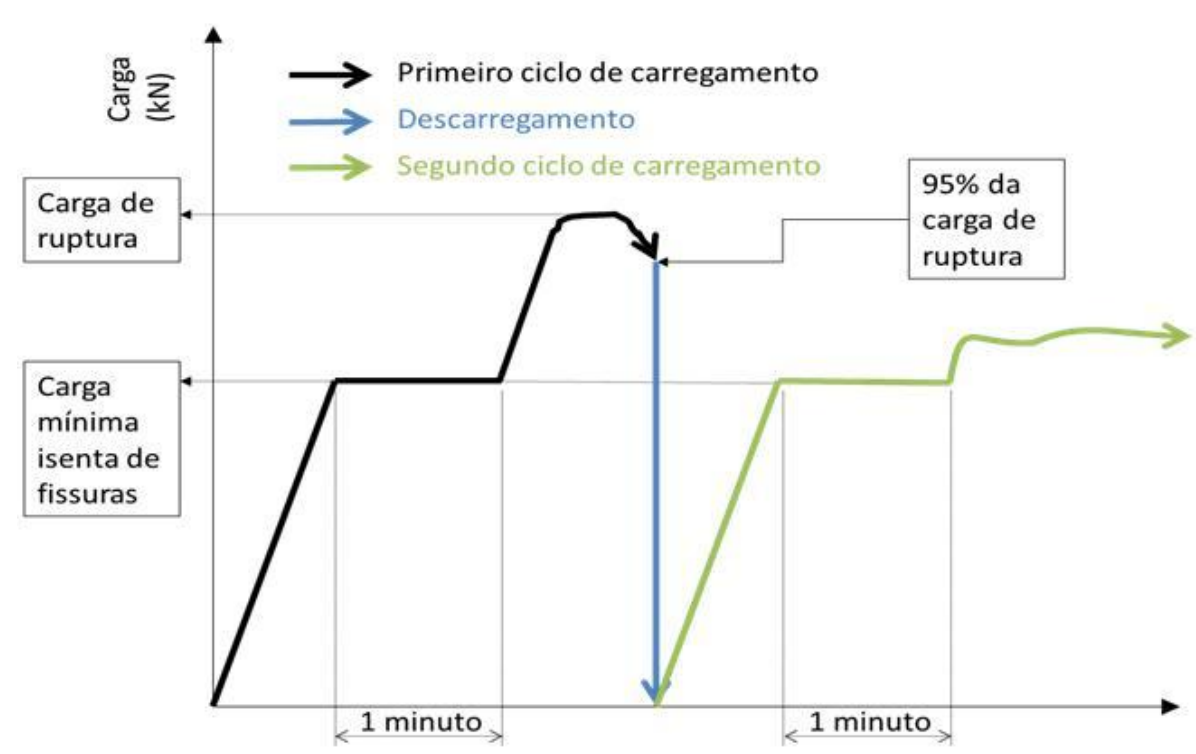

Figura 3.4 - Esquema do plano de carregamento proposto para o ensaio de compressão diametral de tubos de concreto reforçados com fibras. Fonte: ABNT NBR 8890 (2007).

Percebe-se que em momento algum se abordou o nível de deslocamento diametral associado ao carregamento de ensaio, pois se trata de uma variável não controlada. Conforme salienta Chama Neto (2002) e Figueiredo et al. (2007) o ensaio sem esse tipo de controle apresenta maior variabilidade e há dúvidas em relação aos valores de carga de fissura e carga mínima isenta de dano, que ficam na dependência da perícia do técnico que realiza o ensaio. Além disso, a incerteza na quantificação do comportamento pós-fissuração em casos de softening é maior na ausência deste tipo de controle, sendo esse um comportamento frequente para os teores de fibra mais utilizados. Isto mostra a necessidade de implementação de melhorias nesse método de ensaio, como as apresentadas a seguir.

\subsubsection{Compressão diametral de tubos - avanços no procedimento do ensaio}

As normas de ensaio de compressão diametral (ABNT NBR 8890, 2007; EN 1916, 2002; ASTM C-497, 2014) indicam como variável de controle apenas a leitura do nível de carregamento independente do nível de deslocamento diametral a ele associado. Logo, não é solicitado qualquer tipo de controle do nível deslocamento diametral e muito menos do desenvolvimento da abertura de fissuras. Neste sentido, vários trabalhos indicaram o uso de LVDTs posicionados no interior da ponta e da bolsa do tubo, como alternativa para uma melhor qualidade dos resultados medidos (CHAMA NETO, 2002; RAMOS, 2002; FIGUEIREDO et al., 2007; FUGII, 2008; SILVA, 2011; ESCARIZ, 2012). A Figura 3.5 ilustra este tipo de configuração de ensaio. 


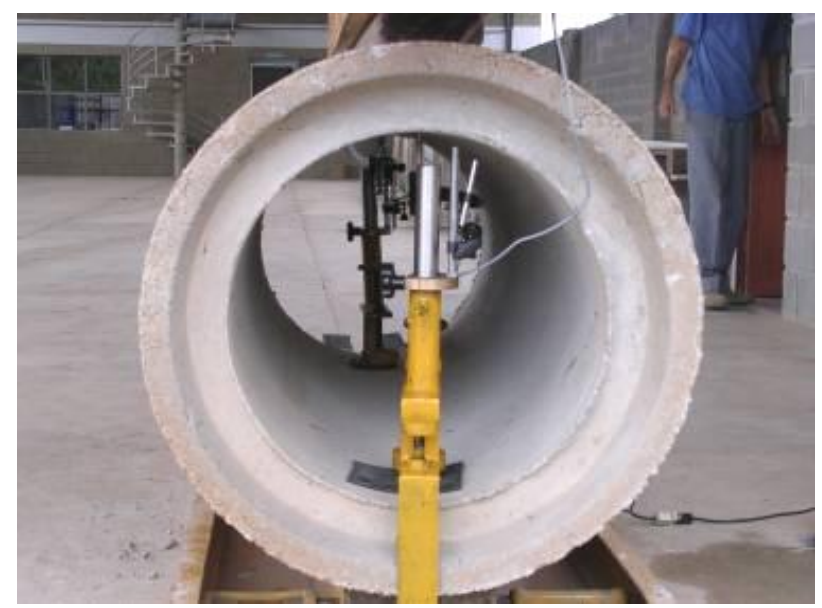

Figura 3.5 - Configuração do ensaio com posicionamento dos LVDTs na ponta e na bolsa para medida do deslocamento diametral. Fonte: Figueiredo et al. (2007).

Através do uso de LVDTs é possível o levantamento da curva de carga por deslocamento diametral do tubo e consequentemente a definição precisa da carga que resulta a primeira fissura. A Figura 3.6 apresenta um resultado de ensaio que utiliza a medida deslocamento diametral através de LVDTs.

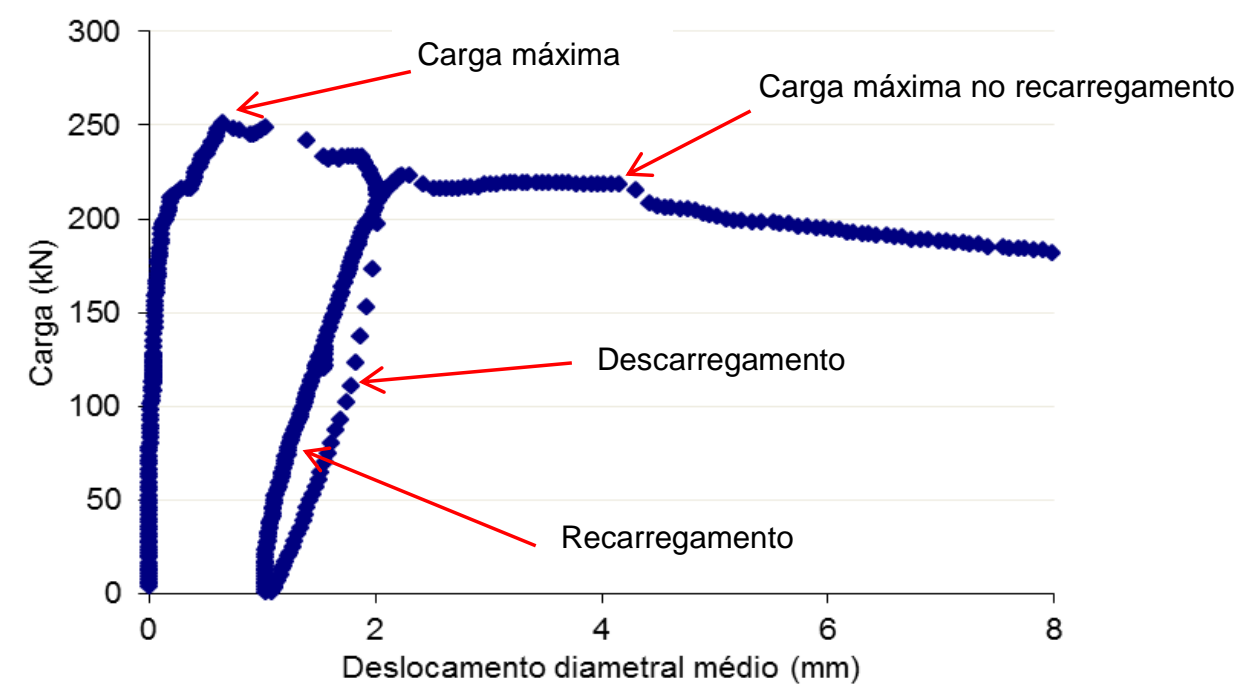

Figura 3.6 - Resultado de um tubo de concreto reforçado com $40 \mathrm{~kg} / \mathrm{m}^{3}$ de fibras de aço ensaiado segundo o procedimento cíclico e com uso de LVDTs. Fonte: Adaptado de Figueiredo et al. (2007).

Figueiredo et al. (2012b) sugere a utilização de um único LVDT posicionado na sua ponta do tubo para o controle do deslocamento diametral. A Figura 3.7 ilustra os resultados de tubos ensaiados com dois LVDTs, posicionados na ponta e na bolsa, e um único LVDT posicionado na ponta. 


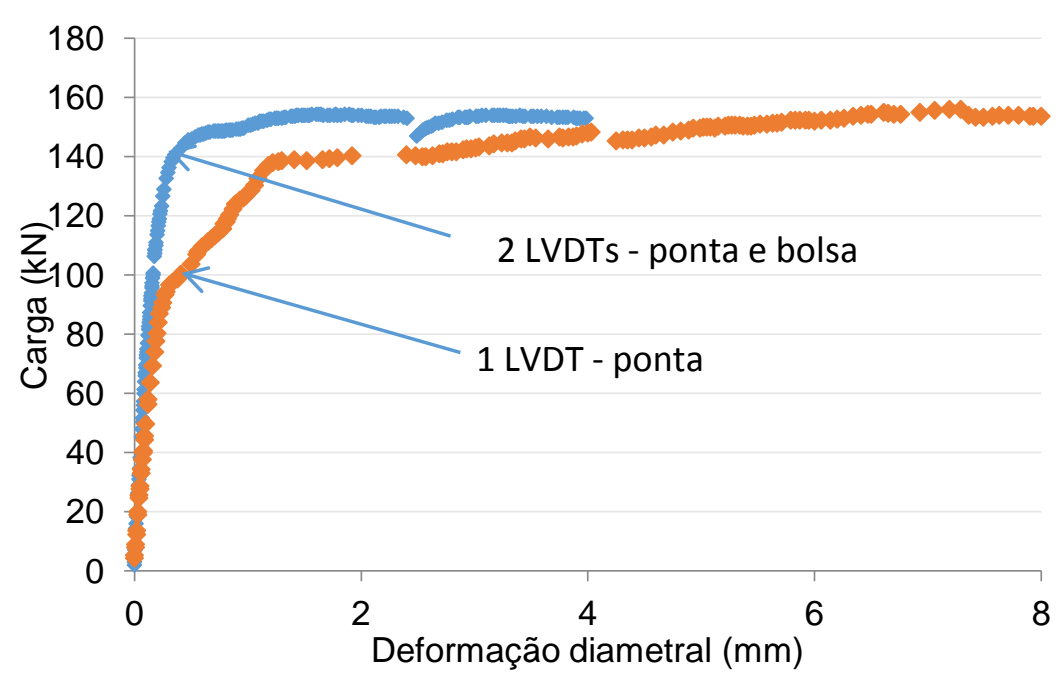

Figura 3.7 - Comparação entre as curvas médias de carregamento medidos na ponta e, na ponta e bolsa para os tubos de concreto reforçados com $40 \mathrm{~kg} / \mathrm{m}^{3}$ de fibra de aço. Fonte: Adaptado de Figueiredo et al. (2012b).

Percebe-se na Figura 3.7 que a configuração com um único LVDT na ponta apresenta um resultado mais flexível. Isto configura uma condição de maior solicitação ao tubo e, portanto mais a favor da segurança (FIGUEIREDO et al., 2012b). Observase também nestes resultados a ausência do ciclo de descarregamento e recarregamento. Essa configuração elimina o carregamento cíclico, indicado nas normas ABNT NBR 8890 (2007) e EN 1916 (2002) para tubos reforçados com fibras, e adota um carregamento contínuo conforme indica a ABNT NBR 8890 (2007) para os tubos com reforço convencional. Os resultados apresentados por Figueiredo (2008) mostram não haver diferenças significativas no resultado do ensaio cíclico ou continuo para os tubos de concreto reforçados com fibras, como apresentado na Figura 3.8.

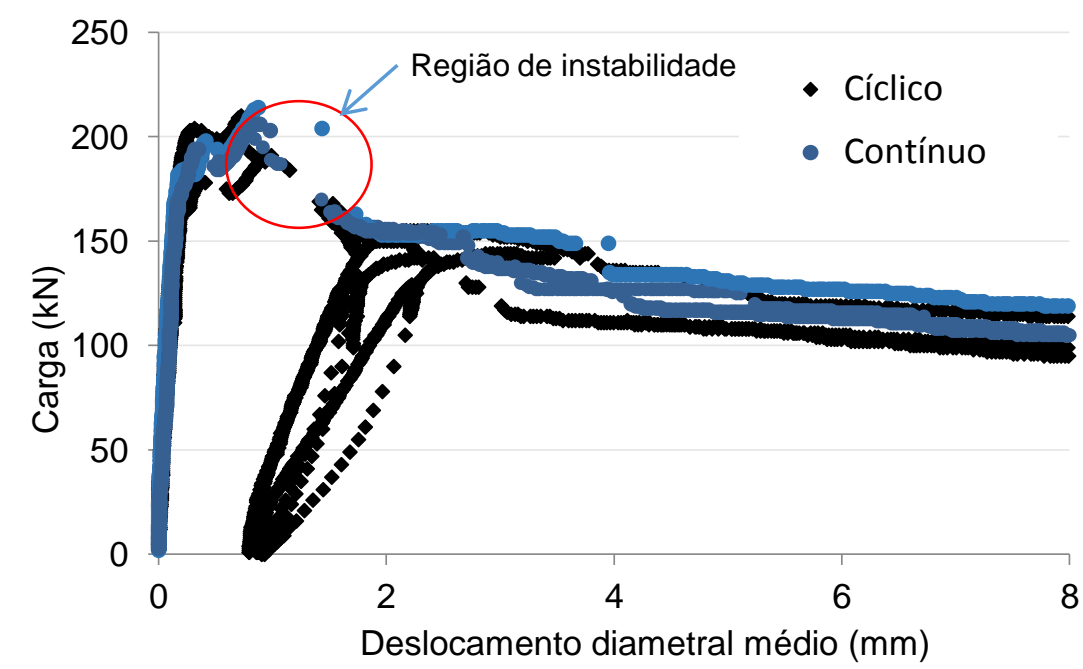

Figura 3.8 - Curvas representativas dos carregamentos cíclico ou contínuo. Fonte: Figueiredo (2008). 
Pela Figura 3.8 percebe-se que a adoção de um carregamento contínuo não implica alteração significativa na envoltória do ensaio. Além disso, a instabilidade póspico, encontrada quando o ensaio é realizada com sistema de controle aberto (openloop) ver item 2.1 do Capítulo 2, ocorre em ambas as configurações de ensaio. A eliminação do ciclo de descarregamento e recarregamento introduz uma grande simplificação no procedimento de ensaio e no tempo de realização do mesmo, aspecto positivo considerando que se trata de um ensaio de controle que deve ser realizado continuamente pela fábrica de tubos. Outra vantagem é que isto aproxima o procedimento do ensaio de compressão diametral ao do ensaio de flexão de vigas, geralmente realizado sem ciclos de carga (FIGUEIREDO et al. 2012a).

O fato de adotar-se um procedimento de ensaio mais análogo ao de flexão de vigas possibilita adotar-se também a sua filosofia para a parametrização do comportamento pós-fissuração, como nos modelos apresentados na Tabela 2.1 do Capítulo 2. Um deles é o indicado no fib Model Code 2010 (FIB, 2013) para projetos de concretos reforçados com fibras com comportamento de softening, representado na Figura 3.9.

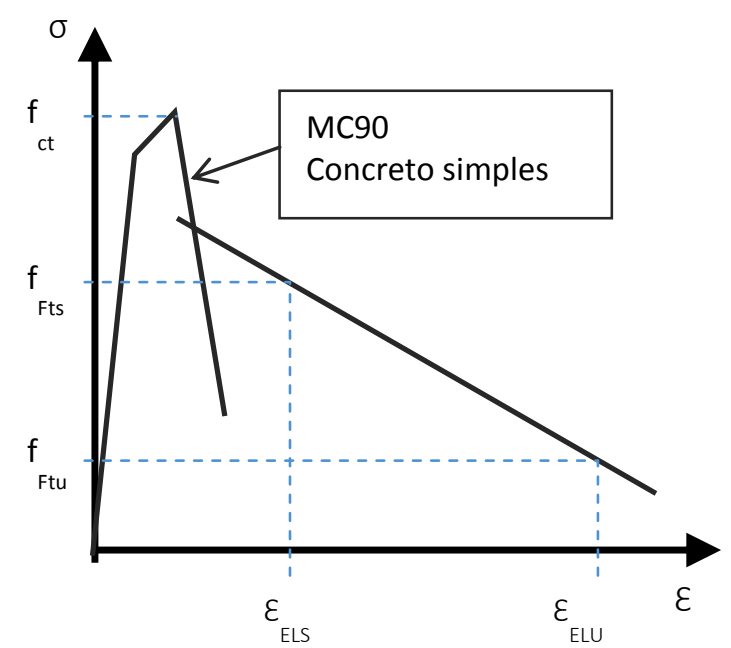

Figura 3.9 - Diagrama tensão versus deformação para comportamento de softening em CRF. Fonte: Adaptado de Fib (2013).

O diagrama da Figura 3.9 apresenta dois estágios. O primeiro representa a contribuição da matriz (MC 90 - concreto simples), caracterizada através da resistência à flexão máxima $\left(f_{c t}\right)$. O segundo estágio ocorre pós-fissuração da matriz e é representado por duas resistências residuais. A primeira é a $f_{F t s}$ referente a resistência residual no estado limite de serviço (ELS) para uma deformação diametral 
específica $\varepsilon_{E L S}$ e correspondente abertura de fissura. A segunda é a $f_{F t u}$ referente a resistência residual no estado limite último (ELU) para uma deformação diametral específica $\varepsilon_{E L U}$ e correspondente abertura de fissura. Uma abordagem semelhante foi adotada por Figueiredo et al. (2012a) para a parametrização do comportamento de softening dos tubos de concreto reforçados com fibras, buscando aproximar o sistema de controle dos tubos à concepção do fib Model Code (FIB, 2013). O gráfico da Figura 3.10 representa a resposta esquemática dos parâmetros do ensaio de compressão diametral do tubo de concreto reforçado com fibras proposto por Figueiredo et al., (2012a).

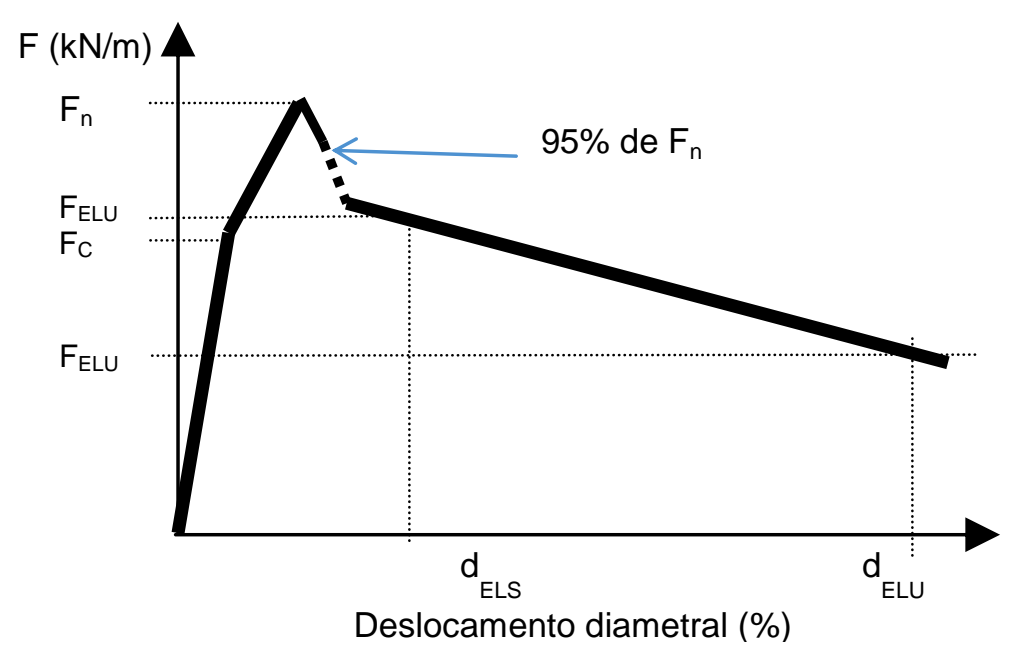

Figura 3.10 - Esquema de comportamento de softening em TCRF. Fonte: Adaptado de Figueiredo et al. (2012a).

Uma vez estabelecido o gráfico de carga versus deslocamento diametral (Figura 3.10) podem ser identificados os parâmetros de controle do ensaio. Primeiramente a carga correspondente à carga mínima isenta de dano $\left(F_{C}\right)$, deve ser verificada se atende ao valor especificado para a classe de resistência do tubo. Em seguida, a carga máxima ou carga de pico $\left(F_{n}\right)$ também deve ser atendida. Além disso, a esses parâmetros adiciona-se a determinação do comportamento pós-fissuração através das resistências residuais associadas a deslocamentos verticais no estado limite de serviço (ELS) e no estado limite último (ELU) (FIGUEIREDO et al., 2012a). Os autores apontam a dificuldade de se estabelecer valores de referência para os deslocamentos diametrais específicos (deslocamento diametral dividido pelo diâmetro do tubo) associados a essas resistências residuais. No estado limite de serviço, o deslocamento diametral específico $\left(d_{E L S}\right)$ deve estar relacionado à carga máxima pósfissuração e não ser afetado pela região de instabilidade pós-pico comum nos ensaios 
realizados com sistema de controle aberto (Figura 3.8). Considerando isso e baseando-se em resultados experimentais anteriores (FIGUEIREDO, 2008; FIGUEIREDO e ESCARIZ, 2011), Figueiredo et al., (2012) indicam que o valor de $0,4 \%$ para o $d_{E L S}$. Já para o deslocamento diametral específico no estado limite último $\left(d_{E L S}\right)$, Figueiredo et al., (2012) recomendam a utilização do valor de $2 \%$, mantendo assim a mesma proporção com o deslocamento no estado limite de serviço indicada no fib Model Code 2010 (FIB, 2013), no qual a $\varepsilon_{E L U}$ é cinco vezes maior que a $\varepsilon_{E L S}$. Estes deslocamentos, no entanto, não foram associados a um nível de abertura de fissura como ocorre com a proposição do fib Model Code (di PRISCO et al., 2010), o que precisaria ser melhor estudado para verificar a pertinência. No deslocamento diametral correspondente ao estado limite de serviço $\left(d_{E L S}\right)$ a resistência residual $\left(F_{E L S}\right)$ deve igual ou superior ao valor estabelecido para a carga mínima isenta de dano $\left(F_{C}\right)$. Por fim é verificado o requisito de resistência residual no estado limite último $\left(F_{E L U}\right)$.

O fib Model Code (FIB, 2013) estabelece também, para a classificação do CRF, faixas para a relação entre as resistências residuais obtidas no ensaio de flexão de vigas. Essa classificação poderia ser adotada como referência para estabelecer diferentes níveis de reforço para os tubos, com comportamento de softening ou hardening, através de relações $F_{E L U} F_{E L S}$, representadas pelas letras a, b, c, d, correspondendo aos seguintes valores:

"a" se $0,5 \leq F_{E L U} / F_{E L S}<0,8$

"b" se $0,8 \leq F_{E L U} / F_{E L S}<1,1$

"C" se $1,1 \leq F_{E L U} / F_{E L S}<1,4$

"d" se $1,4 \leq F_{E L U} / F_{E L S}$

O estabelecimento de parâmetros de controle do ensaio de compressão diametral para um mesmo nível de fissuração do tubo permite uma avaliação mais justa e confiável, independente do tipo de reforço utilizado. Porém, o estabelecimento de correlações entre os deslocamentos diametrais e o nível de abertura de fissura ainda é um aspecto a ser estudado. Isto é fundamental para estabelecer os níveis de deslocamentos diametrais $d_{E L S}$ e $d_{E L U}$, e respectivas resistências residuais a serem adotados. Com o objetivo de avaliar as os avanços propostos na literatura no que se refere ao comportamento mecânico de tubos no ensaio de compressão diametral foi desenvolvido um programa experimental que será apresentado a seguir. 


\subsection{Programa experimental}

Um programa experimental foi realizado com o objetivo de avaliar 0 comportamento mecânico de tubos de concreto reforçados com fibras através do ensaio de compressão diametral com carregamento contínuo e com controle de deslocamento diametral. Além disso, o uso de parâmetros do comportamento pósfissuração dos tubos foi avaliado, buscando aproximar o sistema de controle dos tubos à concepção de modelos mais modernos como o do fib Model Code (FIB, 2013). Esses procedimentos se caracterizam como avanços em relação ao método de ensaio de compressão diametral das normas de ensaio brasileira e estrangeiras. Essa avaliação foi realizada em tubos de $600 \mathrm{~mm}$ de diâmetro reforçados com fibras de aço e polipropileno, em dois teores cada. Como referência foram também produzidos tubos com reforço convencional de tela soldada. Além de sistematizar todos esses avanços, outro diferencial frente a outros estudos foi feita a realização da mensuração do nível de abertura de fissura dos tubos durante a realização do ensaio de compressão diametral, o qual foi correlacionado ao deslocamento diametral medido.

\subsubsection{Produção de tubos de concreto com fibras}

Os tubos de concreto foram moldados na fábrica da Fermix Soluções em Tubos de Concreto, localizada na cidade de Guarulhos - SP. O processo de moldagem utilizado nestes tubos foi de compressão radial, devido à disponibilidade da fábrica para o tipo e a dimensão dos tubos que foi solicitada, PA1-600. As principais dimensões nominais dos tubos produzidos estão indicadas na Figura 3.11.

O equipamento de compressão radial utilizado para a produção dos tubos é constituído por um conjunto de quatro fôrmas e um êmbolo rotativo hidráulico com massas que giram em alta velocidade no interior das formas, comprimindo o concreto contra a parede destas (Figura 3.12). Esta foi a primeira moldagem de tubos reforçados com fibras com este tipo de equipamento de que se tem notícia no Brasil. Anteriormente, os estudos experimentais priorizavam a utilização do sistema vibroprensado (CHAMA NETO, 2002; RAMOS, 2002; FIGUEIREDO e ESCARIZ, 2011; FIGUEIREDO et al., 2012). 


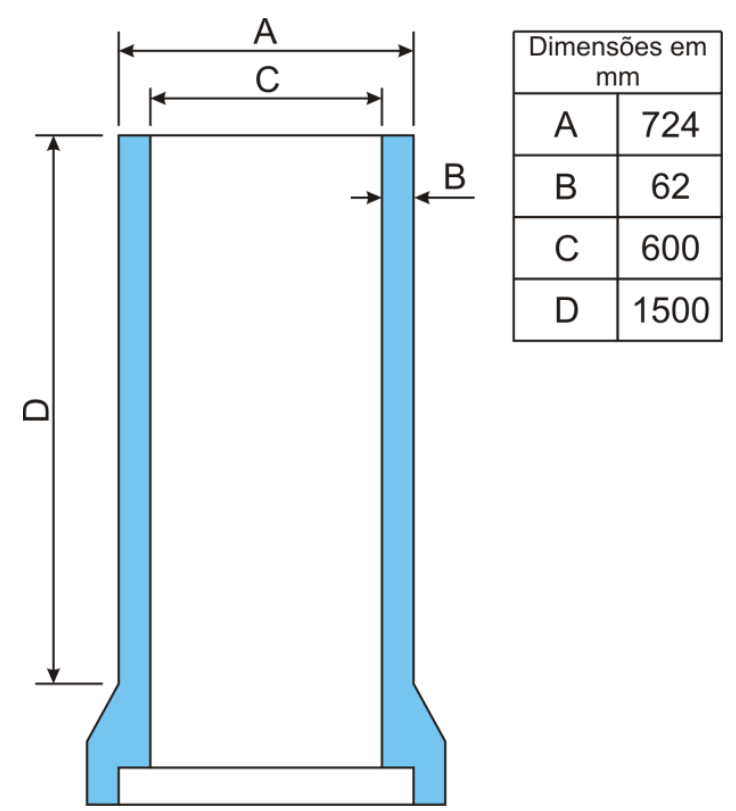

Figura 3.11 - Dimensões nominais dos tubos produzidos.

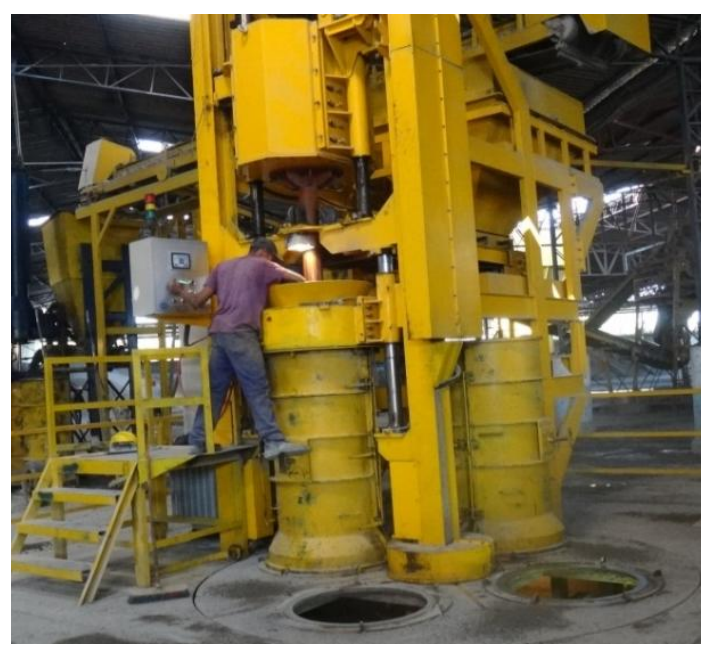

Figura 3.12 - Equipamento de produção de tubos por compressão radial.

Imediatamente após a moldagem do tubo o mesmo foi içado e transportado para o local de desforma (Figura 3.13a). No local de desforma, e ainda preso na empilhadeira, o tubo foi girado para que a bolsa ficasse para a parte de cima. Em seguida o tubo foi descarregado e iniciou-se a retirada da forma (Figura 3.13b). Neste processo de produção não é utilizado o anel de base, ficando o tubo sustentado apenas pela coesão do concreto. Esta operação foi realizada imediatamente após a moldagem, ocorrendo a quebra de alguns tubos na desforma (Figura 3.14). 


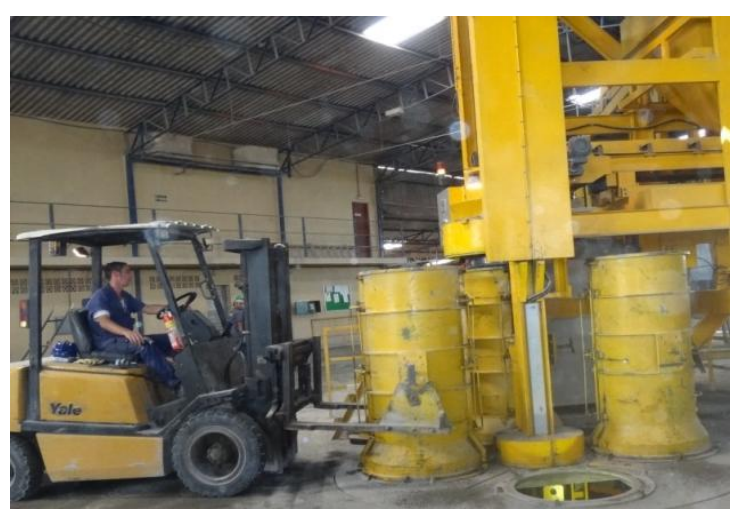

(a)

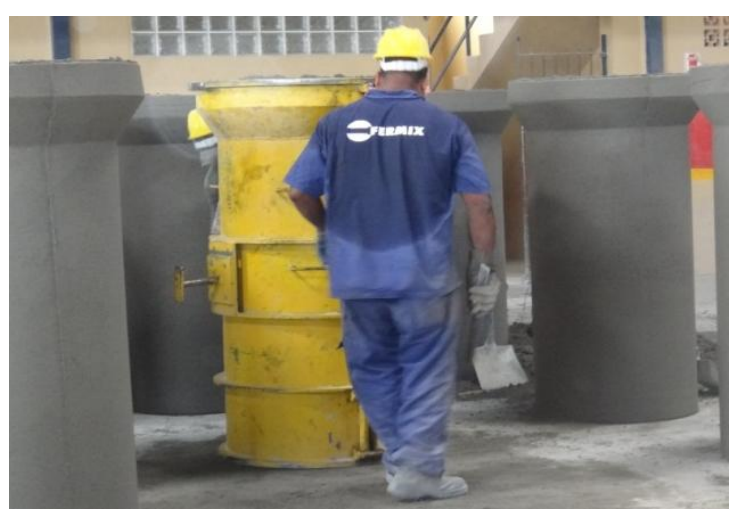

(b)

Figura 3.13 - a) Retirada do tubo do equipamento de moldagem e transporte até o local de desforma; b) Processo de desforma do tubo.

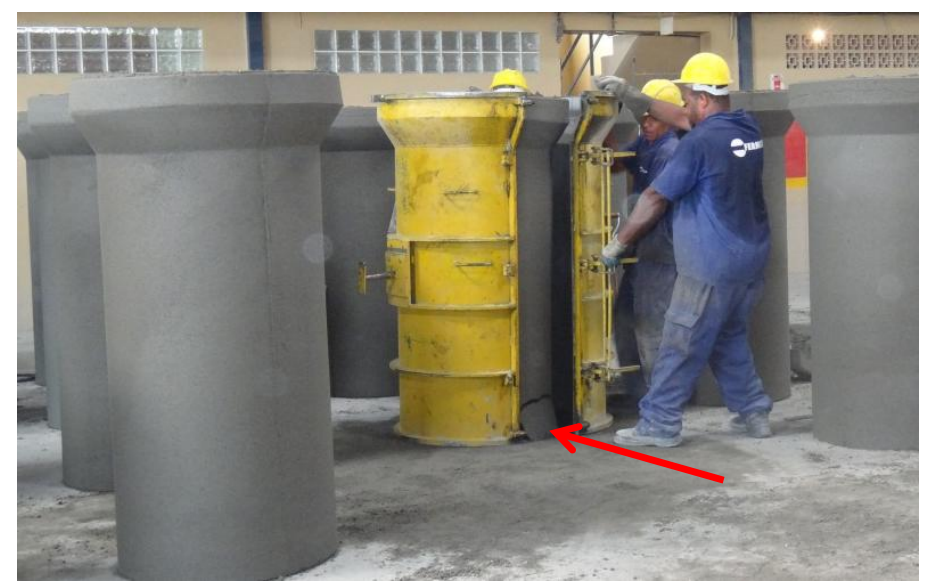

Figura 3.14 - Quebra da ponta durante a desforma do tubo.

Todos os tubos foram moldados em um único dia o que minimizou a variabilidade associada ao processo de produção que utilizou os materiais em condições bem uniformes e o mesmo pessoal da fábrica. Foi inicialmente proposta a moldagem de três tubos de cada composição de tipo de fibra e teor, totalizando doze tubos, e mais três tubos armados convencionalmente com tela metálica. Contudo, durante a moldagem dos tubos com o maior teor de fibras de aço, dois tubos quebraram após a desforma, sendo necessária a moldagem de novos tubos. Os concretos dos tubos que ruíram foram recuperados e utilizados para moldagem de dois tubos extras, sendo devidamente identificados como remoldados. Assim, ao todo foram moldados dezessete tubos de concreto. A Tabela 3.2 apresenta a identificação e as quantidades de tubos moldados de cada composição. 
Tabela 3.2 - Identificação dos tubos de concreto moldados.

\begin{tabular}{|c|c|c|c|}
\hline Tipo de reforço & $\begin{array}{l}\text { Teor de fibras } \\
\quad\left(\mathrm{kg} / \mathrm{m}^{3}\right)\end{array}$ & $\begin{array}{c}\text { Quantidade de } \\
\text { tubos }\end{array}$ & Identificação \\
\hline \multirow{3}{*}{ Tela metálica } & \multirow{3}{*}{-} & \multirow{3}{*}{3} & Tela-Exp1 \\
\hline & & & Tela-Exp2 \\
\hline & & & Tela-Exp3 \\
\hline \multirow{8}{*}{ Fibra de aço (SF) } & \multirow{3}{*}{10} & \multirow{3}{*}{3} & SF10-Exp1 \\
\hline & & & SF10-Exp 2 \\
\hline & & & SF10-Exp 3 \\
\hline & \multirow{5}{*}{20} & \multirow{5}{*}{5} & SF20-Exp1* \\
\hline & & & SF20-Exp2 \\
\hline & & & SF20-Exp3 \\
\hline & & & SF20-Exp4* \\
\hline & & & SF20-Exp5 \\
\hline \multirow{6}{*}{ Fibra de polipropileno (PF) } & \multirow{3}{*}{2,3} & \multirow{3}{*}{3} & PF2,3-Exp1 \\
\hline & & & PF2,3-Exp2 \\
\hline & & & PF2,3-Exp3 \\
\hline & \multirow{3}{*}{4,6} & \multirow{3}{*}{3} & PF4,6-Exp1 \\
\hline & & & PF4,6-Exp2 \\
\hline & & & PF4,6-Exp3** \\
\hline
\end{tabular}

*Tubos que ruíram e foram moldados com reaproveitamento do concreto.

**Perdido durante o processo de transporte.

As telas metálicas foram produzidas com aço CA60 de $6 \mathrm{~mm}$ de diâmetro, utilizando um espaçamento entre espiras de $100 \mathrm{~mm}$. As fibras utilizadas foram uma fibra de aço e uma macrofibra de polipropileno, as mesmas utilizadas no programa experimental do Capítulo 2 e apresentadas na Figura 2.17. A caracterização destas fibras também encontra-se apresentada no Capítulo 2 na Tabela 2.4. Para cada uma das fibras foram utilizados dois teores. O teor em volume da fibra de polipropileno utilizado foi o dobro em relação ao teor da fibra de aço a fim de se obter uma proximidade de desempenho entre as duas fibras conforme estudos anteriores (FIGUEIREDO et al., 2012c; SALVADOR e FIGUEIREDO, 2013) e também utilizado no programa experimental do Capítulo 2, confirmando os resultados desses estudos. Os teores utilizados encontram-se na Tabela 3.3. 
Tabela 3.3 - Teores de fibras utilizados nas moldagens dos tubos.

\begin{tabular}{cccc}
\hline \multicolumn{2}{c}{ FIBRA DE AÇO - SF } & \multicolumn{2}{c}{ FIBRA DE POLIPROPILENO - PF } \\
$\boldsymbol{k g} / \boldsymbol{m}^{\mathbf{3}}$ & $\%^{*}$ & $\boldsymbol{k g} / \boldsymbol{m}^{\mathbf{3}}$ & $\%^{*}$ \\
\hline 10 & 0,125 & 2,3 & 0,25 \\
20 & 0,25 & 4,6 & 0,50 \\
\hline
\end{tabular}

*Percentual em relação ao volume de concreto produzido.

Os concretos utilizados na produção dos tubos foram dosados a partir das proporções indicadas pelo fabricante para a produção de tubos PA1 - DN 600 (ABNT NBR 8890, 2007). Essa proporção para $1 \mathrm{~m}^{3}$ de concreto foi de $300 \mathrm{~kg}$ de cimento, $1600 \mathrm{~kg}$ de areia, $500 \mathrm{~kg}$ de pedrisco e entre 88 e 105 litros de água. A variação da quantidade de água foi devida à umidade da areia ao longo do dia de produção dos tubos.

A mistura foi realizada por meio de um misturador planetário e os materiais foram introduzidos através de uma esteira, com exceção das fibras que foram adicionadas diretamente no misturador para evitar perdas durante o transporte.

\subsubsection{Moldagem de corpos de prova}

$\mathrm{Na}$ fábrica de tubos foram ainda moldados cinco corpos de prova cilíndricos de $15 \times 30 \mathrm{~cm}$ para cada composição de concreto reforçado com fibra utilizado para produção dos tubos (ver Tabela 3.3). Esses corpos de prova foram utilizados para a caracterização física (absorção e porosidade total) e mecânica (resistência à compressão e comportamento pós-fissuração) dos CRFs. Conforme discutido no Capítulo 2 (ver item 2.1), devido à consistência mais seca desses concretos, a moldagem de corpos de prova prismáticos, para caracterização do comportamento pós-fissuração dos CRFs, não apresenta bons resultados. A moldagem dos corpos de prova cilíndricos foi realizada sobre uma mesa vibratória em três camadas (Figura 3.15a), com adensamento enérgico através da aplicação de 50 golpes com um soquete de aço em cada camada (Figura 3.15b). Este procedimento de moldagem busca simular a energia de adensamento ocorrida na moldagem dos tubos, sendo adotada na fábrica para caracterização da resistência mecânica do concreto. Esse procedimento também foi adotado no trabalho realizado por Escariz (2012). 


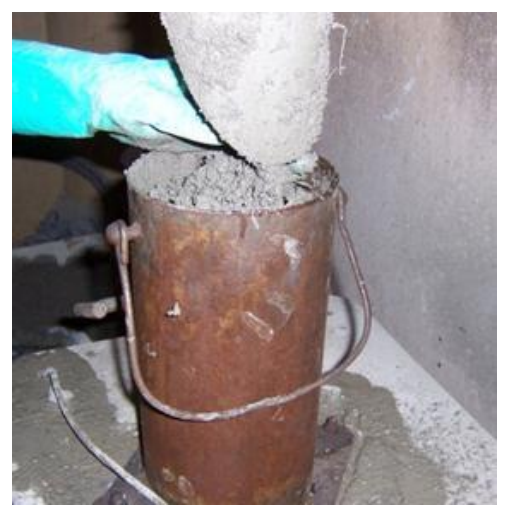

(a)

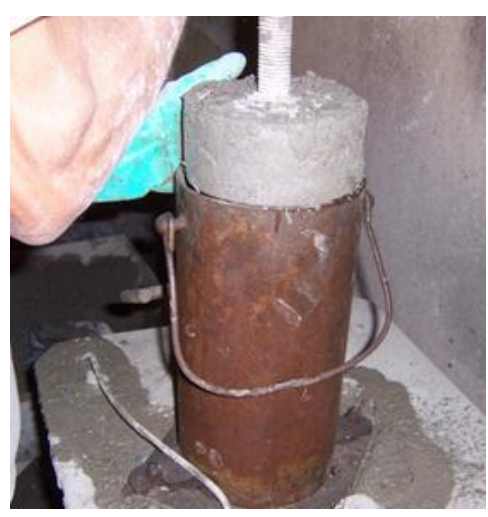

(b)

Figura 3.15 - a) colocação do concreto em camadas; b) adensamento com soquete e sobre mesa vibratória.

Os corpos de prova foram desmoldados após 24 horas e transportados até o laboratório da Escola Politécnica onde foram mantidos estocados em ambiente não controlado até a idade de 28 dias quando foram ensaiados segundo o procedimento indicado na ABNT NBR 5739 (2007). A opção por manter os corpos de prova fora da câmara úmida deve-se as condições de armazenamento dos tubos na fábrica, que são mantidos no pátio da fábrica após um período de cura, cobertos com plástico, que varia entre um e três dias.

\subsubsection{Compressão diametral dos tubos}

O ensaio de compressão diametral foi realizado também na fábrica de tubos Fermix. O método de ensaio adotado foi o de três cutelos, com o apoio do tubo em dois cutelos de madeira inferiores e o carregamento do componente a partir de um cutelo superior articulado, apoiado sobre viga de madeira e colchão de areia, conforme se pode observar na Figura 3.16.

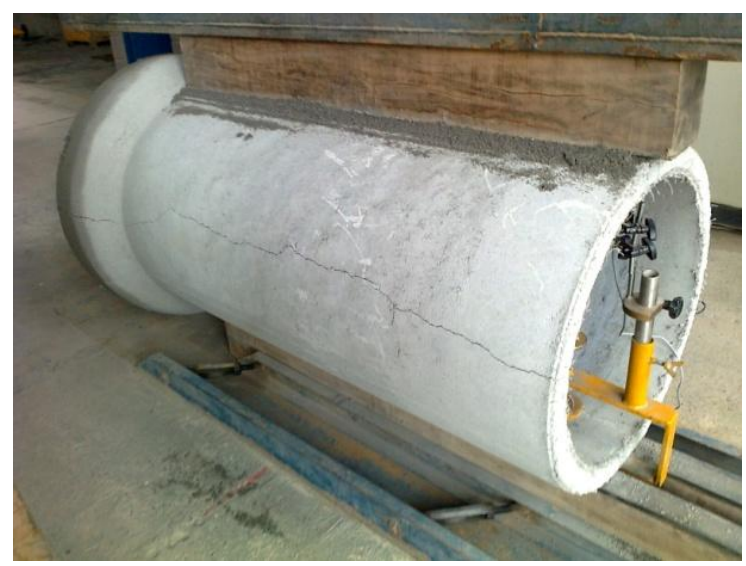

Figura 3.16 - Ensaio de compressão diametral dos TCRF. 
O procedimento de ensaio utilizado para compressão diametral foi o indicado por Figueiredo (2008), no qual se elimina o carregamento cíclico indicado na ABNT NBR 8890 (2007) e aplica-se um carregamento contínuo sem ocorrência de diferenças significativas no resultado do ensaio, conforme discutido no item 3.2.2. Para a leitura dos deslocamentos diametrais foi realizada através de apenas um LVDT posicionado na ponta dos tubos, conforme recomendado por Figueiredo et al., (2012a).

Uma vez medidas as cargas e os respectivos deslocamentos diametrais, foi possível estabelecer o gráfico de carga versus deslocamento diametral ilustrado na Figura 3.10 do item 3.2.2, podendo ser identificados os parâmetros de controle do ensaio. Os parâmetros identificados foram:

- a carga de prova $\left(F_{C}\right)$, que corresponde à carga mínima isenta de dano para os tubos reforçados com fibras e a carga de fissura para os tubos convencionalmente armados;

- a carga máxima ou carga de pico $\left(F_{n}\right)$, para os dois tipos de reforço;

- as resistências residuais associadas a deslocamentos verticais no estado limite de serviço (ELS) e no estado limite último (ELU).

Para determinar essas resistências residuais foram adotados os valores de deslocamento diametral específico (deslocamento diametral dividido pelo diâmetro do tubo) indicados por Figueiredo et al., (2012a). Esses valores são de 0,4\% para o deslocamento diametral específico no ELS $\left(d_{E L S}\right)$ e de $2 \%$ para o deslocamento diametral específico no ELU $\left(d_{E L S}\right)$. Após o aparecimento da primeira fissura na crista do tubo, sua abertura foi acompanhada e registrada (Figura 3.17a), juntamente com a leitura e registo do valor correspondente ao deslocamento diametral (Figura 3.17b).

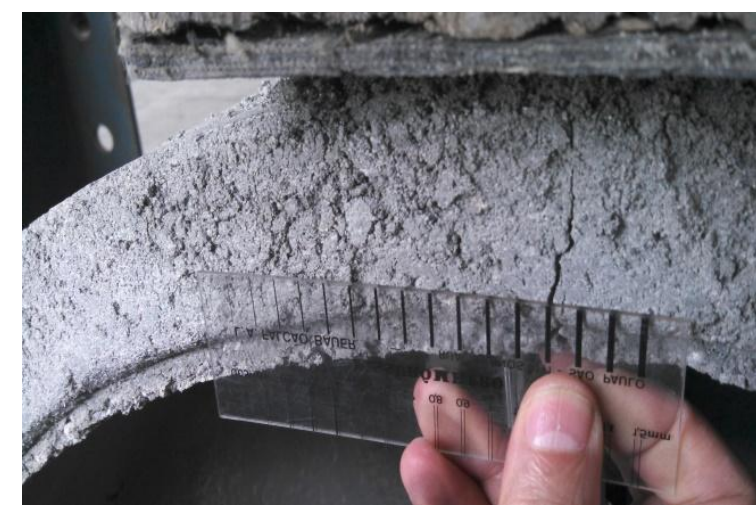

(a)

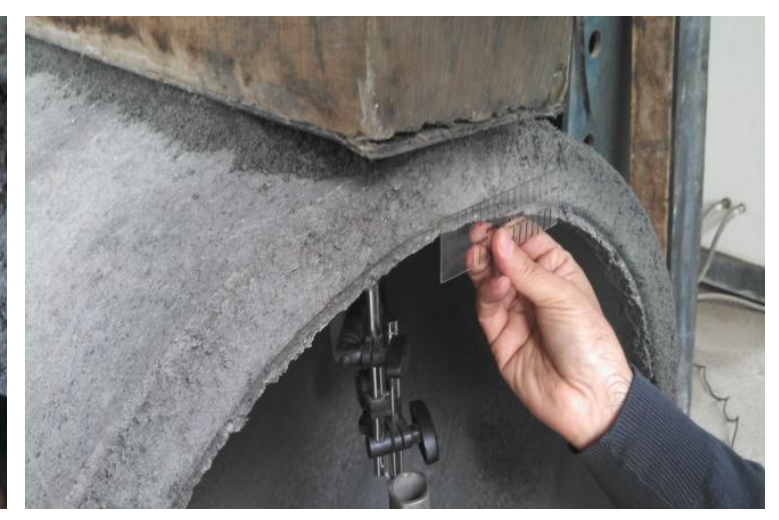

(b)

Figura 3.17: a) Leitura da abertura de fissura; b) registro simultâneo da variação do deslocamento diametral e abertura de fissura na ponta do tubo. 
As medidas de abertura de fissura foram tomadas entre 0,1 e $1,5 \mathrm{~mm}$, em intervalos de $0,1 \mathrm{~mm}$, e para cada abertura de fissura foi medida a correspondente deformação diametral com o LVDT. Assim, será possível a parametrização do ELS e ELU em função de um nível de abertura de fissura, complementando o trabalho anterior proposto por Figueiredo et al., 2012a.

\subsubsection{Extração de testemunhos dos tubos ensaiados}

Finalizados os ensaios de compressão diametral, cinco tubos (um de cada composição) foram utilizados para extrações de doze testemunhos cilíndricos de cada, conforme ilustrado na Figura 3.18a e Figura 3.18b.

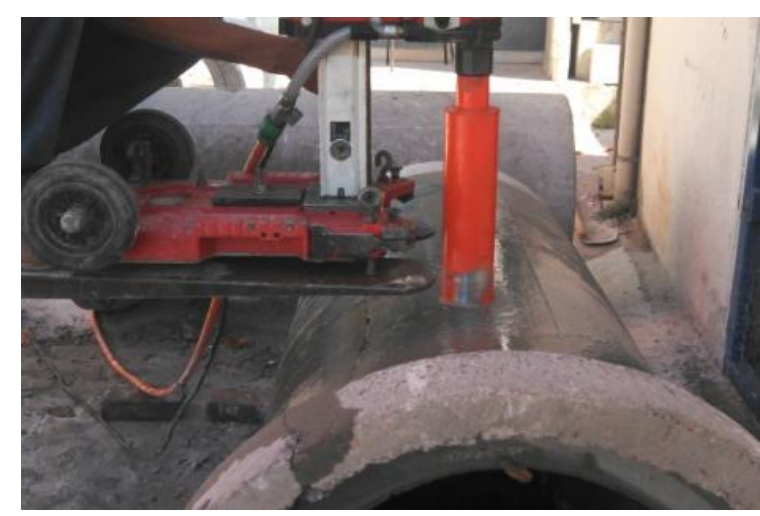

(a)

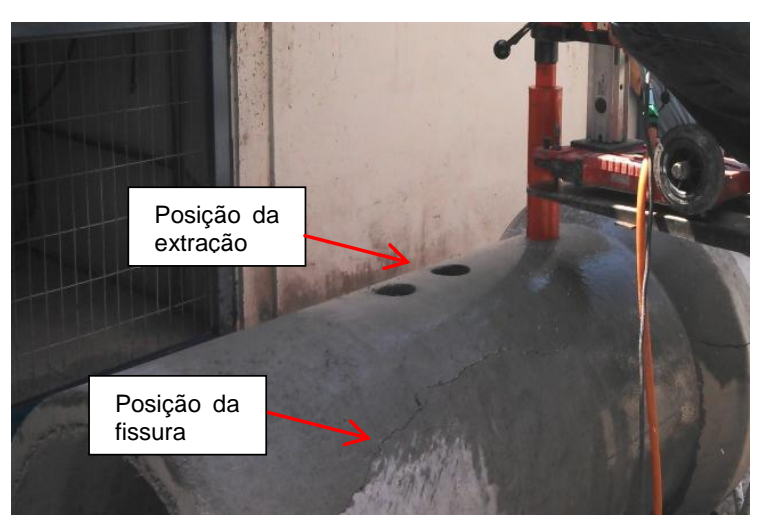

(b)

Figura 3.18 - Extração de testemunhos dos tubos fissurados: a) posicionamento e nivelamento da extratora; b) posicionamento das extrações em relação a fissura.

As extrações foram realizadas com o equipamento nivelado sobre os garfos de uma empilhadeira (Figura 3.18a). A posição das extrações foi centralizada na região entre duas fissuras principais (Figura 3.18b). Desses testemunhos seis foram utilizados para caracterização da absorção de água e índice de vazios e outros seis testemunhos foram utilizados para realização de ensaios Barcelona, que serão apresentados no Capítulo 4. Os resultados dos testemunhos poderão ser comparados com aqueles obtidos com os corpos de prova moldados (item 3.3.2). Assim, pode ser verificado se ouve diferença significativa nas condições de absorção de água e porosidade nessas duas condições. Os procedimentos de ensaio e cálculo da absorção e índice de vazios foram os prescritos na norma ABNT NBR 9778 (2005), conforme equações apresentadas no item 2.3.2 do Capítulo 2. 


\subsection{Resultados e análises}

\subsubsection{Absorção de água e índice de vazios}

A absorção de água e o índice de vários dos concretos dos tubos foram avaliados em dois corpos de prova moldados na fábrica, e em seis testemunhos extraídos dos tubos após ensaio de compressão diametral. A avaliação dessas características é importante para comparar as características do concreto em corpos de prova moldados ou testemunhos extraídos dos tubos. Além disso, esse é um ensaio padrão de qualidade dos tubos, conforme exigido pela norma ABNT NBR 8890 (2007), onde se exige um nível de absorção máxima de $8 \%$ para tubos de águas pluviais. Esses resultados médios e respectivos desvios padrão estão apresentados na Tabela 3.4.

Tabela 3.4 - Resultados médios de absorção de água e índice de vazios dos testemunhos e dos corpos de prova moldados com os concretos dos tubos.

\begin{tabular}{cccccc}
\hline \multirow{6}{*}{ Extraídos } & $\begin{array}{c}\text { Tipo de } \\
\text { reforço }\end{array}$ & $\begin{array}{c}\text { Absorção de } \\
\text { água (\%) }\end{array}$ & $\begin{array}{c}\text { Desvio } \\
\text { padrão (\%) }\end{array}$ & $\begin{array}{c}\text { Índice de } \\
\text { vazios (\%) }\end{array}$ & $\begin{array}{c}\text { Desvio } \\
\text { padrão (\%) }\end{array}$ \\
\hline \multirow{6}{*}{ Moldados } & Tela & 6,6 & 0,6 & 14,8 & 1,1 \\
& SF-10 & 6,9 & 0,3 & 15,4 & 0,7 \\
& SF-20 & 7,5 & 0,3 & 16,5 & 0,6 \\
& PF-2,3 & 6,9 & 0,6 & 15,2 & 1,2 \\
& PF-4,6 & 6,2 & 0,9 & 13,9 & 1,7 \\
\hline & SF-10 & 2,5 & 0,1 & 5,7 & 0,2 \\
& SF-20 & 2,2 & 0,0 & 5,0 & 0,1 \\
& PF-2,3 & 2,6 & 0,1 & 5,9 & 0,2 \\
& PF-4,6 & 2,9 & 0,0 & 6,6 & 0,0 \\
\hline
\end{tabular}

Observa-se na Tabela 3.4 que os corpos de prova moldados a partir dos concretos dos tubos apresentaram resultados de absorção e índice de vazios (porosidade total) três vezes menores quando comparados aos resultados obtidos através dos testemunhos extraídos dos tubos. Diversos fatores poderiam influenciar nessa diferença, como a energia de compactação distinta, o que não foi quantificado, ou a presença de microfissuração nos testemunhos devido ao processo de extração. Porém, em estudo anterior apresentado por Escariz (2012), que avaliou corpos de prova moldados e testemunhos extraídos de tubos reforçados com diversos tipos e teores de fibras, as diferenças foram sensivelmente menores que aquelas observadas na Tabela 3.4, indicando que algum outro parâmetro pode estar ocasionando essa diferença. Um parâmetro avaliado foi a relação entre o volume da amostra e sua área 
superficial, considerando as dimensões utilizadas para os corpos de prova e os testemunhos extraídos. No estudo de Escariz (2012) esta relação foi de $20 \mathrm{l} / \mathrm{m}^{2}$ para corpos de prova moldados e $16 \mathrm{l} / \mathrm{m}^{2}$ para testemunhos extraídos. Para os resultados da Tabela 3.4 esta relação foi de $30 \mathrm{l} / \mathrm{m}^{2}$ para corpos de prova moldados e $12 \mathrm{l} / \mathrm{m}^{2}$ para testemunhos extraídos. Com essa relação sendo considerada como um parâmetro de ponderação geométrica entre os corpos de prova e os testemunhos, a análise de variância indicou, ao nível de significância de 5\%, resultados estatisticamente iguais (a hipótese de igualdade das médias não é rejeitada com valor $\mathrm{p}=0,063$ ). Esses resultados indicam que os corpos de prova moldados podem ser considerados como representativos dos concretos dos tubos em termos de compactação.

É importante lembrar que a norma ABNT NBR 8890 (2007) padroniza a dimensão da amostra para a medida da absorção de água do concreto dos tubos, limitando-a a uma área superficial entre 100 e $150 \mathrm{~cm}^{2}$. Isto não foi adotado neste trabalho, pois o diâmetro de extração foi o mesmo adotado para a realização do ensaio Barcelona (ver item 4.3.3 do Capítulo 4).

\subsubsection{Resistência à compressão}

Os tubos PA-1 de $600 \mathrm{~mm}$ são normalmente produzidos com concreto de resistência característica à compressão $\left(f_{c k}\right)$ igual a $25 \mathrm{MPa}$. Para avaliar a influência da incorporação das fibras na resistência à compressão do concreto, essa característica foi avaliada em dois corpos de prova moldados na fábrica e ensaiados em idade de 28 dias. A Tabela 3.5 apresenta os resultados médios obtidos para cada composição, desvios padrão e coeficiente de variação.

Tabela 3.5 - Resultados de resistência à compressão dos corpos de prova moldados com os concretos dos tubos.

\begin{tabular}{cccc}
\hline Tipo de fibra & $\boldsymbol{f}_{\boldsymbol{c m}, 2 \boldsymbol{2}}(\mathbf{M P a})$ & Desvio padrão (MPa) & $\boldsymbol{C V}$ (\%) \\
\hline SF-10 & 27,8 & 0,2 & 1 \\
SF-20 & 30,3 & 0,6 & 2 \\
PF-2,3 & 27,4 & 0,8 & 3 \\
PF-4,6 & 25,0 & 0,6 & 2 \\
\hline
\end{tabular}

A Tabela 3.5 mostra que os concretos produzidos com fibra de polipropileno (PF) resultaram menor resistência à compressão, quando comparados aos com fibras de aço (SF). Percebe-se também que o aumento no teor de fibra impactou de forma 
distinta o concreto reforçado com fibra de aço (SF) ou de polipropileno (PF). Para avaliar se este resultado é significativo foi realizada uma análise de variância, que avaliou o efeito do tipo e teor das fibras, e o efeito de interação entre essas variáveis (Tabela 2.12).

Tabela 3.6 - Análise de variância da resistência à compressão dos concretos reforçados com fibras para produção dos tubos.

\begin{tabular}{ccccccc}
\hline $\begin{array}{c}\text { Fontes de } \\
\text { variação }\end{array}$ & GL & $\begin{array}{c}\text { Soma de } \\
\text { quadrados }\end{array}$ & $\begin{array}{c}\text { Quadrado } \\
\text { médio }\end{array}$ & Estatística F & Valor $\boldsymbol{P}$ & Significativo \\
\hline Tipo de fibra & 1 & 16,0749 & 16,0749 & 50,55 & 0,002 & Sim \\
Teor de fibra & 1 & 0,0126 & 0,0126 & 0,04 & 0,852 & Não \\
Tipo*teor & 1 & 12,1270 & 12,1270 & 38,14 & 0,003 & Sim \\
Erro & 4 & 1,2720 & 0,3180 & & & \\
Total & 7 & 29,4865 & & & & \\
\hline
\end{tabular}

Verifica-se na Tabela 2.12 que foi confirmado o efeito significativo de interação entre o tipo e o teor de fibra (com valor $p=0,003<0,05$ ). Isto indica que a influência do teor de fibra na resistência à compressão é diferente entre a fibra de aço e de polipropileno. $O$ fato de existir efeito de interação significa que não tem sentido avaliar as variáveis de forma independente, mas sim dependendo do nível da outra variável. Ou seja, para a fibra de aço o aumento no teor de fibras resultou acréscimo na resistência à compressão, enquanto para a fibra de polipropileno o efeito foi oposto. Isto se deve a rigidez da fibra nesse tipo de esforço que, para o caso da fibra de polipropileno é muito menor. A Figura 3.19 ilustra o comportamento distinto das fibras na resistência à compressão dependendo do teor empregado.

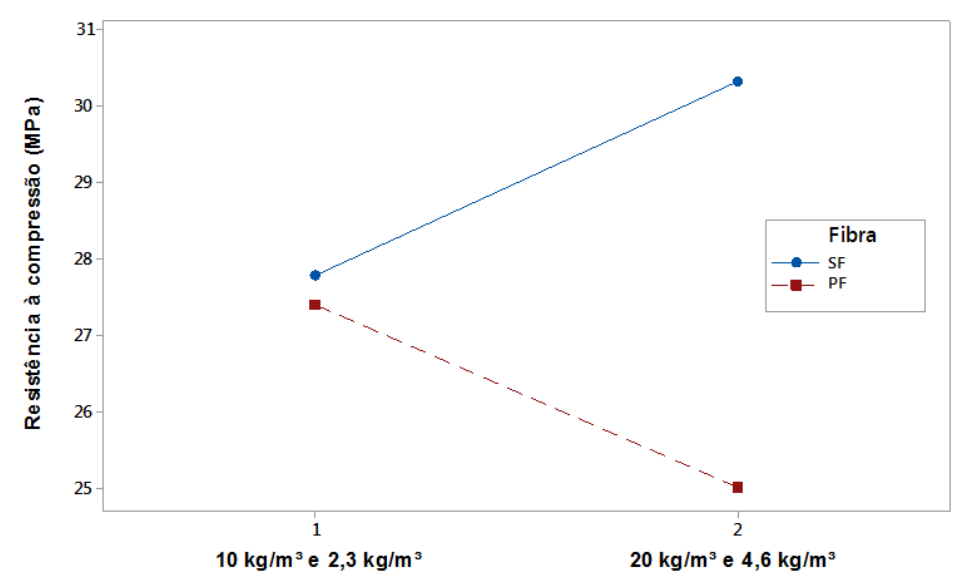

Figura 3.19 - Efeito de interação entre os tipos e teores de fibra na resistência à compressão. 
Observa-se na Figura 3.19 que, para os menores teores de ambas as fibras, os resultados de resistência à compressão foram muito próximos. Já para os maiores teores o comportamento foi oposto, aumentando para a fibra de aço e diminuindo para a fibra de polipropileno.

\subsubsection{Compressão diametral dos tubos}

Os resultados de compressão diametral dos tubos de concreto com reforço convencional e com fibras foram analisados a partir dos seguintes aspectos:

- Análise das curvas individuais de carga versus deslocamento diametral;

- Correlações entre deslocamentos diametrais e aberturas de fissura;

- Análise da dispersão dos resultados em termos das cargas de fissura, cargas máximas e cargas residuais;

- Comparação das curvas médias com relação aos requisitos da norma brasileira e a proposta baseada no fib Model Code 2010.

\section{Análise das curvas individuais}

A Figura 3.20 apresenta as curvas individuais e a curva média de três tubos de concreto com reforço de tela metálica ensaiados na compressão diametral.

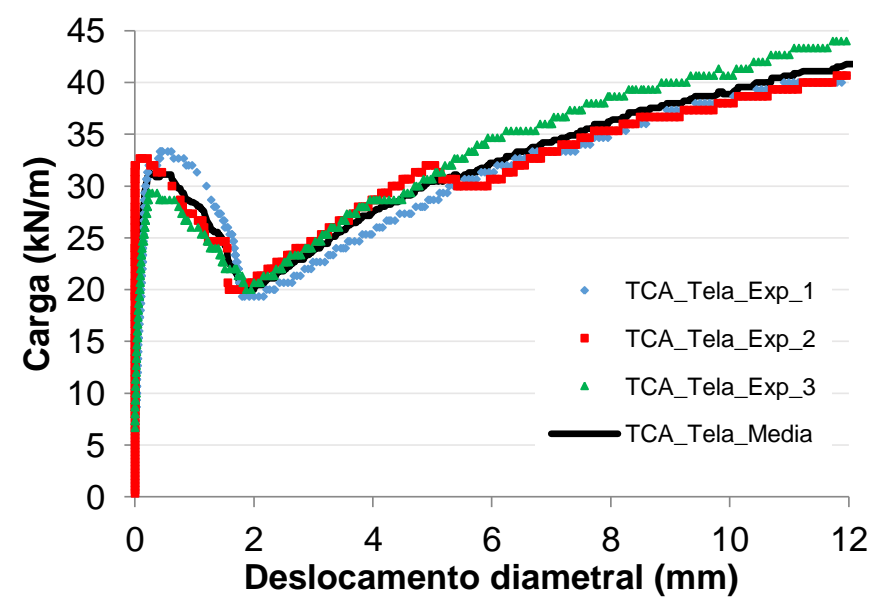

Figura 3.20 - Resultados de compressão diametral dos tubos de concreto com reforço convencional (TCA) em tela metálica.

Analisando as curvas apresentadas na Figura 3.20 verifica-se que os resultados dos três tubos reforçados com tela metálica apresentaram curvas muito próximas ao longo de todo deslocamento diametral avaliado. Imediatamente após a carga de pico, observa-se redução na capacidade resistente até aproximadamente 2 
$\mathrm{mm}$ de deslocamento diametral. Isto ocorre devido o posicionamento da tela metálica ser aproximadamente no centro da espessura do tubo, necessitando que ocorra certa abertura de fissura até que a armadura seja solicitada. A Figura 3.21a apresenta o esquema comparando o posicionamento do reforço utilizando armadura convencional ou fibras e a Figura 3.21b ilustra o posicionamento da armadura simples na seção do tubo.

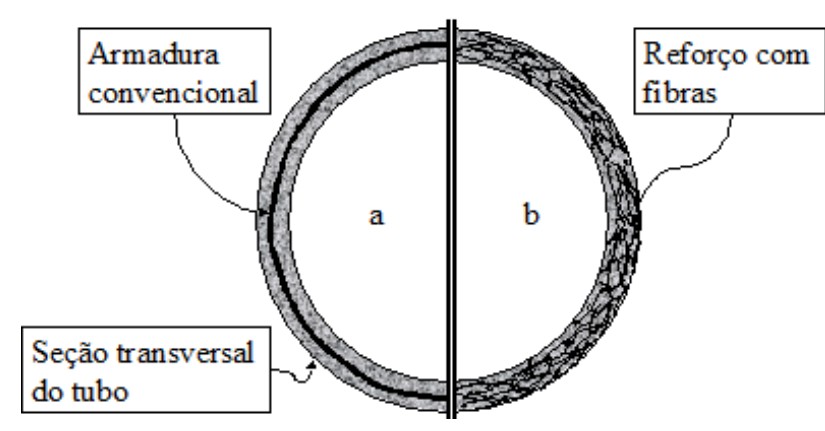

(a)

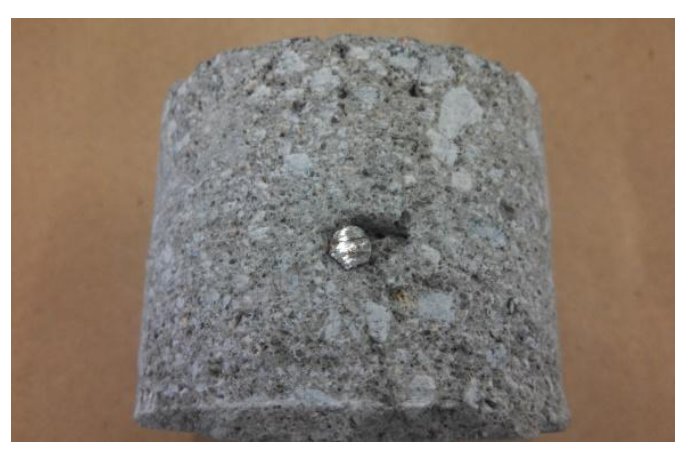

(b)

Figura 3.21 - Distribuição de reforços na seção transversal dos tubos: a) de armadura convencional ou fibras. Fonte: Figueiredo; Chama Neto (2008); b) testemunho extraído mostrando a posição central da armadura convencional no tubo.

Após a mobilização da armadura, os resultados apresentaram nitidamente comportamento de hardening, ou seja, aumento da carga resistente pós-fissuração com o aumento do deslocamento diametral dos tubos.

Para os tubos reforçados com fibras de aço, as curvas estão apresentadas na Figura 3.22.

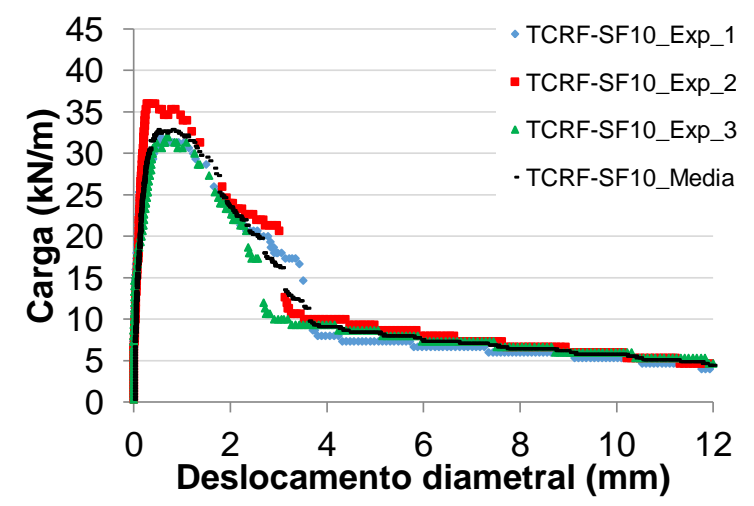

(a)

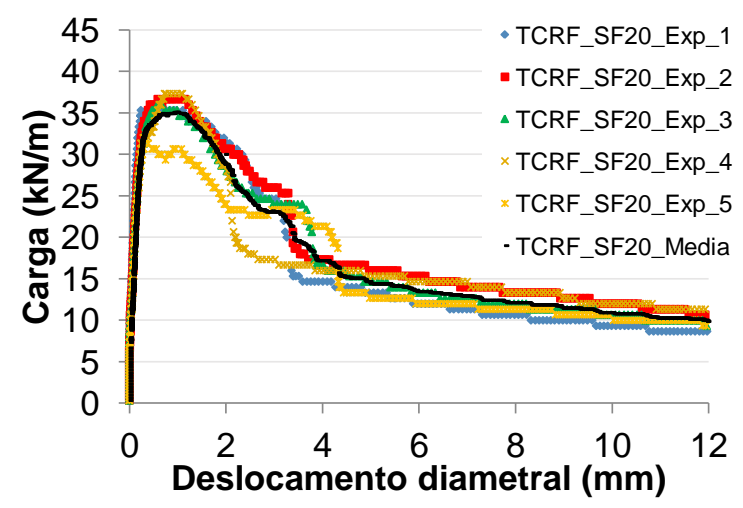

(b)

Figura 3.22 - Resultados de compressão diametral TCRF de aço (SF): a) com $10 \mathrm{~kg} / \mathrm{m}^{3}$ $(0,13 \%) ; b) 20 \mathrm{~kg} / \mathrm{m}^{3}(0,25 \%)$. 
Verifica-se na Figura 3.22a que os resultados dos tubos reforçados com 10 $\mathrm{kg} / \mathrm{m}^{3}$ de fibras de aço apresentaram curvas bastante próximas. Na região entre 2 e 4 $\mathrm{mm}$ de deslocamento diametral percebe-se a instabilidade do ensaio, claramente identificada através do afastamento dos pontos do gráfico para o menor teor de fibra (ver Figura 3.22a). A realização do ensaio utilizando sistema de controle fechado (closed-loop) minimizaria essa instabilidade, conforme discutido para os ensaios de caracterização mecânica do CRF no Capítulo 2. Para o maior teor dessa fibra (Figura 3.22b), não é observado afastamento entre os pontos do gráfico, indicando que 0 aumento no teor de fibra pode ter contribuído para a redução desta instabilidade. Após a carga de pico a capacidade resistente dos tubos diminui progressivamente, caracterizando nítido comportamento de softening. Para o mesmo nível de deslocamento diametral considerado para o tubo com reforço convencional $(2 \mathrm{~mm})$, percebe-se que a capacidade resistente dos tubos com fibra de aço foi maior (TCAtela $20 \mathrm{kN} / \mathrm{m}$, TCRF-SF10 $23 \mathrm{kN} / \mathrm{m}$ e TCRF-SF20 29 kN/m). Isto se deve à distribuição das fibras em toda espessura do tubo, conforme comentado e ilustrado na Figura 3.21. Conforme apresentado no item 3.3.1, dois dos tubos reforçados com $20 \mathrm{~kg} / \mathrm{m}^{3}$ de fibra de aço foram produzidos a partir do reaproveitamento do material de tubos que quebraram durante a desforma, o que resultou um total de cinco tubos moldados com esta composição. Esses tubos foram o SF20_Exp_1 e o SF20_Exp_4, conforme indicado anteriormente na Tabela 3.2. Apesar disso, os resultados obtidos com esses tubos não foram atípicos.

A Figura 3.23 apresenta as curvas individuais e as curvas médias dos tubos de concreto reforçados com fibra de polipropileno.

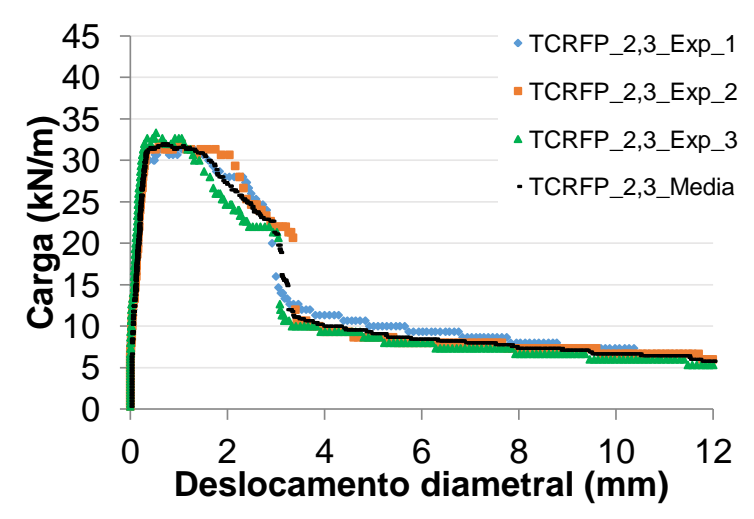

(a)

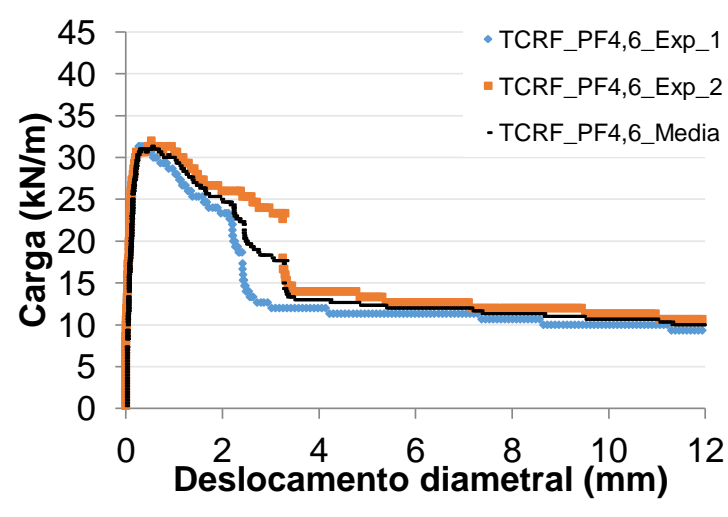

(b)

Figura 3.23 - Resultados de compressão diametral dos TCRF de polipropileno (PF): a) 2,3 $\mathrm{kg} / \mathrm{m}^{3}(0,25 \%) ;$ b) $4,6 \mathrm{~kg} / \mathrm{m}^{3}(0,50 \%)$. 
Analisando a Figura 3.23 a percebe-se nos resultados dos tubos reforçados com $2,3 \mathrm{~kg} / \mathrm{m}^{3}$ de fibra de polipropileno foram muito próximos ao longo de todo o deslocamento diametral. Já para o maior teor dessa fibra (Figura 3.23b), apenas dois tubos foram ensaiados devido à quebra de um deles durante o transporte. Ainda assim, as curvas obtidas apresentaram diferença apenas entre os valores de 2 e $3 \mathrm{~mm}$ de deslocamento diametral, região de instabilidade na maioria dos ensaios realizados nos tubos reforçados com fibra. Quanto à capacidade resistente pós-pico o comportamento obtido com os tubos reforçados com fibra de polipropileno foi de softening, diferente do slip-hardening observado para esta mesma fibra em ensaios de flexão de corpos de prova prismáticos (SALVADOR e FIGUEIREDO, 2013). Quanto à capacidade resistente para um deslocamento diametral de $2 \mathrm{~mm}$, o valor obtido para a fibra de polipropileno foi superior aos dois outros reforços nos menores teores de fibra $\left(T C A \_t e l a=20 \mathrm{kN} / \mathrm{m}, T C R F \_S F 10=23 \mathrm{kN} / \mathrm{m}\right.$ e TCRF_PF2,3 $=27 \mathrm{kN} / \mathrm{m}$ ) e é superior ao reforço convencional nos maiores teores de fibra (TCA_tela $=20 \mathrm{kN} / \mathrm{m}$, TCRF_SF20 $=29 \mathrm{kN} / \mathrm{m}$ e TCRF_PF4,6 $=25 \mathrm{kN} / \mathrm{m})$. A comparação das cargas relevantes do ensaio em termos médios e variabilidade serão avaliadas a seguir.

O valor do deslocamento diametral para a carga de fissura $\left(v_{c r}\right)$ também pode ser analisado. Os resultados obtidos experimentalmente podem ser comparados com valores calculados analiticamente através do teorema de Castigliano, através da Eq. 3-1.

$$
v_{c r}=\frac{\pi^{2}-8}{32 \pi} \cdot \frac{F_{c r}\left(D_{i}+h\right)^{3}}{E_{c m} I}
$$

Onde:

$F_{c r}$ : carga de fissura;

$D_{i}$ : diâmetro nominal do tubo;

$h$ : espessura da parede do tubo;

$E_{c m}$ : módulo de elasticidade médio do concreto;

I: inercia da seção transversal por unidade de comprimento $I=\frac{1}{12} \times h^{3}$.

A Tabela 3.7 apresenta os valores de $v_{c r}$ obtidos experimentalmente e através do teorema de Castigliano, para os diferentes tipos de reforço. Para esses cálculos foram adotadas as cargas médias de fissura obtidas nos ensaios dos tubos, as 
dimensões nominais dos tubos e o módulo de elasticidade da matriz de concreto estimado a partir do seu $f_{c k}$. $O$ erro relativo ( $\xi$ foi calculado através da Eq. 3-2. Os valores de erro positivos indicam que o resultado experimental $\left(v_{\text {exp }}\right)$ são maiores que aqueles determinados numericamente $\left(v_{\text {teo }}\right)$ e vice versa.

$$
\xi=\frac{v_{\text {exp }}-v_{t e o}}{v_{\text {exp }}} \times 100
$$

Tabela 3.7 - Comparação entre os resultados experimentais, com desvios padrão, e analíticos do deslocamento vertical antes da fissuração $\left(v_{c r}\right)$ dos tubos com diferentes tipos de reforço.

\begin{tabular}{|c|c|c|c|}
\hline \multirow{2}{*}{ Tipo de reforço } & \multicolumn{2}{|c|}{ Deslocamento diametral - $v_{c r}(\mathrm{~mm})$} & \multirow{2}{*}{$\xi(\%)$} \\
\hline & Analítico & Experimental (DP) & \\
\hline Tela & 0,28 & $0,21(0,05)$ & -33 \\
\hline SF-10 & 0,26 & $0,21(0,09)$ & -24 \\
\hline SF-20 & 0,29 & $0,24(0,08)$ & -21 \\
\hline PF-2,3 & 0,27 & $0,25(0,04)$ & -8 \\
\hline PF-4,6 & 0,27 & $0,17(0,01)$ & -59 \\
\hline
\end{tabular}

Deve ser enfatizado que, para os teores de fibra utilizados, a contribuição das fibras no comportamento mecânico antes da fissuração deve ser considerada insignificante. Por isso, os resultados obtidos são muito próximos, sejam determinados analítica ou experimentalmente, visto que dependem, além das características geométricas dos tubos, da resistência mecânica e rigidez da matriz, que são semelhantes.

\section{Correlacão entre o deslocamento diametral e a abertura de fissura}

Conforme apresentado no item 3.3.3 foram realizadas leituras da abertura de fissura ( $w$ ) na parte superior da ponta do tubo e do deslocamento diametral $(v)$ através de LVDT também posicionado sob essa ponta. As medidas foram realizadas para todos os 16 tubos ensaiados (um dos 17 tubos moldados quebrou durante 0 transporte). No entanto, os resultados de abertura de fissura de alguns tubos tiveram que ser descartados, pois a formação de microfissuras próximas à fissura principal resultava a desagregação do concreto nesta região (Figura 3.24). 


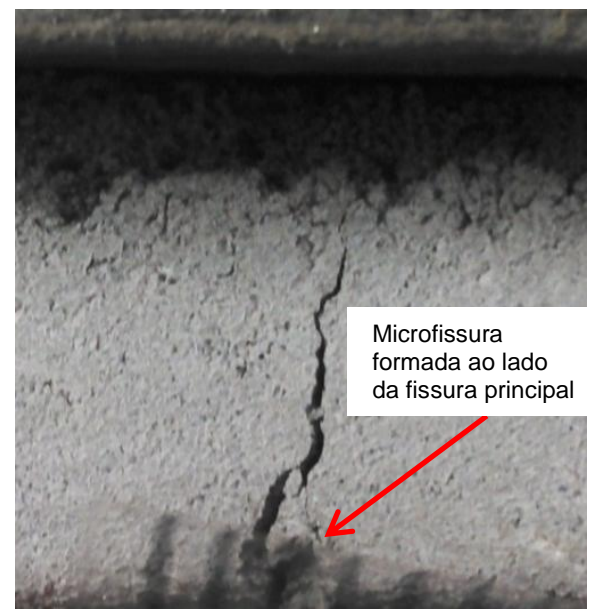

Figura 3.24 - Aparecimento de microfissura na região de medida da abertura de fissura.

O problema de perda de leitura devido à desagregação do concreto ocorreu apenas para um tubo de cada tipo de reforço, tendo sido medidas as aberturas de fissura em 13 tubos (dois TCA, sete TCRF-SF e quatro TCRF-PF). Com esses resultados foi utilizado um modelo de regressão linear simples $(y=\alpha+\beta \times x)$ entre os parâmetros deslocamento diametral $(v)$ e abertura de fissura $(w)$. As equações de regressão foram submetidas à análise de variância da regressão e os coeficientes das equações $(\alpha$ e $\beta$ ) foram testados quanto sua significância, ambos os testes realizados considerando nível de significância de $5 \%$. Os coeficientes de determinação da regressão $\left(R^{2}\right)$ e os coeficientes de determinação para a predição de novos valores de abertura de fissura $\left(R_{\text {pred }}^{2}\right)$ foram calculados. A Figura 3.25 apresenta o gráfico de dispersão das medidas experimentais de abertura de fissura $(W)$ e deslocamento diametral $(v)$, para os tubos de concreto com reforço convencional (TCA).

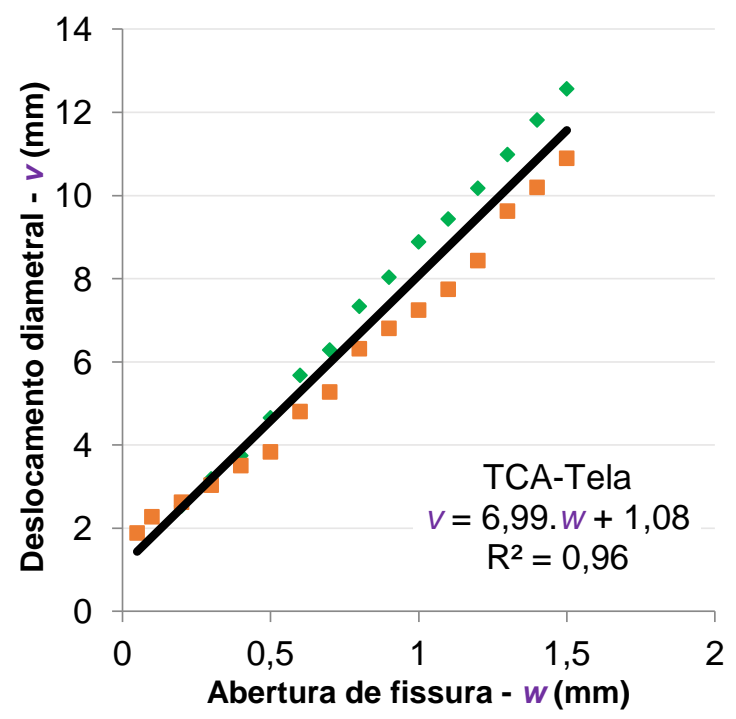

Figura 3.25 - Correlação experimental entre a abertura de fissura $(w)$ e o deslocamento diametral $(v)$ de tubos de concreto com reforço convencional (TCA). 
$\mathrm{Na}$ Figura 3.25 verifica-se que os resultados dos dois tubos foram muito próximos e resultou uma regressão linear com coeficiente de determinação $\left(R^{2}\right)$ igual a 0,96. A Tabela 3.8 apresenta a análise de variância dessa equação de regressão.

Tabela 3.8 - Análise de variância da equação de regressão entre a abertura de fissura (w) e o deslocamento diametral $(v)$ de tubos de concreto com reforço convencional (TCA).

\begin{tabular}{ccccccc}
\hline $\begin{array}{c}\text { Fontes de } \\
\text { variação }\end{array}$ & GL & $\begin{array}{c}\text { Soma de } \\
\text { quadrados }\end{array}$ & $\begin{array}{c}\text { Quadrado } \\
\text { médio }\end{array}$ & Estatística $\boldsymbol{F}$ & Valor $\boldsymbol{P}$ & Significativo \\
\hline Regressão & 1 & 277,331 & 277,331 & 665,55 & 0,000 & Sim \\
$\begin{array}{c}\text { Abertura de } \\
\text { fissura }\end{array}$ & 1 & 277,331 & 277,331 & 665,55 & 0,000 & Sim \\
$\quad$ Erro & 28 & 11,667 & 0,417 & & & \\
Total & 29 & 288,998 & & & & \\
\hline
\end{tabular}

Percebe-se na Tabela 3.8 que a análise de variância apresentou resultado significativo para a equação de regressão e para a variável abertura de fissura ( $w)$. Além da tabela de análise de variância o software estatístico utilizado (Minitab® 17) também apresentou o coeficiente de determinação $R^{2}$ igual a 0,96 (coincide com o calculado através do Excel) e o coeficiente de determinação para a predição de novos dados $\left(\mathrm{R}_{\text {pred }}^{2}\right.$ ) igual a 0,95 . Essa informação é muito importante, pois o $R^{2}$ indica o grau de associação das variáveis e nem sempre valores altos desse coeficiente indicam a capacidade da equação para a predição de dados não observados. Neste caso específico percebe-se que a equação apresentou valores altos tanto para o $\mathrm{R}^{2}$ quanto para $\circ \mathrm{R}_{\text {pred }}^{2}$. A Tabela 3.9 apresenta o teste de significância para os parâmetros da regressão.

Tabela 3.9 - Teste de significância dos parâmetros da equação de regressão entre a abertura de fissura ( $w$ ) e o deslocamento diametral $(v)$ de tubos de concreto com reforço convencional (TCA).

\begin{tabular}{ccccccc}
\hline Termos & Coeficiente & $\begin{array}{c}\text { Desvio } \\
\text { padrão }\end{array}$ & $\begin{array}{c}\text { Estatística } \\
\text { t-student }\end{array}$ & Valor $\boldsymbol{P}$ & VIF $^{*}$ & Significativo \\
\hline $\begin{array}{c}\text { Intercepto } \\
\begin{array}{c}\text { Coeficiente } \\
\text { angular }\end{array}\end{array}$ & 1,083 & 0,246 & 4,40 & 0,000 & & Sim \\
\hline
\end{tabular}

* Valores de VIF próximos ao valor 1 indicam coeficientes de regressão bem estimados.

Percebe-se na Tabela 3.9 que os parâmetros da equação de regressão, intercepto ou constante $(\alpha)$ e o coeficiente angular $(\beta)$ são significativos. 
A Figura 3.26 apresenta o gráfico de dispersão das medidas experimentais de abertura de fissura $(w)$ e deslocamento diametral $(v)$, para os tubos de concreto reforçados com fibras de aço (TCRF-SF).

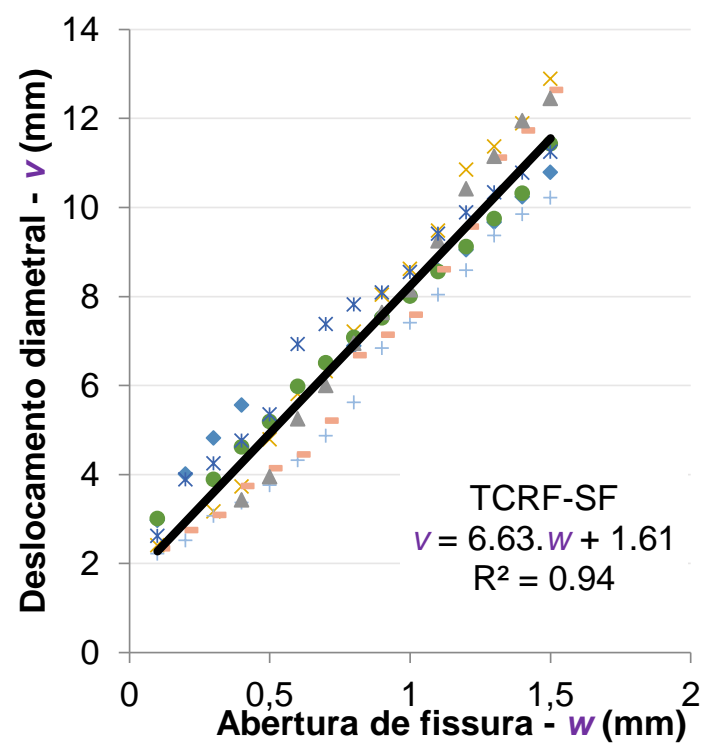

Figura 3.26 - Correlação experimental entre a abertura de fissura $(w)$ e o deslocamento diametral $(v)$ de tubos de concreto com fibras de aço (TCRF-SF).

Na Figura 3.26 verifica-se que os resultados dos sete tubos analisados foram bastante próximos e resultou uma regressão linear com coeficiente de determinação $\left(R^{2}\right)$ igual a 0,94. A Tabela 3.10 apresenta a análise de variância dessa equação de regressão.

Tabela 3.10 - Análise de variância da equação de regressão entre a abertura de fissura (w) e o deslocamento diametral (v) de tubos de concreto reforçados com fibras de aço (TCRF-SF).

\begin{tabular}{ccccccc}
\hline $\begin{array}{c}\text { Fontes de } \\
\text { variação }\end{array}$ & GL & $\begin{array}{c}\text { Soma de } \\
\text { quadrados }\end{array}$ & $\begin{array}{c}\text { Quadrado } \\
\text { médio }\end{array}$ & Estatística F & Valor $\boldsymbol{P}$ & Significativo \\
\hline Regressão & 1 & 768,678 & 768,678 & 1489,15 & 0,000 & Sim \\
$\begin{array}{c}\text { Abertura de } \\
\text { fissura }\end{array}$ & 1 & 768,678 & 768,678 & 1489,15 & 0,000 & Sim \\
$\quad$ Erro & 95 & 49,038 & 0,516 & & & \\
$\quad$ Total & 96 & 817,716 & & & & \\
\hline
\end{tabular}

Compreende-se da Tabela 3.10 resultados significativos na análise de variância da equação de regressão e da variável abertura de fissura $(w)$. O coeficiente de determinação $R^{2}$ igual a 0,94 (indicado no gráfico da Figura 3.26) e o coeficiente de determinação para a predição de novos dados $\left(R_{\text {pred }}^{2}\right)$ igual a 0,94 (calculado pelo software Minitab( $)$. A Tabela 3.11 apresenta o teste de significância para os parâmetros da regressão. 
Tabela 3.11 - Teste de significância dos parâmetros da equação de regressão entre a abertura de fissura (w) e o deslocamento diametral ( $v$ ) de tubos de concreto reforçados com fibras de aço (TCRF-SF).

\begin{tabular}{ccccccc}
\hline Termos & Coeficiente & $\begin{array}{c}\text { Desvio } \\
\text { padrão }\end{array}$ & $\begin{array}{c}\text { Estatística } \\
\text { t-student }\end{array}$ & Valor $\boldsymbol{P}$ & VIF $^{*}$ & Significativo \\
\hline Intercepto & 1,613 & 0,161 & 10,01 & 0,000 & Sim \\
$\begin{array}{c}\text { Coeficiente } \\
\text { angular }\end{array}$ & 6,626 & 0,172 & 38,59 & 0,000 & 1,000 & Sim \\
\hline
\end{tabular}

*Valores de VIF próximos ao valor 1 indicam coeficientes de regressão bem estimados.

$\mathrm{Na}$ Tabela 3.11 verifica-se que ambos os parâmetros da equação de regressão, intercepto ou constante $(\alpha)$ e o coeficiente angular $(\beta)$ são significativos.

Na Figura 3.27 apresenta o gráfico de dispersão das medidas experimentais de abertura de fissura $(w)$ e deslocamento diametral $(v)$, para os tubos de concreto reforçados com fibras de polipropileno (TCRF-PF).

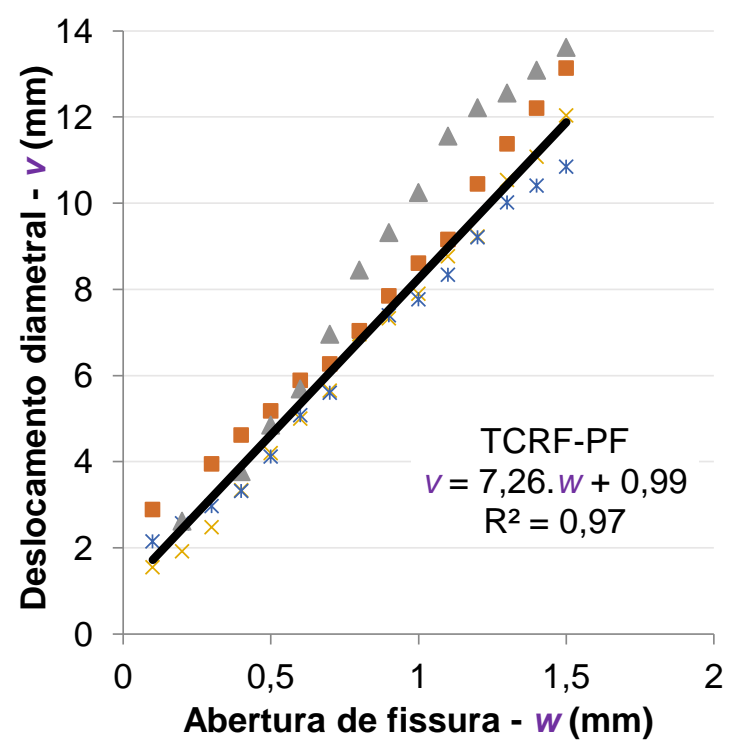

Figura 3.27 - Correlação experimental entre a abertura de fissura $(w)$ e o deslocamento diametral $(v)$ de tubos de concreto com fibras de polipropileno (TCRF-PF).

Percebe-se na Figura 3.27 que os resultados medidos para quatro tubos analisados foram bastante próximos e resultou uma regressão linear com coeficiente de determinação $\left(R^{2}\right)$ igual a 0,97 . Na Tabela 3.12 verifica-se a significância dessa equação de regressão e da variável preditora (deslocamento diametral). 
Tabela 3.12 - Análise de variância da equação de regressão entre a abertura de fissura (w) e o deslocamento diametral (v) de tubos de concreto reforçados com fibras de polipropileno (TCRF-PF).

\begin{tabular}{ccccccc}
\hline $\begin{array}{c}\text { Fontes de } \\
\text { variação }\end{array}$ & GL & $\begin{array}{c}\text { Soma de } \\
\text { quadrados }\end{array}$ & $\begin{array}{c}\text { Quadrado } \\
\text { médio }\end{array}$ & Estatística $\boldsymbol{F}$ & Valor $\boldsymbol{P}$ & Significativo \\
\hline Regressão & 1 & 423,308 & 423,308 & 1311,94 & 0,000 & Sim \\
$\begin{array}{c}\text { Abertura de } \\
\text { fissura }\end{array}$ & 1 & 423,308 & 423,308 & 1311,94 & 0,000 & Sim \\
$\quad$ Erro & 42 & 13,552 & 0,323 & & & \\
Total & 43 & 436,859 & & & & \\
\hline
\end{tabular}

Verifica-se na Tabela 3.12 que a equação de regressão e a variável abertura de fissura são significativas. Além do valor de $R^{2}$ foi calculado também o valor do $\mathrm{R}_{\text {pred }}^{2}$, para a predição de dados futuros, igual a 0,97. A Tabela 3.13 mostra o teste de significância para os parâmetros da regressão.

Tabela 3.13 - Teste de significância dos parâmetros da equação de regressão entre a abertura de fissura $(w)$ e o deslocamento diametral $(v)$ de tubos de concreto reforçados com fibras de polipropileno (TCRF-PF).

\begin{tabular}{ccccccc}
\hline Termos & Coeficiente & $\begin{array}{c}\text { Desvio } \\
\text { padrão }\end{array}$ & $\begin{array}{c}\text { Estatística } \\
\text { t-student }\end{array}$ & Valor $\boldsymbol{P}$ & VIF $^{*}$ & Significativo \\
\hline $\begin{array}{c}\text { Intercepto } \\
\begin{array}{c}\text { Coeficiente } \\
\text { angular }\end{array}\end{array}$ & 0,990 & 0,184 & 5,37 & 0,000 & Sim \\
\hline
\end{tabular}

* Valores de VIF próximos ao valor 1 indicam coeficientes de regressão bem estimados.

Os coeficientes da regressão foram significativos (Tabela 3.13), indicando que foram bem estimados a partir dos resultados experimentais obtidos. Essas equações de regressão podem ser aplicadas para a predição de valores para as aberturas de fissura correspondentes aos deslocamentos diametrais correspondente ao estado limite de serviço $\left(d_{E L S}\right)$ e ao estado limite de último $\left(d_{E L U}\right)$. Considerando valores de $d_{E L S}$ igual a $2,4 \mathrm{~mm}(0,4 \%)$ e $d_{E L U}$ igual a $12 \mathrm{~mm}(2 \%)$, as aberturas de fissura preditas para os TCA, TCRF-SF e TCRF-PF são as apresentadas na Tabela 3.14 .

Observa-se na Tabela 3.14 que os valores preditos para a abertura de fissura correspondente ao $d_{E L S}$ foram inferiores a $0,21 \mathrm{~mm}$. Para os tubos reforçados com fibra de aço o valor estimado foi ligeiramente inferior, mas encontra-se no intervalo de confiança dos valores preditos para os tubos com os outros tipos de reforço. Ainda considerando os intervalos de confiança percebe-se que compreendem valores de abertura de fissura válidos para o ELS. Para $0 d_{E L U}$ as aberturas de fissura obtidas foram de aproximadamente $1,5 \mathrm{~mm}$ e muito próximas para os diferentes reforços 
utilizados. Isso mostra que a relação entre o deslocamento diametral e a abertura de fissura dos tubos foi independente do tipo de reforço utilizado, como indica a Figura 3.28 .

Tabela 3.14 - Aplicação das equações de regressão para a predição da abertura de fissura (w) para os deslocamentos diametrais $d_{E L S}$ e $d_{E L U}$ em tubos de concreto com diferentes reforços.

\begin{tabular}{ccccc}
\hline $\begin{array}{c}\text { Tipo de } \\
\text { reforço }\end{array}$ & $\begin{array}{c}\text { Variável } \\
\text { preditora }\end{array}$ & $\begin{array}{c}\text { Valor predito } \mathbf{w} \\
(\mathbf{m m})\end{array}$ & $\begin{array}{c}\text { Desvio padrão } \\
(\mathbf{m m})\end{array}$ & IC $\mathbf{9 0 \%}$ \\
\hline Tela & & 0,21 & 0,03 & $(0,17 ; 0,26)$ \\
SF & $d_{E L S}=2,4 \mathrm{~mm}$ & 0,16 & 0,02 & $(0,13 ; 0,20)$ \\
PF & & 0,21 & 0,02 & $(0,18 ; 0,25)$ \\
Tela & & 1,53 & 0,03 & $(1,47 ; 1,59)$ \\
SF & $d_{E L U}=12 \mathrm{~mm}$ & 1,52 & 0,02 & $(1,49 ; 1,56)$ \\
PF & & 1,49 & 0,02 & $(1,46 ; 1,53)$ \\
\hline
\end{tabular}

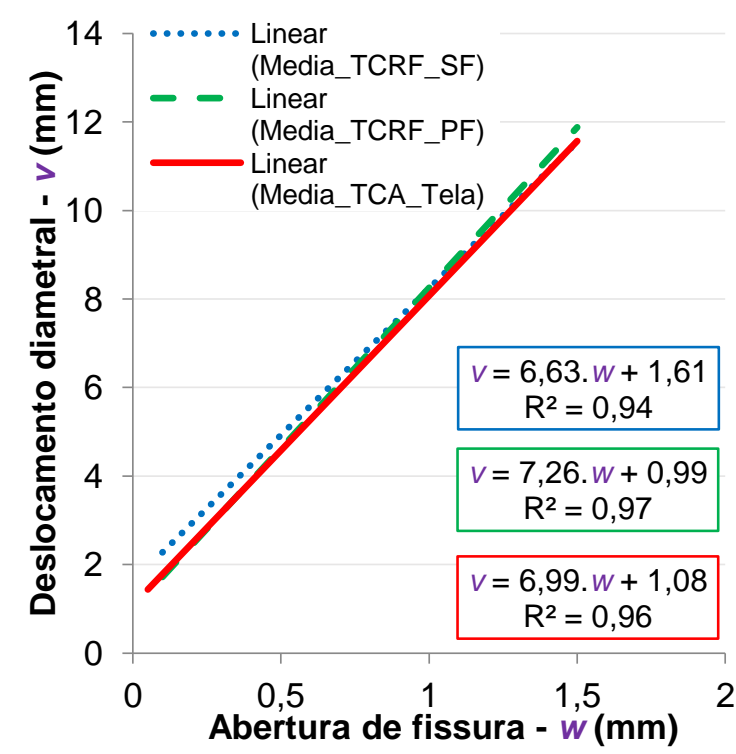

Figura 3.28 - Correlação experimental entre a abertura de fissura $(w)$ e o deslocamento diametral $(v)$ de tubos de concreto com diferentes reforços.

Observa-se na Figura 3.28 que de modo geral a relação entre a abertura de fissura e o deslocamento diametral dos tubos não foi influenciada pelo tipo de reforço empregado. Dessa forma, o tipo de reforço terá influência na capacidade resistente correspondente a cada abertura de fissura ou deslocamento diametral simplesmente. Isto é válido quando se trabalha com teores de fibras abaixo do volume crítico, uma vez que quando os teores de fibras superarem este valor haverá múltipla fissuração e isto tornará esta previsão inválida. Com isso, a proposição de valores de $d_{E L S}$ e $d_{E L U}$ 
equivalentes para reforço com fibras abaixo do volume crítico ou armadura é algo pertinente e razoável. Deve-se ressaltar que o valor de carga associado ao deslocamento diametral de 2,4 $\mathrm{mm}$ está influenciado pela instabilidade do ensaio realizado utilizando controle de velocidade em sistema aberto, o que confere um grau de incerteza nessa medida.

\section{Dispersão dos resultados de carga de fissura, carga máxima e cargas residuais}

Os resultados dos tubos foram analisados em relação à carga de fissura $\left(F_{c r}\right)$, carga máxima $\left(F_{\max }\right)$ e cargas residuais $\left(F_{w}\right)$ associadas a alguns valores de abertura de fissura $(w)$. A Tabela 3.15 apresenta os valores individuais e médios destas cargas para o tubo de concreto com reforço convencional em tela metálica. Na Tabela 3.16 estão apresentados os valores individuais e médios destas cargas para o tubo de concreto reforçado com fibras de aço e polipropileno.

Tabela 3.15 - Cargas relevantes $(\mathrm{kN} / \mathrm{m})$ obtidas no ensaio de compressão diametral de tubos de concreto com reforço convencional (TCA) em tela metálica.

\begin{tabular}{ccccccc}
\hline & \multicolumn{6}{c}{ TCA-Tela } \\
& $F_{c r}$ & $F_{\text {max }}$ & $F_{0,10}$ & $F_{0,25}$ & $F_{0,50}$ & $F_{1,00}$ \\
\hline & 30,7 & 40,7 & 20 & 21,8 & 27,3 & 35,3 \\
& 32 & 41,3 & 20 & 24 & 30,7 & 35,3 \\
& 25,3 & 44,7 & 21,3 & 23,7 & 29,3 & 38,7 \\
\hline Média & 29,3 & 42,2 & 20,4 & 23,2 & 29,1 & 36,4 \\
CV & $12 \%$ & $5 \%$ & $4 \%$ & $5 \%$ & $6 \%$ & $5 \%$ \\
\hline
\end{tabular}


Tabela 3.16 - Cargas relevantes $(\mathrm{kN} / \mathrm{m})$ obtidas no ensaio de compressão diametral dos TCRF de aço (SF) e polipropileno (PF).

\begin{tabular}{ccccccccccccc}
\hline & \multicolumn{1}{c}{ TCRF-SF10 } & \multicolumn{7}{c}{ TCRF-PF2,3 } \\
& $\boldsymbol{F}_{c r}$ & $\boldsymbol{F}_{\max }$ & $\boldsymbol{F}_{0,10}$ & $\boldsymbol{F}_{0,25}$ & $\boldsymbol{F}_{0,50}$ & $\boldsymbol{F}_{1,00}$ & $\boldsymbol{F}_{c r}$ & $\boldsymbol{F}_{\max }$ & $\boldsymbol{F}_{0,10}$ & $\boldsymbol{F}_{0,25}$ & $\boldsymbol{F}_{0,50}$ & $\boldsymbol{F}_{1,00}$ \\
\hline & 24 & 32 & 21 & 17 & 7 & 6 & 29 & 32 & 29 & 24 & 11 & 8 \\
& 30 & 36 & 23 & 11 & 10 & 7 & 27 & 33 & 29 & 22 & 9 & 7 \\
& 27 & 32 & 21 & 9 & 8 & 7 & 29 & 31 & 27 & 22 & 9 & 7 \\
\hline Média & 27 & 33 & 22 & 12 & 8 & 6 & 28 & 32 & 28 & 23 & 10 & 7 \\
CV & $11 \%$ & $7 \%$ & $4 \%$ & $34 \%$ & $16 \%$ & $6 \%$ & $4 \%$ & $3 \%$ & $5 \%$ & $5 \%$ & $11 \%$ & $9 \%$ \\
\hline & & & TCRF-SF20 & & & & & TCRF-PF4,6 & & \\
& $F_{c r}$ & $F_{\max }$ & $F_{0,10}$ & $\boldsymbol{F}_{0,25}$ & $\boldsymbol{F}_{0,50}$ & $\boldsymbol{F}_{1,00}$ & $\boldsymbol{F}_{c r}$ & $\boldsymbol{F}_{\max }$ & $\boldsymbol{F}_{0,10}$ & $\boldsymbol{F}_{0,25}$ & $\boldsymbol{F}_{0,50}$ & $\boldsymbol{F}_{1,00}$ \\
\hline & 26 & 37 & 30 & 20 & 13 & 11 & 27 & 31 & 24 & 13 & 11 & 11 \\
& 31 & 37 & 30 & 25 & 16 & 13 & 28 & 32 & 27 & 24 & 14 & 12 \\
& 31 & 36 & 26 & 24 & 15 & 12 & - & - & - & - & - & - \\
& 29 & 36 & 19 & 17 & 15 & 13 & - & - & - & - & - & - \\
& 32 & 31 & 23 & 23 & 13 & 11 & - & - & - & - & - & - \\
\hline Média & 30 & 36 & 26 & 22 & 15 & 12 & 28 & 32 & 25 & 18 & 13 & 11 \\
CV & $8 \%$ & $7 \%$ & $18 \%$ & $16 \%$ & $8 \%$ & $10 \%$ & $2 \%$ & $2 \%$ & $7 \%$ & $44 \%$ & $15 \%$ & $8 \%$ \\
\hline
\end{tabular}

Os resultados apresentados na Tabela 3.15 mostram que a dispersão da carga máxima e cargas residuais foram pequenas, com coeficiente de variação inferior a $6 \%$. A maior dispersão foi obtida para a carga de fissura ( $C V=12 \%)$, pois foi utilizado um critério visual para sua determinação.

Comparando a carga de fissura obtida nos tubos com reforço convencional (Tabela 3.15) e os tubos com reforço de fibras (Tabela 3.16) a diferença não é significativa considerando nível de significância $(p)$ igual a 0,05 (análise de variância indica valor $\mathrm{p}$ igual a 0,764$)$. No que se refere à carga máxima $\left(F_{\max }\right)$ ela é significativamente maior para o reforço convencional (valor $\mathrm{p}$ igual a 0,000 ). Contudo, esse valor de $\left(F_{\max }\right)$ é atingido para uma grande abertura de fissura ( $w \cong 1,5 \mathrm{~mm}$ ). Comparando os resultados dos diferentes reforços com fibra (Tabela 3.16) percebe-se que a carga de fissura $\left(F_{c r}\right)$ não apresenta diferença significativa para os tipos e consumos de fibra utilizados (análise de variância indica valor $p$ igual a 0,752 para o tipo de fibra e 0,320 para o consumo de fibra). Isto se deve à contribuição das fibras ocorrer após a fissuração da matriz e a carga de fissura ser influenciada pela resistência à tração do concreto e sua magnitude. Os resultados da carga máxima $\left(F_{\text {max }}\right)$ também não apresenta diferença significativa entre os tipos e consumos de fibra (análise de variância indica valor $p$ igual a 0,059 para o tipo de fibra e 0,390 para o consumo de fibra), indicando que a resistência à tração dos concretos é muito similar. No que se refere às cargas residuais, determinadas para aberturas de fissura de 0,1 
$\mathrm{mm}, 0,25 \mathrm{~mm}, 0,5 \mathrm{~mm}$ e $1 \mathrm{~mm}$, as diferenças não foram significativas para nenhuma delas em relação ao consumo de fibras (análise de variância indica valores $p$ respectivamente iguais a 0,$145 ; 0,258 ; 0,803$ e 0,844$)$. Isto se deve à equivalência de desempenho obtida com o uso do dobro do volume da fibra de polipropileno em relação à fibra de aço, similar ao obtido por Figueiredo et al. (2012c). Com respeito ao consumo de fibra as diferenças não foram significativas para as aberturas de fissuras de $0,1 \mathrm{~mm}$ e $0,25 \mathrm{~mm}$ e significativas para $0,5 \mathrm{~mm}$ e $1 \mathrm{~mm}$ (análise de variância indica valores $p$ respectivamente iguais a 0,$547 ; 0,187 ; 0,000$ e 0,000$)$. Isto se deve as aberturas de fissuras menores estarem associadas à região de instabilidade do ensaio, entre 2 e $4 \mathrm{~mm}$ de deslocamento diametral.

\section{Comparacão das curvas médias com relação a classificação da norma}

$\mathrm{Na}$ Figura 3.29a apresentam-se as curvas médias de carga $(\mathrm{kN})$ por deslocamento diametral $(\mathrm{mm})$ para os tubos com diferentes reforços, incluindo os limites de carga mínima de fissura e carga máxima pós-fissuração para a classe de tubo utilizada (PA1-600 mm). Na Figura 3.29b apresentam-se as curvas médias de carga $(\mathrm{kN})$ por deslocamento diametral específico (\%) para os tubos com diferentes reforços, incluindo os critérios propostos por Figueiredo et al. (2012a) para a definição das cargas residuais no estado limite de serviço $\left(F_{E L S}\right)$ e estado limite último $\left(F_{E L U}\right)$.

No que se refere à classificação da norma ABNT NBR 8890 (2007) para os tubos de concreto PA1 de 600 mm, percebe-se na Figura 3.29a e o requisito de carga de fissura $\left(F_{c r}\right)$ de $24 \mathrm{kN} / \mathrm{m}$ foi atendido para todos os tipos de reforço. Já para a carga máxima pós-fissuração, o requisito de $36 \mathrm{kN} / \mathrm{m}$ foi atendido apenas para o reforço convencional com tela metálica. Porém, esse valor de carga foi atingido para um deslocamento diametral de $8 \mathrm{~mm}$, correspondendo a uma abertura de fissura $w \cong 1$ $\mathrm{mm}$. Esse nível de abertura de fissura é muito alto, considerando as condições de durabilidade da armadura, sendo em muito superior ao estabelecido pela ABNT NBR 6118 (2014) que é de 0,3 mm. Considerando o nível máximo de abertura de fissura indicado na ABNT NBR 6118 (2014) as cargas dos tubos com os diferentes reforços são mais próximas. 


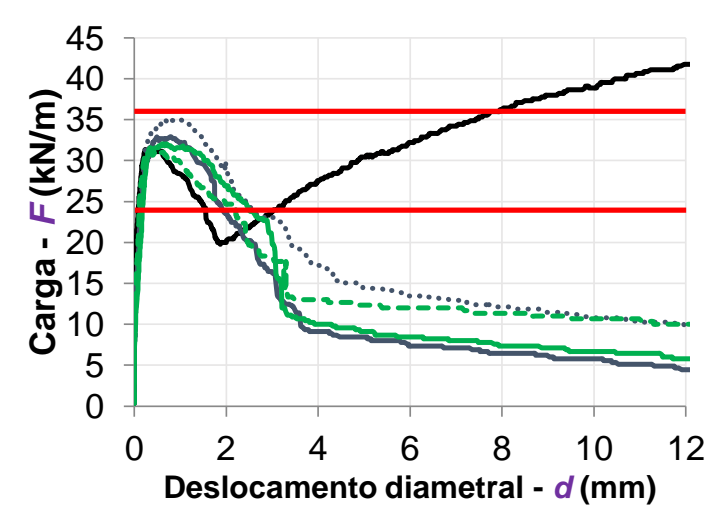

(a)

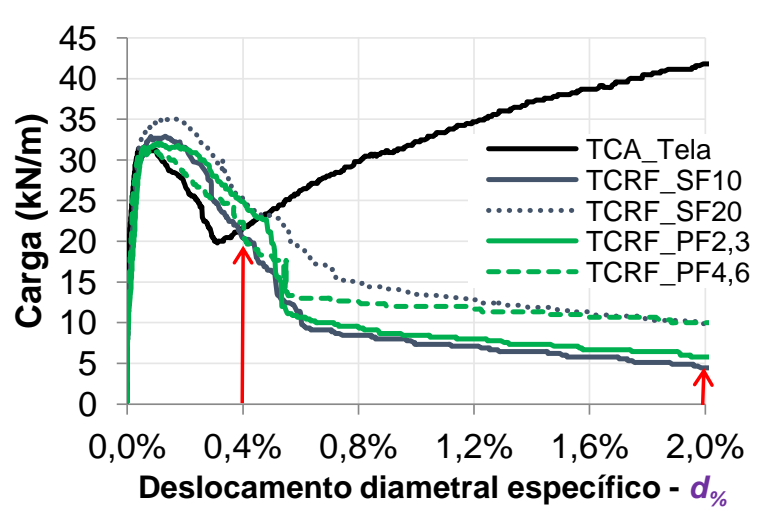

(b)

Figura 3.29 - Curvas médias do ensaio de compressão diametral dos tubos com diferentes reforços: a) F-d, com requisitos da NBR 8890 para um tubo PA1-600; b) $F-d_{\%}$, com deslocamentos associados ao ELS e ELU.

Considerando os níveis de descolamento diametral pós-fissuração propostos por Figueiredo et al (2012a) para os tubos em condições de serviço $d_{E L S}=0,4 \%$ e últimas $d_{E L U}=2 \%$, e indicados na Figura $3.29 \mathrm{~b}$, os valores de cargas residuais foram obtidos. A Tabela 3.17 apresenta os valores médios das cargas residuais correspondentes ao estado limite de serviço $\left(F_{E L S}\right)$ e estado limite último $\left(F_{E L U}\right)$ para os tubos com diferentes reforços.

Tabela 3.17 - Resultados das cargas residuais no estado limite de serviço $\left(F_{E L S}\right)$ e estado limite último $\left(F_{E L U}\right)$ dos tubos de concreto com diferentes reforços.

\begin{tabular}{ccccccc}
\hline \multirow{2}{*}{$\begin{array}{c}\text { Tipo de } \\
\text { reforço }\end{array}$} & \multicolumn{3}{c}{$\boldsymbol{F}_{E L S}(\mathbf{k N} / \mathbf{m})$} & \multicolumn{3}{c}{$\boldsymbol{F}_{E L U}(\mathbf{k N} / \mathbf{m})$} \\
\cline { 2 - 7 } & Média & Desvio padrão & $\boldsymbol{C V}$ & Média & Desvio padrão & $\boldsymbol{C V}$ \\
\hline Tela & 22 & 1 & $3 \%$ & 42 & 2 & $5 \%$ \\
SF-10 & 20 & 2 & $11 \%$ & 4,4 & 0,4 & $9 \%$ \\
SF-20 & 25 & 4 & $18 \%$ & 9,7 & 0,9 & $9 \%$ \\
PF-2,3 & 25 & 2 & $9 \%$ & 5,8 & 0,4 & $7 \%$ \\
PF-4,6 & 21 & 6 & $29 \%$ & 10 & 0,9 & $9 \%$ \\
\hline
\end{tabular}

Como pode ser observado na Tabela 3.17 a variabilidade para a determinação das cargas residuais nos componentes é muito menor do que nos ensaios de caracterização em corpos de prova de concreto reforçados com fibras, apresentados no item 2.4.6 do Capítulo 2. Além disso, a dispersão foi superior na determinação das cargas residuais no ELS, devido a maior instabilidade do ensaio nesta região. $O$ deslocamento diametral específico no ELS $(0,4 \%)$ corresponde a aberturas de fissura (w) de aproximadamente $0,2 \mathrm{~mm}$, independente do tipo de reforço, conforme apresentado e discutido na Tabela 3.14. Percebe-se que carga correspondente a 
essas aberturas de fissura são muito próximas, sendo consideradas estatisticamente iguais considerando nível de significância $(p)$ igual a 0,05 (não rejeito hipótese de igualdade com valor $p=0,853$ ). Salienta-se que os teores de fibras empregados foram baixos e ainda assim os tubos alcançaram, para a condição de serviço, reforço equivalente àqueles produzidos com tela metálica, sendo superado para aberturas de fissuras superiores a 0,3 $\mathrm{mm}$ (ver Figura 3.29b). Quando analisado a carga residual no ELU o reforço com tela metálica tem desempenho muito superior ao reforço com fibras. Comparando apenas os tubos com fibras, devido a menor dispersão do ensaio nessa região, os resultados são considerados significativamente diferentes para um nível de significância $(p)$ igual a 0,05 (valor $p=0,000$ ) entre os teores de fibra menores (SF10 e PF2,3) e maiores (SF20 e PF4,6). Entre os tipos de fibra, a diferença não foi significativa para um nível de significância ( $p$ ) igual a 0,05 (valor $p=0,092$ ), confirmando que o comportamento é semelhante quando utilizado o dobro do volume de fibra de polipropileno em relação à fibra de aço.

\subsection{Conclusões do capítulo}

Neste Capítulo foram avaliados tubos de concreto reforçados com fibras. Essa avaliação envolveu, além da caracterização física e mecânica do material, o comportamento mecânico dos tubos através do ensaio de compressão diametral. Os procedimentos utilizados para esse ensaio sistematizou avanços propostos pela literatura e incluiu a mensuração do nível de abertura de fissura dos tubos durante a realização do ensaio, correlacionando-a ao deslocamento diametral medido. A partir dos resultados obtidos as seguintes conclusões podem ser destacas:

- A absorção de água e a porosidade total dos concretos reforçado com fibras, utilizados para a produção dos tubos, não foram influenciadas significativamente pela presença das fibras. Porém, a dimensão dos corpos de prova utilizada no ensaio exerceu forte influência, devendo ser respeitado o uso de dimensões dentro de uma faixa restrita de variação para que possam ser comparadas.

- Apesar disso, a moldagem de corpos de prova cilíndricos destinados ao ensaio Barcelona mostrou-se factível e capaz de reproduzir minimamente a condição de compactação do material ao contrario do 
que ocorreu com os corpos de prova prismáticos em pesquisas anteriores.

- Quanto à resistência à compressão dos concretos a incorporação de fibras de polipropileno resulta valores menores de resistência, devido sua menor rigidez. Esse efeito aumenta com o acréscimo no teor, enquanto as fibras de aço não apresentam influencia negativa na faixa de teor avaliado.

- A compressão diametral dos tubos mostrou a eficiência das fibras no reforço dos tubos a baixos níveis de deformação, quando comparadas ao reforço convencional.

- A realização dos ensaios de compressão diametral com carregamento contínuo e utilizando LVDT para medida do deslocamento diametral permitiu uma avaliação mais confiável do reforço, tornando o procedimento de ensaio menos suscetível ao erro operacional.

- O estabelecimento de correlações entre o deslocamento diametral e a abertura de fissura dos tubos identificou que estas independem do tipo de reforço. Com isso foi possível estabelecer requisitos de cargas residuais equivalentes em termos de abertura de fissura para tubos com reforço de armadura convencional ou fibras. Isto resulta uma condição mais justa para as fibras, pois os critérios existentes na normalização vigente limitam-se a verificação de atendimento a uma carga mínima isenta de fissuras, enquanto para os tubos armados aberturas de fissura de até $0,25 \mathrm{~mm}$ são permitidas.

- O estudo também demonstrou ser possível realizar o controle dos tubos em condições mais próximas do que é proposto pelos novos modelos de dimensionamento para as aplicações estruturais do CRF. Nesta situação, controla-se a capacidade resistente máxima do elemento e suas resistências residuais no ELS e ELU, numa abordagem muito próxima ao que é proposto para o controle do CRF em outras aplicações estruturais. Uma limitação observada se refere ao fato da resistência residual associada ao ELS ser influenciada negativamente pela instabilidade do ensaio, o que deve ser alvo de futuros estudos. 


\section{SIMULAÇÃO NUMÉRICA DO COMPORTAMENTO MECÂNICOO DOS TUBOS DE CONCRETO REFORÇADOS COM FIBRAS}

\subsection{Introdução}

Os tubos de concreto simples e os tubos de concreto com armadura convencional são tradicionalmente dimensionados de forma direta através de modelos de cálculo consagrados ou indiretamente através da determinação experimental da capacidade resistente no ensaio de compressão diametral. Esses métodos foram introduzidos no item 3.2 do Capítulo 3, juntamente com a apresentação do ensaio de compressão diametral dos tubos.

No caso dos tubos de concreto reforçados com fibras (TCRF) 0 dimensionamento através de execução de programa experimental baseado na tentativa e erro para a determinação da classe do tubo através do ensaio de compressão diametral se torna antieconômico. Isto porque para os concretos reforçados com fibras (CRF) o comportamento pós-fissuração deve ser analisado para variados tipos e teores de fibra, e sua interação com a matriz pode exercer forte influência na resposta pós-fissuração. Banthia et al. (2012) salienta a importância de uma abordagem sistêmica no uso do CRF em componentes pré-moldados, considerando a sua formulação, a cura, o transporte e os métodos de cálculo apropriados.

Algumas alternativas têm sido propostas para o projeto dos TCRF. Peyvandi, Soroushian e Jahangirnejad (2014) propuseram equações para projeto de tubos de concreto considerando o uso de fibras. Nessas equações as fibras são consideradas como único reforço ou como um reforço híbrido em conjunto com a armadura convencional. A dificuldade de aplicação de tais equações está na determinação das tensões de tração das fibras na região da fissura, que podem ser calculadas considerando a ocorrência predominante de ruptura das fibras ou de seu arrancamento da matriz (pullout). Em ambos os casos a determinação experimental destas tensões não é uma tarefa trivial, pois envolve equipamentos de precisão encontrados geralmente apenas em universidades ou centros de pesquisa. $O$ método proposto por de la Fuente, Aguado e Molins (2011) é uma ferramenta de projeto e verificação dos tubos de concreto com reforço de armadura convencional e/ou fibras estruturais. O modelo reproduz o comportamento dos tubos até a ruptura no ensaio de 
compressão diametral. Esse modelo vem sendo aplicado em diversas campanhas experimentais com resultados satisfatórios mesmo com variações nos tipos de reforços e dimensões de tubos (de la FUENTE et al., 2011; de la FUENTE et al., 2012a; de la FUENTE et al., 2013). A principal limitação está na parametrização do comportamento pós-fissuração do CRF, que vinha sendo realizada através de equações empíricas da literatura (BARROS et al., 2005) ou campanha experimental específicas envolvendo ensaios de flexão de vigas (SALVADOR; FIGUEIREDO, 2013). Quanto à utilização de equações empíricas a principal dificuldade é que estas não podem ser extrapoladas para outros tipos de fibra, devendo restringir seu emprego ao uso da mesma fibra. No caso de campanhas experimentais envolvendo ensaios de flexão de vigas a moldagem desses corpos de prova utilizando o concreto de consistência seca é muito difícil, conforme discutido no Capítulo 2. A utilização de resultados obtidos com concretos plásticos pode ser contestada por apresentar diferentes características de matriz e, consequentemente, uma potencial diferença na interação com as fibras. Portanto, esse método pode ser otimizado se 0 comportamento pós-fissuração do CRF for melhor parametrizado e em condições mais próximas com o material efetivamente empregado nos tubos.

Diante deste cenário, este capítulo apresenta uma revisão do método de projeto dos tubos de concreto proposto por de la Fuente, Aguado e Molins (2011) e um programa experimental que parametriza o comportamento mecânico do CRF através do ensaio Barcelona. Os parâmetros obtidos permitem a simulação do comportamento dos componentes no ensaio de compressão diametral e a comparação com os resultados experimentais dos tubos apresentados no Capítulo 3.

\subsubsection{Objetivo do capítulo}

O objetivo deste capítulo é propor que a parametrização do comportamento mecânico de concretos reforçado com fibras seja realizada através de ensaios Barcelona, para que seja simulado numericamente o comportamento dos tubos de concreto reforçados com fibras no ensaio de compressão diametral. Dessa forma, o ensaio experimental pode ser utilizado apenas na validação final do componente.

\subsubsection{Organização do capítulo}

Primeiramente, o item 4.2 apresenta o modelo numérico para a simulação do comportamento de tubos de concreto no ensaio de compressão diametral. No item 4.3 é apresentado o programa experimental para parametrização do comportamento 
mecânico do CRF e as considerações para a simulação numérica. Os resultados experimentais e numéricos estão apresentados no item 4.4. Os ensaios Barcelona em corpos de prova moldados e testemunhos extraídos dos tubos são apresentados e analisados no item 4.4.1. As simulações numéricas e as comparações com os resultados experimentais de compressão diametral dos tubos estão apresentados e discutidos no item 4.4.2. Após a análise desses resultados as conclusões do capítulo são apresentadas no item 4.5.

\subsection{Modelo numérico para simulação do ensaio de compressão diametral de tubos de concreto}

O modelo de análise não linear para tubos de concreto desenvolvido por de la Fuente, Aguado e Molins (2011), o modelo MAP (Model for the Analysis of Pipes), permite a simulação numérica do ensaio de compressão diametral. Essa ferramenta possibilita estudar:

- A influência de diferentes geometrias de tubo e parâmetros do comportamento mecânico dos materiais;

- Configurações de armadura e classes resistentes não abordadas nas normas técnicas disponíveis;

- A inclusão de fibras estruturais como reforço e quantificar seu desempenho;

- O comportamento de reforços híbridos de armadura convencional e fibras.

Assim, o MAP pode ser utilizado para otimizar o reforço e adequar o projeto do componente às necessidades estruturais de aplicação. Com isso o comportamento estrutural deixa de ser avaliado por tentativa e erro, o que é dispendioso tendo em vista as várias de possibilidades de geometrias de tubo (diâmetro e espessura) e materiais de reforço (tipos e teores de fibra, por exemplo).

As características gerais do ensaio de compressão diametral dos tubos foram introduzidas no item 3.2.1 do Capítulo 3. Porém, o comportamento estrutural dos tubos de concreto quando submetidos a esse ensaio estão mais bem detalhados a seguir. 
4.2.1 Comportamento estrutural do tubo de concreto no ensaio de compressão diametral

No ensaio de compressão diametral o tubo está sujeito a uma força distribuída uniformemente ao longo do seu comprimento útil (Figura 4.1b). O comportamento tubo é analisado para duas seções críticas, onde os esforços solicitantes e deslocamentos são máximos, a seção da coroa/base e a seção dos flancos (Figura 4.1a).
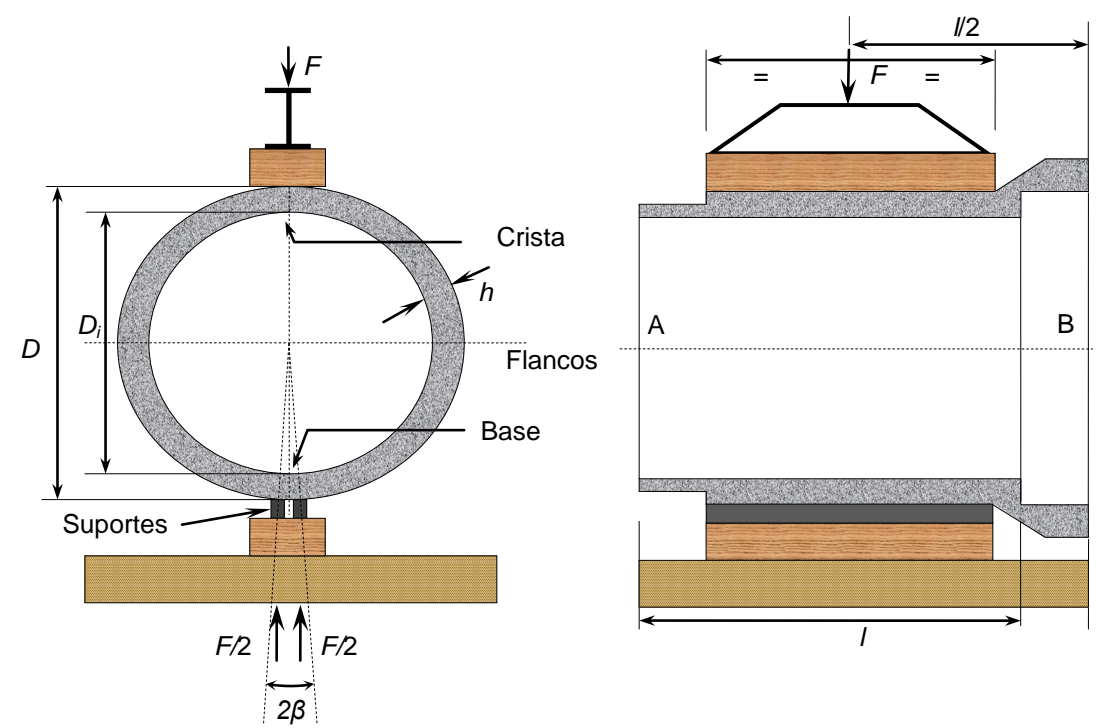

Figura 4.1 - Ensaio de compressão diametral: (a) seção transversal; (b) seção longitudinal. Fonte: Adaptado de de la FUENTE et al. (2010).

O comportamento mecânico do TCRF submetido ao ensaio de compressão diametral depende da sua geometria ( $D i$ e $h$ ), e do tipo e consumo de fibras $\left(C_{f}\right)$ empregadas. A este respeito, as diferentes respostas obtidas nos ensaios conduzidos coincidem com um dos três padrões de comportamento apresentados na Figura 4.2, independentemente do ensaio ser realizado de forma contínua ou cíclica.

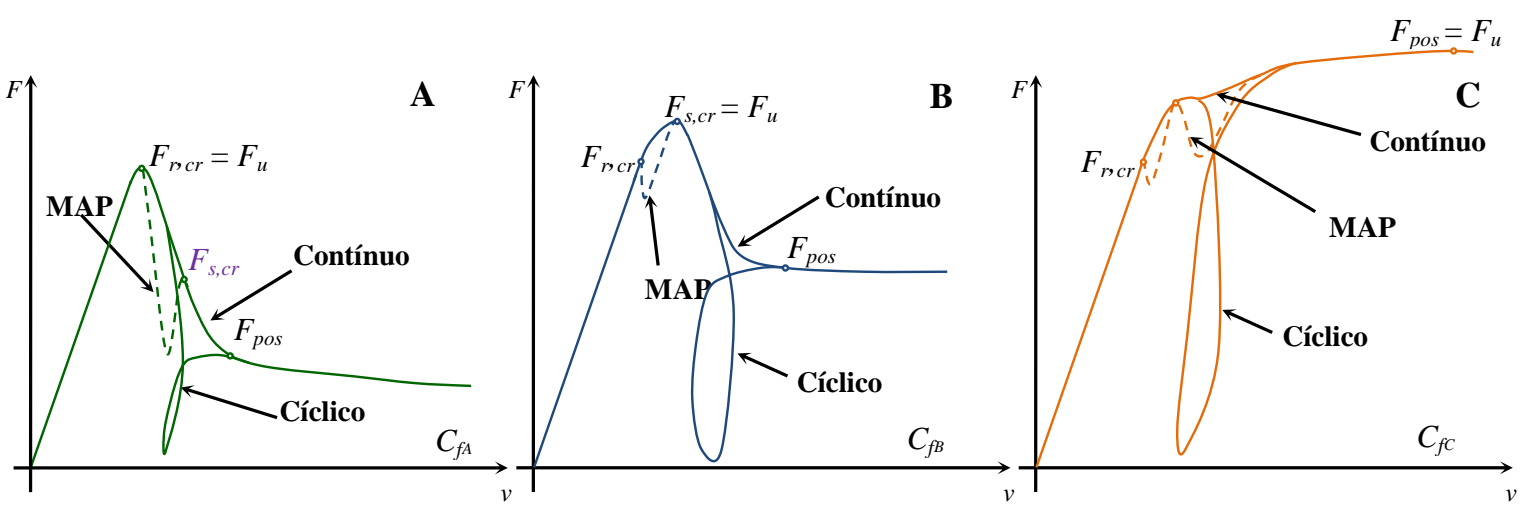

Figura 4.2 - Comportamento esperado do TCRF no ensaio de compressão diametral, considerando o teor de fibras $\left(\mathrm{C}_{\mathrm{f}}\right) \mathrm{C}_{\mathrm{fA}}<\mathrm{C}_{\mathrm{fB}}<\mathrm{C}_{\mathrm{fC}}$. Fonte: de la Fuente et al. (2013). 
O comportamento global de um TCRF pode ser descrito por essas três fases, cada fase governada por um tipo particular de resposta das duas seções críticas do tubo:

- Fase 1 - Comportamento elástico linear em todo o tubo, terminando quando a primeira fissura aparece na parte superior do tubo (topo ou coroa) uma vez que a carga de fissuração $\left(F_{r, c r}\right)$ é alcançada. $O$ valor desta carga depende da geometria do tubo (Di e $h)$ e da resistência à flexão da matriz de concreto $\left(f_{c t, f f}\right)$.

- Fase 2 - Após o aparecimento da primeira fissura na coroa esta começa a trabalhar em regime fissurado, enquanto o resto do tubo se comporta ainda elasticamente. As fibras que costuram a fissura começam a trabalhar gradualmente e, por esta razão, ocorre uma redução e subsequente recuperação da carga. Para um mesmo tubo, quanto menor for teor de fibras maior será a queda da carga no regime pósfissuração e vice-versa. A fase 2 termina com a fissuração da base e dos flancos com a carga $F_{s, c r}$. Assim, se o teor de fibras é baixo em comparação com as dimensões do tubo (caso A), a carga $F_{s, c r}$ não alcançará novamente o mesmo nível de $F_{r, c r}$, sendo que a carga $F_{r, c r}$ é a carga de fissuração e $F_{u}$ a carga última do tubo. Além disso, no caso de quantidades moderadas a altas de fibras, $F_{s, c r}$ pode exceder $F_{r, c r}$ e, portanto, pode ocorrer uma resposta supra crítica (casos B e C).

- Fase 3 - Esta fase corresponde àquela em que o padrão de fissuração do componente já está totalmente estabelecido, com uma fissura na coroa, uma na base e uma em cada flanco. Nesta fase podem ser obtidos dois tipos de comportamento dependendo da quantidade de fibras: amolecimento (casos A e B), quando o teor de fibras é baixo ou moderado, ou endurecimento (caso C) quando o teor de fibras é elevado em relação às dimensões do tubo. Também deve ser notado que na fase 3 pode-se identificar uma carga máxima pós-ruptura

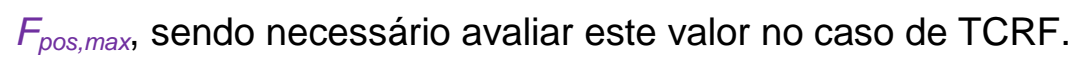

A simulação do ensaio de compressão diametral dos tubos até altos níveis de deslocamento utilizando o modelo MAP inclui como sub-rotina um modelo de análise não linear de seções, que permite múltiplas configurações de reforço (de la FUENTE et al., 2010). O modelo numérico empregado foi desenvolvido por de la Fuente, 
Aguado e Molins (2008), denominado AES (Analysis of Evolutionary Sections), apresentado no item 4.2.2.

\subsubsection{Modelo de análise seccional}

\section{Modelagem dos materiais}

O modelo AES é um modelo numérico implementado com código MATLAB®. $\mathrm{O}$ concreto é discretizado em elementos com área diferencial $\left(d A_{c}\right)$, e a armadura em elementos com área concentrada $\left(A_{s, i}\right)$ no centro de gravidade do elemento $\left(y_{s, i}\right)$. Com a seção discretizada (Figura 4.3a), um modelo constitutivo adequado para cada material deve ser adotado, como representado na Figura 4.3b.

(a)

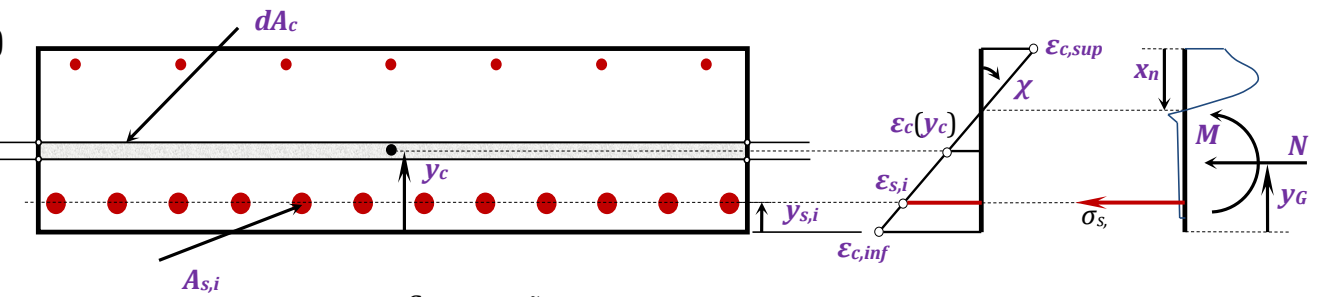

(b)

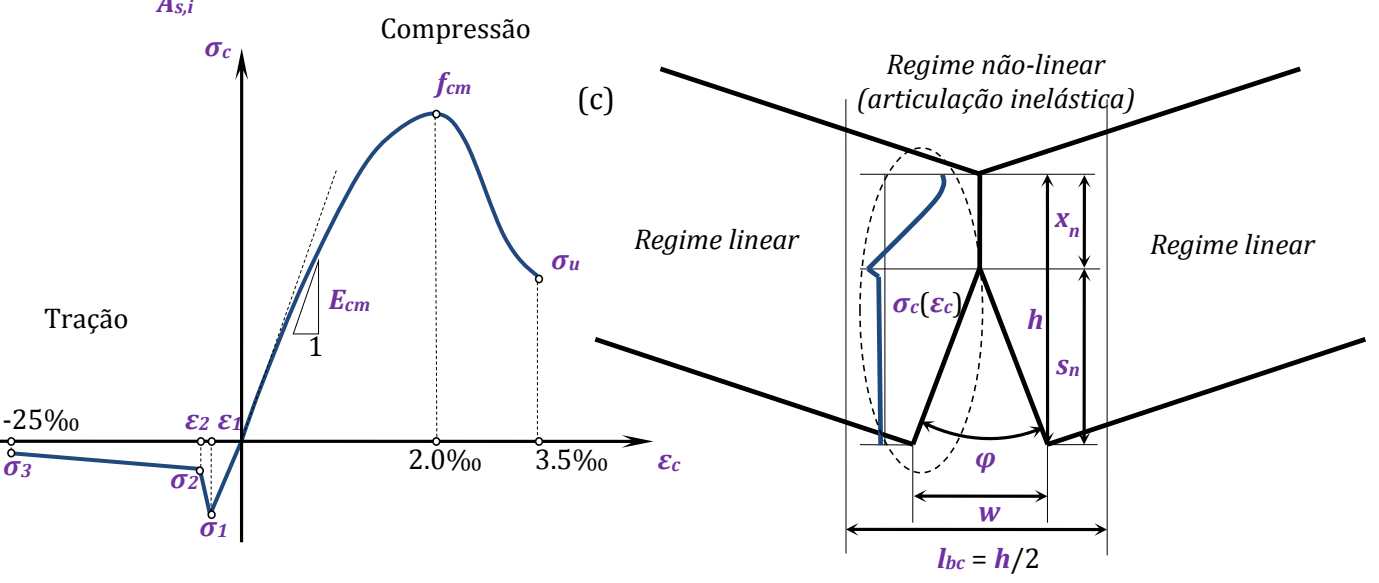

Figura 4.3 - a) discretização da seção; b) modelo constitutivo para o CRF; c) esquema de corpo rígido articulado para avaliar a abertura de fissura $(w)$. Fonte: Adaptado de de la FUENTE et al. (2012a).

Para a simulação do comportamento à compressão do concreto armado convencionalmente, de la Fuente, Aguado e Molins (2011) sugerem a utilização do diagrama proposto por Thorenfeldt, Tomaszewicz e Jensen (1987). Isto porque os autores salientam que tal diagrama permite ajustar adequadamente uma faixa ampla de resistências para o concreto e simular adequadamente sua resposta pósfissuração. Já para o comportamento à tração e enrijecimento entre as fissuras a equação proposta por Collins e Mitchell (1987) foi indicada. 
Barros e Figueiras (1999) apresentam um modelo constitutivo para o CRF na compressão. Para o comportamento à tração do CRF diversos modelos constitutivos podem ser implementados, como as equações propostas por Laranjeira, Aguado e Molins (2008), pelo RILEM TC 162-TDF (VANDEVALLE et al. 2003) ou através do fib Model Code 2010 (FIB, 2013). A Figura 4.3b ilustra os modelos constitutivos propostos por Barros e Figueiras (1999) e Vandewalle et al. (2003).

A abertura de fissura (w) é calculada considerando que a seção rotacional como um corpo rígido, como representado na Figura 4.3c, formando o ângulo $\varphi$ entre as faces da fissura. Esse cálculo baseia-se na proposta de Pedersen (1995), que considera o comprimento da rótula $I_{b c}=h / 2$ e depende da curvatura da seção $\chi$, através da Eq. 4-1.

$$
w=s_{n} \tan \varphi=s_{n} \tan \left(l_{c b} \chi\right)
$$

\section{Hipóteses básicas}

Para a modelização a nível seccional, de la Fuente, Aguado e Molins (2011) assumem as seguintes hipóteses:

- As seções apresentam um eixo de simetria e estão submetidas a estados de flexo-compressão reta;

- A aderência perfeita entre os materiais que compõem a seção;

- As seções inicialmente planas permanecem planas após as cargas e deformações impostas;

- As deformações de esforço cortante são desprezíveis e, portanto não consideradas;

- Os efeitos da curvatura do elemento sobre a distribuição de tensões e deformações dos materiais que constituem a seção são desprezados.

\section{Equacões de equilíbrio e compatibilidade}

O estado de tensões e deformações resultantes da combinação de cargas externas (força normal $N$ e momento à flexão $M$ ) é definido através da distribuição de tensões nos materiais que constituem a seção, do plano de deformações formado na camada mais inferior da seção de concreto (Figura 4.3a) e a curvatura seccional $\left(\varepsilon_{c, \text { inf, }}\right.$ $\chi$ ). Esse estado é obtido através da aplicação de equações de balanço interno (Eq. 4-2 
e Eq. 4-3) e estabelecendo hipóteses de aderência perfeita entre o concreto e o reforço (Eq. 4-4) (de la FUENTE et al., 2012a).

$$
\begin{gathered}
N=\int \sigma_{c}\left(\varepsilon_{c}\right) d A_{c}+\sum_{i=0}^{n_{s}} \sigma_{s, i}\left(\varepsilon_{s, i}\right) A_{s, i} \\
M=\int \sigma_{c}\left(\varepsilon_{c}\right)\left(y_{c}-y_{G}\right) d A_{c}+\sum_{i=0}^{n_{s}} \sigma_{s, i}\left(\varepsilon_{s, i}\right)\left(y_{s, i}-y_{G}\right) A_{s, i} \\
\varepsilon(y)=\varepsilon_{c, i n f}+\chi \cdot y
\end{gathered}
$$

Essas equações formam um sistema de equações não linear resolvido através do método de interação de Newton-Raphson, determinando os parâmetros que definem o plano de deformação $\left(\varepsilon_{c, \text { inf, }} \chi\right)$.

Conforme apresentado anteriormente o modelo de análises seccional (AES) foi utilizado como sub-rotina para o modelo de análise estrutural dos tubos de concreto que será apresentado na sequência.

\subsubsection{Modelo de análise estrutural}

Para simular o comportamento mecânico dos TCRFs no ensaio de compressão diametral foi adotado, para esta tese, o modelo MAP proposto por de la Fuente, Aguado e Molins (2011). Este consiste em um modelo de dano progressivo similar ao apresentado por Pedersen (1995) e, posteriormente, Amorim, Proença e Florez-Lopez (2014), cujo resultado foi satisfatoriamente verificado para tubos reforçados com fibras de aço em de la Fuente et al. (2012a) e para tubos reforçados com fibras de polipropileno em de la Fuente et al. (2013). As hipóteses adotadas no modelo estão detalhadas em de la Fuente, Aguado e Molins (2011) e de la Fuente et al. (2012a), mas um resumo de suas principais características está apresentado a seguir.

Especificamente, o modelo MAP simula o comportamento do tubo submetido às condições de contorno impostas pelo ensaio de compressão diametral, considerando que na seção de coroa/base $(R)$ e nos flancos $(S)$ concentram-se os fenômenos não-lineares (Figura 4.4), enquanto o restante do tubo se comporta linearmente (PEDERSEN, 1995). Em síntese, consiste em um modelo de análise nãolinear de rótulas que permite identificar as seguintes fases:

- Comportamento elástico linear global (Figura 4.4a) até que se alcança a carga de fissuração na coroa $F_{c, c r}$. 
- Comportamento linear com fissuração na coroa (Figura 4.4b). Ao se detectar a primeira fissura, se produz uma perda de rigidez ativando à primeira rótula plástica $(R)$, enquanto o resto do tubo responde de forma elástica. Esta fase se prolonga até alcançar a carga de fissuração nas seções dos flancos $\left(F_{s, c r}\right)$, em que aparecem a segunda e última rótula plástica $(S)$.

- Comportamento totalmente fissurado (Figura 4.4c). A resposta está governada por ambas as rótulas plásticas, que estão conectas por um segmento de circunferência que se comporta de forma elástica.

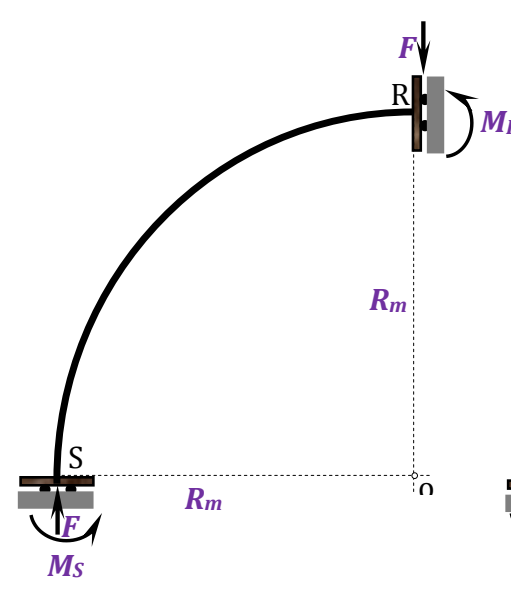

(a)

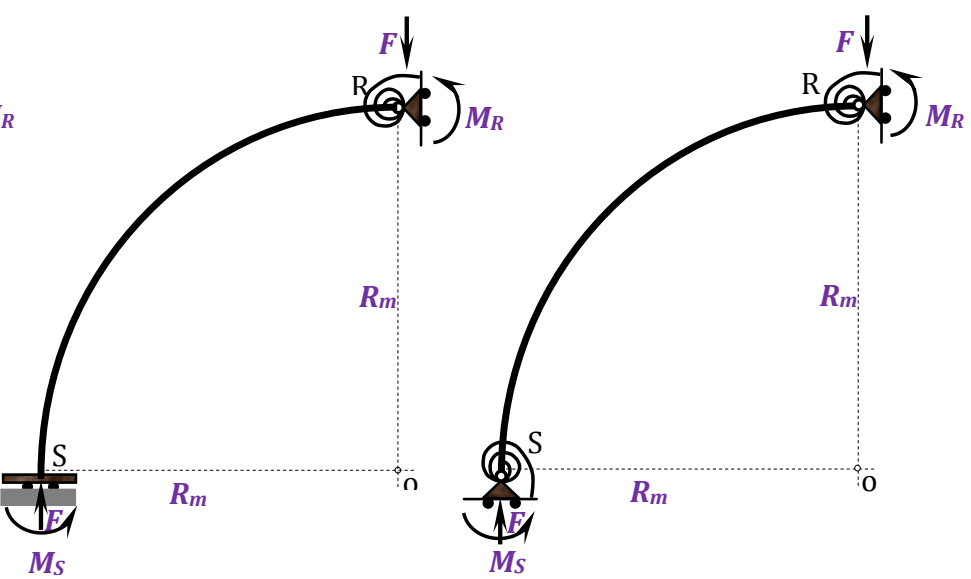

(b) (c)

Figura 4.4 - Esquema do comportamento do tubo em: a) regime linear; b) regime linear com fissuração em $R$; c) regime linear com fissuração em $R$ e em $S$. Fonte: de la Fuente (2011).

A simulação da resposta mecânica das rótulas plásticas se aborda com o modelo AES, apresentado no item anterior. Através dele discretizam-se as rótulas $R \mathrm{e}$ $S$ em elementos tipo área $(d A c)$ e obtém-se o comportamento tensão-deformação (Figura 4.3a), solucionando as equações de equilíbrio (Eq. 4-2 e Eq. 4-3) e compatibilidade (Eq. 4-4).

No modelo AES foram implementadas as equações constitutivas propostas nas normas europeias para reproduzir o comportamento à tração do CRF (BLANCO, et al., 2010). Nos estudos de la Fuente et al. (2012a, 2013) foram utilizados o modelo constitutivo proposto por Vandewalle, et al. (2003) para simular a resposta à tração do CRF, que considera o ensaio de flexão de vigas. Conforme comentado no item 4.1 deste Capítulo e anteriormente no Capítulo 2, o ensaio de flexão de vigas não é adequado para caracterizar o concreto de produção dos tubos, devido sua consistência seca dificultar a moldagem de corpos de prova prismáticos. Por isso, o estudo realizado no Capítulo 2 propõe como ensaio alternativo o puncionamento de 
cilindros ou ensaio Barcelona, procedimento adotado nesta tese para a aplicação do modelo numérico.

Diante disso, um programa experimental foi desenvolvido para caracterizar o comportamento pós-fissuração dos CRFs, utilizados na produção de tubos, através do ensaio Barcelona. Esses resultados foram utilizados como parâmetros para a simulação numérica do comportamento dos tubos no ensaio de compressão diametral.

\subsection{Programa experimental e simulação numérica}

No Capítulo 3 foi avaliado o comportamento de tubos de concreto reforçados com fibras no ensaio de compressão diametral e estabelecidas correlações entre o deslocamento diametral e a abertura de fissura na região crítica do tubo. O Capítulo 2 identificou que o ensaio Barcelona pode ser utilizado como alternativa para a caracterização do comportamento mecânico do CRF utilizado na produção dos tubos, utilizando corpos de prova cilíndricos ou extração de testemunhos.

Neste capítulo foi apresentado um modelo de simulação numérica do ensaio de compressão diametral de tubos de concreto. Esse método prescinde da caracterização do comportamento pós-fissuração do concreto reforçado com fibras, até o momento com a utilização de ensaios de flexão. Por isso, um programa experimental foi desenvolvido com o objetivo de caracterizar o comportamento mecânico dos concretos utilizados na produção dos tubos e extrair parâmetros para simular o comportamento desses tubos no ensaio de compressão diametral. Para essa caracterização foram empregados os concretos produzidos para a moldagem dos tubos avaliados no Capítulo 3. A caracterização foi realizada através do ensaio Barcelona em corpos de prova moldados e em testemunhos extraídos dos tubos previamente ensaiados. A partir desses resultados, parâmetros do comportamento à tração do CRF foram determinados e utilizados no modelo de simulação numérica do ensaio de compressão diametral dos tubos. Os resultados da simulação foram comparados com os experimentais apresentados no Capítulo 3. As comparações foram feitas em relação ao comportamento geral das curvas de carga versus deslocamento diametral, erros relativos para alguns valores de carga relevantes, e para as correlações entre o deslocamento vertical e a abertura de fissura. 


\subsubsection{Produção dos concretos}

Os concretos reforçados com fibras utilizados neste programa experimental foram amostrados durante a produção dos tubos apresentados no item 3.3.1 do Capítulo 3. Após a mistura, o concreto é transportado por esteira até o equipamento de produção dos tubos. A coleta do concreto foi realizada na saída dessa esteira utilizando e transportado até o local da fábrica onde são realizadas as moldagens de corpos de prova.

\subsubsection{Moldagem de corpos de prova e extração de testemunhos}

A moldagem dos corpos de prova foi realizada seguindo o procedimento apresentado no item 3.3.2 do Capítulo 3. Ao todo foram moldados cinco corpos de prova cilíndricos de $\Phi 150 \times 300 \mathrm{~mm}$, sendo dois para caracterização da absorção de água, índice de vazios e resistência à compressão (resultados apresentados e discutidos no Capítulo 3) e três para o ensaio Barcelona. Conforme apresentado no Capítulo 2 o ensaio Barcelona é realizado em corpos de prova de relação altura/diâmetro igual a um. Por isso, os corpos de prova foram cortados ao meio, resultando seis peças de aproximadamente $\Phi 150 \times 150 \mathrm{~mm}$. Considerando que a consistência do concreto é bastante seca, necessitando empregar forte energia para seu adensamento, não é esperado que ocorra segregação durante a moldagem. Assim, acredita-se que o resultado do ensaio não deve ser influenciado significativamente se o corpo de prova corresponde à fatia inferior ou superior do corpo de prova original.

Os ensaios Barcelona também foram realizados em testemunhos extraídos dos tubos. Essas extrações foram realizadas após os ensaios de compressão diametral dos tubos, seguindo o procedimento apresentado no item 3.3.4 do Capítulo 3. Para cada composição de tubo foram extraídos doze testemunhos. Desses, seis foram utilizados para caracterização da absorção de água e índice de vazios (resultados apresentados e discutidos no Capítulo 3) e os outros seis para o ensaio Barcelona. As dimensões dos testemunhos foram influenciadas pela espessura da parede dos tubos e diâmetros de serras copo diamantadas disponíveis. A espessura da parede limitou a altura do testemunho a aproximadamente $62 \mathrm{~mm}$. Já os diâmetros poderiam ser de 50 $\mathrm{mm}$ ou $75 \mathrm{~mm}$, o que resultaria relações altura/diâmetro menores ou maiores que o indicado para o ensaio. Optou-se pelo diâmetro maior para maximizar o volume da amostra e proporcionar melhor representatividade do comportamento do material. 
Assim, a dimensão do testemunho utilizado para o ensaio Barcelona foi de aproximadamente $\Phi 75 \times 62 \mathrm{~mm}$.

\subsubsection{Ensaio Barcelona}

A configuração original do ensaio Barcelona normalizado através da AENOR UNE 83815 (2010) foi apresentada no item 2.2.1. A possibilidade de simplificação do procedimento do ensaio através da medida do deslocamento vertical da máquina de ensaio foi discutida no item 2.2.2, tendo sido o procedimento de ensaio adotado neste estudo.

O puncionamento foi feito através de discos de carga, produzidos em aço inoxidável, cujas dimensões dependem do diâmetro e altura do corpo de prova utilizado. A Tabela 4.1 ilustra as dimensões nominais dos corpos de prova/testemunhos e respectivas dimensões utilizadas para os discos de carga.

Tabela 4.1 - Dimensões dos discos de carga dos corpos de prova e testemunhos utilizados nos ensaios Barcelona.

\begin{tabular}{ccc}
\hline Tipo & $\begin{array}{c}\text { Dimensões dos discos de carga }(\mathbf{m m}) \\
\text { Diâmetro }-\boldsymbol{a}\end{array}$ & Altura $-\boldsymbol{h}$ \\
\hline $\begin{array}{c}\text { Corpos de prova: } \\
\text { Diâmetro }-d \cong 150 \mathrm{~mm} \\
\text { Altura }-H \cong 150 \mathrm{~mm}\end{array}$ & 37,5 & 30 \\
\hline $\begin{array}{c}\text { Testemunhos: } \\
\text { Diâmetro }-d \cong 75 \mathrm{~mm} \\
\text { Altura }-H \cong 62 \mathrm{~mm}\end{array}$ & 18,75 & 12,4 \\
\hline
\end{tabular}

Antes do ensaio, todos os corpos de prova e testemunhos foram medidos com uso de paquímetro. A velocidade de deslocamento da máquina de ensaio foi de 0,5 $\mathrm{mm} / \mathrm{min}$ para todos os ensaios. Os ensaios Barcelona estão ilustrados na Figura 4.5a, para os corpos de prova e na Figura 4.5b, para os testemunhos. Finalizados os ensaios, o número de fissuras (Figura 4.5c) resultantes em cada corpo de prova ou testemunho foi anotado.

As curvas de carga versus deslocamento vertical obtidas nos ensaios Barcelona realizados nos corpos de prova moldados e nos testemunhos extraídos dos tubos estão apresentados e analisados no item 4.4.1. 


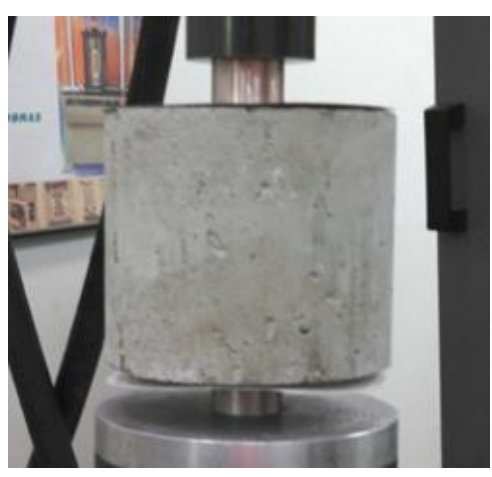

(a)

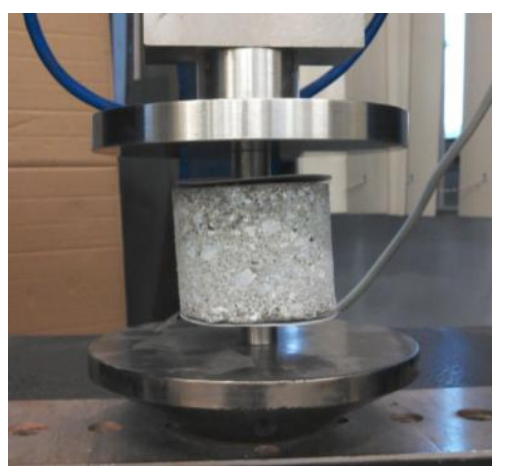

(b)

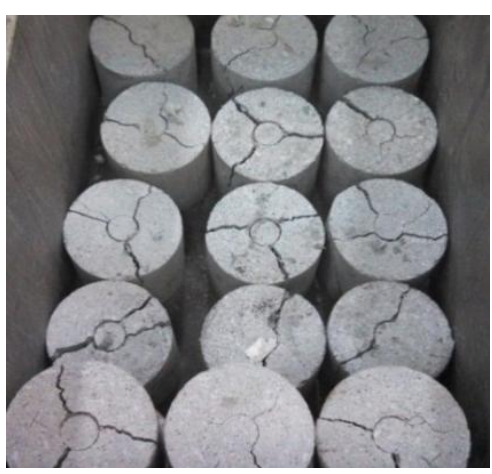

(c)

Figura 4.5 - a) Ensaio Barcelona em corpos de prova moldados; b) Ensaio Barcelona em testemunhos extraídos dos tubos; c) corpos de prova após o término do ensaio.

\subsubsection{Simulação numérica}

Para a simulação numérica da compressão diametral dos tubos foi adotado o modelo MAP (Model for the Analysis of Pipes) desenvolvido por de la Fuente, Aguado e Molins (2011) e apresentado no item 4.2.3. Esse modelo tem como sub-rotina um modelo de análise seccional, apresentado no item 4.2.2, no qual são introduzidos os parâmetros do comportamento à compressão e à tração dos concretos reforçados com fibras. A parametrização do concreto reforçado com fibras na compressão tem sido realizada a partir da equação constitutiva proposta por Barros e Figueiras (1999), sendo mantida nesta tese. Quanto ao comportamento à tração, a parametrização adotando modelos constitutivos baseados em ensaios de flexão foi substituída por um modelo constitutivo simplificado baseado no ensaio Barcelona. Isto permitiu que os parâmetros pudessem ser obtidos através de corpos de prova moldados a partir dos concretos utilizados na produção dos tubos ou por meio de testemunhos extraídos dos tubos.

O modelo constitutivo tensão-deformação baseado no ensaio Barcelona e proposto por Blanco (2013) foi introduzido no item 2.2.5 do Capítulo 2, e está representado na Figura 4.6a. Esse modelo é multilinear e para aproximá-lo ao modelo proposto pela RILEM TC 162-TDF (VANDEVALLE et al. 2003) que encontra-se implementado no modelo de análise seccional (AES) foi proposta uma simplificação para um modelo trilinear, como mostra a Figura 4.6b. 


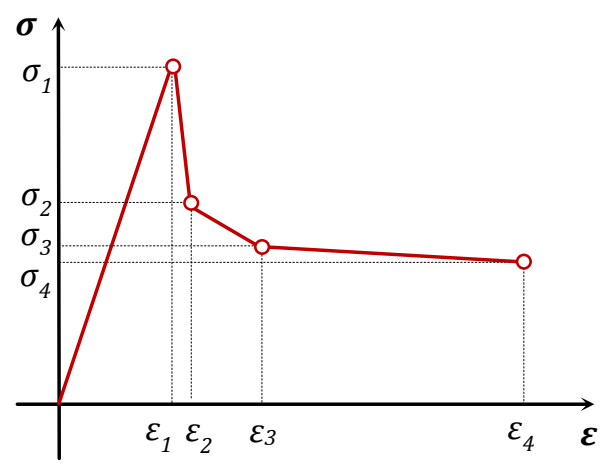

(a)

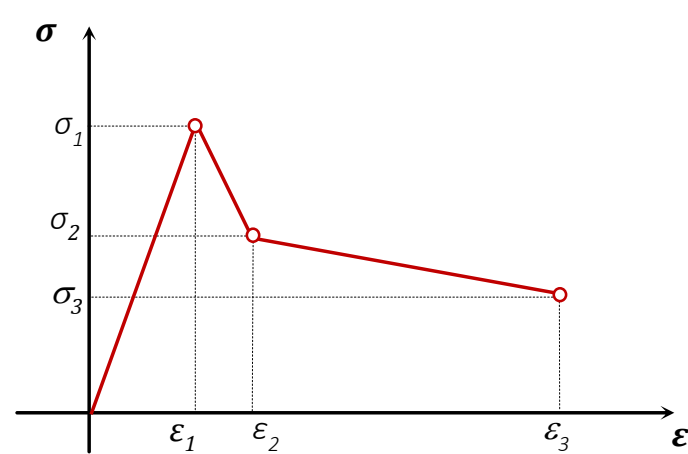

(b)

Figura 4.6 - a) Diagrama multilinear $\sigma-\varepsilon$. Fonte: Blanco (2013); b) Diagrama trilinear $\sigma-\varepsilon$ simplificado.

O modelo constitutivo proposto por Blanco (2013) apresenta formato multilinear para melhor ajustá-lo à simulação numérica do ensaio Barcelona, como mostra a Figura 4.7a para um concreto reforçado com $40 \mathrm{~kg} / \mathrm{m}^{3}$ de fibra de aço.

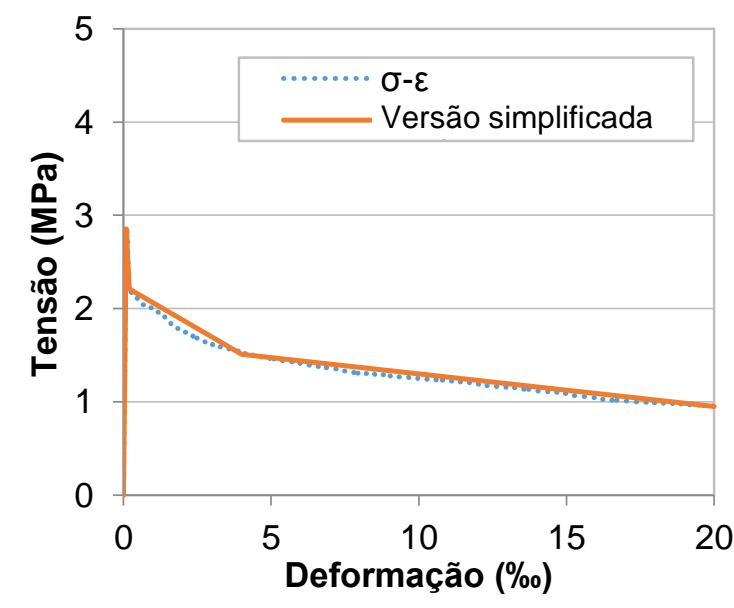

(a)

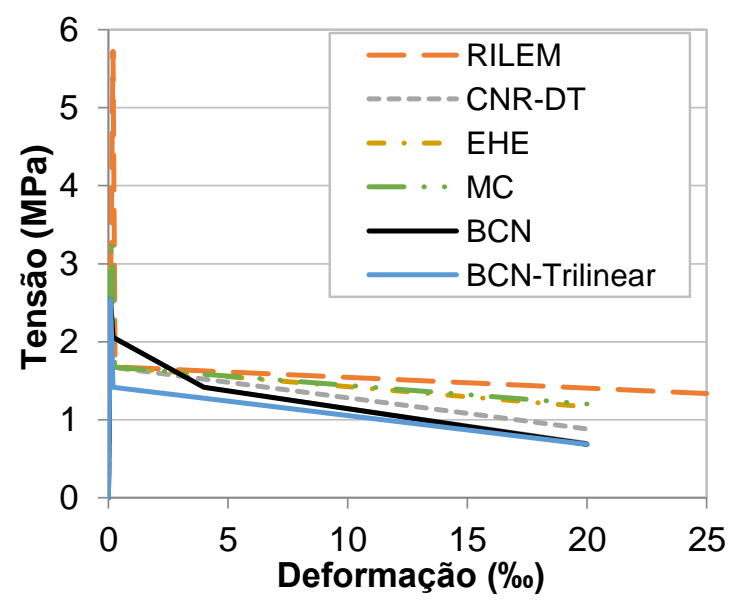

(b)

Figura 4.7 - a) Comparação entre o diagrama $\sigma-\varepsilon$ completo e o multilinear; b) Comparação da formulação baseada no ensaio Barcelona, multilinear e trilinear, com modelos constitutivos baseados em flexão de prismas. Fonte: Adaptado de Blanco et al. (2014).

Quando comparados aos modelos constitutivos de flexão de prismas, apresentado na Figura $4.7 \mathrm{~b}$ para $30 \mathrm{~kg} / \mathrm{m}^{3}$ de fibra de aço, percebe-se que a utilização do modelo multilinear ou trilinear mantém a inclinação mais acentuada que a maioria dos outros modelos constitutivos. Esse comportamento pode ser atribuído ao parâmetro coeficiente de atrito cinético que ainda necessita ser apropriadamente estudado. Percebe-se também que a adoção do modelo trilinear é mais conservadora, 
principalmente na região associada à condição de serviço, além de permitir comparação mais fácil com outros modelos constitutivos.

As equações que compõem o diagrama tensão-deformação baseado no ensaio Barcelona foram apresentadas no item 2.2.5 do Capítulo 2, mas encontram-se sintetizadas na Tabela 4.2.

Tabela 4.2 - Parâmetros para construção do diagrama $\sigma-\varepsilon$ simplificado a partir do ensaio de Barcelona.

\begin{tabular}{ccc}
\hline Deformação (\%) & Corpos de prova & Tensão (MPa) \\
\hline$\varepsilon_{1}=\frac{\sigma_{1}}{E_{c m}}$ & $\sigma_{1}=\frac{4 \times F_{P, \max }}{9 \times \pi \times a \times H}$ & $\sigma_{1}=\frac{4 \times F_{P, \max }}{9 \times \pi \times a \times H}$ \\
$\varepsilon_{2}=\varepsilon_{1}+0,1$ & $\sigma_{2}=\frac{F_{P, 0,02 \mathrm{~mm}}}{2 \cdot \pi \cdot A} \cdot \frac{\cos \beta-\mu_{k} \cdot \sin \beta}{\sin \beta+\mu_{k} \cdot \cos \beta}$ & $\sigma_{2}=\frac{F_{P, 0,01 \mathrm{~mm}}}{2 \cdot \pi \cdot A} \cdot \frac{\cos \beta-\mu_{k} \cdot \sin \beta}{\sin \beta+\mu_{k} \cdot \cos \beta}$ \\
$\varepsilon_{3}=20$ & $\sigma_{3}=\frac{F_{P, 4 \mathrm{~mm}}}{2 \cdot \pi \cdot A} \cdot \frac{\cos \beta-\mu_{k} \cdot \sin \beta}{\sin \beta+\mu_{k} \cdot \cos \beta}$ & $\sigma_{3}=\frac{F_{P, 2,4 \mathrm{~mm}}}{2 \cdot \pi \cdot A} \cdot \frac{\cos \beta-\mu_{k} \cdot \sin \beta}{\sin \beta+\mu_{k} \cdot \cos \beta}$ \\
\hline
\end{tabular}

Para o cálculo da tensão máxima $\left(\sigma_{1}\right)$ a preferência pela equação baseada no modelo de bielas e tirantes (MOLINS; AGUADO; SALUDES, 2009) em detrimento à equação proposta por Blanco (2013) deve-se a esta última necessitar do valor do coeficiente de atrito cinético $\left(\mu_{k}\right)$. Segundo Blanco (2013) os resultados obtidos através dessas duas equações são muito próximos, mas preferiu-se utilizar a primeira para evitar ter que estimar um valor ao coeficiente de atrito no momento da formação da cunha. No caso das tensões residuais, estas foram calculadas a partir dos valores médios das cargas residuais para deslocamentos verticais de 0,02 $\mathrm{mm}$ e $4 \mathrm{~mm}$ para os corpos de prova, e 0,01 $\mathrm{mm}$ e $2,4 \mathrm{~mm}$ para os testemunhos extraídos. Estes valores de deslocamentos verticais foram calculados através da Eq. 2-13 do Capítulo 2 , em função das dimensões dos corpos de prova/testemunhos. O valor adotado para o coeficiente de atrito cinético $\left(\mu_{k}\right)$ em ambos os casos foi de 0,7 , conforme indicado por Blanco et al., (2014). 


\subsection{Resultados e análises}

\subsubsection{Ensaios Barcelona}

\section{Corpos de prova moldados}

A Figura 4.8 apresenta as curvas de carga de puncionamento $\left(F_{p}\right)$ por deslocamento vertical $\left(\delta_{p}\right)$ no ensaio Barcelona para cada um dos seis corpos de prova moldados com os CRFs de aço (SF) e de polipropileno (PF).

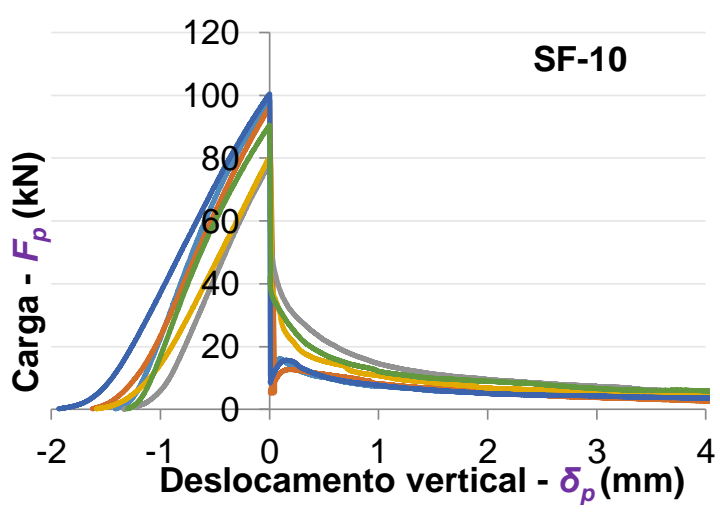

(a)

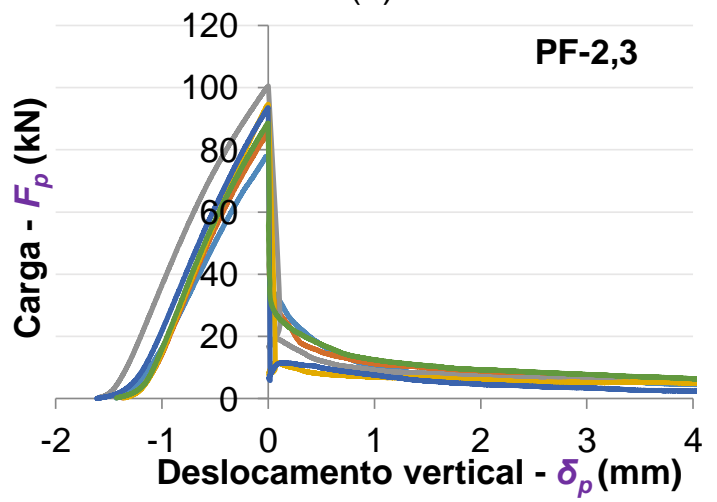

(c)

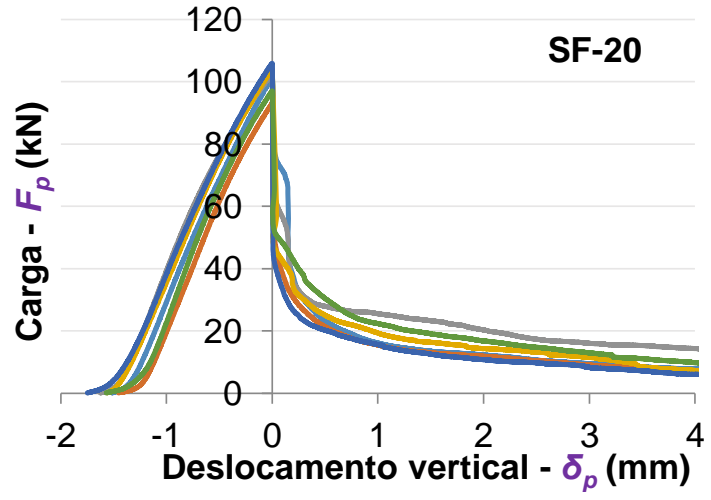

(b)

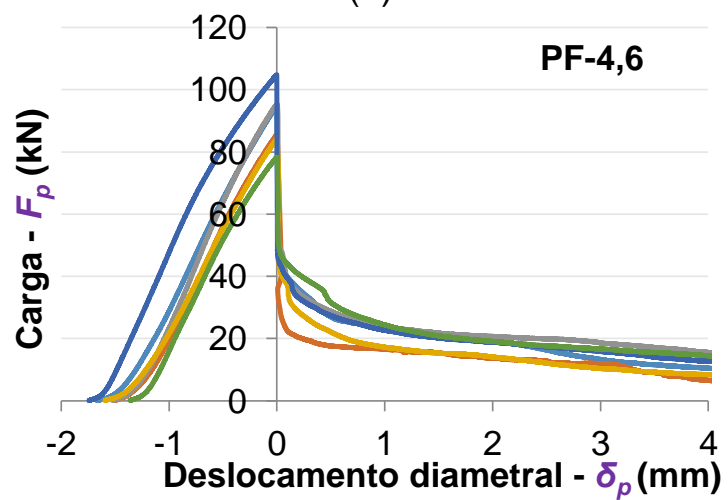

(d)

Figura 4.8 - Curvas de carga de puncionamento $\left(F_{p}\right)$ em função do deslocamento vertical $\left(\delta_{p}\right)$ para os ensaios Barcelona dos corpos de prova moldados.

Observa-se na Figura 4.8 que as curvas são semelhantes entre os teores de 10 $\mathrm{kg} / \mathrm{m}^{3}$ de SF e $2,3 \mathrm{~kg} / \mathrm{m}^{3}$ de PF e entre os teores de $20 \mathrm{~kg} / \mathrm{m}^{3}$ de SF e $4,6 \mathrm{~kg} / \mathrm{m}^{3}$ de PF. Esses teores correspondem ao dobro do volume de fibras de polipropileno em relação às fibras de aço. Os tubos para esses teores de fibra também apresentaram comportamento semelhante, conforme demonstrado na Figura 3.24a do Capítulo 3. As cargas máximas de puncionamento $\left(F_{p, \max }\right)$, e cargas residuais $F_{p, 0,02 \mathrm{~mm}}$ e $F_{p, 4 \mathrm{~mm}}$ estão apresentadas na Tabela 4.3, acompanhadas dos respectivos coeficientes de variação. 
Tabela 4.3 - Resultados médios de cargas de puncionamento máximas e residuais para os corpos de prova moldados no ensaio Barcelona.

\begin{tabular}{ccccc}
\hline Tipo de reforço & $\begin{array}{c}\text { Teor de fibras } \\
\left(\mathbf{k g} / \mathbf{m}^{3}\right)\end{array}$ & \multicolumn{3}{c}{ Cargas de puncionamento (kN) } \\
& 10 & $\boldsymbol{F}_{p, \max }(\mathbf{C V})$ & $\boldsymbol{F}_{p, 0,02 \mathrm{~mm}}(\mathbf{C V})$ & $\boldsymbol{F}_{p, 4 \mathrm{~mm}}(\mathbf{C V})$ \\
\hline \multirow{2}{*}{$\mathrm{SF}$} & 20 & $96,4(4 \%)$ & $31,1(33 \%)$ & $5,4(11 \%)$ \\
& 2,3 & $90,6(5 \%)$ & $47,6(20 \%)$ & $8,8(35 \%)$ \\
\multirow{2}{*}{ PF } & 4,6 & $90,5(6 \%)$ & $29,0(24 \%)$ & $5,3(13 \%)$ \\
& & & $42,3(8 \%)$ & $13,4(16 \%)$ \\
\hline
\end{tabular}

Percebe-se na Tabela 4.3 que a dispersão foi menor para as cargas máximas quando comparadas à maioria das cargas residuais. Isto também foi observado para os resultados dos corpos de prova apresentados no Capítulo 2, que foram moldados em ambiente controlado de laboratório e utilizando concreto de consistência plástica. Para avaliar se as diferenças entre as cargas foram significativas entre os tipos e teores de fibras foram realizados testes de análises de variância. A Tabela 4.4 mostra uma síntese dos resultados obtidos, analisados a um nível de significância (p) igual a 0,05 .

Tabela 4.4 - Resultados de análises de variância de cargas relevantes do ensaio Barcelona dos corpos de prova moldados.

\begin{tabular}{ccccc}
\hline & & $\boldsymbol{F}_{p, \max }$ & $\boldsymbol{F}_{p, 0,02 \mathrm{~mm}}$ & $\boldsymbol{F}_{p, 4 \mathrm{~mm}}$ \\
\hline \multirow{2}{*}{ Tipo de fibra } & Valor $\mathrm{p}$ & 0,021 & 0,353 & 0,042 \\
& Significativo & Sim & Não & Sim \\
\multirow{2}{*}{ Teor de fibra } & Valor $\mathrm{p}$ & 0,774 & 0,002 & 0,000 \\
& Significativo & Não & Sim & Sim \\
\hline
\end{tabular}

$\mathrm{Na}$ Tabela 4.4 percebe-se que a diferença entre as cargas máximas $\left(F_{p, \text { max }}\right)$ da fibra de aço e polipropileno foi significativa, sendo maior para a fibra de aço. Quanto ao acréscimo no teor de fibra, a variação na carga máxima $\left(F_{p, \max }\right)$ não foi significativa, para ambas as fibras avaliadas. Esse resultado também foi obtido para a resistência à compressão, como mostrado na Tabela 3.6. Isso mostra mais uma vez a sinergia entre os resultados do ensaio Barcelona e compressão em termos de carga máxima, como foi discutido no Capítulo 2. Para as resistências residuais, a única diferença não significativa foi entre as resistências residuais $F_{p 0,02 m m}$ entre a fibra de aço e de polipropileno. Era esperado que para a resistência residual $F_{p 4 m m}$ a diferença entre as fibras de aço e polipropileno também não fosse significativa, pois as curvas mostravam comportamento semelhante entre elas (Figura 4.8). Porém, a fibra de polipropileno 
apresentou, para o teor de $4,6 \mathrm{~kg} / \mathrm{m}^{3}$, resistência residual significativamente superior em comparação ao teor de $20 \mathrm{~kg} / \mathrm{m}^{3}$ da fibra de aço.

\section{Testemunhos extraídos dos tubos}

Para os testemunhos extraídos dos tubos as curvas de carga de puncionamento $\left(F_{p}\right)$ por deslocamento vertical $\left(\delta_{p}\right)$ dos ensaios Barcelona estão apresentadas na Figura 4.9.

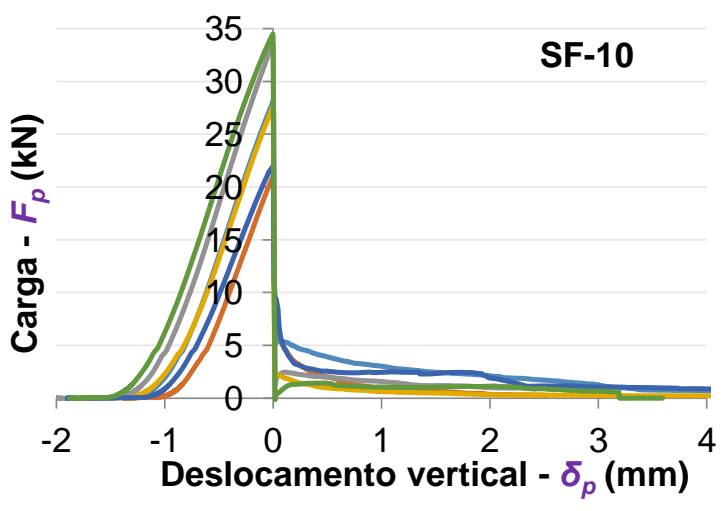

(a)

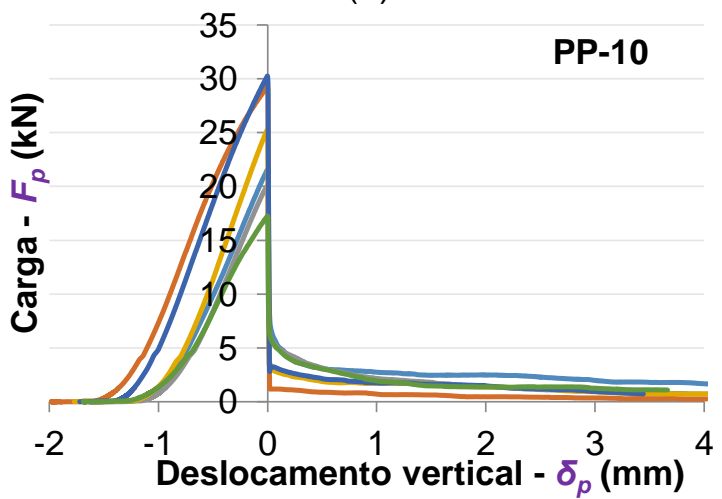

(c)

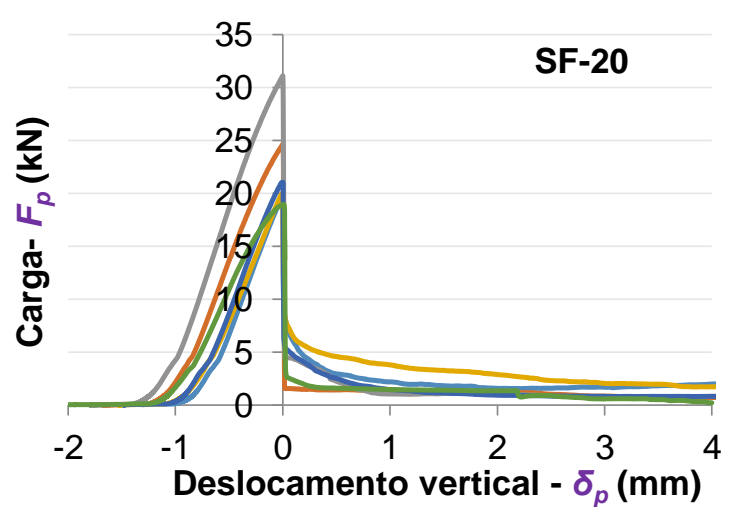

(b)

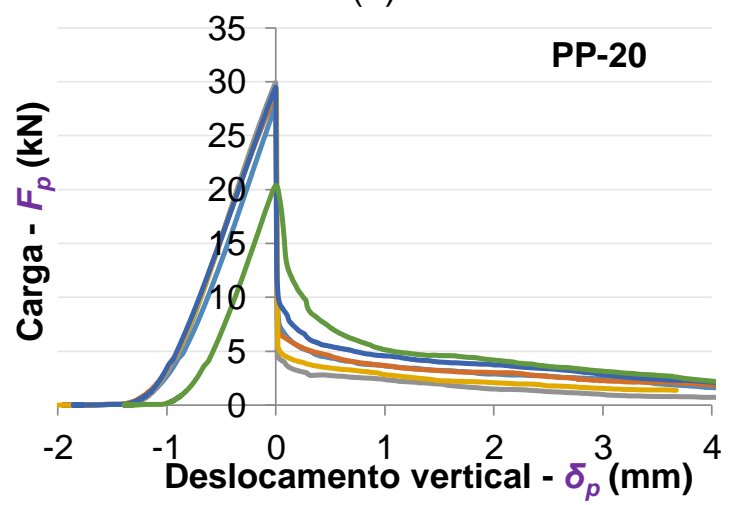

(d)

Figura 4.9 - Curvas de carga de puncionamento $\left(F_{p}\right)$ em função do deslocamento vertical $\left(\delta_{p}\right)$ para os ensaios Barcelona dos testemunhos extraídos dos tubos.

Verifica-se na Figura 4.9 que, no caso dos testemunhos extraídos, as curvas apresentaram dispersão muito mais acentuada para a carga máxima obtida no ensaio $\left(F_{p, \text { max }}\right)$. Quando ao comportamento residual percebe-se curvas semelhantes entre os teores de $10 \mathrm{~kg} / \mathrm{m}^{3}$ de SF e $2,3 \mathrm{~kg} / \mathrm{m}^{3}$ de PF. Já para os teores de $20 \mathrm{~kg} / \mathrm{m}^{3}$ de SF e $4,6 \mathrm{~kg} / \mathrm{m}^{3}$ de PF observa-se comportamento residual maior para a fibra de polipropileno. Os resultados das cargas máximas de puncionamento $\left(F_{p, \max }\right)$, e cargas residuais $F_{p, 0,01 \mathrm{~mm}}$ e $F_{p, 2,4 \mathrm{~mm}}$ estão apresentadas na Tabela 4.5 , juntamente com os respectivos coeficientes de variação. 
Tabela 4.5 - Resultados médios de cargas de puncionamento máximas e residuais para os testemunhos extraídos no ensaio Barcelona.

\begin{tabular}{ccccc}
\hline Tipo de fibra & $\begin{array}{c}\text { Teor de fibras } \\
\left(\mathbf{k g} / \mathbf{m}^{3}\right)\end{array}$ & \multicolumn{3}{c}{ Cargas de puncionamento (kN) } \\
& 10 & $27,8(20 \%)$ & $3,7(50 \%)$ & $0,9(61 \%)$ \\
SF & 20 & $22,6(20 \%)$ & $4,7(49 \%)$ & $1,3(46 \%)$ \\
& 2,3 & $24,0(22 \%)$ & $4,9(29 \%)$ & $1,5(33 \%)$ \\
\multirow{2}{*}{ PF } & 4,6 & $27,7(13 \%)$ & $6,9(28 \%)$ & $2,6(32 \%)$ \\
\hline
\end{tabular}

Percebe-se na Tabela 4.5 que as dispersões dos resultados obtidos com os testemunhos extraídos foram muito superiores àquelas obtidas para os corpos de prova moldados, para a maioria dos casos. Isto inclui a carga máxima de puncionamento que nos corpos de prova variou entre 4 e $11 \%$ e para os testemunhos extraídos foi entre 13 e $22 \%$. Além disso, os resultados de carga máxima não apresentam boa correlação com os resultados obtidos na compressão, diferente com o que ocorreu com os corpos de prova moldados. Para as resistências residuais os coeficientes de variação foram ainda mais altos, principalmente para a fibra de aço onde alcançou patamar de $60 \%$. Isto deve-se à pequena dimensão do corpo de prova, que pode ter seu resultado mais afetado por uma pequena variação no número de fibras presente na seção fissurada. Estes resultados indicam que para tubos de espessura de parede pequena a extração de testemunhos cilíndricos para o ensaio Barcelona não é uma alternativa adequada, sendo preferível a moldagem de corpos de prova para avaliação do comportamento mecânico do material.

\subsubsection{Simulações numéricas}

A partir dos resultados dos ensaios Barcelona e utilizando as equações sintetizadas na Tabela 4.2 foram calculados os parâmetros do CRF para realizar as simulações numéricas. A Tabela 4.6 apresenta os parâmetros dos CRF utilizados para as simulações do ensaio de compressão diametral de TCRF. 
Tabela 4.6 - Parâmetros do CRF utilizados para a simulação numérica da compressão diametral dos TCRF.

\begin{tabular}{cccccccc}
\hline $\begin{array}{c}\text { Tipo de } \\
\text { fibra }\end{array}$ & $\begin{array}{c}\boldsymbol{C}_{\boldsymbol{f}} \\
\left(\mathbf{k g} / \mathbf{m}^{\mathbf{3}}\right)\end{array}$ & $\begin{array}{c}\sigma_{1^{*}} \\
(\mathbf{M P a})\end{array}$ & $\begin{array}{c}\boldsymbol{\varepsilon}_{1} \\
(\%)\end{array}$ & $\begin{array}{c}\sigma_{2} \\
(\mathbf{M P a})\end{array}$ & $\begin{array}{c}\boldsymbol{\varepsilon}_{2} \\
(\%)\end{array}$ & $\begin{array}{c}\sigma_{3} \\
(\mathbf{M P a})\end{array}$ & $\begin{array}{c}\varepsilon_{3} \\
(\%)\end{array}$ \\
\hline \multirow{2}{*}{$\mathrm{SF}$} & 10 & 4,7 & 0,172 & 0,65 & 0,272 & 0,12 & 25 \\
& 20 & 4,9 & 0,179 & 1,01 & 0,279 & 0,20 & 25 \\
\multirow{2}{*}{$\mathrm{PF}$} & 2,3 & 4,5 & 0,165 & 0,62 & 0,265 & 0,12 & 25 \\
& 4,6 & 4,4 & 0,161 & 0,89 & 0,261 & 0,30 & 25 \\
\hline
\end{tabular}

A tensão de tração $\sigma_{1}$, conforme indicado no item 4.3.4, foi calculada através do método de bielas e tirantes a partir da carga máxima de puncionamento no ensaio Barcelona. Porém, no tubo quando submetido ao ensaio de compressão diametral sofre um esforço de flexão, que origina sua fissuração. Por isso, um coeficiente de majoração para $\sigma_{1}$ foi adotado. Para determinar esse coeficiente foi utilizada a Eq. 2-2, indicada pelo fib Model Code 2010 (FIB, 2013) para estimação da tensão de tração uniaxial em função da tensão de tração na flexão. O parâmetro de tensão de tração na flexão $\left(\sigma_{1}^{*}\right)$ foi então calculado através da Eq. 4-6.

$$
\begin{gathered}
\alpha=\frac{0,06 \times h^{0,7}}{1+0,06 \times h^{0,7}} \\
\sigma_{1}^{*}=\frac{\sigma_{1}}{\alpha}
\end{gathered}
$$

A simulação foi realizada utilizando o software Matlab® versão R2012a. Os códigos para implementação dos modelos de análise seccional (AES) e de análise estrutural (MAP) foram cordialmente cedidos pelo Prof. Dr. Albert de la Fuente Antequera para realização deste trabalho. Os parâmetros dos materiais foram introduzidos ao modelo, juntamente com as características dos tubos estudados (diâmetro interno, comprimento e espessura de parede). O deslocamento máximo a ser atingido na simulação foi definido e o programa foi executado.

Os resultados obtidos através da simulação numérica estão apresentados na Figura 4.10 e na Figura 4.11, em conjunto com os resultados de compressão diametral obtidos experimentalmente e que foram discutidos no item 3.4.3 do Capítulo 3. 

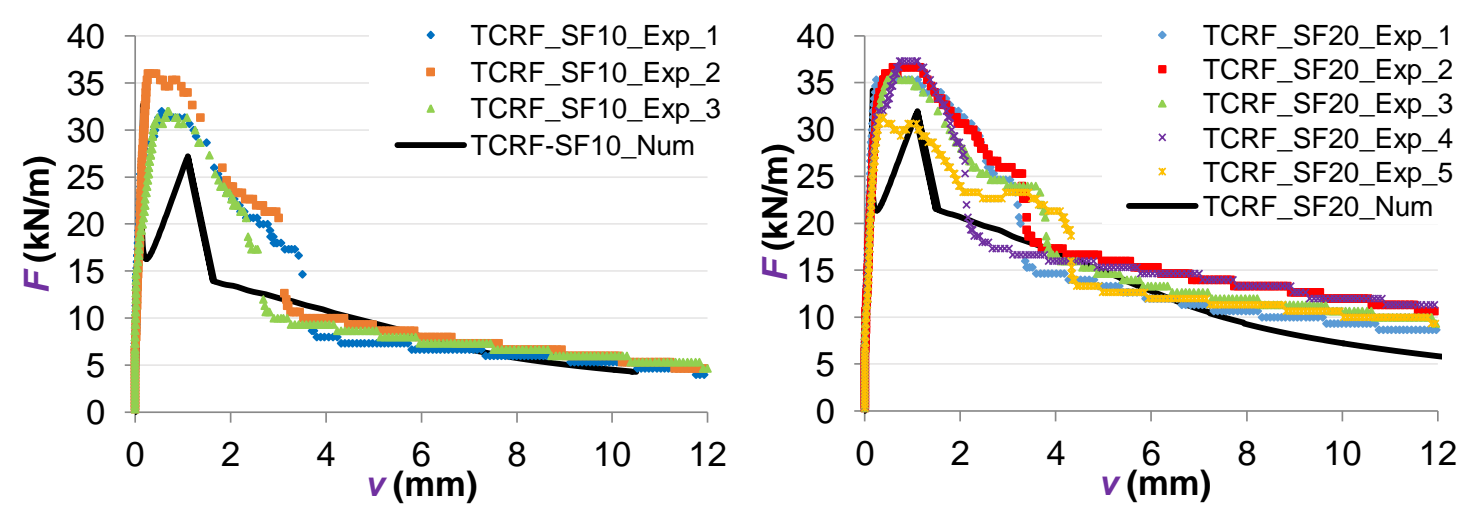

Figura 4.10 - Resultados de carga versus deslocamento diametral $(F-v)$ experimentais e numéricos para os TCRF com $10 \mathrm{~kg} / \mathrm{m}^{3}(0,13 \%)$ e $20 \mathrm{~kg} / \mathrm{m}^{3}(0,26 \%)$ de SF.
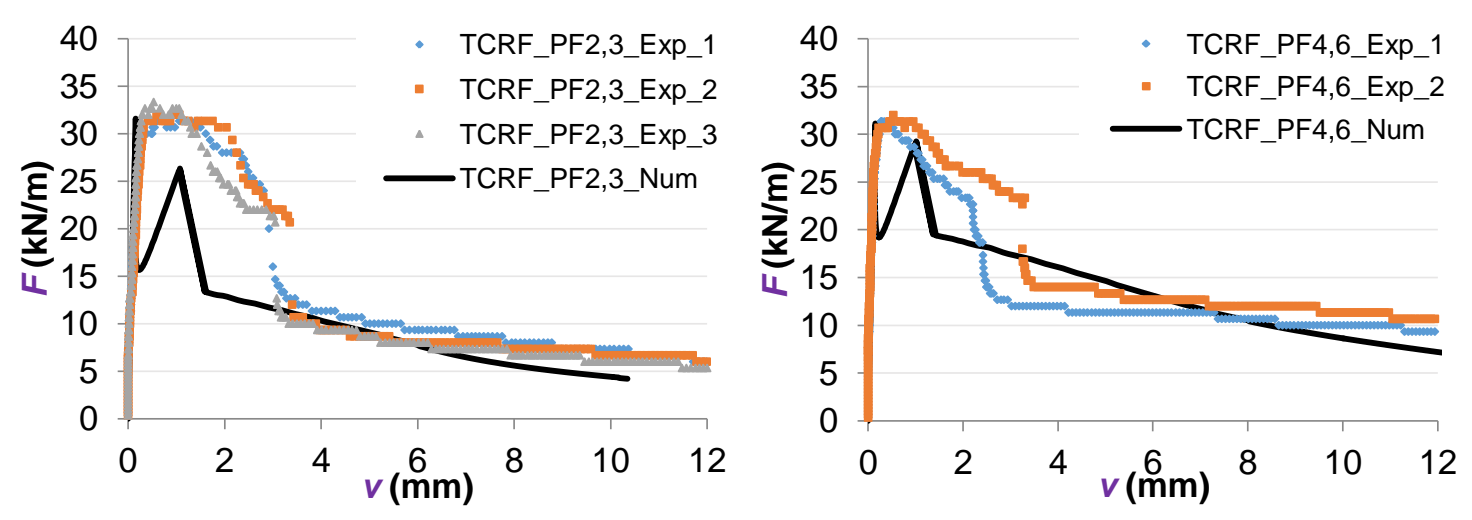

Figura 4.11 - Resultados de carga versus deslocamento diametral $(F-V)$, experimentais e numéricos, para os TCRF $2,3 \mathrm{~kg} / \mathrm{m}^{3}(0,26 \%)$ e $4,6 \mathrm{~kg} / \mathrm{m}^{3}(0,52 \%)$ de PF.

Pode ser observado na Figura 4.10 e na Figura 4.11 que os resultados obtidos através da simulação numérica, considerando os parâmetros do comportamento do CRF obtidos no ensaio Barcelona, ajustaram bem a tendência global dos resultados experimentais. Porém, um ligeiro descompasso com os resultados experimentais na região imediatamente após a carga de pico é observada. Pelo modelo, a queda intensa de capacidade resistente do tubo nesta região ocorre até um deslocamento inferior a $2 \mathrm{~mm}$. No entanto, os resultados experimentais apresentam um deslocamento bem maior nesse trecho descendente, chegando próximo a $4 \mathrm{~mm}$. Esta diferença pode ser atribuída ao fato do ensaio de compressão diametral não ser realizado com sistema fechado (closed loop) o que gera uma instabilidade pós-pico devido à grande diferença entre a capacidade resistente da matriz íntegra e a proporcionada pela fibra na região pós-fissuração. Este é um comportamento semelhante ao que ocorre nos ensaios de flexão de prismas (GOPALARATNAM e 
GETTU, 1995). No entanto, este tipo de comportamento não ocorre com o mesmo nível de intensidade no ensaio Barcelona, apesar do mesmo não utilizar sistema fechado de controle, conforme já discutido no capítulo 2. Assim, como o modelo não é concebido para simular condições de instabilidade do ensaio, ocorre este tipo de deslocamento. Ressalte-se que em estudos anteriores realizados com tubos reforçados com uma fibra de aço de maior comprimento e fator de forma, onde a capacidade resistente residual proporcionada pela fibra era próxima da carga de pico, este tipo de descompasso não foi observado (de la Fuente et al., 2012a). Pressupõese então que a situação ideal seria aquela em que o ensaio fosse realizado com sistema fechado de controle de deslocamento, o que aproximaria o comportamento medido do previsto pelo modelo numérico. A comparação pode ser mais facilmente avaliada através da Tabela 4.7, que apresenta os resultados experimentais médios e numéricos para cargas de fissuração $\left(F_{c r}\right)$, máximas $\left(F_{\text {max }}\right)$ e para diferentes níveis de abertura de fissura $\left(F_{w}\right)$.

Tabela 4.7 - Comparação entre os resultados experimentais médios e os simulados numericamente para cargas de fissuração $\left(F_{c r}\right)$, máximas $\left(F_{\max }\right)$ e para diferentes níveis de abertura de fissura $\left(F_{w}\right)$.

\begin{tabular}{|c|c|c|c|c|c|c|c|c|c|c|c|c|}
\hline & \multicolumn{3}{|c|}{ TCRF-SF10 } & \multicolumn{3}{|c|}{ TCRF-SF20 } & \multicolumn{3}{|c|}{ TCRF-PF2,3 } & \multicolumn{3}{|c|}{ TCRF-PF4,6 } \\
\hline & $\begin{array}{c}\text { Exp. } \\
(k N / m)\end{array}$ & $\begin{array}{c}M A P \\
(k N / m)\end{array}$ & $\begin{array}{c}\xi \\
(\%)\end{array}$ & $\begin{array}{c}\text { Exp. } \\
(k N / m)\end{array}$ & $\begin{array}{c}M A P \\
(k N / m)\end{array}$ & $\begin{array}{c}\xi \\
(\%)\end{array}$ & $\begin{array}{c}\text { Exp. } \\
(k N / m)\end{array}$ & $\begin{array}{c}M A P \\
(k N / m)\end{array}$ & $\begin{array}{c}\xi \\
(\%)\end{array}$ & $\begin{array}{c}\text { Exp. } \\
(k N / m)\end{array}$ & $\begin{array}{c}M A P \\
(k N / m)\end{array}$ & $\begin{array}{c}\equiv \\
(\%)\end{array}$ \\
\hline$F_{c r}$ & 27 & 33 & -21 & 30 & 34 & -15 & 29 & 32 & -10 & 28 & 31 & -13 \\
\hline$F_{\max }$ & 33 & 33 & 1 & 36 & 34 & 4 & 32 & 32 & 2 & 32 & 31 & 1 \\
\hline$F_{0,10}$ & 22 & 13 & 39 & 26 & 20 & 22 & 28 & 12 & 57 & 25 & 18 & 28 \\
\hline$F_{0,25}$ & 12 & 11 & 9 & 22 & 18 & 19 & 23 & 11 & 52 & 18 & 17 & 9 \\
\hline$F_{0,50}$ & 8 & 8 & 1 & 15 & 13 & 8 & 10 & 8 & 14 & 13 & 13 & 2 \\
\hline$F_{1,00}$ & 6 & 5 & 29 & 12 & 7 & 39 & 7 & 5 & 39 & 11 & 9 & 22 \\
\hline
\end{tabular}

O erro relativo ( $\xi$ ) foi calculado através da Eq. 4-7. Os valores de erro positivos indicam que o resultado experimental $\left(\bar{F}_{\text {exp }}\right)$ são maiores que aqueles determinados numericamente $\left(F_{\text {num }}\right)$ e vice versa.

$$
\xi=\frac{\bar{F}_{\text {exp }}-F_{\text {num }}}{\bar{F}_{\text {exp }}} \times 100
$$

O modelo MAP tende a sobrestimar o valor de carga de fissuração $F_{c r}$ entre $10 \%$ (TCRF-PF-2,3) até 21\% (TCRF-SF-10), apresentando erro médio de $15 \%$ em relação aos resultados experimentais. Esse erro, apesar de estar contra a segurança, 
pode estar associado ao erro de estimação da resistência à tração na flexão $\left(\sigma_{1}^{*}\right)$ a partir do ensaio Barcelona. Estudos experimentais já realizados comparando os ensaios Barcelona e de flexão podem ser utilizados para propor uma equação mais adequada a essa estimação, em substituição a Eq. 2-2 que foi utilizada. Observa-se também que os resultados numéricos das cargas $F_{c r}$ e $F_{\max }$ são estritamente iguais para todos os tubos avaliados. No caso dos resultados experimentais, esses apresentam um ligeiro acréscimo na capacidade de carga pós-fissuração $\left(F_{\max } / F_{c r} \approx\right.$ 1,20 para os TCRF-SF e $F_{\text {max }} / F_{c r} \approx 1,10$ para os TCRF-PF, independente do teor de fibras utilizado em ambos os casos). Essa diferença pode também estar associada a superestimação de $\sigma_{1}^{*}$, o que aumenta sua diferença para a resistência residual pósfissuração e , portanto, resulta um comportamento frágil no modelo MAP. Quanto ao comportamento pós-fissuração, avaliados para aberturas de fissura entre 0,1 e $1 \mathrm{~mm}$, verifica-se que os valores preditos pelo modelo MAP estão entre 1\% (TCRF-SF10) a $57 \%$ (TCRF-PF2,3) abaixo dos resultados médios experimentais. Em média, esse desvio é de $24 \%$ a favor da segurança. Isto mostra que os parâmetros do comportamento pós-fissuração $\left(\sigma_{i}, \varepsilon_{i}\right)$, derivados do ensaio Barcelona, tendem a subestimar o comportamento do CRF. Tal condição deve ser mais bem estudada em trabalhos futuros. Esses resultados podem ser considerados adequados para propósitos de projeto, além de não ter sido aplicado fator de segurança a esses valores. Destaca-se ainda que os teores de fibra empregados foram baixos, o que aumenta a variabilidade dos resultados do comportamento pós-fissuração tanto na análise do material quanto do componente.

Com os resultados numéricos também foi possível obter curvas de correlação entre o deslocamento diametral e a abertura de fissura. Essas curvas estão apresentadas na Figura 4.12, comparando-as com as curvas de correlação obtidas experimentalmente. 


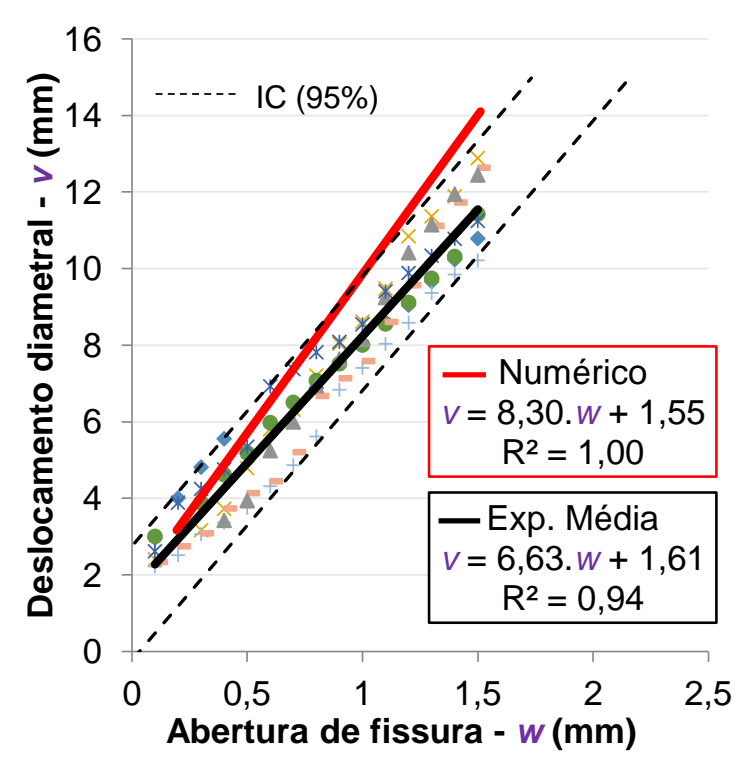

(a)

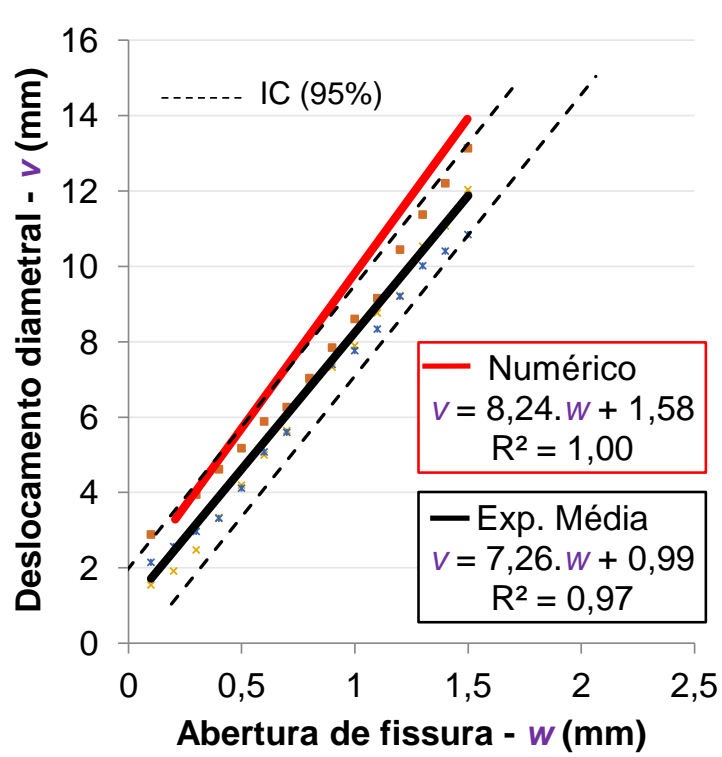

(b)

Figura 4.12 - Correlação numérica e experimental entre a abertura de fissura $(w)$ e o deslocamento diametral ( $v$ ) para: a ) TCRF-SF; b) TCRF-PF.

Os resultados apresentados na Figura 4.12 mostram que as relações entre a abertura de fissura $(w)$ e o deslocamento diametral $(v)$ para os resultados numéricos e experimentais tendem a comportamentos semelhantes, para ambos os tipos de reforço. Isto pode ser visto através dos valores de coeficiente angular das equações de regressão, cujos valores são próximos e praticamente idênticos para os resultados da simulação numérica de TCRF com fibra de aço ou de polipropileno. A proximidade de comportamento entre os teores mais baixos e mais altos para as duas fibras era esperado, pois também foi observado comportamento semelhante no ensaio Barcelona (Figura 4.8) e nos ensaios dos tubos (ver Figura 3.24 do Capítulo 3). Percebe-se também que os resultados do modelo numérico estão no interior ou muito próximos ao intervalo de confiança dos resultados experimentais, representado pela linha descontínua. Estudos futuros realizados com ensaios de compressão diametral em sistema fechado (closed-loop) poderão aproximar ainda mais os resultados experimentais e numéricos.

A previsão obtida através da simulação numérica para a relação entre o deslocamento diametral e a abertura de fissura também mostra a independência do tipo de reforço utilizado. Isto porque se trata de uma relação essencialmente geométrica. 


\subsection{Conclusões do capítulo}

Neste Capítulo foram simulados os comportamentos de tubos de concretos reforçados com fibras de aço e de polipropileno no ensaio de compressão diametral. Essas simulações foram realizadas utilizando parâmetros do comportamento pósfissuração obtidos através do ensaio Barcelona. A partir dos resultados obtidos as seguintes conclusões podem ser destacadas:

- O ensaio Barcelona mostrou-se adequado para avaliação e parametrização do comportamento mecânico do concreto reforçado com fibras utilizado para produção de tubos. Essa avaliação deve, preferencialmente, ser realizada em corpos de prova moldados, especialmente quando a espessura da parede do tubo não permitir extração de testemunhos de maiores dimensões.

- A simulação numérica utilizando os parâmetros do comportamento pósfissuração do CRF a partir de resultados do ensaio Barcelona mostrouse capaz de representar o comportamento dos tubos no ensaio de compressão diametral. Os resultados numéricos apresentam erro máximo de $4 \%$ para a carga máxima e erro médio de $24 \%$ para o comportamento pós-fissuração, sempre a favor da segurança. Algumas diferenças, como a ocorrida na região pós-pico, pode ser atribuída a limitações do ensaio de compressão diametral que, por ser realizado com sistema aberto de controle de deslocamento, possibilita uma maior instabilidade do ensaio.

- A simulação numérica também apresentou uma relação linear entre o deslocamento diametral e a abertura de fissura, independente do tipo de reforço utilizado. Além disso, os resultados numéricos encontram-se próximos aos intervalos de confiança obtidos experimentalmente. 


\section{CONCLUSÕES}

Neste capítulo são apresentadas as principais conclusões gerais e específicas, derivadas dos diferentes estudos realizados ao longo da tese.

As conclusões gerais dão resposta ao objetivo principal da tese que é propor uma metodologia para a caracterização e controle do comportamento mecânico do concreto reforçado com fibras para a produção de tubos, que permita modelar o comportamento do componente no ensaio de compressão diametral. Neste sentido foram abordados aspectos da caracterização mecânica do material, do ensaio experimental da compressão diametral do componente e a simulação numérica da resposta esperada neste ensaio. Com isso se pretende superar as dificuldades de projetar os tubos de concreto reforçados com fibras através da exaustiva produção de tubos com diferentes diâmetros, tipos e teores de fibra para avaliação mecânica.

As conclusões específicas se apresentam na mesma sequência dos estudos dos capítulos de corpo da tese, ressaltando as principais contribuições que puderam ser depreendidas de cada um.

Por último, algumas sugestões de pesquisas e campanhas experimentais futuras são apresentadas para dar respostas a tópicos não cobertos por esta tese.

\subsection{Conclusões gerais}

Para a caracterização e controle do comportamento mecânico do concreto reforçado com fibras para a produção de tubos esta tese propõe a utilização do ensaio Barcelona. Os resultados dessa caracterização podem subsidiar simulações numéricas do comportamento do componente no ensaio de compressão diametral. Isto permite que ábacos de projeto de tubos de concreto reforçados com diferentes tipos de fibras possam ser desenvolvidos, identificando as classes resistentes que serão atendidas dependendo do diâmetro do tubo e do teor de fibras empregados. Nesta condição é possível afirmar que se obteve uma metodologia de controle adequada à verificação da adequação do CRF a uma aplicação estrutural específica: o tubo de concreto. 


\subsection{Conclusões específicas}

O estudo realizado comprovou a viabilidade do ensaio Barcelona como um método alternativo ao ensaio de flexão de prismas para a caracterização do comportamento pós-fissuração do CRF para fins estruturais. Ainda que tenha sido realizado adotando o sistema aberto de controle de velocidade, o ensaio Barcelona resulta instabilidade sensivelmente menor ou não percebida, mostrando a robustez do método em relação a esse procedimento de controle de velocidade. Além disso, pode ser considerado um método de fácil execução e que não necessita de instrumentação laboratorial complexa, condição favorável para a reprodutibilidade do ensaio uma vez que o ensaio de flexão não mostrou resultados positivos neste sentido em pesquisa anterior (GUIMARÃES; FIGUEIREDO, 2002).

A correlação entre o ensaio Barcelona e o ensaio de flexão JSCE-SF4 é linear em termos de tenacidade e de resistência residual pós-fissuração, possibilitando a utilização de um ou outro método de ensaio para avaliação destas características e facilitar a aceitação do ensaio Barcelona como método alternativo ao tradicional ensaio de flexão adotado por projetistas e consultores.

O uso do sistema aberto para controle de velocidade em ensaios de flexão deve ser abandonado, devido à elevada instabilidade, principalmente para baixos teores de fibras e baixos níveis de deslocamento ou abertura de fissura. Isto confirma a necessidade de estudos e normas para a realização do ensaio com sistema fechado, ou seja, a deformação imposta pelo ensaio deve ser controlada pelo deslocamento medido no corpo de prova. Por isso, a utilização de um método de ensaio confiável, mas de procedimento de controle mais simples, permitirá qualificar minimamente e de maneira mais fácil um maior número de laboratórios de controle no Brasil para que possam realizar o controle tecnológico de obras que empreguem o CRF como material estrutural de maior responsabilidade.

A realização de ensaios de compressão diametral com carregamento contínuo e utilizando LVDT para medida do deslocamento diametral permite uma avaliação mais confiável do reforço, tornando o procedimento de ensaio menos suscetível ao erro operacional. Porém, a utilização de controle de velocidade com sistema aberto resulta em certa instabilidade na região associada ao estado limite de serviço, principalmente para condições de reforço mais desfavorável. 
A relação entre o deslocamento diametral e a abertura de fissura dos tubos independe do tipo de reforço. O estabelecimento desta relação possibilita definir requisitos de cargas residuais equivalentes em termos de abertura de fissura ou deslocamento diametral para tubos com reforço de armadura convencional ou fibras. Com isto, sugere-se uma revisão na normalização vigente, estabelecendo critérios relacionados ao comportamento pós-fissuração que avaliem o estado limite de serviço e o estado limite último. Isto permitirá uma avaliação homogênea do tipo de reforço e tornará mais adequada a comparação entre distintos tipos de reforço (fibras ou convencional).

O ensaio Barcelona pode ser considerado adequado para avaliação e parametrização do comportamento mecânico do concreto reforçado com fibras utilizado para produção de tubos. A moldagem de corpos de prova cilíndricos pode reproduzir as condições de compactação dos tubos de concreto reforçados com fibras, podendo ser considerado um formato adequado para a caracterização e controle do material. A extração de testemunhos para essa finalidade é uma alternativa, desde que a espessura da parede do tubo permita uma dimensão representativa.

A simulação numérica utilizando os parâmetros do comportamento pósfissuração do CRF a partir de resultados do ensaio Barcelona representa bem o comportamento dos tubos no ensaio de compressão diametral. Os erros médios são muito baixos para a carga máxima (2\%) e maiores para o comportamento pósfissuração (24\%), sempre a favor da segurança. Essas diferenças, mais intensas logo após na região pós-pico, podem ser atribuídas a limitações do ensaio de compressão diametral que, por ser realizado com sistema aberto de controle de deslocamento, possibilita uma maior instabilidade do ensaio.

A previsão obtida através da simulação numérica para a relação entre o deslocamento diametral e a abertura de fissura confirma a independência do tipo de reforço utilizado. Isto porque se trata de uma relação essencialmente geométrica. 


\subsection{Sugestões para pesquisas futuras}

Ainda que esta tese tenha contribuído para a evolução na caracterização e controle do concreto reforçado com fibras para produção de tubos alguns aspectos ainda carecem de estudo. Por isso, algumas sugestões de pesquisa e programas experimentais são propostas.

Realização de ensaios de compressão diametral com sistema fechado de controle de deslocamento para melhor avaliação do comportamento dos tubos com baixo teor de fibras na região do ELS. Esses ensaios dever ser realizados buscando manter um mesmo padrão de avaliação, independente do tipo de reforço, o que permitirá comparar efetivamente o comportamento estrutural dos elementos de CRF, vergalhões ou sistemas mistos.

Avaliação do ensaio Barcelona em corpos de prova moldados e extraídos utilizando fibras de maiores comprimentos, como as utilizadas em estudos anteriores com muito bom resultados, de modo a validar a metodologia para uma condição mais crítica de ensaio em pequenos corpos de prova. Além disso, também seria interessante utilizar o sistema fechado para o ensaio Barcelona para avaliar condições de baixo nível de reforço para melhor analisar a influência da instabilidade pós-pico na resistência residual no ELS.

Desenvolvimento de metodologia de controle dos tubos de concreto reforçado com fibras a partir de ensaios de menor escala, como o ensaio Barcelona, devendo ser correlacionados parâmetros de carga máxima e resistências residuais pósfissuração. Para isso, o estabelecimento de critérios para a formação de lotes e amostragens é necessário. Além disso, a avaliação do direcionamento das fibras na parede dos tubos e em corpos de prova através de métodos não destrutivos, como a tomografia e a indutância, possibilita o estabelecimento de fatores de orientação que podem ser utilizados para melhor ajuste dos modelos de controle.

Outro importante aspecto que merece atenção em pesquisas futuras são os temas relacionados à durabilidade do CRF e também dos sistemas híbridos de reforço. Este aspecto continua demandando parâmetros para o estabelecimento de modelos de previsão de vida útil para as estruturas de CRF. 


\section{Referências bibliográficas}

ABOLMAALI, A. et al. Performance of Steel Fiber-Reinforced Concrete Pipes. Transportation Research Record: Journal of the Transportation Research Board, v. 2313, n. 1, p. 168-177. 2012.

AMERICAN SOCIETY FOR TESTING MATERIALS. ASTM C76: standard specification for reinforced concrete culvert, storm drain, and sewer pipe. Philadelphia, 2014. 11p.

ASTM C497: standard test methods for concrete pipe, manhole sections or tile. Philadelphia, 2014. 13p.

ASTM C1609: standard test method for flexural performance of fiber-reinforce concrete (using beam with third-point loading). Philadelphia, 2010. 8p

AMORIM, D. L. N., PROENÇA, S. P. B., FLÓREZ-LÓPEZ, J. Simplified modeling of cracking in concrete: Application in tunnel linings. Engineering Structures, v. 70, p. 23-35. 2014.

ASOCIACIÓN ESPAÑOLA DE NORMALIZACIÓN Y CERTIFICACIÓN. UNE 83515: hormigones con fibras - determinación de la resistencia a fisuración, tenacidad y resistencia residual a tracción - método Barcelona. España, 2010. 10p.

UNE-EN 127916: concrete pipes and fittings, unreinforced, steel fiber and reinforced. National complement to the standard UNE-EN 1916:2002, 2008. 47p.

ASSOCIAÇÃO BRASILEIRA DE NORMAS TÉCNICAS. NBR 5739: concreto - ensaios de compressão de corpos-de-prova cilíndricos. Rio de Janeiro, 2007. 9p.

2014. 238p.

NBR 6118: projeto de estruturas de concreto - Procedimento. Rio de Janeiro,

NBR 8890: tubo de concreto de seção circular para águas pluviais e esgotos sanitários - requisitos e métodos de ensaio. Rio de Janeiro, 2007. 30p.

NBR 9778: argamassas e concretos endurecidos - Determinação da absorção de água por imersão, índice de vazios e massa específica. Rio de Janeiro, 2005. 4p. 2007. 7p.

NBR 15530: Fibras de aço para concreto - Especificação, 7p, Rio de Janeiro,

BANTHIA, N., DUBEY, A. Measurement of flexural toughness of fiber-reinforced concrete using a novel technique - Part 1: Assessment and Calibration. ACI Materials Journal, v. 96, n. 6, p. 651-656, 1999.

BANTHIA, N. et al. Fiber-reinforced concrete in precast concrete applications: Research leads to innovative products. PCI Journal, v. 57, n.3, p. 33-46, Summer 2012.

BARROS, J. A. O., et al. Post-cracking behaviour of steel fibre reinforced concrete. Materials and Structures, v. 38, n. 1, p. 47-56, jan.-fev. 2005.

BARROS, J. A. O.; FIGUEIRAS, J. A. Flexural behaviour of SFRC: Testing and modelling. ASCE Journal of Materials in Civil Engineering, v. 11, n. 4, p. 331-339, 1999.

BENCARDINO, F.; et al. Stress-strain behavior of steel fiber-reinforced concrete in compression. ASCE Journal of Materials in Civil Engineering, v. 20, n. 3, p. 255-63, mar. 2008.

BLANCO A. Characterization and modelling of SFRC elements. 2013. 282p. Thesis Doctoral, Universitat Politècnica de Catalunya, Spain, 2013. 
BLANCO, A. et al. Application of constitutive models in European codes to RC-FRC. Construction and Building Materials, v. 40, p. 246-259. Mar. 2013.

BLANCO, A. et al. Comparative analysis of constitutive models of fibre reinforced concrete. Hormigón y Acero. v. 61, n. 256, p. 83-100. 2010.

BLANCO, A. et al. Constitutive model for fiber reinforced concrete based on the Barcelona test. Cement and Concrete Composites, v. 54, p. 327-340. Oct. 2014.

BORGES, L. A. C.; MONTE, R.; FIGUEIREDO, A. D. Análise do efeito da orientação das fibras na resistência pós-fissuração por meio do ensaio de compressão de corpos de prova com duplo entalhe em cunha. In: CONGRESSO BRASILEIRO DO CONCRETO. 56., 2014, Natal. Anais... As construções em concreto como fator de integração entre as nações. São Paulo: Instituto Brasileiro do Concreto, 2014.

BURATTI, N.; MAZZOTTI, C.; SAVOIA, M. Post-cracking behavior of stell and macrosynthetic fibre-reinforced concretes. Construction and Building Materials. v. 25, p. 2713-22, 2011.

CARMONA S, AGUADO A, MOLINS C. Generalization of the Barcelona test for the toughness control of FRC. Materials and Structures, v. 45, n. 7, p. 1053-69, 2012.

CARROMEU, C. C.; et al. A importância da acreditação laboratorial e da certificação de mão de oba no controle de aceitação do concreto. In: CONGRESSO BRASILEIRO DO CONCRETO DO INSTITUTO BRASILEIRO DO CONCRETO, 54., 2012, Maceió. Anais... São Paulo: Instituto Brasileiro do Concreto, 2012.

CAVALARO, S. H. P. et al. Improved assessment of fibre content and orientation with inductive method in SFRC. Materials and Structures, 2014. No prelo.

CECCATO, M. R., NUNES, N. L., FIGUEIREDO, A. D. Estudo do controle da trabalhabilidade do concreto reforçado com fibras de aço. In: CONGRESSO IBEROAMERICANO DE PATOLOGIA DAS CONSTRUÇÕES, 4., 1997. Porto Alegre.

Anais... Porto Alegre: UFRGS, 1997. v. 2, p. 539-546.

CERVO T. C. et al. Influence of curing procedures and porosity in the flexural resistance of concretes for paving. Revista IBRACON de Estruturas e Materiais, v. 3, p. 390-395, 2010.

CHAMA NETO, P. J. Avaliação de desempenho de tubos de concreto reforçados com fibras de aço. 2002. 87 p. Dissertação (Mestrado) - Escola Politécnica, Universidade de São Paulo, São Paulo, 2002.

CHAMA NETO, P. J. Histórico e principais aplicações. In: CHAMA NETO, P. J. (coord.). Manual técnico de drenagem e esgoto sanitário. 1. ed. Ribeirão Preto: Associação Brasileira dos Produtores de Tubos de Concreto, 2008. 332p.

CHEN, W. F. Double punch test for tensile strength of concrete. ACl Materials Journal, v. 67, n. 2, p. 993-995, 1970.

COLLINS M. P.; MITCHELL, D. Prestressed concrete basics. Canadian Prestressed Institute, Ontario (Canada), 1987.614p.

COMISIÓN PERMANENTE DEL HORMIGÓN. EHE - 08: Instrucción del Hormigón Estructural. Ministerio de Fomento, Madrid, 2008. 620p.

CONSIGLIO NAZIONALE DELLE RICERCHE. CNR - DT 204: Guide for the Design and Construction of Fiber - Reinforced Concrete Structures. Italian National Research Council, Rome, 2006. 55p.

de la FUENTE A.; ARMENGOU J. Aplicaciones estructurales del HRFA: Tubos de saneamiento, paneles de cerramiento y placas de suelo reforzado. In: APLICACIONES 
ESTRUCTURALES DEL HRFA - JORNADA TÉCNICA, 9 de Octubre de 2007, Barcelona-Spain, Proceedings..., UPC, 2007.

de la FUENTE A.; AGUADO A.; MOLINS C. Numerical model for the non linear analysis of precast and sequentially constructed sections. Hormigon y Acero, v. 57, p. 69-87, 2008.

de la FUENTE, A. et al. Análisis de Viabilidad del Uso de Fibras Metálicas en Tubos de Hormigón. Parte 2: Modelo Numérico. In: CONGRESSO BRASILEIRO DO CONCRETO. 52., 2010, Fortaleza. Anais... São Paulo: Instituto Brasileiro do Concreto - IBRACON, 2010.

de la FUENTE, A. et al. Experimental and numerical simulation of Steel fibre reinforced concrete pipes. Materiales de Construcción, v. 61, n. 302, p. 275-88. 2011.

de la FUENTE, A. Nueva metodología para el diseño de tubos de hormigón estructural. Tesis Doctoral. UPC, Barcelona, España, 2011.

de la FUENTE, A.; AGUADO, A.; MOLINS, C. Integral optimum design of concrete pipes. Hormigón y Acero, v. 62, n. 260, p. 77-91. Abril-jun. 2011.

de la Fuente, A. et al. A new design method for steel fiber reinforced concrete pipes. Construction and Building Materials, v. 30, p. 547-55. May 2012a.

de la FUENTE, A. et al. J. Steel fibre reinforced concrete pipes. Part 2: Numerical model to simulate the crushing test. Revista IBRACON de Estruturas e Materiais, v. 5, n. 1, p. 12-25, 2012b.

de la Fuente, A. et al. Design of macro - synthetic fiber reinforced concrete pipes. Construction and Building Materials, v. 43, p. 523 - 532. June 2013.

DEUTSCHER BETON- UND BAUTECHNIK-VEREIN E.V. DBV: Guide to Good Practice - Steel Fibre Concrete, German Society for Concrete and Construction Technology, Berlin, 2001. 79p.

di PRISCO, M.; FERRARA, L.; LAMPERTI, M. G. L. Double edge wedge splitting (DEWS): an indirect tension test to identify post-cracking behavior of fibre reinforced cementitious composites. Materials and structures, v. 46, n. 11, p. 1893-1918. 2013.

di PRISCO, M.; PLIZZARI, G.; VANDEWALLE, L. Fibre reinforced concrete: new design perspectives. Materials and structures, v. 42, n. 9, p. 1261-1281. Nov. 2009.

EL DEBS, M. K. Projeto estrutural. In: CHAMA NETO, P. J. (coord.). Manual técnico de drenagem e esgoto sanitário. 1 ed. Ribeirão Preto, SP: Associação Brasileira dos Produtores de Tubos de Concreto, 2008. 332 p.

ESCARIZ, R. C. Análise comparativa de desempenho mecânico de tubos de concreto reforçados com macrofibras poliméricas e fibras de aço. 2012. 131p. Dissertação (Mestrado) - Escola Politécnica, Universidade de São Paulo, São Paulo, 2012.

EUROPEAN COMMITTEE FOR STANDARDIZATION. EN 1916: concrete pipes and fittings, unreinforced, steel fiber and reinforced. Brussels, 2002. 90p.

EUROPEAN COMMITTEE FOR STANDARDIZATION. EN 14651. Test Method FOR Metallic Fiber Concrete - Measuring the Flexural Tensile Strength (Limit of Proportionality, Residual), 2007. 20p.

FÉDÉRATION INTERNATIONALE DU BÉTON - FIB. Fib Model Code for Concrete Structures 2010. Switzerland, 2013. 402p. 
FIGUEIREDO, A. D.; CHAMA NETO, P. J. Estudo da utilização de tubos de concreto com baixos teores de fibras. In: SIMPÓSIO EPUSP SOBRE ESTRUTURAS DE CONCRETO, 6., 2006, São Paulo. Anais... São Paulo: EPUSP, 2006.

FIGUEIREDO, A. D.; CHAMA NETO, P. J.; QUINTA, M. T.; GIMENEZ, A. B. Avaliação de metodologia de ensaio de tubos de concreto reforçado com fibras para esgoto. Revista Concreto, v. 34, p. 44-51, 2007.

FIGUEIREDO, A. D. Evaluation of the test method for crushing strength of steel fiber reinforced concrete pipes. In: INTERNATIONAL RILEM SYMPOSIUM ON FIBER REINFORCED CONCRETE: DESIGN AND APPLICATIONS (BEFIB 2008), 7., 2008, Chennai, India. Proceedings... Fiber Reinforced Concrete: Design and Applications. Babneux - France: RILEM Publications S.A.R.L. v. 1, p. 989-1000, 2008.

FIGUEIREDO, A. D. Concreto reforçado com fibras. 2011. 248p. Tese (LivreDocência) - Escola Politécnica, Universidade de São Paulo, São Paulo, 2011.

FIGUEIREDO, A. D.; ESCARIZ, R. C. Drainage concrete pipes with hybrid reinforcement. In: INTERNATIONAL CONFERENCE ON STRAIN HARDENING CEMENTITOUS COMPOSITES, 2., 2011, Rio de Janeiro. Proceedings... Strain Hardening Cementitous Composites (SHCC2-Rio). Babneux: RILEM Publications S.A.R.L., 2011. p. 391-398. 2011.

FIGUEIREDO, A. D. et al. A new approach on crushing strength test for fibre reinforced concrete pipes. In: RILEM INTERNATIONAL SYMPOSIUM ON FIBRE REINFORCED CONCRETE (BEFIB 2012), 8., 2012, Guimarães. Proceedings... Fibre Reinforced Concrete: challenges and opportunities. Bagneux: RILEM Publications SARL, Proceedings, $2012 \mathrm{a}$.

FIGUEIREDO, A. D. et al. Steel fiber reinforced concrete pipes. Part 1: technological analysis of the mechanical behavior. Revista IBRACON de Estruturas e Materiais, v. 5, p. 1-11, 2012b.

FIGUEIREDO, A. D. et al. Fibras plásticas como reforço de tubos de concreto. Parte 1: Caracterização tecnológica. In: CONGRESSO BRASILEIRO DO CONCRETO, 54., 2012, Maceió. Anais... Fortalecendo o concreto no Brasil. São Paulo: Instituto Brasileiro do Concreto IBRACON, 2012c.

FIGUEIREDO, A. D. et al. Steel fiber reinforced concrete pipes. Part 1: technological analysis of the mechanical behavior. Revista IBRACON de Estruturas e Materiais, v. 5, n. 1, p. 1-11, Fev. 2012b.

FUGIl, A. P. Avaliação de tubos de concreto reforçados com fibras de aço segundo a NBR 8890. 2008. 161 p. Dissertação (Mestrado) - Universidade Estadual Paulista Júlio de Mesquita Filho, llha Solteira, 2008.

GOPALARATNAM, V. S., GETTU, R. On the characterization of flexural toughness in fiber reinforced concretes. Cement and Concrete Composites, v. 17, n.3, p. 239-254, 1995.

GUIMARÃES, M. C. N., FIGUEIREDO, A. D. Análise da repetibilidade e reprodutibilidade do ensaio de tenacidade à flexão dos concretos. In: Congresso Brasileiro do Concreto. 44., 2002. Belo Horizonte. Anais... São Paulo: Instituto Brasileiro do Concreto, 2002.

HEGER F. J., LIEPINS A. A., SELIG E. T. SPIDA: An analysis and design systems for buried concrete pipe. In: INTERNATIONAL CONFERENCE ASCE. 1985. Madison-WI. Proceedings... Advanced in underground pipeline engineering. New York, NY: American Society of Civil Engineers. p. 143-154. Aug. 27-29, 1985 
HEGER F. J., McGRATH T. J. Design methods for reinforced concrete pipe and box sections. Simpson Gumpertz \& Heger Inc. Report submitted to ACPA, Dec. 1982.

INSTITUT BELGE DE NORMALISATION. NBN B 15-238: Test on fibre reinforced concrete bending test on prismatic simples. Brussels, 1992. 10p.

KOOIMAN, A. Modelling Steel Fibre Reinforced Concrete for Structural Design. Doctoral Thesis, Delft University of Technology, Delft, 2000. 184p.

KURDIZIEL J. M., TIMOTHY J. M. SPIDA method for reinforced concrete pipe design. Journal of transportation engineering, v. 117, n. 4, p. 371-381, 1991.

LARANJEIRA F. et al. Framework to predict the orientation of fibers in FRC: a novel philosophy. Cement and Concrete Research, v. 42, n. 6, p. 752-68, 2012.

LARANJEIRA, F., AGUADO, A., MOLINS, C. Equação constitutiva de betão reforçado com fibras. In: CONGRESSO NACIONAL DE PREFABRICAÇÃO EM BETÃO, 2., 2008, Lisboa. Anais... Lisboa, 2008.

MAGALHÃES, F. C. et al. Concreto não conforme - Análise da influência do local do ensaio nos resultados de resistência á compressão de um mesmo lote. In: CONGRESSO BRASILEIRO DO CONCRETO, 55., 2013, Gramado. Anais... Ações concretas para o futuro da construção em concreto no Brasil. São Paulo: Instituto Brasileiro do Concreto (IBRACON), 2013.

MINDESS, S.; CHEN, L.; MORGAN, D.R. Determination of the first-crack strength and flexural toughness of steel fiber-reinforced concrete. Advanced Cement Based Materials, v. 1, n. 5, p. 201-208, 1994.

MOHAMED, N., SOLIMAN, A., NEHDI, M. Full-scale pipes using dry-cast steel fibrereinforced concrete. Construction and Building Materials, v. 72, p. 411-422. Dec. 2014.

MOHAMED, N., SOLIMAN, A., NEHDI, M. Mechanical performance of full-scale precast steel fibre-reinforced concrete pipes. Engineering Structures, v. 84, p. 287299. Feb. 2015.

MOLINS, C., AGUADO, A., SALUDES, S. Double Punch Test to control the tensile properties of FRC (Barcelona test). Materials and Structures, v. 42, n. 4, p. 415-425, 2009.

MONTE, R.; TOALDO, G. S.; FIGUEIREDO, A. D. Avaliação da tenacidade de concretos reforçados com fibras através de ensaios com sistema aberto. Matéria (UFRJ), v. 19, p. 132-149, 2014.

PARK, Y. et al. Time-dependent behavior of synthetic fiber-reinforced concrete pipes under long-term sustained loading. Transportation Research Record: Journal of the Transportation Research Board, n. 2407, p. 71-79. 2014.

PARK, Y. et al. Structural performance of dry-cast rubberized concrete pipes with steel and synthetic fibers. Construction and Building Materials, v. 77, p. 218-226. Feb. 2015.

PEDERSEN, C. The moment-rotation relationship with implementation of stresscrack width relationships. Department of Structural Engineering. Technical University of Denmark, 1995.

PEYVANDI, A., SOROUSHIAN, P., JAHANGIRNEJAD, S. Enhancement of the structural efficiency and performance of concrete pipes through fiber reinforcement. Construction and Building Materials, v. 45, pp. 36-44. Aug. 2013. 
PEYVANDI, A., SOROUSHIAN, P., JAHANGIRNEJAD, S. Structural design methodologies for concrete pipes with steel and synthetic fiber reinforcement. ACI Structural Journal, v. 111, n. 1, pp. 83-91. Jan-Feb. 2014.

PEYVANDI, A., SOROUSHIAN, P. Structural performance of dry-cast concrete nanocomposite pipes. Materials and Structures, v. 48, n. 1-2, p. 461-470. Jan. 2015.

PUJADAS, P. Caracterización y diseño del hormigón reforzado com fibras plásticas. 2013. 263p.Tesis Doctoral. UPC, Barcelona, España, 2013.

PUJADAS, P. et al. New analytical model to generalize the Barcelona test using axial displacement. Journal of Civil Engineering and Management, v. 19, n. 2, p. 259-71, 2013.

PUJADAS, P. et al. Multidirectional double punch test to assess the post-cracking behaviour and fibre orientation on FRC. Construction and Building Materials, v. 58, p. 214-224, 2014.

RAMBO, D. A. S.; SILVA, F. A.; TOLEDO FILHO, R. D. Mechanical behavior of hybrid steel-fiber self-consolidating concrete: materials and structural aspects. Materials and Design, v. 54, p. 32-42, 2014.

RAMOS, M. F. Análise experimental de tubos de concreto reforçado com fibras de aço. 2002. 130 p. Dissertação (Mestrado) - Faculdade de Engenharia Civil, Universidade Estadual de Campinas, Campinas. 2002.

SALUDES, S. R. Ensayo de doble punzonamiento aplicado al hormigón reforzado con fibras (Ensayo Barcelona). Minor Thesis, UPC, Barcelona, España, 2006.

SALVADOR, R. P. Avaliação de desempenho mecânico de concreto reforçado com macrofibras sintéticas utilizando sistema de controle fechado de deformação. 2013. 178p. Dissertação (Mestrado) - Escola Politécnica. São Paulo, 2013.

SALVADOR, R. P., FIGUEIREDO, A. D. Análise comparativa de comportamento mecânico de concreto reforçado com macrofibra polimérica e com fibra de aço. Matéria (UFRJ), v. 18, n. 2, p. 1273-1285, 2013.

SILVA, J. L.; EL DEBS, M. K.; BECK, A.T. Reliability evaluation of reinforced concrete pipes in crack opening limit state. Revista IBRACON de Estruturas e Materiais, v. 1, p. 314-330, 2008.

SILVA, J. L. Análise de tubos circulares de concreto armado para o ensaio de compressão diametral com base na teoria de confiabilidade. 2011. 154p. Tese (Doutorado) - Escola de Engenharia de São Carlos da Universidade de São Paulo, 2011.

Sistema Nacional de Informações sobre Saneamento. SNIS: diagnóstico dos serviços de água e esgotos - 2008. Brasília: SNSA/MCIDADES, 2010. 408p.

Sistema Nacional de Informações sobre Saneamento. SNIS: diagnóstico dos Serviços de Água e Esgotos - 2013. Brasília: SNSA/MCIDADES, 2014. 181 p.

SU-TAE, K.; JIN-KEUN, K. The relation between fibre orientation and tensile behavior in an Ultra High Performance Fibre Reinforced Cementitious Composites (UHPFRCC). Cement and Concrete Research, v. 41, n. 10, p. 1001-14, 2011.

THE JAPAN SOCIETY OF CIVIL ENGINEERS. JSCE-SF4: Method of tests for flexural strength and flexural toughness of steel fiber reinforced concrete. Part III-2 Method of tests for steel fiber reinforced concrete. n. 3, p. 58-61. Concrete library of JSCE, 1984 
THORENFELDT, E.; TOMASZEWICZ, A.; JENSEN J. J. Mechanical properties of high-strength concrete and application in design. In: SYMPOSIUM UTILIZATION OF HIGH STRENGTH CONCRETE. Stavanger, June 1987. Proceedings... p. 149-59. Tapir, Trondheim. 1987.

TIGUMAN. M. P. Estudo comparativo entre métodos de quantificação de tenacidade usando concreto reforçado com macrofibras de polipropileno. 2004. 84 p. Dissertação (Mestrado) - Escola Politécnica, Universidade de São Paulo, 2004.

VANDEWALLE, L. et al. Test and design methods for steel fibre reinforced concrete. $\sigma$ $\varepsilon$ design method. Materials and Structures, v. 36, p. 560-567, 2003.

VIÑOLAS, B.; AGUADO, A.; JOSA, A. Valoració de la sostenibilitat dels tubs de sanejament. In: CONGRÉS UPC SOSTENIBLE 2015, 2., Proceedings... Barcelona, 2009.

WATKINS R. K., ANDERSON L. R. Structural mechanics of buried pipes. 1. ed. Boca Raton, FL: Taylor \& Francis, 1999. 444 p.

ZAIDLER, W. Projetos estruturais de tubos enterrados. São Paulo: Pini, 1983. $106 p$. 